MAESTRÍA EN DIRECCIÓN DE EMPRESAS

FACULTAD DE CIENCIAS ECONÓMICAS

UNIVERSIDAD NACIONAL DE LA PLATA

Trabajo de tesis para optar al título de Magister

Tema:

\title{
StART-UPS TECNOLÓgicAS en ARgentinA: FACTORES QUE IMPULSAN SU DESARROLLO
}

Autor: Lic. M. Belén AlmazÁn

DiRector de tesis: Mg. Matías Poggio

LA PLATA, JUNIO DE 2018 

ÍNDICE

$\begin{array}{ll}\text { JUSTIFICACIÓN/FUNDAMENTACIÓN DEL TEMA } & 6\end{array}$

$\begin{array}{ll}\text { Planteamiento del Problema } & 7\end{array}$

$\begin{array}{ll}\text { Objetivo general } & 7\end{array}$

$\begin{array}{ll}\text { OBJetiVOS ESPECÍFICOS } & 7\end{array}$

$\begin{array}{lr}\text { ANTECEDENTES } & 8\end{array}$

$\begin{array}{ll}\text { MARCO TEÓRICO } & 10\end{array}$

$\begin{array}{ll}\text { 1. Start-ups } & 10\end{array}$

1.1. Conceptualización 10

$\begin{array}{ll}\text { 1.2. Importancia } & 11\end{array}$

1.3. Características 11

$\begin{array}{lll}\text { 1.4. Fases } & 12\end{array}$

$\begin{array}{ll}\text { 1.5. } & \text { Actividades } \\ & 13\end{array}$

1.6. Problemas que enfrenta una start-up 13

1.7. ¿Qué es el éxito en una start-up? 14

$\begin{array}{lll}\text { 1.8. } & \text { Start-ups de alto impacto } & 14\end{array}$

2. Start-ups IT 16

$\begin{array}{ll}2.1 \text { Conceptualización } & 16\end{array}$

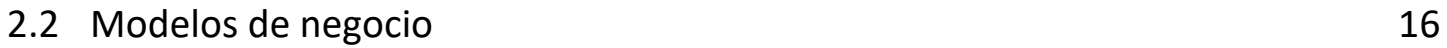

$\begin{array}{ll}2.3 & \text { Tasa de crecimiento } \\ \end{array}$

$\begin{array}{lll}2.4 & \text { Agentes de cambio }\end{array}$

2.5 Canales de marketing 24

2.6 Etapas de financiamiento: de la idea a la Bolsa 26

2.6.1.1. Inversión de los emprendedores 28

2.6.1.2. FFF (Friends, Family and Fools) 28

2.6.2. Aceleradora o incubadora 28

$\begin{array}{ll}\text { 2.6.3. Plataformas de inversión online } & 28\end{array}$

2.6.4. Inversores ángeles (Business Angels) 29

2.6.5. Fondos de inversión (Seed Capital) 29 
2.6.6. Fondos de inversión (Growth Capital) 29

2.6.7. Venta 29

$\begin{array}{lll}2.7 & \text { El ecosistema de Silicon Valley } & 30\end{array}$

3. El emprendedurismo en Argentina 35

3.1. Evolución 35

3.2. Factores que influyen en el emprendedurismo argentino 36

3.3. Comparación con otros países 37

3.4. Inversión en Ciencia y Tecnología (СуT) 38

3.5. Acceso a financiamiento 38

4. Factores críticos de éxito y fracaso en start-ups 40

Metodología y técnicas Para el diagnóstico 44

$\begin{array}{ll}\text { RESULTADOS DE LA INVESTIGACIÓN } & 47\end{array}$

Análisis de los resultados de las entrevistas

Datos del emprendedor y del emprendimiento 47

Datos del equipo emprendedor $\quad 50$

$\begin{array}{ll}\text { Motivaciones } & 51\end{array}$

Desarrollo del emprendimiento y planificación estratégica 52

Factores internos de éxito y fracaso

Factores externos de éxito y fracaso $\quad 60$

ANÁLISIS DE PODCASTS Y ENTREVISTAS PÚBLICAS 66

$\begin{array}{ll}\text { CONCLUSIONES } & 72\end{array}$

$\begin{array}{ll}\text { FUTURAS LÍNEAS DE INVESTIGACIÓN } & 76\end{array}$

$\begin{array}{ll}\text { BibLIOGRAFÍA } & 77\end{array}$

$\begin{array}{ll}\text { ANEXOS } & 86\end{array}$

Anexo 1: Modelo de entrevista a emprendedores 86

Anexo 2: Resultados de las entrevistas a emprendedores 95

$\begin{array}{ll}\text { Entrevista № } 1 & 95\end{array}$

Datos del emprendedor y del emprendimiento 95

Datos del equipo emprendedor 96

$\begin{array}{ll}\text { Motivaciones } & 97\end{array}$

Desarrollo del emprendimiento y planificación estratégica 97 
Factores internos de éxito y fracaso 100

Factores externos de éxito y fracaso 101

$\begin{array}{ll}\text { Entrevista № } 2 & 104\end{array}$

Datos del emprendedor y del emprendimiento 104

$\begin{array}{ll}\text { Datos del equipo emprendedor } & 105\end{array}$

$\begin{array}{ll}\text { Motivaciones } & 106\end{array}$

Desarrollo del emprendimiento y planificación estratégica 106

Factores internos de éxito y fracaso 109

Factores externos de éxito y fracaso 111

$\begin{array}{ll}\text { Entrevista № } 3 & 113\end{array}$

Datos del emprendedor y del emprendimiento 113

Datos del equipo emprendedor $\quad 114$

$\begin{array}{ll}\text { Motivaciones } & 115\end{array}$

Desarrollo del emprendimiento y planificación estratégica 116

$\begin{array}{ll}\text { Factores internos de éxito y fracaso } & 118\end{array}$

$\begin{array}{ll}\text { Factores externos de éxito y fracaso } & 120\end{array}$

$\begin{array}{ll}\text { Entrevista № } 4 & 122\end{array}$

Datos del emprendedor y del emprendimiento 122

Datos del equipo emprendedor 123

$\begin{array}{ll}\text { Motivaciones } & 124\end{array}$

Desarrollo del emprendimiento y planificación estratégica 125

$\begin{array}{ll}\text { Factores internos de éxito y fracaso } & 127\end{array}$

Factores externos de éxito y fracaso 129

$\begin{array}{ll}\text { Entrevista № } 5 & 131\end{array}$

Datos del emprendedor y del emprendimiento 131

Datos del equipo emprendedor 132

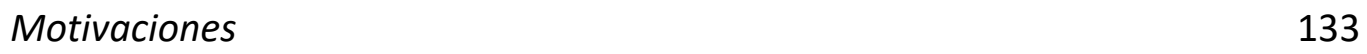

Desarrollo del emprendimiento y planificación estratégica 133

Factores internos de éxito y fracaso 135

$\begin{array}{ll}\text { Factores externos de éxito y fracaso } & 137\end{array}$

$\begin{array}{ll}\text { Entrevista № } 6 & 139\end{array}$ 
Datos del emprendedor y del emprendimiento

Datos del equipo emprendedor

Motivaciones

Desarrollo del emprendimiento y planificación estratégica

Factores internos de éxito y fracaso

Factores externos de éxito y fracaso

Entrevista № 7

Datos del emprendedor y del emprendimiento

Datos del equipo emprendedor

Motivaciones

Desarrollo del emprendimiento y planificación estratégica

Factores internos de éxito y fracaso

Factores externos de éxito y fracaso

Entrevista № 8

Datos del emprendedor y del emprendimiento

Datos del equipo emprendedor

Motivaciones

Desarrollo del emprendimiento y planificación estratégica

Factores internos de éxito y fracaso

Factores externos de éxito y fracaso

Entrevista № 9

Datos del emprendedor y del emprendimiento

Datos del equipo emprendedor 166

Motivaciones

Desarrollo del emprendimiento y planificación estratégica

Factores internos de éxito y fracaso

Factores externos de éxito y fracaso

Entrevista № 10

Datos del emprendedor y del emprendimiento

Datos del equipo emprendedor 
Desarrollo del emprendimiento y planificación estratégica 176

Factores internos de éxito y fracaso 178

Factores externos de éxito y fracaso

Entrevista № 11

Datos del emprendedor y del emprendimiento

Datos del equipo emprendedor

Motivaciones

Desarrollo del emprendimiento y planificación estratégica

Factores internos de éxito y fracaso

Factores externos de éxito y fracaso

Entrevista № 12

Datos del emprendedor y del emprendimiento

Datos del equipo emprendedor

Motivaciones

Desarrollo del emprendimiento y planificación estratégica

Factores internos de éxito y fracaso

Factores externos de éxito y fracaso 198

Anexo 3: Clasificación de resultados de entrevistas a emprendedores

Datos del emprendedor y del emprendimiento

Datos del equipo emprendedor

Motivaciones

Desarrollo del emprendimiento y planificación estratégica

Factores internos de éxito y fracaso

Factores externos de éxito y fracaso 


\section{JUSTIFICACIÓN/FUNDAMENTACIÓN DEL TEMA}

El surgimiento de gran cantidad de nuevas empresas con las características de las start-ups hace que resulte muy interesante estudiarlas. Si bien el término start-up puede aplicarse a cualquier compañía, normalmente se lo asocia a las empresas que poseen un fuerte componente tecnológico, es decir, que están vinculadas directamente con Internet y las tecnologías de la información y las comunicaciones (TIC). Asimismo, cabe mencionar que generalmente intentan explotar nichos de mercado con un recorrido potencialmente alto, pero delimitado en el tiempo, como, por ejemplo, una herramienta, sistema o aparato tecnológico que esté de moda.

No es menor mencionar que Google comenzó siendo una start-up, al igual que Twitter y Facebook. Este tipo de compañías suelen diferenciarse de otras empresas jóvenes en sus posibilidades de crecimiento y necesidades de capital, además de que tienen un alto impacto en la economía en general y, sobre todo, en la generación de empleo. En este sentido, las start-ups están mejor posicionadas que las empresas multinacionales, ya que, según RIVKIN \& PORTER en su libro What Business Should Do to Restore U. S. Competitiveness, la innovación es la clave para la creación de trabajo, y al ser el principal componente de estos emprendimientos los ubica en una posición ventajosa frente a otro tipo de empresas. Según el Ministerio de Trabajo de la Nación, dos de cada tres firmas son fundadas por jóvenes y el 55 \% de las pequeñas y medianas empresas (PyMES) locales son propiedad de empresarios que tienen entre 18 y 40 años, lo que suma un total de 335.500 compañías. Asimismo, de acuerdo al registro publicado en el sitio Angel List, entre 2011 y 2014, se registraron 484 start-ups, la mayoría de ellas en Buenos Aires. 158 de dichas compañías datan de 2014, mientras que 81 están registradas desde el año 2012, y existen centenares más que no aparecen en ningún registro. En el caso de las start-ups de tecnología, que incluyen a los sectores de la informática y las telecomunicaciones, crecieron en 2011, respecto al año 1980, un $210 \%$, a diferencia de las compañías del sector privado general, donde la cantidad de empresas decreció un 9 \% en el mismo período ( $L a$ Voz, 2017).

De lo anteriormente mencionado se puede concluir que las empresas start-ups generan una ola de puestos de trabajo, lo cual contribuye al desarrollo de la economía. Pero ¿cómo logran estas empresas su crecimiento? y ¿cómo consiguen generar una necesidad en gran parte de la sociedad y aumentar rápidamente el número de usuarios? A pesar de que existen diversos estudios en los que se analiza este tipo de empresas, no se encuentra ninguno en Argentina que explore las diferentes causas de crecimiento de las empresas de base tecnológica del país. Esto, sumado a que la temática está emparentada con lo visto en varios de los módulos del programa MBA (FCE-UNLP), justifica la elección del fenómeno como tema susceptible de ser elegido para el presente trabajo de tesis. 
En los últimos años las empresas start-ups han tenido un fuerte impacto en el crecimiento de la economía, generando fuentes de trabajo y aportando valor a la sociedad. Por este motivo, debe ser interés del Estado fomentar el crecimiento de este tipo de empresas. Esta cuestión está generando cada vez más atracción en los legisladores y representantes del gobierno. En este sentido, han surgido diferentes tipos de financiamientos y ayudas no reembolsables para startups, otorgados en nuestro país por los gobiernos provinciales y por el gobierno nacional. Asimismo, se encuentran las llamadas incubadoras de start-ups, que también están creciendo exponencialmente en número, y centran su atención en ideas innovadoras y de alto potencial futuro.

Más allá de que existan planes de ayuda económica, no es posible afirmar que aportarán al crecimiento de las start-ups en Argentina, si no existe antes un estudio previo sobre cuáles son las causas o vías que contribuyen a dicho crecimiento. El principal desafío es lograr que se implementen políticas y programas públicos y privados efectivos, que desarrollen un mejor marco para los empresarios y permitan a las empresas crecer.

A partir de este trabajo exploratorio, se intentará detectar si existen o no patrones que describan el crecimiento de las empresas start-ups, identificando cuáles son las variables más significativas que favorecen su desarrollo.

\section{OBJETIVOS}

\section{Objetivo general}

Analizar la dinámica de crecimiento de empresas del tipo conocido como start-ups en el ámbito de un país como Argentina, con foco de análisis en la información generada a partir de opinantes calificados de quienes conducen algunas de ellas en la ciudad de La Plata.

\section{Objetivos específicos}

Identificar, sin la pretensión de que sea una formulación taxativa, factores/características/prácticas que hacen al fomento del crecimiento y desarrollo de startups de tecnología, en general y también en un ámbito específico como es el escenario económico argentino.

Analizar la existencia de factores limitantes al crecimiento y desarrollo de start-ups, precisamente por estar inmersas en un escenario económico como el argentino. 
El tema que se pretende estudiar está sumamente emparentado con lo actual, con la innovación y el cambio, y existen para él muchas limitaciones en la manera que se ha abordado en los estudios precedentes. Las investigaciones que se pueden encontrar sobre la temática se centran habitualmente en la personalidad del emprendedor, en sus orígenes y experiencias laborales del pasado (CARLAND et al., 1984), así como también en los recursos, tangibles e intangibles, que son requeridos a lo largo del camino empresarial (KATZ, 1984), como el capital social, humano, financiero y organizacional (BRUNET, 2004).

Se han encontrado diversos estudios, mayormente en Estados Unidos, realizados por diferentes organismos de inversión, principalmente por business angels (inversores ángeles), que analizan los motivos de crecimiento de las start-ups. Por ejemplo, un estudio de Emprear Business Angels (2015) titulado “¿Por qué hoy en día las start-ups crecen más rápido?”, afirma que este crecimiento se genera a partir de tres tendencias claves. En primer lugar, los canales de marketing utilizados hoy en día por este tipo de empresas son mucho más eficientes que hace veinte años, lo que hace que tengan llegada a una mayor cantidad de potenciales clientes en un período de tiempo mucho menor. En segundo lugar, los compradores (consumidores finales o empresas) compran a las start-ups con facilidad. Por último, si la start-up tiene gran posibilidad de crecimiento, los inversores privados invierten en ella a pesar de que las posibles pérdidas puedan ser mayores a causa de su alta velocidad de crecimiento.

Siguiendo en la línea de la influencia de los inversores en capital de riesgo sobre el crecimiento de las start-ups, TETEN et al. (2011) publicaron un artículo científico denominado "The Lower-Risk Startup: How Venture Capitalists Increase the Odds of Startup Success": se trata de un estudio sobre cómo los capitalistas de riesgo ayudan al crecimiento de las start-ups, más allá de simplemente proporcionar el capital necesario. Su hipótesis se basa en que el desarrollo y la institucionalización de técnicas de gestión que permiten mejores índices de éxito en el inicio, aumentan la disponibilidad de tecnologías disruptivas, al tiempo que aumentan también los retornos de inversión y las tasas de éxito de los emprendedores. La metodología que utilizan se basa en la realización de más de cincuenta entrevistas en profundidad a capitalistas de riesgo, emprendedores, consultores e incubadoras de start-ups; un amplio escaneo de publicaciones académicas y de profesionales enfocadas en temas de emprendedurismo e inversión de riesgo; y, por último, en la experiencia personal de los autores trabajando con capital de riesgo, startups de tecnología y consultoría estratégica.

El estudio arrojó como resultado que los inversores en capital de riesgo podrían tener aún más impacto si pudieran mejorar su tasa de éxito, y que para lograr una mayor eficiencia es crucial entender sus activos y elegir una estrategia que aproveche sus fortalezas y mitigue sus debilidades. "Existen una serie de variables en el proceso de toma de decisión que son propias del inversor, tales como su actitud ante el riesgo, horizonte temporal de inversión, y su preferencia por liquidez y mapa de posibles opciones en las que separar el total de su riqueza" (MATAlLín SÁEz et al., 1999). Pero, al fin y al cabo, todo depende del entorno probabilístico y de 
la aleatoriedad para que un emprendimiento fracase y otro tenga éxito. Sobre esto, Luis Martín CABIEDES (2016), business angel y fundador de Cabiedes \& Partners, argumenta: "Yo hago unas diez inversiones al año, más o menos, en las que ya sé de partida que el $80 \%$ va a salir mal y como mucho el $20 \%$ saldrán bien, y cuando esto ocurre no es porque tú hayas tenido un ojo especial, sino porque has tenido suerte". CIRIACO et al. (2003), en su estudio "¿Tienen los inversores habilidades de selección? Resultados con fondos de inversión", no han podido encontrar evidencias favorables que muestren la existencia y/o la utilización de habilidades de selección por parte de los inversores. Se trata entonces de hacer una buena gestión de las probabilidades y de las rentabilidades asociadas, analizar la performance de los fondos y de entender que lo que está en juego es un capital de alto riesgo.

Por otro lado, KORUNKA et al. (2011) desarrollaron una investigación titulada "Conditions for growth in one-person startups: A longitudinal study spanning eight years". Este trabajo analiza el potencial de crecimiento de las empresas unipersonales -one-person businesses (OPB)postulando cinco grupos de predictores clave para el crecimiento de la empresa: rasgos de personalidad, recursos, estrategias, industria y estructuras de organización y sistemas. La metodología utilizada consistió en obtener datos longitudinales de 188 OPB que fueron observadas durante un período de ocho años. El estudio obtuvo como resultado que el género del fundador, los requisitos de capital en el momento de establecimiento y la estrategia de crecimiento demostraron ser los predictores más importantes del crecimiento. Además, resultó que los recursos de capital humano también tendían a tener un impacto positivo, pero no lograron encontrar un efecto significativo de los rasgos de personalidad sobre el crecimiento.

En contraparte, Gallup (2007) ha identificado características de la personalidad que son críticas durante la fase inicial de creación de una empresa, como la creatividad en la propuesta de valor de una idea emprendedora, un fuerte sentido de la responsabilidad y la competencia, y otras diferentes son las que facilitan la expansión y el crecimiento de la empresa como la autoeficacia, la orientación a los beneficios y la capacidad de delegar tareas.

Respecto a estudios sobre emprendedurismo realizados en Argentina particularmente, se pueden analizar los datos del Global Entrepreneurship Monitor (GEM). A lo largo del tiempo se observa una cierta correlación entre la tasa total de actividades emprendedoras en etapa temprana (TEA) y la anticipación de la crisis. En 2000 y 2001, Argentina sufrió una profunda crisis económica y política, que fue acompañada por un aumento en la actividad empresarial impulsada por la necesidad. Incluso antes de la crisis económica mundial hacia fines de 2008, Argentina se encontraba en medio de una crisis económica interna debido a problemas políticos, lo cual se ve reflejado en las tasas GEM TEA de 2007 y 2008, y en un aumento en el porcentaje de empresarios impulsados por la necesidad. En 2009, casi el $50 \%$ de todos los emprendedores en etapa inicial estaban comenzando un negocio debido a que no tenían otra opción de trabajo. Hacia 2013, Argentina volvió a entrar en otro período de crisis, que la tasa TEA comenzó a reflejar con un año de anticipación. A partir de esto, se puede decir que la actividad empresarial en Argentina se ve fuertemente afectada por los cambios políticos y económicos, y que de alguna manera, los anticipa. 


\section{START-UPS}

\subsection{Conceptualización}

El término start-up ha surgido de manera reciente y está muy latente en la actualidad en el mundo empresarial. Este concepto se puede traducir al español como "arrancar" y significa iniciar, emprender o simplemente montar un nuevo negocio. Se trata entonces de "una institución humana diseñada para crear nuevos productos y servicios en unas condiciones de incertidumbre extrema" (RIES, 2012). En este sentido, el proceso emprendedor comprende "todas las actividades relacionadas con detectar oportunidades y crear organizaciones para concretarlas" (FREIRE, 2004). Por otra parte, una oportunidad de mercado es aquella "necesidad, deseo o tendencia que se ha identificado recientemente en un mercado y que todavía nadie (ningún competidor) ha satisfecho" (BILL, 2015).

Según GómEZ GrAS et al. (2012), la búsqueda y explotación de la oportunidad se asocia con dos tipos de estándares de comportamiento. El primero está relacionado con la vocación emprendedora (persecución de oportunidades), mientras que el otro se asocia a la reacción ante circunstancias adversas en lo laboral. Esta diferenciación es reconocida en el ámbito del proyecto GEM (GómEZ GRAS et al., 2012), donde surgen dos motivaciones o impulsos fundamentales: el primero es "emprender por oportunidad", cuando se trata de explotar oportunidades previamente buscadas y/o detectadas, mientras que el otro es "emprender por necesidad", y se refiere a una búsqueda de oportunidad inducida por una necesidad personal, debido a circunstancias adversas o a la ausencia de otras alternativas laborales. A estos dos impulsos se le puede agregar un tercero, correspondiente a la motivación de "emprender por deseo", comprendiendo el deseo de lograr independencia y riqueza (AUTIO \& KAURANNEN, 1994), así como también el deseo de superación y progreso que lleva a los individuos a buscar siempre un estado superior en sus actividades (VARELA \& BEDOYA, 2006).

Este conjunto de actividades es llevada a cabo por un "emprendedor", cuya función consiste en "reformar o revolucionar el patrón de producción al explotar una invención, o más comúnmente, una posibilidad técnica no probada, para producir un nuevo producto o uno viejo de una nueva manera; o bien proveer de una nueva fuente de insumos o un material nuevo; o reorganizar una industria, etc." (SCHUMPETER, 1942). Es decir, los emprendedores son individuos capaces de causar inestabilidad en los mercados a través de sus acciones; son personas dinámicas, disruptivas, que promueven la innovación, que "consiste precisamente en la ruptura con la tradición y en crear una nueva" y "si bien esto se aplica primariamente a su actuación económica, puede hacerse extensivo a sus consecuencias morales, culturales y sociales" (SEGURA, 2006).

La mayoría de las start-ups tienen un fuerte componente tecnológico, además de destacarse en calidad, y se caracterizan por un rápido crecimiento en pocos años, a pesar de la falta de recursos o financiación que puede enfrentar un negocio en su etapa incipiente. 


\subsection{Importancia}

Su importancia yace en la capacidad de innovar, al apostar por ideas nuevas que permiten simplificar diferentes procesos y satisfacer las necesidades del consumidor.

Este tipo de empresas posee un alto impacto en la generación de empleos, al mismo tiempo que pueden ser adquiridas por compañías con mayor trayectoria en el mercado, lo que les otorga un gran atractivo dentro de la industria.

Asimismo, suelen mantenerse a flote (y en algunos casos crecer) cuando la economía y los empleos comunes no están pasando por un buen momento. Esto se debe probablemente a que las personas tienden a montar sus propios negocios porque no hay otra alternativa viable. Esto se relaciona con lo que Nassim TALEB (2013) denomina "antifragilidad", en su libro Antifrágil: las cosas que se benefician del desorden, tratándose del término opuesto a fragilidad y va más allá de la resiliencia o la robustez. El resiliente resiste los golpes y permanece igual e intacto. El antifrágil se vuelve mejor con los golpes. La antifragilidad se hace fuerte con la aleatoriedad, la incerteza, lo volátil, lo desconocido, lo incomprensible y los errores.

En el caso de Argentina, la crisis ha generado, para una parte significativa de la población (más del 15 \% según GEM), la necesidad de explorar la iniciativa de emprender. Como expone ESTENSSORO (2017) en su libro La Argentina innovadora, los argentinos adquirieron una gran resiliencia por desenvolverse en un entorno tan negativo, ya que surgieron y se consolidaron mientras el país fracasaba, cuando lo razonable hubiese sido no innovar. Según TALEB, "el mundo es demasiado aleatorio e impredecible para poder fijar las normas sobre la predicción del futuro", por lo tanto las empresas que estén encasilladas únicamente en la planificación tienden a fracasar.

Los mecanismos de la antifragilidad permiten la actitud no preventiva en los procesos de toma de decisiones en el entorno de incertidumbre, porque, siguiendo con lo que expone TALEB, "resulta mucho más fácil saber si algo es frágil que predecir los sucesos que lo pueden dañar". Las empresas start-ups acostumbran a estar listas a sacar provecho o beneficiarse del estrés, de los errores y del cambio, "es una actividad arriesgada y heroica, necesaria para el crecimiento o incluso la mera supervivencia de la economía".

\subsection{Características}

Si bien puede tratarse de emprendimientos con diferentes propósitos y multidisciplinares, cada uno de ellos comparte ciertas características claves que hacen que se los pueda ubicar dentro del marco de las start-ups. Estas características son:

$\square \quad$ Innovación: Son compañías jóvenes, creativas, innovadoras que asumen riesgos y buscan fórmulas disruptivas para la resolución de problemas. Por otro lado, la variedad de perfiles profesionales enriquece la estructura corporativa.

Feedback: El contacto directo con el cliente target y un feedback temprano son dos factores que permiten que la empresa conozca las necesidades de los consumidores y así hallar soluciones nuevas e innovadoras. Las start-ups aprenden de los errores para poder evolucionar, la rapidez con la que se adaptan a los cambios es otro de sus rasgos particulares. Según RIES, 
medir la respuesta de los consumidores y aprender cuándo pivotar o perseverar es la actividad fundamental de una start-up y todos los procesos de creación de start-ups exitosas deberían orientarse a acelerar este circuito de feedback (RIES, 2011).

Buena comunicación y motivación: En el ambiente laboral de este tipo de empresas es clave que exista una alta motivación y satisfacción por parte de todos los miembros del equipo, y sobre todo una buena comunicación.

Escalabilidad: Esta es una característica clave que debe poseer una start-up que requiera atraer financiamiento externo. Deben ser capaces tanto de replicar su modelo de negocio en distintos mercados, como de entregar el mismo producto a grandes escalas sin un gran aumento en los costos de producción. Para que una compañía alcance alta escalabilidad debe generar un alto retorno de inversión. Para ello se deben tomar en cuenta las condiciones del entorno y proyección futura, así como también estrategias que permitan subir las barreras ante la competencia. Endeavor, considera como emprendedores de alto impacto aquellos cuyo negocio, entre otras cosas, tiene capacidad comprobada de escalabilidad regional o global, y esta escalabilidad genera de forma exponencial empleos y/o riqueza, impactando la economía.

Tecnología: La necesidad de ser escalable y replicable requiere, en la mayoría de los casos, que el modelo de negocios de las start-ups tenga un fuerte componente tecnológico.

Incertidumbre: La incertidumbre está dada por la innovación y la búsqueda de inversionistas. Nadie puede asegurar que la compañía podrá sostenerse por sí sola, ya que la idea es nueva y debe ponerse en práctica para atraer la demanda. Por este motivo es que la financiación de una start-up se considera como una inversión de riesgo.

\subsection{Fases}

Tal como lo indica el libro 100 buenas prácticas en emprendimiento universitario, existen cinco fases principales por las que atraviesa un emprendimiento, desde el surgimiento de una idea o un resultado de investigación hasta que se convierte en un proyecto empresarial: I+D+i (Investigación, Desarrollo e innovación), preincubación, incubación, aceleración y consolidación (Asón TocA et al., 2012).

I+D+i: Se trata de la etapa en el proceso del emprendimiento en la que se desarrollan nuevos productos o procesos dentro de grupos de investigación, que pueden servir de base para la constitución de una nueva actividad empresarial.

- Preincubación: Etapa que comprende desde la concepción de una nueva idea hasta la concreción del proyecto con la constitución de una nueva empresa.

Incubación: Etapa inicial de la vida de la start-up en la cual desarrolla su actividad bajo una cierta tutela o dependencia del grupo de investigación de la que ha surgido, con el objeto de maximizar su probabilidad de éxito.

Aceleración: Etapa en la cual el proyecto, tras sus primeros años de vida, ha conseguido ocupar un determinado nicho de mercado y empieza a crecer de forma exponencial tanto en empleo como en volumen de negocio con el objeto de maximizar su beneficio. 
- Consolidación: Una vez que la empresa ha alcanzado un tamaño óptimo en función del área o sector en el que desarrolla su actividad, dicha estructura le permitirá ampliar el horizonte de sus actuaciones en el mercado. En esta etapa la empresa comienza una estrategia de internacionalización y diversificación de sus actividades.

\subsection{Actividades}

A partir de las fases anteriormente citadas, tal como lo indican Asón TOCA et al. (2012) se desprenden una serie de actividades complementarias para apoyar el crecimiento de los emprendimientos. A continuación se mencionan en orden algunas de ellas:

- Formación: Actividades dirigidas a asegurar una adecuada adquisición de aptitudes y habilidades de gestión por parte de los emprendedores.

Gestión: Actividades que apoyen la gestión empresarial mediante el desarrollo de herramientas o la promoción de regulaciones y normativas que faciliten el emprendimiento.

- Propiedad intelectual: Se considerarán en este punto las actividades que faciliten la adecuada protección de la propiedad intelectual y/o industrial en la empresa para su posible valorización posterior en el mercado.

Comercialización: Actividades dirigidas a poner el producto en el mercado de la forma más eficaz y eficiente.

Alianzas/Redes: Alude a las actividades dirigidas a utilizar redes y establecer contactos en beneficio de la empresa. Esto implica un importante capital relacional que genera un valor añadido a la compañía.

Internacionalización: Ya sea comercial o productiva, se refiere al proceso de acceso a mercados más amplios que el nacional.

\subsection{Problemas que enfrenta una start-up}

Las start-ups suelen enfrentarse con diversos problemas para sostenerse y seguir adelante, sobre todo en la etapa de iniciación. Entre otros, se pueden encontrar los siguientes problemas:

$\square$ Gestionar los recursos humanos: el emprendedor debe enfrentar problemas de motivación y adaptación de los RRHH y debe tener la habilidad de atraer y retener talentos y personas clave en la empresa.

- Trabajar bajo estrés: "en toda start-up se presentan situaciones de incertidumbre, cambio y estrés" (MORIANO et al., 2006). El emprendedor debe tener la aptitud de trabajar bajo este tipo de situaciones y enfrentarlas.

Alinearse con las necesidades del mercado: muchas veces se desarrollan productos o servicios que no son adoptados por la sociedad y no logran insertarse en el mercado. En este punto, entra en juego la capacidad del emprendedor para desarrollar sus productos sobre 
necesidades que se encuentren insatisfechas y crear una oferta que no exista en el mercado. En este punto, es clave determinar el timing de la oportunidad, como manifiesta Musso (2012): puede ser que la idea de negocio sea excelente, que se pueda ejecutar sin problemas con las propias capacidades, que cree valor, que tenga altas probabilidades de escalar y ser altamente rentable, pero puede que no sea el momento para desarrollarla. Aquí, el autor menciona el ejemplo de Microsoft que "desarrolló un tablet PC cerca de cinco años antes de que Apple introdujera su iPad y fracasó (...) No era su momento, porque no estaban dadas las condiciones de conectividad inalámbrica, ni se había desarrollado suficientemente la tecnología de las pantallas táctiles; condiciones absolutamente esenciales". El timing debe ser preciso: un emprendimiento no debe surgir ni muy temprano como para que no se pueda desarrollar un mercado ni las necesidades necesarias para dar el siguiente paso, pero tampoco muy tarde como para que ya haya competencia establecida, lo que lo obligará a hacer algo distinto (BBVA, 2014).

Conseguir financiamiento: es habitual en este tipo de empresas, por ser de alto riesgo, que en lugar de recurrir a vías tradicionales de financiamiento como créditos o préstamos bancarios, deban apelar a figuras como la del business angel, empleando capital aportado por inversores a cambio de un porcentaje de la empresa, así como también al apoyo de incubadoras y aceleradoras de empresas, que aportan la inyección necesaria de dinero hasta generar un flujo de ingresos constante para lograr apalancar el crecimiento. No es sencillo conseguir financiamiento, ya que en la mayoría de los casos, se requiere que el proyecto esté avanzado, que exista algún prototipo o algo para mostrar, para que el inversor acceda. Para llegar a esto, el emprendedor tuvo que invertir tiempo y dinero con rentabilidad cero, hasta demostrar "que el negocio generará valor para sus clientes, e ingresos para sus fundadores" (Musso, 2012), lo cual no siempre es sencillo.

\section{7. ¿Qué es el éxito en una start-up?}

FRESE \& RAUCH (2014) definen el éxito empresarial como el establecimiento de metas y estrategias, a lo cual MINER (1997-1, 1997-2) añade que no es solo la definición de una estrategia sino que el éxito se logra con el desarrollo de acciones gerenciales y estratégicas para obtener un resultado.

En términos económicos y financieros, el mantenimiento del negocio en el mercado, es decir, que sea sostenible en el tiempo, como se plantea en el estudio de organizaciones realizado por MEYER \& ZUCKER (1989) es un indicador de éxito.

Por lo tanto, en el presente trabajo de tesis se considera como éxito empresarial tanto a la definición como a la acción estratégica, produciendo resultados y ganancias para el mercado o la economía (DRUCKER, 1993) y consiguiendo además una ventaja competitiva, como se sugiere en la literatura sobre gestión estratégica (PORTER, 1980; GHEMAWAT, 1999) y que sea sostenible en el tiempo.

\subsection{Start-ups de alto impacto}

Son aquellas que poseen "un modelo de negocios con una ventaja sostenible y escalable, 
generadoras de empleos de calidad, y con aportes importantes al producto bruto interno del país" (GARCÍA FUENTES, 2013).

En particular, son objeto de estudio de la presente tesis, los denominados emprendimientos "unicornio", término introducido por primera vez por Aileen LeE (2013), fundadora de Cowboy Ventures, en su artículo "Welcome to the Unicorn Club: Learning from Billion-Dollar Startups". Lee analizó las startups de software fundadas en la década de 2000 y estimó que sólo el 0,07 \% de ellas alcanzaron una valuación de mil millones de dólares. Según la autora, estos "unicornios" solían ser un mito o una fantasía, pero en la actualidad surgen por lo menos cuatro de este tipo de compañías al año.

De las siete empresas tecnológicas valuadas en más de mil millones de dólares en Latinoamérica, y alrededor de doscientas empresas en el mundo, cuatro son argentinas: Mercado Libre, la principal plataforma de comercio electrónico de habla hispana y líder a nivel mundial; Globant, la primera compañía desarrolladora de software elegida por Google como su aliada tecnológica; Despegar, la quinta agencia de turismo del planeta; y OLX, una plataforma de avisos clasificados online presente en cientodieciocho países y que lidera en mercados masivos como India y Paquistán.

Recientemente, en paralelo con el momento en que se estaba entregando este trabajo de tesis, surgió un quinto unicornio argentino. Se trata de la empresa de seguridad Auth0, líder global en protección y gestión de identidades digitales. Tras una ronda de financiación de 103 millones de dólares, se convirtió en la quinta compañía argentina con una valuación de más de mil millones de dólares (REDACCIÓN MDZ, 2019). 


\section{START-UPS IT}

\subsection{Conceptualización}

Según el Observatorio Virtual de Transferencia de Tecnología (OVTT), las start-ups IT son un tipo de empresa de base tecnológica (EBT), que corresponden a "organizaciones que basan su actividad empresarial en la innovación tecnológica orientada al mercado, dedicándose a la comercialización y rentabilización de productos y servicios innovadores generados a partir de un uso intensivo del conocimiento científico y tecnológico, y que cuentan con personal investigador y técnico de alta cualificación en sus equipos" (OVTT, 2018).

Las start-ups IT son emprendimientos emergentes que surgen desde el entorno productivo y empresarial para convertir el conocimiento tecnológico generado por profesionales en nuevos productos, procesos o servicios aptos para su introducción y explotación en el mercado. Basan su actividad en el dominio intensivo del conocimiento científico y tecnológico, y cuentan con una alta capacidad innovadora, haciendo foco en la investigación, el desarrollo y la innovación $(1+D+i)$.

\subsection{Modelos de negocio}

A la hora de emprender o invertir en una start-up, surge el interrogante de qué modelo de negocio tiene más ventajas, y entran entonces en juego el riesgo, la rentabilidad, el timing y los recursos disponibles a la hora de escoger un modelo $u$ otro.

La evolución de los patrones de modelos de negocios digitales puede describirse como un derivado de la Teoría de las Cuatro Olas de Internet, detalladas por MonToya (2015) de la siguiente manera:

1. Primera ola: corresponde al boom de las puntocom, empresas financiadas a través de capital puro, de las cuales nunca se supo cuál era el modelo de negocio que ofrecían.

2. Segunda ola: la aparición de las redes sociales (como Facebook, Twitter, entre otras) representó empresarialmente una revolución para el modelo de negocios tradicional de la publicidad y el marketing.

3. Tercera ola: las aplicaciones móviles y la tecnología de redes revolucionaron y sigue revolucionando a toda la economía, específicamente los sectores de transporte, movilidad, mercadeo de la música, turismo, servicios y comercio.

4. Cuarta ola: el Internet de las Cosas o Internet of Things (IOT), que surge recientemente como una red de objetos físicos o cosas interrelacionadas con la electrónica, el software, los sensores y la conectividad de red, que permite mejorar la calidad de vida de la población y el desarollo de ciencias como la medicina, la astrofísica y la tecnología espacial, mediante la recolección, el intercambio y el uso inteligente de los datos (big data). Todos estos dispositivos conectados a Internet requieren de alguna clase de sistema de seguridad que los mantenga unidos y haga que sus datos permanezcan seguros (RANDS, 2018, julio 31). Aquí es donde aparece la tecnología blockchain, o "cadena de bloques", que "crea un registro inmutable de la existencia, integridad y propiedad de documentos y archivos" (BARAONA POHL \& NAJERA REYES, 
2018), y que, aunque fue creada originalmente para guardar el historial de transacciones de bitcoin (la criptomoneda más exitosa hasta el momento, utilizada como alternativa de pago), con el tiempo y debido a su gran potencial comenzó a ser aplicada en otros ámbitos (DOLADER ReTAMAL et al., s.f.). El papel de la blockchain en esta revolución del loT es el de devolver la confianza de los usuarios en las empresas e instituciones. "Este sistema descentralizado resulta inquebrantable criptográficamente y, además, la colaboración y consenso entre los diferentes nodos imposibilita que cada uno actúe independientemente de los otros, pudiendo perjudicar los datos almacenados, resultando confiable en vista de que este esquema llega a alcanzar a gobiernos y organizaciones mayores, que definitivamente necesitan replantear su papel en el mundo moderno" (ESPARRAGOZA, 2016).

Cada una de estas olas de Internet ha llevado a nuevos patrones de modelos de negocios digitales. A partir de la FIGURA 1, puede describirse el comportamiento a través del tiempo:

$\square \quad$ Un primer conjunto de nuevos patrones de modelos de negocios IT aparece entre 1995 y 2000. Estos patrones de modelo de negocio están basados en lo que se conoce como Web 1.0, cuando Internet comenzó a verse y usarse por primera vez como parte de la infraestructura comercial. Según FLEISCH et al. (2014), estos patrones incluyen comercio electrónico, freemium, apalancamiento de datos del cliente, código abierto y digitalización.

- Alrededor de 2005 apareció otro conjunto de patrones de modelos de negocio IT, basados en la Web 2.0, donde Internet hacía posible que hasta los usuarios comunes aportaran contenido. Estos comprenden: User Designed, Crowdsourcing, Crowdfunding, Long Tail y código abierto.

- Hacia el 2015, y junto con la cuarta ola, surge, como se dijo, la internet de las cosas, que sigue dominando en la actualidad.

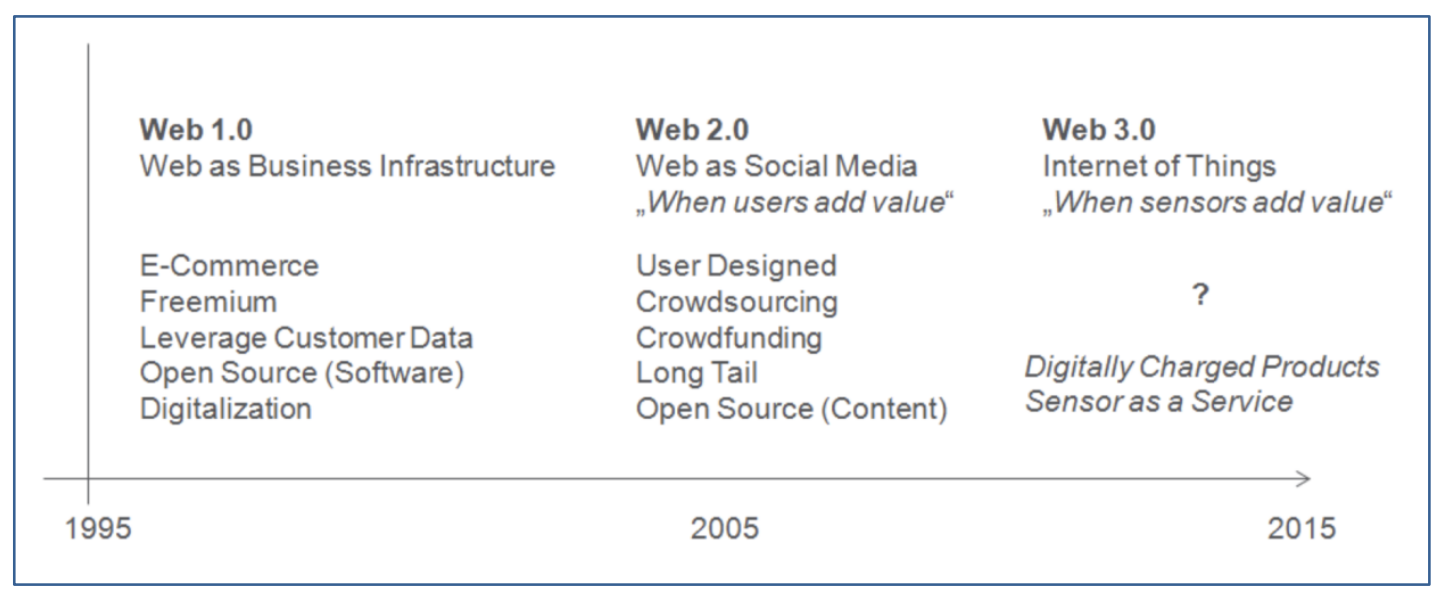

FIGURA 1

Las olas de Internet y los patrones del modelo de negocio digital

Fuente: FLEISCH et al. (2014) 
Asimismo, se pueden encontrar diferentes clasificaciones de modelos de negocio. Se los puede dividir entre los que ofrecen productos versus los que ofrecen servicios, así como también se lo puede dividir en estrategias dependiendo de quién es el que vende y a quién le está vendiendo (B2B, B2C, C2C); también pueden combinarse ambas clasificaciones.

Los servicios difieren fundamentalmente de los productos en que los primeros se brindan en el sitio del cliente mientras se colabora, y en general se pagan en cantidades pequeñas, distribuidas a lo largo del tiempo. "La fusión de los mundos físico y digital hace que la parte digital de una solución híbrida sea siempre un servicio" (FLEISCH et al., 2014).

Las diferentes características de los productos físicos y digitales son particularmente notables en el desarrollo de productos. En el negocio del hardware y en el mundo de la informática integrada, un error en un producto que ya ha sido vendido generalmente resulta extremadamente costoso. En contraparte, en el mundo digital, los procesos de desarrollo ágiles son los protagonistas, el feedback es constante, y los errores se detectan en etapas tempranas, así como también el costo de introducir una modificación al producto es bajo ya que generalmente se hace antes de que esté terminado. Dos conceptos clave entran en juego en este punto: el de mínimo producto viable (MVP), una versión de producto que, con un gasto mínimo, ofrece el máximo conocimiento sobre el cliente y sale al mercado tan pronto sea posible, y el de mejora continua, donde se promueven las iteraciones y el feedback constante del cliente/usuario.

A continuación, nos centraremos en el segundo tipo de clasificación de modelos de negocio mencionada anteriormente para analizar ventajas y desventajas.

B2B (Business to Business): Empresas que venden sus productos o servicios a otras empresas. Desde su nacimiento, cuentan con clientes que están dispuestos a pagar un precio medio-alto, por lo tanto son rentables con un menor número de clientes; esto otorga la ventaja de gestionar un grupo razonable de clientes, aunque cada uno de éstos puede requerir un elevado nivel de atención y personalización. Un inversor que se plantee apostar por una startup de este tipo tendrá en cuenta desde el principio cuáles son sus ingresos. El modelo de negocio no cambiará demasiado, ya que el cliente generalmente suele pagar desde el principio por un servicio que, si es bueno, convertirá a esa empresa en un cliente recurrente. Este modelo favorece la autofinanciación del proyecto empresarial ya que tendrá una monetización rápida y clara, reduciendo las necesidades de inversión externa.

$\square \quad$ B2C (Business to Consumer): Empresas que comercializan bienes o servicios para consumidores. En este caso, suele plantearse la necesidad de llegar al mercado de masas para alcanzar el umbral de rentabilidad. Frecuentemente requiere una elevada inversión en marketing para dar a conocer el producto o servicio en el mercado, acudiendo a campañas de medios (TV, online, etc.), surgiendo la necesidad de captar financiación externa. En este modelo de negocio, el riesgo aumenta considerablemente, ya que solo tienen dos opciones: triunfar o fracasar, aunque si el modelo funciona, suele escalar en mayor medida que los B2B, es decir, son potencialmente más rentables. El número de usuarios, su activación y su retención, son algunas de las métricas que puede valorar un inversor de este tipo de negocios. Como propuesta de valor debe ofrecerse un producto o servicio atractivo, barato y fácil de usar para captar a los usuarios y generar una buena imagen para que estos las recomienden. 
C2C (Consumer to Consumer, o Peer to Peer): Consumidores que venden a otros consumidores. Aquí la start-up se convierte en un una plataforma de intermediación entre pares, actuando como moderadora pero no como vendedora. Esto equivale a perder el control sobre la oferta de producto o servicio, añadiendo cierto nivel de riesgo, pero al mismo tiempo se traduce en ahorro de costos y logística al actuar únicamente como intermediario. Los costos en marketing para dar a conocer la plataforma son elevados al igual que en B2C. Un ejemplo conocido de este tipo de plataformas es Airbnb.

A continuación, se presenta un cuadro con la combinación de las clasificaciones de modelos de negocio y que es lo que necesita cada una para lograr una mayor cantidad de usuarios.

\begin{tabular}{|c|c|c|}
\hline & PRODUCTO & SERVICIO \\
\hline B2B & $\begin{array}{l}\text { Centrarse en las } \\
\text { características objetivas del } \\
\text { producto en el mercado y su } \\
\text { funcionalidad, además de un } \\
\text { buen servicio de postventa. } \\
\text { Ejemplo: CRM, ERP. }\end{array}$ & $\begin{array}{l}\text { Ser funcional y solucionar un } \\
\text { problema concreto con el } \\
\text { que se encuentran las } \\
\text { empresas. Disponer de la } \\
\text { mayor información } \\
\text { documentación posible. } \\
\text { Ejemplo: Slack, Dropbox } \\
\text { Business, empresas de } \\
\text { desarrollo de software a } \\
\text { medida como Celerative o } \\
\text { Globant. }\end{array}$ \\
\hline B2C & $\begin{array}{l}\text { Estrategias de marketing } \\
\text { enfocadas a la captación y } \\
\text { fidelización, hacer hincapié } \\
\text { sobre los beneficios del } \\
\text { producto. Ejemplo: tiendas } \\
\text { en línea como Garbarino o } \\
\text { Frávega. }\end{array}$ & $\begin{array}{l}\text { Atractivo, barato, y fácil de } \\
\text { usar. Período de prueba. } \\
\text { Ejemplo: Netflix. }\end{array}$ \\
\hline $\mathrm{C} 2 \mathrm{C}$ & $\begin{array}{l}\text { Confiabilidad, seguridad, } \\
\text { bajos costos de logística o } \\
\text { cercanía de los } \\
\text { consumidores, facilidades de } \\
\text { pago. Ejemplo: Mercado } \\
\text { Libre. }\end{array}$ & $\begin{array}{lr}\text { Costos mínimos por } & \text { por } \\
\text { transacción, amigable para } \\
\text { el usuario, muchas } \\
\text { facilidades de pago, } \\
\text { transacciones } & \text { seguras. } \\
\text { Ejemplo: Airbnb. } & \end{array}$ \\
\hline
\end{tabular}

CUADRO 1

Clasificación de modelos de negocio de las start-ups 


\subsection{Tasa de crecimiento}

Un factor determinante en el éxito de una start-up es la estimación de la proyección de ingresos, esto es, a qué tasa deberían crecer los ingresos para que la empresa tenga futuro. Esta estimación es compleja, considerando además que el comportamiento de las start-ups, por su escala, es muy diferente al del resto de las empresas. Por lo tanto, la proyección del comportamiento de un emprendimiento no debe basarse en patrones de empresas maduras ya que no existe relación alguna.

Generalmente el crecimiento de las start-ups exitosas pasa por tres etapas de la curva S, como se muestra en la FIGURA 2:

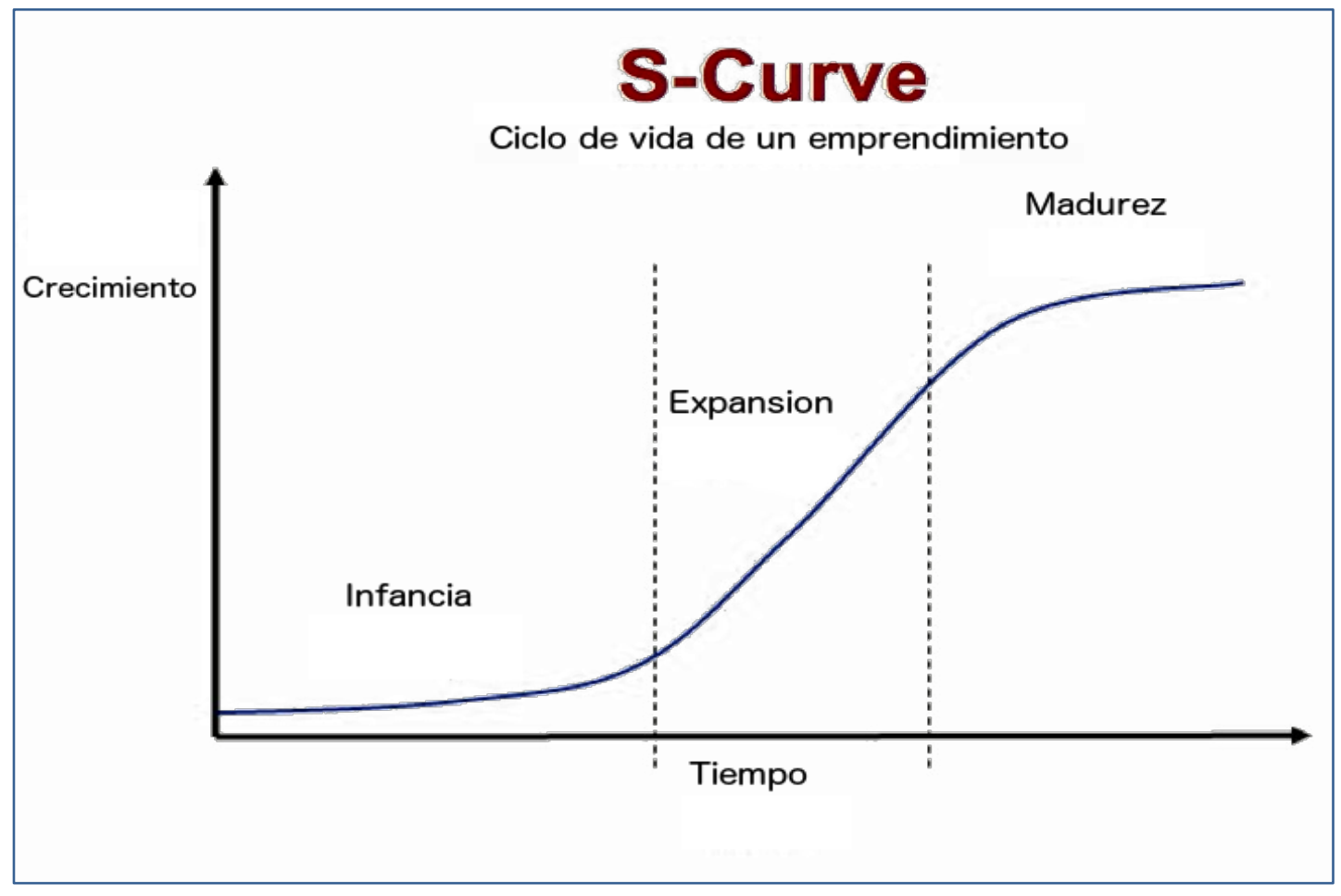

FIGURA 2

S-Curve: Ciclo de vida de un emprendimiento

Fuente: Insane Growth

$\square \quad$ Infancia: la etapa inicial es aquella en la cual la start-up tiene un crecimiento muy lento o nulo mientras trata de organizar el negocio.

- Expansión: es un período de rápido crecimiento, donde la empresa ya está más organizada y entiende a sus clientes, conoce sus deseos y es capaz de ofrecerles lo que buscan. 
- Madurez: si la start-up se transforma en una empresa grande, el crecimiento comienza a ser más lento, principalmente por limitaciones internas y de mercado.

Según Paul Graham (2012), famoso inversor de capital de riesgo y fundador de Ycombinator, "la tasa de crecimiento ideal para una start-up va entre un 5 a un $7 \%$ a la semana". Esa referencia de éxito indica que tasas superiores a ese valor son muy buenas, pero inferiores son causas de preocupación. Trevor Blackwell, su socio, creó la herramienta Startup Growth Calculator (ver FIGURA 3) para calcular si el crecimiento de una start-up logra cubrir los costos. Allí se puede apreciar que las tasas de crecimiento para las start-ups en etapa temprana son muy elevadas, y cuando alcanzan un cierto tamaño, sus tasas son más bajas, pero siguen siendo significativamente superiores a las empresas maduras y consolidadas.

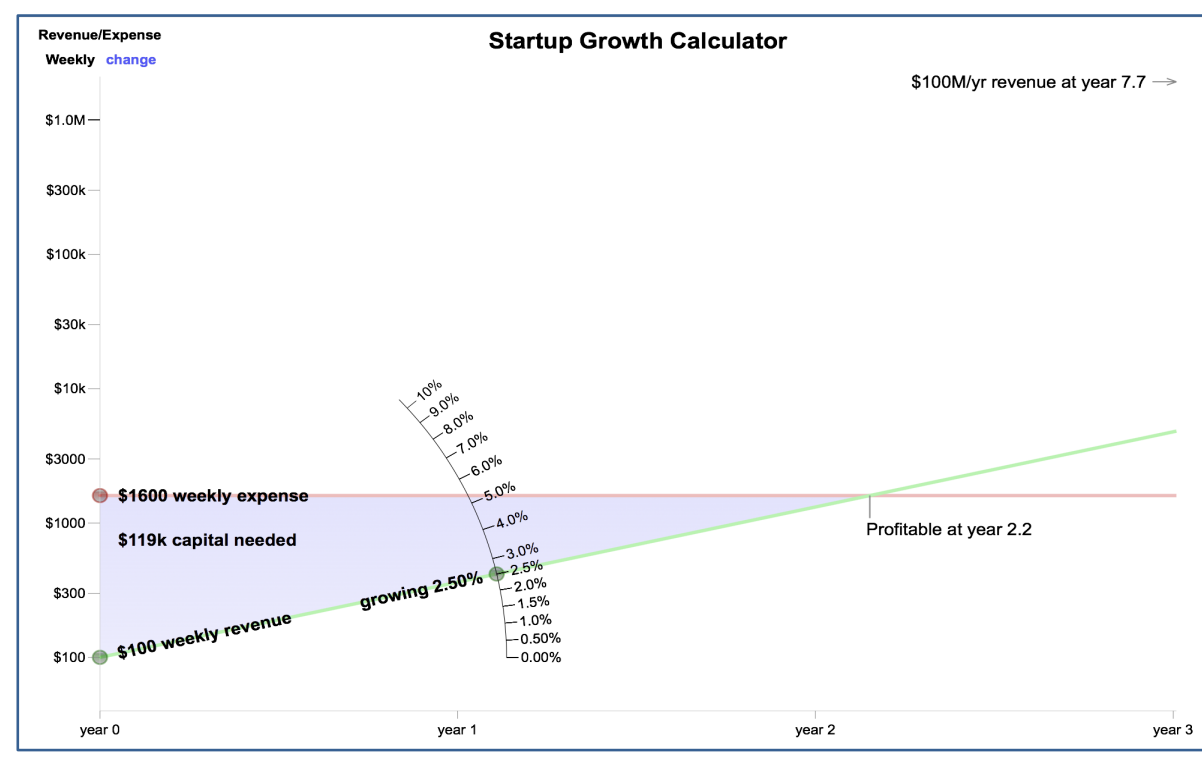

FIGURA 3

Calculadora de crecimiento de start-ups

Fuente: BLACKWELL (2014)

Sin embargo, este crecimiento no se da fácilmente en todas las start-ups, de hecho la tasa de fracaso es "superior al $90 \%$ en relación a las empresas que efectivamente logran sobrevivir respecto de todas las que lo intentan" (Musso, 2012). A la hora de emprender, el mayor riesgo se encuentra en el inicio del proceso, en la etapa denominada "El Valle de la Muerte", según Musso, y corresponde al período que transcurre "desde que un emprendedor inicia su proyecto y empieza a realizar gastos, hasta que eventualmente logra que su empresa esté en equilibrio, es decir, hasta que consigue al menos tener ingresos iguales a sus gastos." 


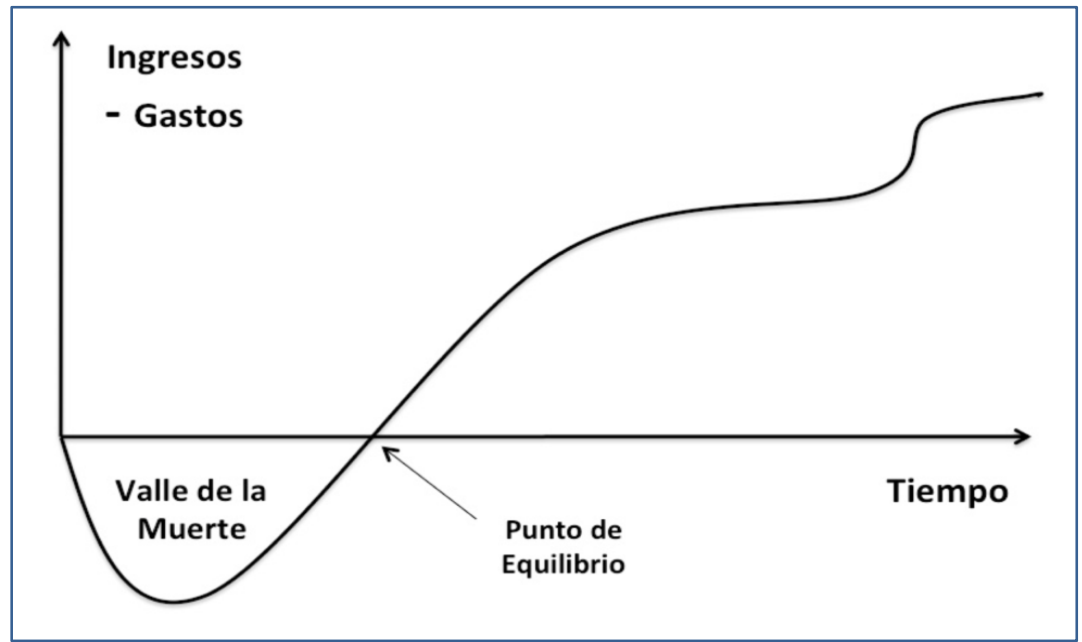

FIGURA 4

El valle de la muerte

Fuente: Musso (2012)

En el diagrama de la FIGURA 4 se puede ver cómo el nivel de utilidad operacional (ingresos menos gastos) varía desde el inicio del proyecto hasta el instante en que los ingresos y los gastos se igualan. El período inicial del proceso de creación de una empresa, es cuando los emprendimientos son más frágiles, es "la fase en que la mayor parte de los emprendimientos fracasa y muere" (Musso, 2012).

Todos los inversionistas en etapas tempranas, como Paul Graham, mencionado anteriormente, buscan invertir en start-ups que tengan un crecimiento acelerado. Esto es especialmente importante para negocios B2C donde generalmente la rentabilidad del negocio está basada en tener grandes volúmenes de usuarios y/o clientes. El término growth hacking, introducido por primera vez por Andrew CHEN (2012) en su blog, y que se refiere a tener como único norte el crecimiento de la compañía, se torna vital en empresas B2C que ofrecen productos, ya que da prioridad al lanzamiento de un MVP previamente validado (es decir, habiendo estudiado el mercado y sabiendo que el valor percibido de lo que se va a ofrecer es alto), con el mínimo presupuesto posible, distribuyéndolo por canales y acciones que intentan explotar al máximo la información, los usuarios y sus características para lograr alcanzar el mayor número de usuarios posibles.

El crecimiento en este tipo de negocios valida que el producto ofrecido tiene la capacidad de atraer clientes/usuarios. En la medida que estos usuarios repitan su interacción, la base de usuarios/clientes crecerá, idealmente de forma exponencial. Por el contrario, si el incremento de número de usuarios se vuelve constante, ese crecimiento como tasa sobre la base de usuarios irá disminuyendo.

El crecimiento asimismo está fuertemente ligado a la valuación de la start-up, dado que una tasa de crecimiento mayor es un indicador de que el negocio podría llegar a alcanzar mayor rentabilidad en el futuro y/o lograr rentabilidad en un plazo menor.

Para que el producto no pierda atractividad entre sus usuarios, la start-up debe lograr un 
crecimiento orgánico en su etapa más temprana, esto es, debe poder captar nuevos usuarios/clientes utilizando su propia energía y recursos y no pagando para conseguirlo. Es por esto que la inversión en marketing en etapas tempranas no es un factor determinante para acelerar su crecimiento, pero sí se vuelve crítica cuando la base de usuarios ha crecido.

\subsection{Agentes de cambio}

Para cualquier tipo de empresas, diferentes de una start-up, la premisa es llegar lo antes posible al mercado de masas, es decir al centro de la campana de Gauss (FIGURA 5) que es donde están la mayoría de los clientes y donde se puede captar un gran volumen de negocio.

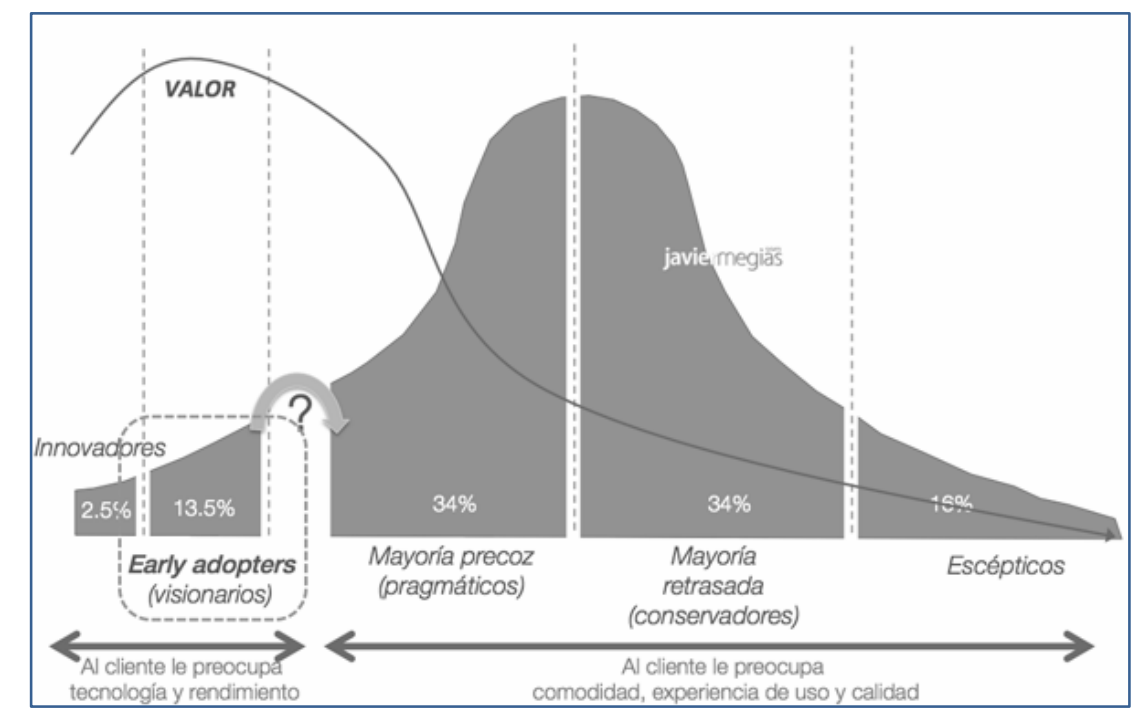

FIGURA 5

Teoría de la difusión de innovaciones

Fuente: ROGERS (1995)

Para las start-ups esto no es tan así, ya que se estarían enfrentando a una competencia difícil de un mercado con cierta antigüedad, donde suele haber mayor número de competidores con mayor experiencia y recursos, por lo que se debería optar por una estrategia de competencia por precio, o bien educar al mercado. Como consecuencia, se vería disminuida la propuesta de valor ya que al intentar satisfacer las necesidades de los clientes que ya están acostumbrados a la oferta de un mercado con cierta antigüedad, el producto se volvería más genérico y perdería su esencia de innovador.

Por esta razón, quizá una buena estrategia para una start-up no sea llegar al mercado de masas, sino buscar nuevos mercados, generar o despertar nuevas necesidades en el consumidor, o suplir necesidades insatisfechas hasta entonces por la oferta actual. Como sugiere Peter THIEL (2014), una start-up no debería enfocarse en competir sino en crear un monopolio. La clave en este punto es centrarse en un mercado que vaya a ser grande dentro de unos años y no precisamente ahora, es decir un mercado incipiente con grandes posibilidades. De esta manera, 
la start-up tendría una posición de líder desde el momento cero. El objetivo no es pensar en un producto que sea escalable, sino en su propuesta de valor para un segmento de personas, aunque sea pequeño y con la idea de que ese grupo crecerá rápidamente.

Según Rogers (1995), hay personas u empresas que son más receptivas que otras a adoptar un nuevo producto o servicio innovador. Así, clasifica a los stakeholders o personas involucradas en cinco grupos (FIGURA 5):

1. Los innovadores: son los primeros que adoptan cualquier producto y asumen los riesgos de introducir y difundir la innovación. Generalmente, son los propios productores de la innovación, acompañados de un grupo de usuarios entusiastas, que pueden ejercer influencia sobre otras personas, o bien personas a las cuales les fascina la tecnologia y se preocupan por descubrir nuevos usos de un producto, y se enfocan en la funcionalidad y no en la forma.

2. Visionarios o adoptantes tempranos (early adopters): son quienes adoptan la innovación por primera vez, cuando entienden que su uso puede ser beneficioso para su negocio. Pueden actuar como líderes e influir en su entorno para que otros actores adopten la innovación.

3. La mayoría temprana (pragmáticos): es la gran masa y espera un producto terminado. Comprende a actores que no están dispuestos a correr riesgos de diversa índole y arriesgar tiempo y otros recursos. Tienen cierta resistencia al cambio, analizan y reflexionan cuidadosamente antes de tomar una decisión. Sin embargo, son propensos a aceptar la innovación después de tener ciertas referencias de otros usuarios.

4. La mayoría tardía (conservadores): son sumamente resistentes a cambiar, son más tradicionales y cautelosos, difíciles de persuadir para adoptar una innovación; solo lo hacen cuando la nueva tecnología o producto es de uso común en la sociedad.

5. Rezagados o escépticos: es la categoría de personas más resistentes al cambio, se muestran indiferentes ante cualquier innovación e incluso llegan a oponerse a ella y a combatirla activamente. Son muy tradicionales, amantes del status quo y con frecuencia nunca llegan a adoptar la innovación o solo lo hacen si existe una fuerte presión en su entorno para hacerlo.

Luego de haber identificado correctamente el público meta, es decir, el segmento al que la start-up apuntará, es el momento de iniciar acciones para captar debidamente a dichas personas. ROGERS (1995) resalta la difusión como el proceso por medio del cual una innovación es comunicada al segmento a través de determinados canales durante cierto tiempo. Se destacan los procesos de difusión que comienzan lentamente entre los early adopters, que luego pasan a ser una comunidad creciente de usuarios adoptivos. Este tipo de usuarios/clientes dará feedback para mejorar el producto o servicio hasta llegar a una versión que sea capaz de ser adoptada por el resto de los stakeholders.

\subsection{Canales de marketing}

La promoción y comercialización en general se consideran como la clave de la supervivencia, 
el desarrollo y el éxito de pequeñas o nuevas empresas (CARSON, CROMIE et al., 1995).

Antiguamente se asumía que las start-ups requerían una versión simplificada de las prácticas de marketing sofisticadas que se desarrollaron para empresas más grandes (KRAUs et al., 2010). Allí se introdujo el concepto de marketing emprendedor (EM), definido por BJERKE et al. (2004) como la "comercialización de pequeñas empresas que crecen a través del emprendimiento". También las definen MORRIS et al. (2002), como "las acciones de marketing visionarias no planificadas, no lineales del emprendedor" y STOKES $(2002,04)$ como "marketing llevado a cabo por empresarios o propietarios/gerentes de empresas emprendedoras". Finalmente, KRAUS (2010) define el concepto de marketing emprendedor como "una función organizacional y un conjunto de procesos para crear, comunicar y entregar valor a los clientes y administrar las relaciones con los mismos de manera que beneficien a la organización y sus partes interesadas, y que se caracterice por su capacidad de innovación, asunción de riesgos, proactividad, y se pueda llevar a cabo sin los recursos actualmente controlados".

Hoy en día, llevado a la práctica, existen tres formas conocidas de EM, el marketing de opinión (buzz marketing), el marketing de guerrilla y el marketing viral (KRAUS, 2010):

Marketing de opinión: este enfoque utiliza el correo electrónico del destinatario o las redes de telefonía celular para generar un "zumbido" alrededor de un producto o una marca, aumentando así el interés de los clientes. Estas acciones pueden ser, por ejemplo, un evento o una actividad que cause entusiasmo, genere publicidad y un deseo de obtener más información sobre el producto, lo que conduce a la creación de marca (AHUJA et al., 2007). Algunos estudios, respaldados por estadísticas reales (Nielsen BuzzMetrics), muestran que este enfoque no es tan eficiente para todo tipo de producto o servicio. De hecho, para ser un buen candidato para este tipo de marketing, un producto tiene que ser único en algunas características en comparación con sus competidores (por ejemplo, funcionalidad, facilidad de uso, precio) y altamente visible. Las campañas de promoción de Harry Potter o Pokémon han sido ejemplos populares efectivos de este tipo de marketing (DYE, 2000).

Marketing de guerrilla: este término fue popularizado por Jay Conrad LEVINSON (2007), quien identificó una variedad de técnicas de mercadotecnia de bajo costo y alto impacto que permiten a las pequeñas empresas y/o individuos actuar como grandes compañías. Hoy este concepto ha sido adaptado y aplicado a la economía moderna, introduciendo un uso extensivo de nuevos canales sociales y móviles. Uno de los más exitosos en técnicas de marketing de guerrillas es Red-Bull, con su estrategia de promoción poco convencional, junto con otras grandes empresas, como Nike o McDonalds (LEVINSON \& LEVINSON, 2011).

Marketing viral: este término describe una mecanismo de marketing que utiliza las redes sociales para llamar la atención sobre las marcas, los productos o las campañas mediante la difusión de mensajes a una velocidad comparable con la de un virus (PHELPS et al., 2004). Es importante tener en cuenta que tanto el marketing buzz como el viral pueden considerarse como marketing de boca en boca, pero el marketing viral es la versión impersonal (sin comunicación cara a cara) y es respaldada por tecnología del marketing de buzz (MOHR \& SPEKMAN, 1994). Los enfoques más recientes del marketing viral sugieren un modelo híbrido que usa medios tradicionales para sembrar las primeras etapas de las campañas. No obstante, el éxito de la campaña se basa en gran medida en la capacidad de compartir que brindan las redes 
sociales (WATTS \& PERETTI, 2007). Un ejemplo clásico de marketing viral eficaz es la campaña "Obtenga su correo privado y gratuito en http://www.hotmail.com" de Hotmail.com, que llegó a 12 millones de usuarios en menos de 18 meses (JURVETSON, 2000).

La principal ventaja de cada uno de los enfoques discutidos es el costo extraordinariamente bajo de implementación mediante el uso de canales de comunicación nuevos y económicos, como lo son Internet y el correo electrónico (ZILBER et al., 2012), características que hacen que el EM sea ideal para start-ups.

\subsection{Etapas de financiamiento: de la idea a la Bolsa}

Una de las dificultades a la hora de emprender, como se vio en la SECCIÓN 1.6, es el acceso al financiamiento, las barreras que existen para conseguirlo, y saber además identificar en qué momento se necesita realmente y a quién acudir.

Segun Carlos BLANCO (2014), inversor ángel de la Asociación Española de Business Angels (AEBAN), existen siete fases de inversión que toda start-up debería seguir, que están fuertemente relacionadas con las diferentes fases por las que atraviesa un emprendimiento (SECCIÓN 1.4), y por lo tanto a la etapa de desarrollo en la que se encuentra según la curva S (ver FIGURA 2), aunque se debe tener en claro que no todos los negocios requieren siempre del mismo tipo de inversión. Cabe aclarar que el capital de los fundadores y de los inversores iniciales se irá diluyendo a lo largo de las etapas de financiamiento, con la progresiva pérdida de poder en la toma de decisiones que esto conlleva, pero es un riesgo que vale la pena correr para que la startup logre triunfar.

La infografía siguiente (FIGURA 6) representa cómo funciona el financiamiento de las start-ups desde la idea hasta la Oferta Pública Inicial (OPI), es decir, la primera venta de acciones de una empresa privada al público: 


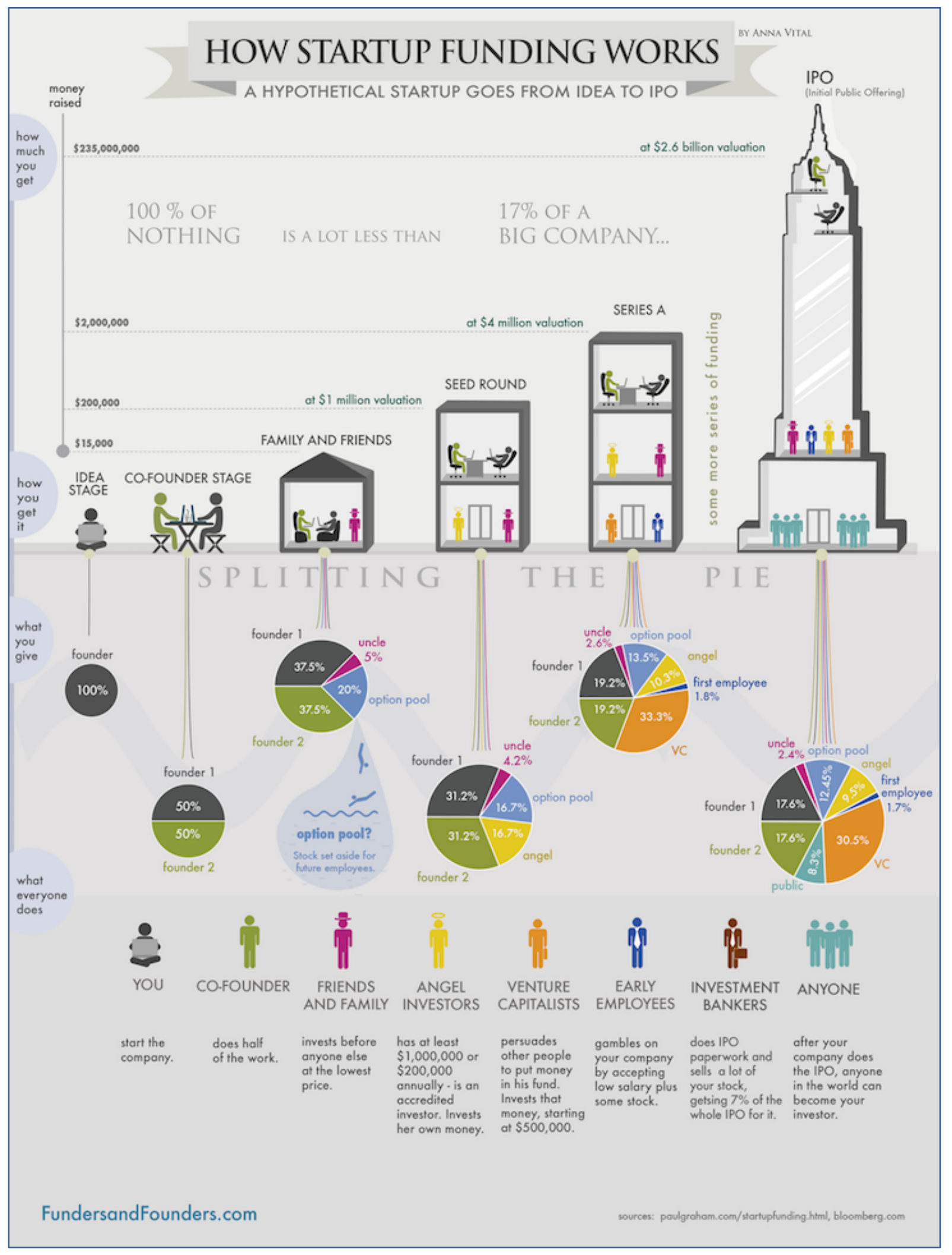

FIGURA 6

Financiamiento en start-ups

Fuente: Funders and Founders 
A continuación se describen cada una de las etapas, de acuerdo al análisis de Carlos BLANCO (2014):

\subsubsection{Inversión de los emprendedores}

Los primeros en invertir en la empresa dentro de sus posibilidades deben ser los propios emprendedores/fundadores, y esto será sumamente valorado posteriormente por los inversores en etapas futuras. Algunos lo hacen con dinero que tienen ahorrado, otros piden algún tipo de préstamo o utilizan la indemnización de su trabajo anterior, etc.

\subsubsection{FFF (Friends, Family and Fools)}

Amigos, familia y "tontos" son las personas del entorno del emprendedor, contactos del presente o del pasado que confían en su proyecto, y que con un mínimo aporte de todos ellos se puede conseguir una buena suma para impulsar el negocio, y que también influirá cuando un inversor posteriormente tenga que invertir en su proyecto, al ver que la persona demuestra confiabilidad.

\subsubsection{Aceleradora o incubadora}

Una aceleradora o incubadora de start-ups puede ayudar al emprendedor a encauzarse en su camino, brindando servicios de mentorías, espacio de trabajo y principalmente contactos, y ayuda en la definición del modelo de negocios. De todos modos BLANCO (2014), recomienda para la fase de pre-incubación (SECCIÓN 1.4), que el equipo trabaje en construir el producto mínimo viable (MVP) o prototipo sin "vicios", con sus propios recursos y siguiendo la metodología "Lean Startup" (RIES, 2012). Una vez lanzado el MVP, y habiendo recolectado mínimamente información de los usuarios y el mercado de manera tal de poder aplicar métricas, la start-up está en condiciones de ingresar en una aceleradora.

\subsubsection{Plataformas de inversión online}

Este tipo de plataformas, denominadas plataformas de crowfunding, podría sustituir a la fase de FFF, o servir tanto como ronda de inversión previa a la de business angels, que se describe en la próxima subsección, o ayudar a completar dicha etapa. Básicamente el crowdfunding se trata de un mecanismo colectivo de financiación de proyectos, basado en plataformas de inversión de riesgo, que permiten al emprendedor subir su proyecto, buscando inversión a cambio de acciones/equity, regalías o la adquisición del producto/servicio a un costo menor al valor del mercado. First Tuesday, Afluenta, South Ventures, The Crowd Angel, Kickstarter, Lanzanos, entre otras, son ejemplos de plataformas de este estilo. 


\subsubsection{Inversores ángeles (Business Angels)}

En el momento en el que el emprendimiento logra cierta tracción de usuarios/clientes, ha comenzado a facturar y a tener métricas cuantificables del negocio, deja de ser solo viable y pasa a tener cierto atractivo para el ojo inversor. Ese es el momento de acudir a un business angel, que son inversores que invierten hasta aproximadamente U\$D 500.000. Según Domingo GUERRA (EI Valle de los Tercos, 17 de enero de 2019), "en un mundo ideal, es mejor no tener inversionistas si podes financiar el proyecto de tu bolsillo, de esta manera no hay que ceder ningún porcentaje de la empresa, pero esto no es así en la realidad, ya que si no levantás capital, no tenés ayuda de negocios ni económica, que es necesaria para salir adelante". Conviene siempre conseguir smart money, es decir, dinero de inversores ángeles que saben de la temática y aportan conocimiento además de capital, y, cuanto más se pueda subsistir y crecer con recursos propios, mejores herramientas tendrá el emprendedor para afrontar las negociaciones con los inversores. Los inversores ángeles están tendiendo cada vez más a agruparse en redes de inversores, Business Angels Networks (BAN), o ir de la mano de aceleradoras como Conector o SeedRocket.

\subsubsection{Fondos de inversión (Seed Capital)}

Cuando el emprendimiento se vuelve aún más interesante para los inversores, es cuando surgen los fondos especializados en capital semilla (Seed Capital), en su mayoría inversores locales que invierten una mayor suma de dinero que los business angels, y si la start-up se encuentra en una etapa de expansión global y crecimiento exponencial, pueden llegar a invertir más de un millón de dólares en ella.

\subsubsection{Fondos de inversión (Growth Capital)}

Entran en juego cuando la compañía está consolidada en el mercado, tiene un producto terminado, y ya se encuentra facturando varios millones, es decir que posee una valoración alta, y se precisa una ronda de inversión grande. Son fondos internacionales o Venture Capitals (VC). En esta etapa, la start-up puede obtener una inversión superior a un millón de dólares. Una vez realizada la inversión, el fondo obtendrá un porcentaje de la start-up en acciones, que estará ligado a la valoración de la start-up.

$\square$ Valoración pre-money: el valor de la start-up antes de cerrar la ronda de inversión.

Valoración post-money: el valor de la start-up después de haber recibido la inversión, es decir, la suma de la valoración pre-money más la nueva inversión.

Accel Partners, Earlybird, Point Nine e Index Venture son algunos de los fondos de inversión internacional más conocidos.

\subsubsection{Venta}

Habiendo pasado por varias rondas de capital riesgo existen dos opciones: 
1. Vender la start-up a alguna gran firma (como por ejemplo, Mercado Libre que adquirió deRemate.com [STARTUPS WAY, 6 de julio de 2015], o Waze que fue comprada por Google).

2. Salir a bolsa de valores, que sea cual fuere, es una decisión sustancial para una start-up, que podría tomar luego de haber pasado por varias rondas de financiación. Este cambio implica migrar del capital privado a público y acceder a numerosos beneficios como financiación para el crecimiento de la empresa, liquidez para los accionistas, valoración objetiva de la compañía, apoyo en la internacionalización, etc.

Sin embargo, desde el punto de vista del inversor, existen otras opciones de salida, que son estipuladas en el "pacto de socios" previo a su entrada en la compañía. En líneas generales, en este pacto, según HeRNÁNDEZ-PuÉRTOLAS PAVÍA (2018, marzo 26) "se regulan aquellas situaciones que tienen consideración de evento de liquidez y en el caso que ocurran, se regula el mecanismo por el cual se produce la desinversión y las formas de valoración de la misma". El autor alega que estas alternativas están ligadas a la capacidad de la start-up de aportar valor económico, a través de su propio funcionamiento, o bien por financiación externa mediante la entrada de nuevos inversores o entidades de crédito (eventos de liquidez). "En definitiva, lo que se intenta en este pacto de socios es dar tranquilidad a los inversores, para que en el caso de que por algún motivo la compañía llegue a un momento en que cuenta con recursos suficientes, el inversor pueda recuperar su inversión (parcial o totalmente) con un margen de ganancia" (HERNÁNDEZPUÉRTOLAS PAVÍA, 2018, marzo 26). Un buen ejemplo de este escenario es la salida parcial de la start-up de reparto Glovo, uno de los éxitos de financiación de The Crowd Angel (DE LA VEGA, 2017), que levantó 30 millones de euros a finales del 2018 y que debido a ello, algunos de los inversores que habían ingresado como socios en la compañía pudieron vender sus acciones, multiplicando el capital invertido y obteniendo beneficios en tan sólo dos años, completando así todo el ciclo de la inversión (THE CROWD ANGEL, 2018).

\subsection{El ecosistema de Silicon Valley}

Hace más de medio siglo, este valle ubicado en California, en una franja de 60 millas en el Área de la Bahía entre San Francisco y San José, es el epicentro de la innovación y el emprendedurismo. Siendo el principal punto de acceso de alta tecnología en el mundo, y habiendo logrado una renovación constante, alberga más start-ups que cualquier otra región, así como también a los gigantes del mundo IT como Google, Apple, HP, Oracle, Cisco, Facebook, LinkedIn, Uber, Airbnb, WhatsApp, Twitter, Dropbox, Instagram, Salesforce, VMWare y muchos más. Todas estas empresas en sus inicios fueron start-ups, y hoy han logrado cambiar por completo el estilo de vida, la forma de pensar, trabajar y comunicarse de toda la humanidad.

La economía de esta región es innovadora y recibe constantemente emprendedores ambiciosos, apasionados, que tienen como objetivo romper con los mercados y las tecnologías convencionales. Según ESTER (2017, 01), Silicon Valley es "un ecosistema bien integrado y equilibrado en el que todos los elementos constitutivos se alinean para promover y sostener la innovación de vanguardia y el emprendimiento pionero"; "es un imán para los emprendedores de alta tecnología que desean sobresalir, y su clima de negocios se basa en una combinación única de talento, ideas, creatividad, competitividad, perseverancia y pasión" (ESTER, 2017, 02). 
En este sentido MUNROE (2009) agrega "es un sistema casi orgánico y prototípico que genera un hábitat duradero y resistente para que la innovación y las nuevas empresas prosperen".

En Silicon Valley casi la mitad de todas las nuevas empresas están fundadas por inmigrantes de primera generación, particularmente de India y China. Algunos empresarios inmigrantes se han vuelto extremadamente exitosos y son importantes modelos a seguir: Sergey Brin (Google), Andrew Grove (Intel), Vinod Khosla (Sun Microsystems), Jan Koum (WhatsApp) y Elon Musk (Tesla).

En el ecosistema de innovación del Valle, podemos encontrar los siguientes elementos clave (FIGURA 7), cada uno con roles diferentes, pero que se apoyan entre sí (MUNROE, 2009):

1. Universidades de investigación de clase mundial

2. Emprendedores

3. Capital de inversión

4. Una fuerza laboral talentosa y bien educada

5. Redes sociales y profesionales

6. Un clima de negocios favorable

7. Un cociente de alta calidad de vida

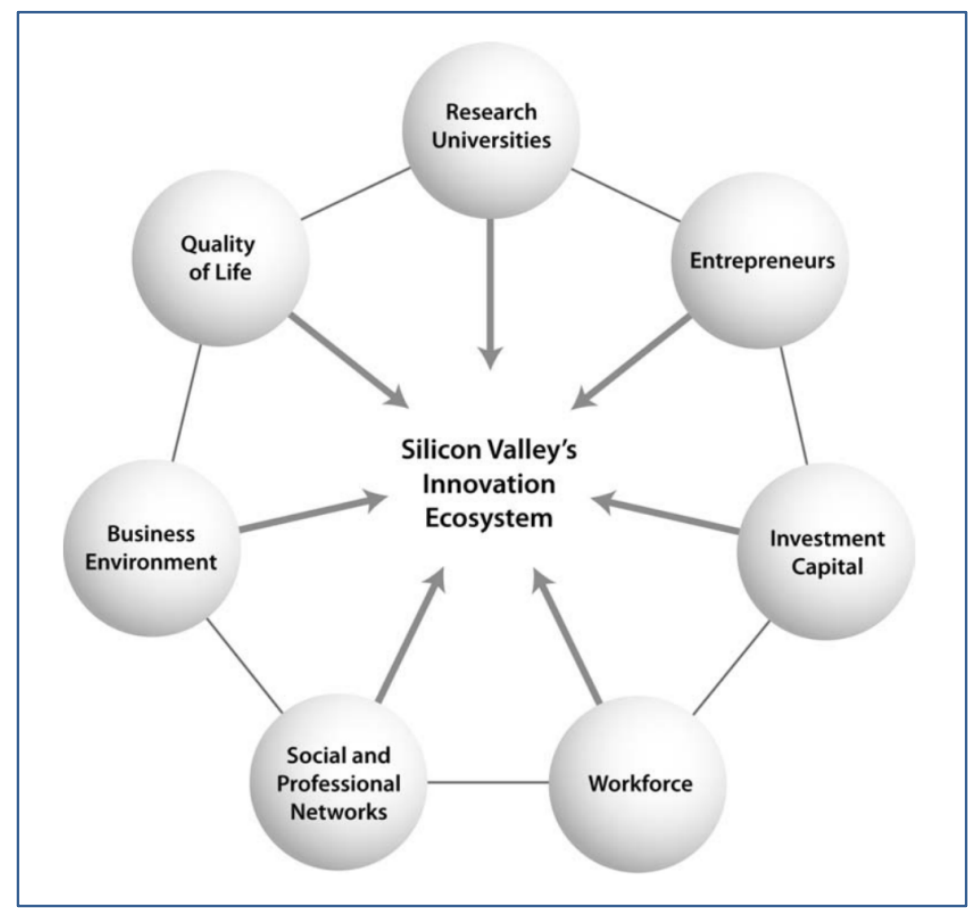

FIGURA 7

Los siete elementos claves del ecosistema de innovación de Silicon Valley

Fuente: MUNROE (2009) 
Cada uno de estos elementos contribuye de muchas maneras interconectadas al éxito de las start-ups, y al hacerlo, contribuyen a su propia prosperidad y a la prosperidad de la región. La innovación y el cambio tecnológico son, sin duda, los principales motores del crecimiento económico a nivel organizativo, industrial y macroeconómico. El punto fundamental es que sin innovación no hay aumento en la productividad, y sin productividad, no hay aumento en la prosperidad. La suma del ecosistema de Silicon Valley es mayor que sus partes. La siguiente figura (FIGURA 8) representa el modelo de innovación y start-up de Silicon Valley:

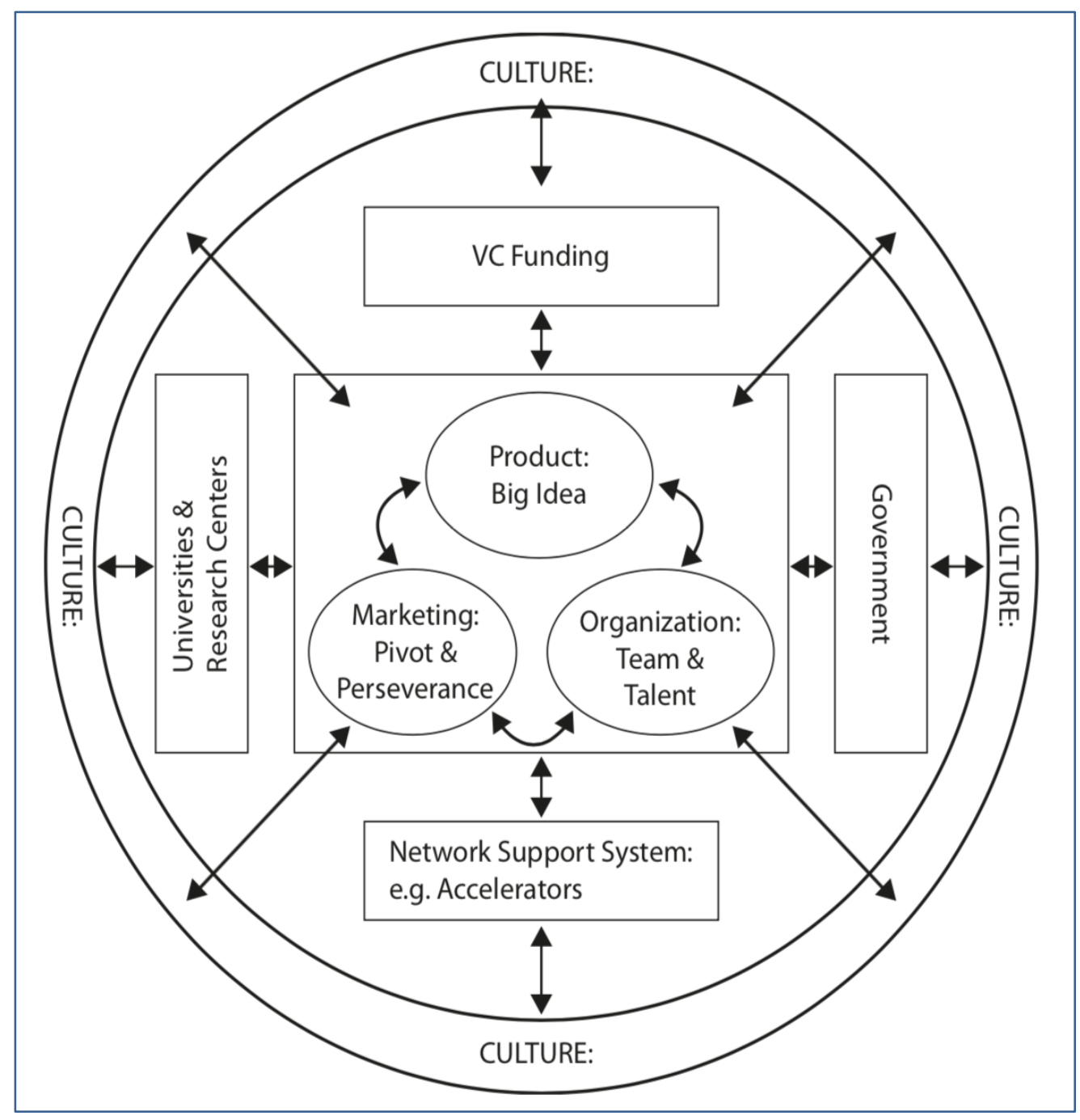

FIGURA 8

The Silicon Valley Innovation and Startup Model

Fuente: $\operatorname{ESTER}(2017,01)$

Acorde a lo expuesto por ESTER $(2017,01)$, este modelo distingue tres niveles diferentes que interactúan entre sí: 
1. El "nivel micro" (bloque central, anillo interior) especifica tres factores principales que se relacionan con la manera en que se encuadra el éxito esperado de la start-up en el Valle:

a. la start-up debe basarse en una gran idea que realmente sacudirá y cambiará el mercado (producto/servicio);

b. la nueva empresa debe ser dirigida por un equipo fuerte, que tenga éxito en la contratación de los mejores y más talentosos recursos disponibles (equipo y talento);

c. Los fundadores deben ser capaces de pivotar oportunamente su estrategia de negocio original cuando las circunstancias cambian rápidamente (pivot y perseverancia).

2. El "nivel meso" (bloques externos, anillo interior) identifica cuatro instituciones que han sido fuertemente influyentes en la creación del ecosistema de Silicon Valley:

a. acceso a una amplia financiación de nuevos negocios de capital de riesgo;

b. acceso a universidades y centros de investigación de alto nivel que sobresalen en innovación, trabajan en estrecha colaboración con la industria y promueven activamente nuevas empresas;

c. un gobierno que invierte en innovación, cree en este tipo de economía de emprendedurismo, y es quien establece el conjunto de reglas de mercado;

d. la presencia de un sólido sistema de redes de agencias de soporte de start-ups, como aceleradoras, asesores legales y mentores. Las aceleradoras ayudan a las nuevas empresas en su proceso de desarrollar y hacer pivotar su producto y llevarlo al mercado, refinan su modelo de negocios y estrategia de marketing, capacitan a los equipos fundadores y mejoran sus habilidades, ofrecen acceso a fondos, les ayudan a conseguir sus primeros clientes y ventas, entre otras cosas.

3. El "nivel macro" (anillo exterior) apunta a la cultura típica de Silicon Valley que aplaude el espíritu empresarial y comparte la innovación, favorece la búsqueda apasionada de los grandes sueños, enfatiza la apertura y el aprendizaje, es propenso al riesgo y tolera el fracaso, y proporciona encuadre perfecto para la mente de un emprendedor. Es una cultura que también afecta a los otros dos niveles.

En lo que a números respecta, conforme a los cálculos citados por ESTER $(2017,02)$, resulta ser que si el Área de la Bahía, con Silicon Valley como su núcleo tecnológico y económico, fuera un país, ocuparía el puesto 19 en términos de PBI. Asimismo, este estudio revela que el Valle tiene, desde hace décadas, la mayor concentración de start-ups (entre 14.000 y 19.000) en el mundo. “Alberga más compañías de los Estados Unidos y Fortune Global 500 (un escalafón de las primeras 500 empresas de todo el mundo, medidas por los ingresos) que en cualquier lugar de los Estados Unidos, excepto Nueva York". Siguiendo con las estadísticas, el autor indica que 5 de cada 10 dólares de capital de riesgo de los Estados Unidos se gastan en Silicon Valley, lo que refleja la amplia disponibilidad de fondos de capital de riesgo allí. Ha lanzado más unicornios que cualquier otro lugar en los Estados Unidos. Solo en 2014, el Valle tuvo 14 OPI, que fue un poco menos del $10 \%$ del número total en Estados Unidos. El volumen de salida a la bolsa de Silicon Valley representa la mitad del valor de las salidas de start-ups dentro de los veinte 
principales ecosistemas de start-ups globales y domina estas clasificaciones principales en términos de rendimiento, financiamiento y talento.

Su enfoque en la alta tecnología se refleja en la gran cantidad de patentes que se originan en allí: casi 16.000 en 2013 (13\% del total de Estados Unidos en ese año). La I+D en esta región es vital ya que sus negocios se basan en la innovación; es por esta razón que Apple y Google, dos de los principales jugadores de Silicon Valley, gastan más de 12,5 billones de dólares en sus esfuerzos de investigación y desarrollo. Con universidades de clase mundial privadas y públicas, como Stanford y Berkeley, en su medio, el Valle ofrece acceso a un abundante grupo de graduados talentosos e investigación fundamental y aplicada de alta calidad. Además, la región alberga un gran número de reconocidos laboratorios de I+D corporativos y no corporativos. Como desventaja, como dijo Santiago TeMPONE (EI Valle de los Tercos, 28 de marzo de 2019), "el acceso a recursos del valle se dificulta, además de tener un costo muchísimo mayor", por eso muchas veces las start-ups tienen equipos de desarrollo distribuidos fuera del Valle, y allí solamente prevalecen los altos mandos y el equipo de negocios. 


\section{El EMPRENDEDURISMO EN ARgENTINA}

\subsection{Evolución}

Según el GEM, la actividad emprendedora en Argentina ha crecido en la última década y su comportamiento ha demostrado ser cíclico, copiando el contexto económico prevaleciente.

Luego de un largo período de recesión y depresión iniciado en 1998, fue recién hacia finales de 2003 que comenzó a revertirse la dinámica empresarial negativa que se venía dando en el país. Así, según los datos elaborados por el Observatorio del Empleo y la Dinámica Empresarial del Ministerio de Trabajo, Empleo y Seguridad Social, en el período 2003-2007 el proceso de creación de empresas fue positivo, ya que de un stock de 343.000 empresas al 31/12/2002, se pasó a un total de 451.000 firmas al 31/12/2007, incorporándose formalmente a la economía argentina algo más de 100.000 nuevas empresas.

La mitad de la creación bruta de empleo y más de la mitad del cambio neto fue generado por empresas jóvenes (CASTILLO et al., 2006). La tasa de empresas emergentes (menores a tres meses) ha crecido casi un $40 \%$ desde 2001, mientras que la tasa de "nuevos empresarios" (entre tres y cuarenta y dos meses) se ha más que duplicado en la última década, alcanzando un máximo en 2009-2010. Siguiendo esta tendencia, el espíritu empresarial en las mujeres ha crecido a más del doble desde 2000. Según ENDEAVOR (2013), "13 de cada 100 mujeres adultas en la Argentina desarrolla alguna actividad emprendedora, desde un proyecto en paralelo a un trabajo en relación de dependencia hasta una empresa en vías de consolidación".

Segun Ascúa (2009), "en el año 2007 nacieron unas 57.000 empresas y murieron 46.000 firmas; 2005 fue el mejor año de la post-convertibilidad, con 62.000 nuevas empresas y 26.000 cierres. En el 2002, en lo peor de la crisis, abrieron sólo 19.000 empresas y cerraron 38.000 , y el stock de empresas se ubicó, ese año, en el piso de 343.000 empresas". En el período 1996-2007, las empresas jóvenes explicaron el $44 \%$ del empleo total, el $72 \%$ de la creación bruta y el $60 \%$ de la destrucción bruta de puestos. En este grupo de empresas jóvenes, operan dos variables en sentido inverso: en el inicio el crecimiento es más rápido pero, a su vez, la mortalidad temprana de empresas jóvenes es también elevada. 


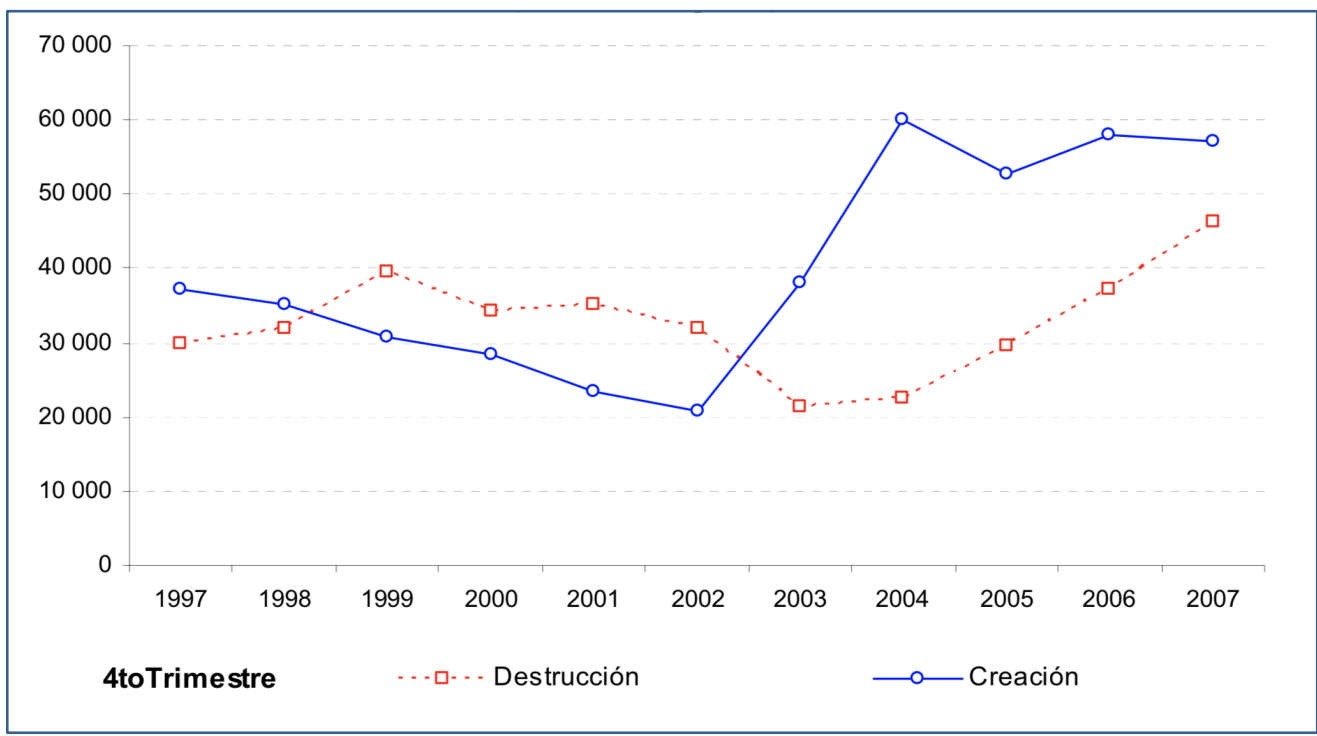

FIGURA 9

Evolución empresarial argentina

En general, las empresas ingresan al mercado con un tamaño inicial reducido y tienen un crecimiento acelerado que les permite alcanzar el tamaño medio de establecimiento de toda la economía en sus primeros años de operaciones, para luego seguir una trayectoria estable (MATA, Portugal \& GUIMARAes, 1995). Para el caso argentino, el tamaño inicial ronda los 4 ocupados promedio y es menor en los años de crecimiento ( 3 empleados) debido a que, en los períodos expansivos, suele incrementarse la tasa de entrada de firmas (FIGURA 10).

\begin{tabular}{|lcccccccccc|}
\hline Cohorte & 1996 & 1997 & 1998 & 1999 & 2000 & 2001 & 2002 & 2003 & 2004 & 2005 \\
\hline Tamaño medio inical & 3,9 & 3,5 & 3,5 & 3,4 & 3,6 & 3,6 & 3,8 & 3,6 & 2,9 & 3,0 \\
Nacimientos (miles) & 38,8 & 37,7 & 35,4 & 31,0 & 28,8 & 23,7 & 20,7 & 39,9 & 60,0 & 52,9 \\
\hline
\end{tabular}

FIGURA 10

Tamaño medio inicial de las empresas creadas a partir de 1996 según cohorte, en número de ocupados

Fuente: Observatorio de Empleo y Dinámica Empresarial DGEYEL, SSPTYEL, MTEYSS, en base al SIJyP

\subsection{Factores que influyen en el emprendedurismo argentino}

El emprendimiento impulsado por la oportunidad está creciendo, aunque su contraparte basada en la necesidad todavía juega un papel importante. Dos de cada tres nuevos 
emprendedores están motivados por la oportunidad y el restante comienza su propio negocio por necesidad. Esta proporción varía según la etapa del ciclo económico de Argentina que se mida.

Los empresarios de Argentina se destacan por ser innovadores, y por confiar en sus habilidades y conocimiento para comenzar nuevas empresas. Sin embargo, existe un sentimiento creciente entre la población sobre la falta de oportunidades para el emprendimiento, debido al contexto económico y político. En su mayoría se trata de hombres, con una edad promedio entre los 25 y 44 años, y con un nivel superior de educación. La mayoría de las nuevas empresas se dedican a la venta al por menor, la agricultura y los servicios profesionales.

La Encuesta Nacional de Expertos de GEM arroja como resultado que la política gubernamental es el factor principal que afecta negativamente al emprendimiento en Argentina, seguido por los mercados financieros. En particular, la falta de capital de riesgo y un estado de derecho claro, las cargas regulatorias y un entorno político y económico difícil son los principales desafíos a los cuales los empresarios deben enfrentarse y superar.

Según los mismos expertos, los principales factores que impactan positivamente en el emprendimiento en Argentina son la apertura del mercado, las normas culturales y sociales, la infraestructura física, los servicios profesionales y la educación. Las iniciativas que apoyan y estimulan el emprendimiento en Argentina son las lideradas por ONG, universidades, inversores ángeles, corporaciones y algunos gobiernos locales, a través de la educación, la inversión y las políticas públicas.

En el ámbito público se ha comenzado a trabajar en iniciativas a nivel nacional y local con distintos grados de intensidad. A través de la Secretaría de PYME, el gobierno nacional ha desarrollado diferentes programas para alentar el crecimiento de nuevas empresas, pero no han tenido demasiado éxito. Estos incluyen Innovar, Fonsoft, Fontar, Pacc y Capital Semilla, entre otros.

El gobierno de la ciudad de Buenos Aires ha sido el pionero, con los primeros programas de coinversión para empresarios e incubación para empresas de diseño y tecnología. Estos incluyen Desarrollo Emprendedor, Buenos Aires Emprende, Incuba y Baitec. Asimismo, se ha lanzado una iniciativa centrada en la creación y financiación de nuevos aceleradores de la innovación. Las dos primeras aceleradoras privadas dedicadas a la tecnología fundadas en Buenos Aires son Wayra (Telefónica) y NXTP Labs.

Además, interesantes programas de colaboración como NAVES La Pampa, Incutex en Córdoba y la Ley de Emprendedores en Jujuy demuestran cómo el ecosistema emprendedor argentino está creciendo.

\subsection{Comparación con otros países}

En comparación con otros países de la región de América Latina, Argentina generalmente se ubicó en el medio, con la mayoría de sus tasas de actividad y actitudes empresariales cercanas al promedio regional. 
Analizando cada país, ESTENSSORO (2017) cita a GARCíA ROBLES, una especialista argentina que lidera los programas de inversiones de capital semilla y capital emprendedor del Fondo Multilateral de Inversiones del Banco Interamericano de Desarrollo para América Latina y el Caribe, quien señala: "Como Brasil es tan grande, durante mucho tiempo sus emprendedores solo pensaron en proyectos nacionales, tardaron más en internacionalizarse. En México, el otro gran mercado, la cultura es muy jerárquica, por eso a los emprendedores les costó hacerse oír. Chile tiene las mejores políticas públicas pero sus emprendedores no tienden a asumir grandes riesgos, les cuesta sacudir el bote". Colombia también tiene políticas activas excelentes para incentivar el emprendedurismo, pero prevalece una visión localista, en la que les es difícil "pensar en grande". En contraparte, los argentinos son más agresivos, demuestran más confianza en sí mismos y en general son más abiertos para trabajar y armar equipos con personas de distintos países y culturas.

\subsection{Inversión en Ciencia y Tecnología (СyT)}

Mientras el Consejo Asesor de Ciencia de las Naciones Unidas recomienda que los países inviertan al menos el 3,5\% de su PBI en CyT, la Argentina apenas invierte 0,6 \% (ESTENSSORO, 2017). El presupuesto para investigación en Argentina ascendió en 2016 a 4.650 millones de dólares, cifra cien veces menor a la invertida por Estados Unidos y 8,5 veces inferior que Brasil.

Si bien las pequeñas empresas son las que más invierten en I+D en relación con su facturación $(0,74 \%$ de sus ventas anuales), proporción que prácticamente quintuplica a la correspondiente a las grandes empresas $(0,15 \%)$, son también las que revelan un mayor grado de informalidad en este tipo de tareas. Según un estudio realizado por AZPIAZU et al. (2000), sólo el $13 \%$ de las pequeñas empresas tienen estructuras formales de I+D, y en las medianas firmas alcanza al $33 \%$.

Tanto el gobierno como el sector privado deben incrementar sustancialmente la inversión en $1+D$, para poder convertir a la Argentina en un país que sea sinónimo de innovación científica y tecnológica aplicada a la producción de bienes y servicios en todas las áreas de la economía. Para esto, se debe tener en cuenta que se requiere de mucha perseverancia y seriedad, "apostar al ecosistema y no al egosistema" (ESTENSSORO, 2017).

\subsection{Acceso a financiamiento}

La reestructuración de la economía argentina de las últimas décadas trajo aparejada una profundización de las tradicionales disparidades en el financiamiento de las empresas e, incluso, la irrupción de otras nuevas asimetrías. Todas ellas aumentaron sustancialmente las diferencias ya existentes en favor de las grandes firmas en detrimento de las pequeñas y medianas empresas.

Según AZPIAZU et al. (2000), en los últimos años ciertos rasgos característicos del desempeño de las PYMES emergieron como sus fuentes de financiamiento preponderantes (pero no excluyentes), como la reinversión de utilidades, el crédito de proveedores, y los propios aportes de recursos genuinos por parte de los socios. De esta manera, la participación en el crédito 
ofrecido por el sistema financiero local se vuelve más acotado, excluyente y más caro, concentrándose acentuadamente en el financiamiento del consumo y del núcleo de los sectores empresarios más concentrados: las grandes firmas de capital local y transnacional.

En ese marco, surge como constante el racionamiento y las altas tasas de interés para las PyMES, e incluso para firmas mediano-grandes de capital nacional no integradas a grandes grupos económicos. En tal sentido, el mercado de capitales local continúa resultando irrelevante en materia de financiamiento de las empresas, en general, y de prácticamente nula gravitación en el caso de las Pymes. En otras palabras, el creciente grado de concentración del crédito bancario en un número muy acotado de grandes empresas, regiones y sectores de actividad, el reducido plazo promedio de los préstamos, y las muy elevadas tasas de interés real atentan contra las posibilidades de apoyo financiero al desarrollo de las PyMES. 


\section{FACTORES CRÍTICOS DE ÉXITO Y FRACASO EN START-UPS}

Los cinco factores más importantes para el éxito en más de doscientas compañías (FIGURA 11) según Bill GROSS, en su charla TED "La razón más importante por la que las start-ups tienen éxito", son los siguientes:

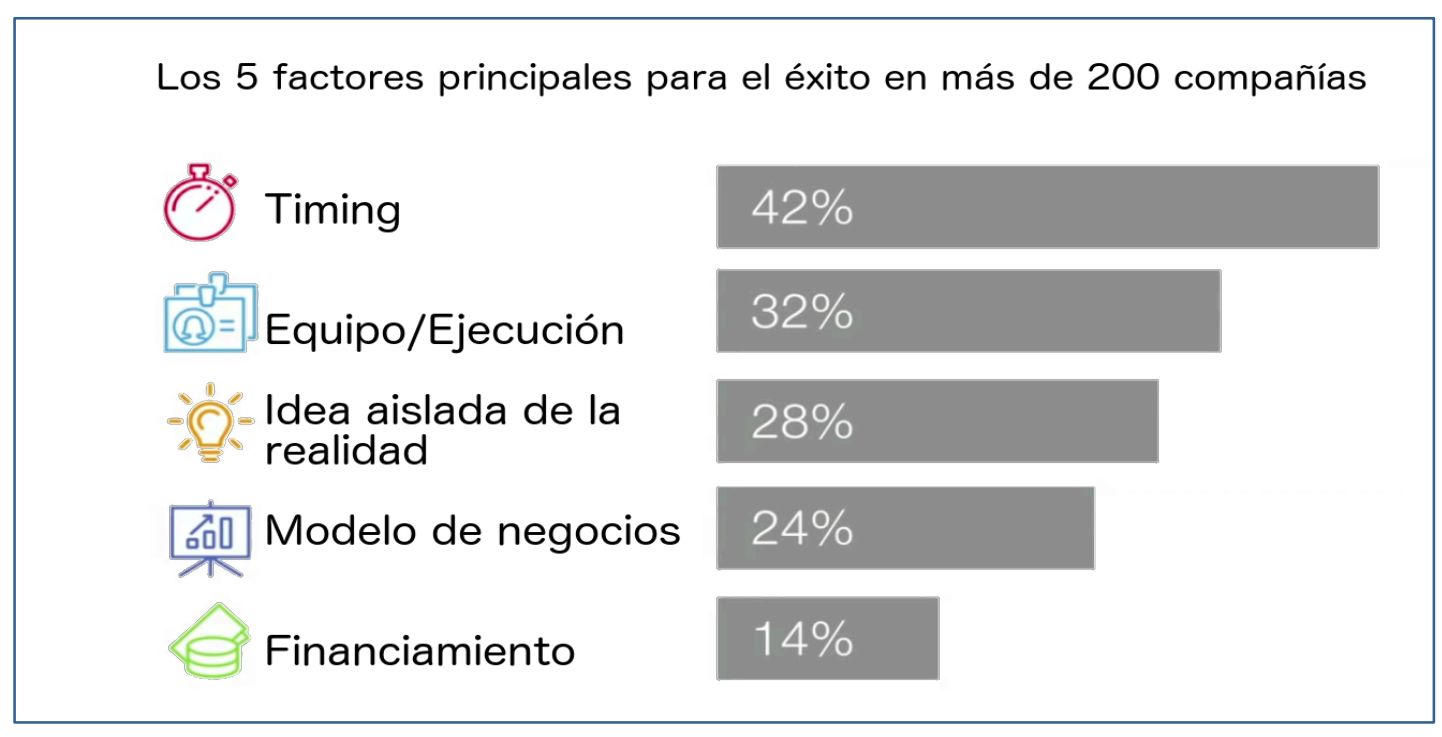

FIGURA 11

Los cinco factores principales para el éxito en más de doscientas compañías

Por su parte, para explorar los motivos por los cuales las start-ups fracasan, CB Insights, una consultora especializada en prospectiva, es decir, en estudiar las causas técnicas, científicas, económicas y sociales que aceleran la evolución del mundo moderno, y la previsión de las situaciones que podrían derivarse en el futuro, realizó un análisis de más de cien empresas que han fracasado. Este estudio revela que entre el 50 y el $80 \%$ de las start-ups fracasa entre el año y los cinco de haber comenzado. En la siguiente figura (FIGURA 12) se resumen los diez principales motivos de fracaso de las start-ups: 


\section{Los 10 principales motivos por los que fracasan las 'startups'}

\section{Basado en los textos de despedida de 101 fundadores al cerrar sus empresas}

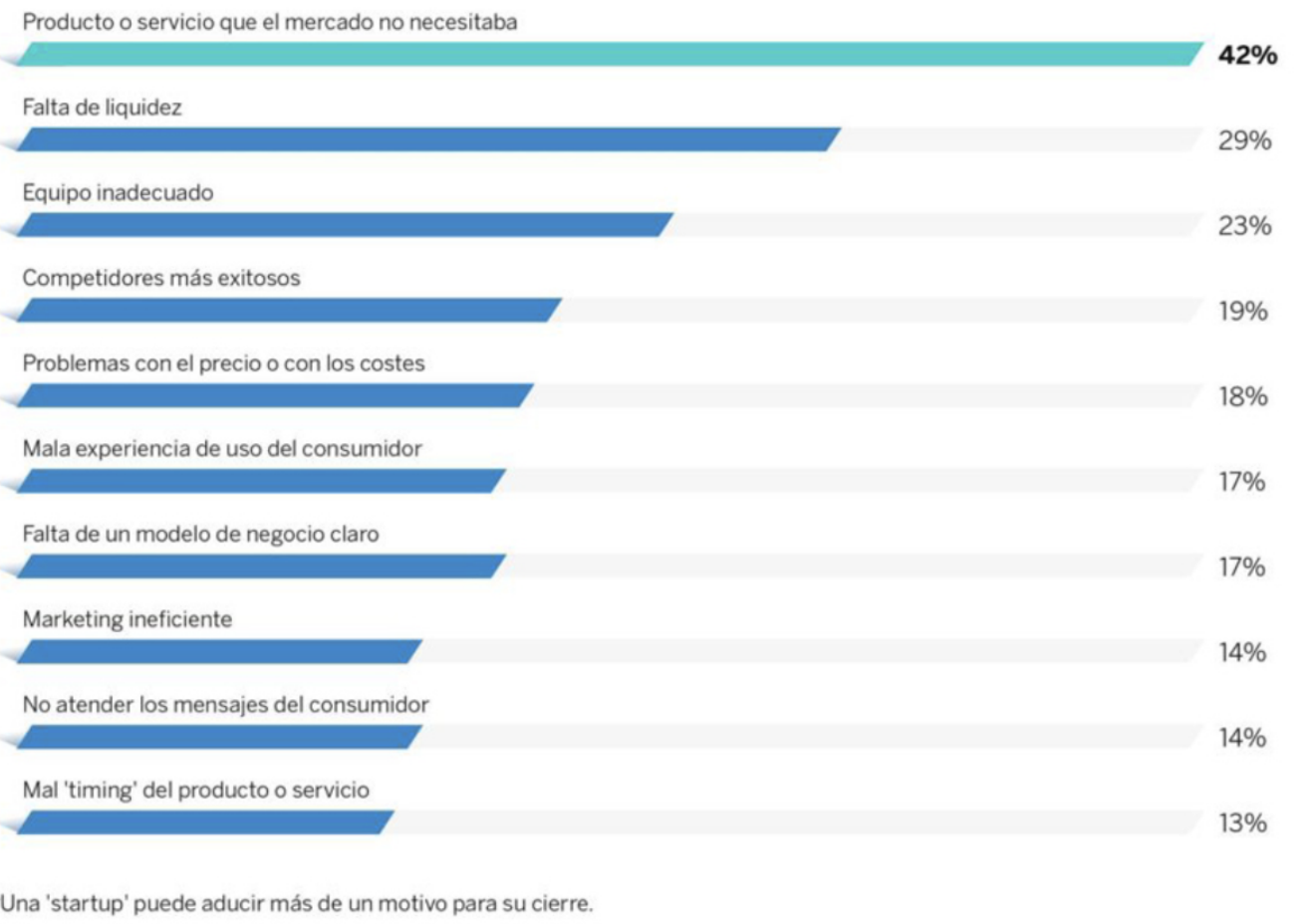

FIGURA 12

Los diez principales motivos por los que fracasan las start-ups

Fuente: CB INSIGHTS (2018)

Se puede ver entonces que los principales factores que hacen que una start-up tenga éxito son los mismos que pueden hacer que fracase.

Lo que ambos estudios revelan está claro: el principal factor por el cual el $42 \%$ de las startups fracasan es que no ofrecen lo que el mercado demanda, y el $28 \%$ de las que lo hacen consiguen el éxito. El consumidor no busca premiar al emprendedor más competente, sino resolver una necesidad.

La segunda razón corresponde a quedarse sin fondos, y está ligado a otras razones del fracaso de la puesta en marcha, incluida la falla para encontrar el ajuste del producto o servicio a las necesidades del mercado y los pivotes fallidos. El dinero y el tiempo son finitos, y deben asignarse con austeridad y prudencia, ya que este punto es la clave número 5 para alcanzar el éxito. Se debe investigar mucho antes de gastar el dinero, validar la idea, saber que lo que se está haciendo no se ha hecho antes sin éxito, y asumir que la financiación inicial que se tendrá será únicamente la propia o la que puedan brindar la familia o unos pocos amigos. Solo un porcentaje muy pequeño de nuevas empresas obtienen financiamiento de Venture Capital (VC) $y$, de hecho, la burbuja de financiamiento está colapsada, eso significa que las nuevas empresas 
en etapa inicial están recibiendo poco o nada de empresas de capital externo. Por lo tanto, hay que "hacer que cada peso valga" como dijo Roberto Souviron, CEO y fundador de despegar.com (DEL RIO, 16 de diciembre de 2015). En este sentido, sería deseable que en el plan de negocios inicial esté delineado un camino hacia la rentabilidad y la sostenibilidad antes de que se agote el dinero.

En esa línea, uno de los principales desafíos a la hora de emprender, y luego de haber definido el producto o servicio, es definir una política donde el precio sea lo suficientemente alto para cubrir los costos y generar beneficios, pero se mantenga lo más bajo posible para atraer usuarios/clientes. El $18 \%$ de los fracasos corresponden a no haber encontrado esa fórmula para poder subsistir.

Un equipo complementario, con diferentes conjuntos de habilidades es el segundo factor crítico para el éxito de una empresa. Según Domingo GUERRA, fundador de Appthority (EI Valle de los Tercos, 17 de enero de 2019), "el equipo es clave, ya que por más de que quieras y puedas hacer todo solo, no es posible, y hay gente más inteligente y capacitada que puede ayudarte". Es importante "que el equipo se conforme de personas que sean primero buena gente, después, inteligente, gente de mundo, que sea abierta, trabajando de manera coordinada y con 'mucha hambre' puede lograr cosas extraordinarias" (STARTUPS WAY, 6 de julio de 2015). La dificultad de conformar un equipo con esta diversidad es la tercera causa de fracaso en start-ups según este análisis.

A pesar de que las start-ups no deberían obsesionarse con la competencia, la realidad es que una vez que una idea fue validada en el mercado, pueden existir muchos participantes para el mismo nicho, e ignorarlos por completo es también una causa de fracaso en el $19 \%$ de los casos. "La competencia es permanente y cuanto más crece el emprendimiento más competencia tiene" (PROPTECH, 10 de agosto de 2018). Pero, como dijo Alec OXENFORD (STARTUPS WAY, 6 de julio de 2015), "en el negocio de la tecnología, lo único importante es estar siempre un poquito delante de la competencia, alcanza con estar por delante, no es necesario ser perfecto".

Ignorar lo que que un usuario/cliente quiere y necesita, ya sea consciente o accidentalmente es la causa del $17 \%$ de los fracasos. Es fundamental en la industria de la tecnología brindar un producto o servicio amigable, fácil de usar y que se adapte a las necesidades de los consumidores, como menciona el co-fundador de Sky Teddy (CODER FM, agosto de 2018): "Constantemente debemos enfocarnos en mejorar la experiencia de compra, adaptándola a las necesidades del cliente, según el feedback obtenido por diferentes medios". Mantener la visión dentro del túnel e ignorar lo que pasa fuera de él, sin recopilar el feedback de los usuarios son fallas fatales para la mayoría de las nuevas empresas (no atender los mensajes del consumidor: $14 \%)$.

Tanto los emprendedores que han fracasado como los que alcanzaron el éxito, también resaltan la importancia de tener un modelo de negocios definido. Una gran idea o un buen producto no es suficiente, mantenerse conectado a un solo canal o no tener claro cuál será la manera en que se logrará ganar dinero a escala deja a los inversores indecisos y a los fundadores incapaces de capitalizar cualquier impulso ganado. El modelo de negocios debe incluir todos los costos anticipados, marketing, fabricación, tecnología requerida y personal, y asimismo preveer cómo se comercializará y/o venderá el producto o servicio. 
Conocer al público objetivo y saber cómo captar su atención para convertirlo en potenciales clientes y, finalmente lograr que adopten la nueva tecnología, es una de las habilidades más importantes de un negocio exitoso. Pero la incapacidad para comercializar, y lograr esa tracción, según el análisis de CB Insights, fue un factor común de fracaso en el 14 \% de los casos.

El último factor causante del fracaso en las start-ups y el principal factor influyente en su éxito se trata del timing. Si el producto o servicio es lanzado demasiado pronto, puede no haber demanda o no ser lo suficientemente bueno para los usuarios, lo que dificultará recuperarlos posteriormente si esa primera impresión fue negativa. Por el contrario, si el producto es lanzado demasiado tarde, es posible que haya perdido su ventana de oportunidad en el mercado. "Muchas veces lanzar un producto que está bien a tiempo, es mucho mejor que lanzar el producto perfecto después (...) Si hubiéramos querido levantar capital para hacer OLX dos o tres años antes, no hubiésemos podido, porque no estaba maduro el interés por ese modelo de negocios. En cambio, si lo hubiéramos hecho dos años después, no hubiese tenido sentido porque ya había competidores con mucho peso que nos hubieran ganado" (STARTUPS WAY, 6 de julio de 2015). Entonces, se trata de encontrar el momento preciso en donde debe lanzarse el producto o servicio, no es antes ni tampoco después. Así, es fundamental que a la hora de emprender, se estudien las necesidades principales que prevalecen en la industria objetivo, para poder brindarles una solución al problema.

La pérdida de foco en el negocio, la falta de "química" o entendimiento entre el emprendedor y el inversor, o falta de interés o involucramiento de este último, "casarse" con la idea y no tomar las decisiones apropiadas en el momento justo, la falta de pasión y dedicación de los fundadores, la ubicación geográfica inapropiada, problemas legales o de patentes, la falta de una red de contactos o mal uso de ella, el agotamiento empresarial y personal, también están entre las principales causas de fracaso de un emprendimiento según el mismo análisis de $C B$ Insights. 


\section{MetOdología Y TÉCNICAS PARA EL DIAGNÓSTICO}

El tipo de estudio destinado para el trabajo de esta tesis es exploratorio y el tipo de diseño que se utiliza es de tipo no experimental, transversal.

Los emprendedores y empleados de las organizaciones son la unidad de análisis del trabajo. Como instrumento de recolección de datos se realizaron entrevistas locales y se tomaron entrevistas públicas y podcasts a emprendedores reconocidos.

Respecto a la población, la misma está conformada por todas las start-ups de tecnología de Argentina que surgieron desde el año 2000 en adelante. Se tomó una muestra aleatoria de emprendedores argentinos que tienen o han tenido start-ups IT. Como fuente de datos primaria, se entrevistó a doce emprendedores tecnológicos, que forman parte del programa Usina de Ideas, de la Facultad de Ciencias Económicas de la UNLP o pertenecen al Polo IT de La Plata. Por otra parte, se analizaron los casos más importantes de start-ups argentinas, correspondientes a aquellas cuatro que lograron alcanzar el mayor de los éxitos y convertirse en unicornios (Mercado Libre, Globant, OLX y Despegar), quedando excluido del presente análisis el último unicornio surgido, Auth0, por tratarse de un hecho reciente y no disponer de la información necesaria debidamente verificada.

Se realizó una investigación sobre documentación pública disponible, hallando contenidos ricos en información, en entrevistas públicas de canales de noticias, canales de YouTube de emprendedurismo y podcasts ${ }^{1}$ de la temática. De esta investigación, también se extrajeron dieciséis casos de emprendedores argentinos y latinoamericanos que comparten su experiencia en el mundo del emprendedurismo, y se considera que aportan gran valor al presente trabajo de tesis.

Los métodos utilizados para analizar los resultados de las entrevistas son cualitativos, intentando describir con claridad y en detalle los factores críticos de éxito de las start-ups IT. Utilizando la misma metodología, se realizó un tratamiento cuantitativo de los datos cualitativos para el análisis de las fuentes secundarias; más precisamente, se analiza frecuencia de ocurrencia de palabras para su interpretación.

El modelo de investigación se encuadra entonces como uno de diseño mixto específico (HERNÁNDEZ SAMPIERI et al., 2014: 551-565), y puntualmente, como un diseño anidado o incrustado concurrente de modelo dominante; siendo el modelo dominante el relacionado con la perspectiva cualitativa, y el anidado o incrustado el de la perspectiva cuantitativa.

\footnotetext{
${ }^{1}$ Un podcast es, según SolAno Fernández et al. (2010), un archivo multimedia, que puede ser de audio o video, que puede distribuirse a través de internet mediante un sistema de redifusión (RSS) que permite su revisión automática y periódica y está siempre a disposición del posible usuario.
} 
Al ser un estudio de tipo exploratorio, se respalda en la bibliografía existente sobre el tema y en datos de crecimiento de estas empresas que se pueden encontrar en revistas, entrevistas, programas o podcasts de emprendedurismo.

Para las entrevistas a emprendedores locales, se utilizó un cuestionario web confeccionado con la herramienta de software gratuita Google Forms, que permite crear formularios en línea con diversas opciones de preguntas, según tipos de respuesta (de elección única, de elección múltiple, escalas, textos largos o cortos, etc.), y posteriormente clasificar las respuestas. Se tomaron de la base de datos de Usina de Ideas todos los emprendimientos tecnológicos que pasaron por el programa desde el 2016, y se les envió el formulario a cada uno por mail para que respondieran en línea. De la misma manera, se envió el formulario a integrantes del Polo IT de La Plata que dirigen o forman parte de una start-up de tecnología. Además, algunos de los entrevistados enviaron el cuestionario a amigos o conocidos que también tenían emprendimientos tecnológicos. Se consideró que con la muestra recogida se alcanzó la saturación teórica que debe buscarse en el tipo de análisis del modelo de investigación elegido.

Con respecto a la confección del formulario, ninguna de las preguntas eran de carácter obligatorio, con el objetivo de que el entrevistado se sintiera con libertad a la hora de responder. Si bien es un estudio exploratorio, donde la mayoría de los interrogantes tienden a ser de carácter abierto, se intentó dar a todos diferentes opciones, siempre añadiendo una opción "Otro..." en estos casos, para dejar esa parte de la pregunta abierta, y no forzar al entrevistado a que elija una opción que no refleje su respuesta. A las preguntas cerradas que tienen que ver con opinión personal, con opciones "Sí" o "No", se les agregó la opción "Tal vez", para no forzarlo a responder de forma tan cerrada, simplemente por no dejar la respuesta en blanco.

Las preguntas fueron organizadas en seis secciones (ANEXO 1), con el criterio de agruparlas lógicamente según su contenido e intención de la siguiente manera:

1. Datos del emprendedor y del emprendimiento: En esta sección se busca conocer al entrevistado y a su start-up, son preguntas de carácter introductorio que comprenden desde su nombre, lo que ofrece y de qué se trata, hasta el tiempo que hace que trabaja en ello y las funciones que cumple dentro de ella.

2. Datos del equipo emprendedor: Aquí nos concentramos en el grupo humano que compone el emprendimiento, se buscan por un lado estadísticas de género, edad, y nivel de educación, y por otro, conocer las razones por las cuales decidieron unirse y la dinámica de trabajo del equipo, como distribución de tareas y lugar de trabajo.

3. Motivaciones: En este bloque se comienza con las preguntas más blandas, por qué y cómo fue que el entrevistado decidió emprender.

4. Desarrollo del emprendimiento y planificación estratégica: Aquí se pretende analizar el proceso emprendedor, desde la idea a la ejecución, con la planificación y los cambios que este camino implica, así como también la relación con clientes/usuarios y competidores directos o indirectos.

5. Factores internos de éxito y fracaso: Se analizan las capacidades, experiencia, cualidades y rasgos del emprendedor, es decir, todas las competencias inherentes al perfil del emprendedor entrevistado. 
6. Factores externos de éxito y fracaso: En este espacio, fueron considerados los diferentes recursos, infraestructura y relaciones entabladas al momento de comenzar con el emprendimiento y durante su desarrollo. En este sentido, se analiza el entorno del emprendedor y de la start-up, cómo interviene el entorno familiar, la sociedad, las normas culturales, en especial el papel y las oportunidades que tiene la mujer en relación con el emprendedurismo, y se estudian las ventajas y desventajas de Argentina como país para emprender y cómo influye a la start-up la situación actual del país. 


\section{RESULTADOS DE LA INVESTIGACIÓN}

\section{Análisis de los resultados de las entrevistas}

Las respuestas al formulario de la entrevista se fueron almacenando de forma automática a medida que los entrevistados la iban completando, en el mismo formulario, desde donde pueden exportarse a una hoja de cálculo de Google para ser analizadas, ordenadas y representadas gráficamente (ver ANEXOS 2 y 3 ).

Una vez creada la base de datos, se procedió a realizar el análisis de los resultados, con la problemática de la variedad de la información recogida, ya que muchas de las preguntas eran abiertas, con el objetivo de recoger de la forma más precisa posible la visión del grupo de emprendedores que completaron la entrevista. Para facilitar esta tarea se recurrió a otra herramienta de software gratuito para la creación de nubes semánticas, denominada Wordle. Este software dio como resultado, para cada caso, una visualización gráfica de las principales palabras, conceptos e ideas que conformaban cada valor en forma de nubes de tags, donde los tamaños de letra son proporcionales al peso (frecuencia) de cada palabra o término introducido.

\section{DATOS DEL EMPRENDEDOR Y DEL EMPRENDIMIENTO}

Los doce entrevistados, en su mayoría directores (CEO u otro), fundaron las siguientes startups de tecnología:

$\square$ Positrip

Babel Viajes

口 AccessHoy

G Go4Clic

$\square$ Mipublicidad.com.ar

口 Está Reservado

口 Celerative

口 Sherlock

( Tiendup

च intriper

ㄷlbot

Topic 
De estos emprendimientos, siete ofrecen servicios mientras que cinco de ellos ofrecen productos (ver ANEXO 3-2). El propósito de todos ellos, puede verse sintetizado en la siguiente nube de palabras:

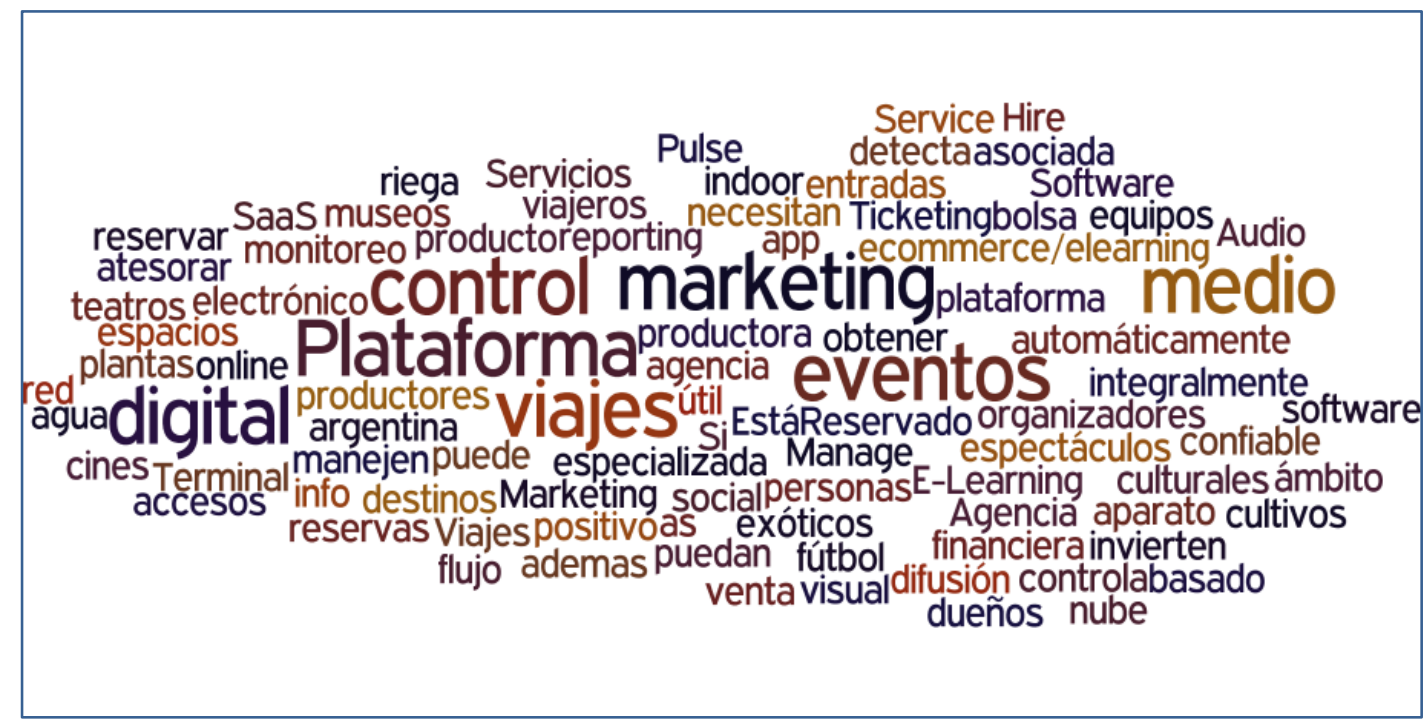

FIGURA 13

Propósito de las start-ups

Fuente: Elaboración propia

Aquí, encontramos que la mayoría son plataformas digitales, de viajes, ticketing para eventos o espectáculos, reservas, medios, e-learning, e-commerce, finanzas. Otras ofrecen servicios de marketing, de contratación de recursos o de información para viajes. Uno de los emprendimientos consiste en un aparato tecnológico para controlar cultivos de interior.

Si bien todas estas start-ups tienen un fuerte componente tecnológico, muy pocas tienen presencia en las redes sociales. La mayoría ( $72,7 \%$ ) tiene una página web, casi la mitad de ellas tiene Facebook $(45,5 \%)$, en tercer lugar cerca de un $30 \%$ tiene Twitter. Sólo dos tienen Instagram, y apenas una Twitter. Las redes sociales dan visibilidad al emprendimiento, pero es cierto que si existe la cuenta, es mandatorio subir contenido al menos una o dos veces por semana. La mayoría de estos emprendimientos, que recién están arrancando, quizá no cuentan con el tiempo suficiente para ocuparse de las redes, ni tienen recursos como para contratar a una persona que se encargue de mantenerlas actualizadas, por eso aún no están presentes allí. 


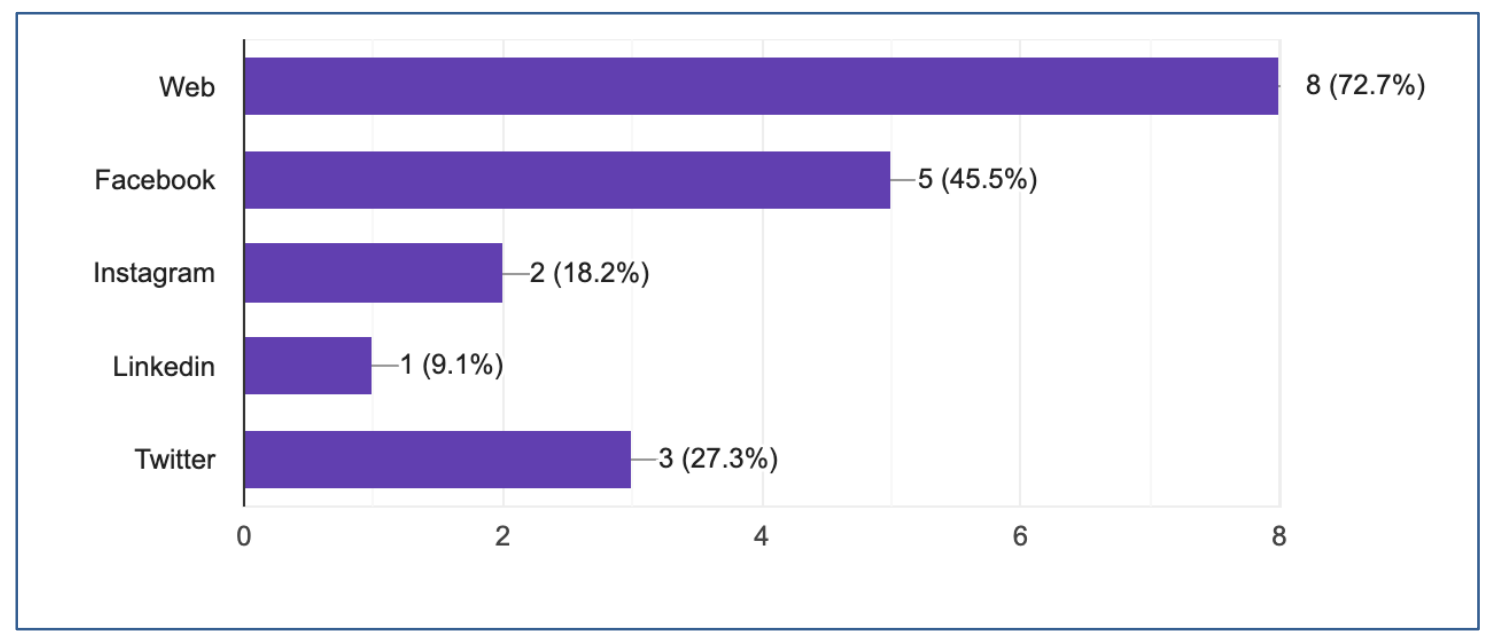

FIGURA 14

Presencia de start-ups en redes sociales

Fuente: Elaboración propia

Para ser más exactos con la antigüedad de las start-ups de los entrevistados, se puede examinar la siguiente figura (FIGURA 15):

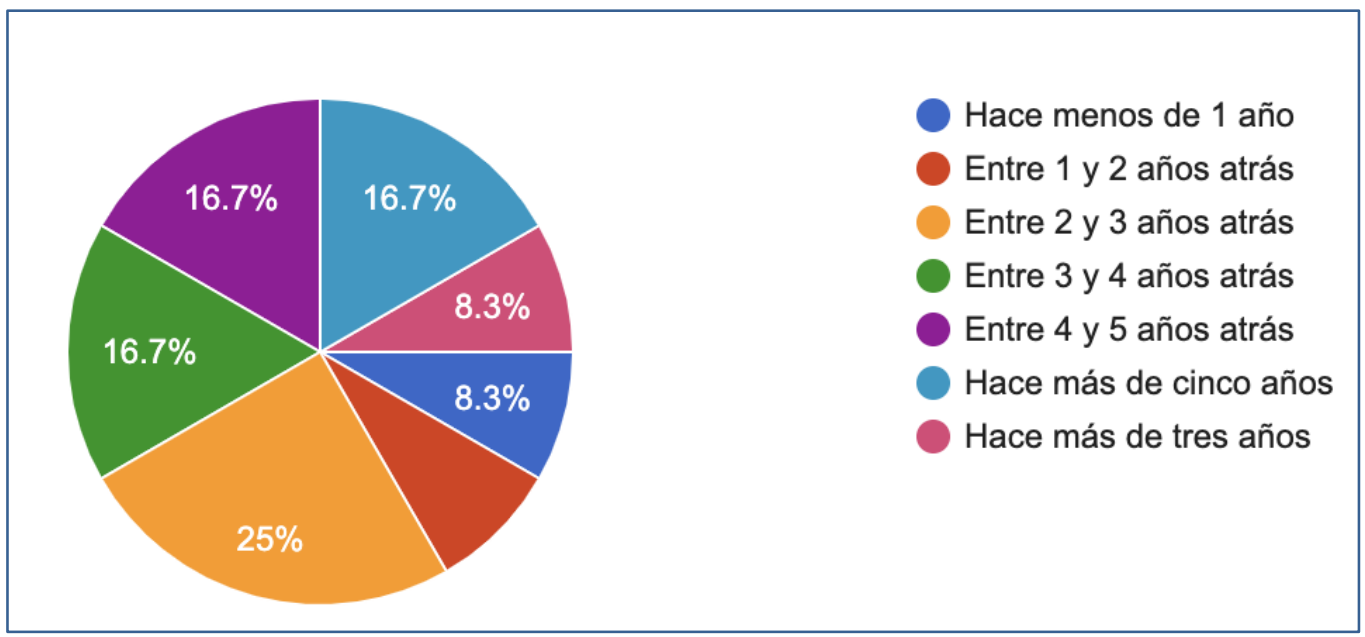

FiguRA 15

Antigüedad de start-ups

Fuente: Elaboración propia

Se observa que muchas de ellas comenzaron a trabajar entre el 2016 y el 2017, pero la mayoría lo hizo hace más de tres años (7 de las 12 totales). La antigüedad está fuertemente relacionada con el crecimiento de cada una de estas start-ups: las de mayor antigüedad, se encuentran en una etapa más avanzada de desarrollo, aunque todas son son empresas relativamente jóvenes. 


\section{DATOS DEL EQUIPO EMPRENDEDOR}

De los equipos que conforman estos emprendimientos, se observa que en su mayoría están compuestos de hombres, solo cinco de ellos se conforman de un $45 \%$ de mujeres (ver ANEXO 37), el resto la diferencia es mucho mayor (va del 18 al $9 \%$ de mujeres sobre el total del equipo) y el rango de edad va de 21 a 43 años. En este marco la edad representa un factor importante dado que denota madurez y una percepción más crítica para asumir riesgos, y ser determinantes al momento de asumir compromisos o tomar decisiones dentro de la start-up.

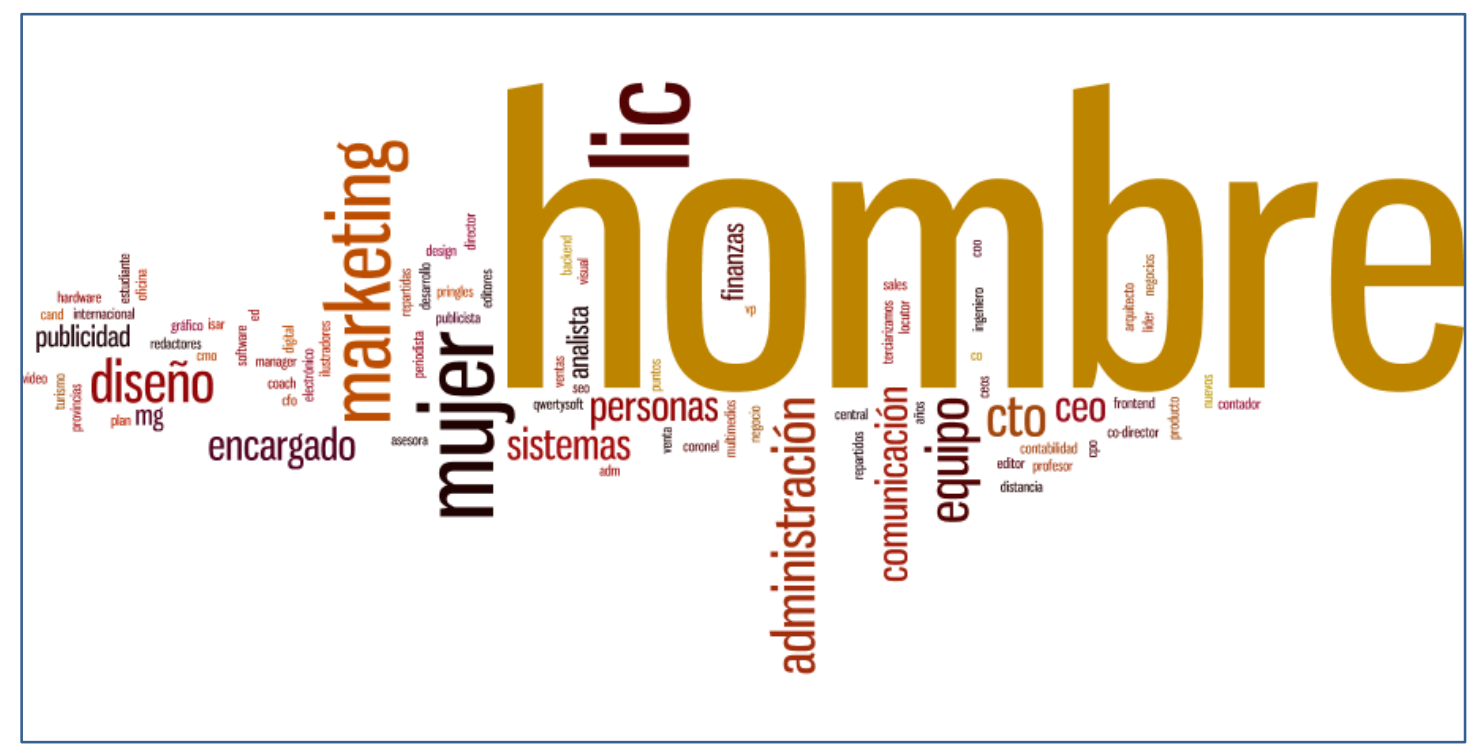

FIGURA 16

Integrantes de las start-ups

Fuente: Elaboración propia

Existen diversos estudios donde se evidencia que aquellas empresas con tasas de crecimiento más altas fueron fundadas por personas con estudios universitarios (WESTHEAD \& COWLING, 1995; ALMUS, 2002). A partir de la nube de la FIGURA 16 se advierte que el nivel de educación de los integrantes de las start-ups de la muestra es muy bueno, con un grado de escolaridad universitario o de posgrado, la mayoría son licenciados, muchos de sistemas y de marketing y publicidad, otros de administración, comunicación, finanzas, diseño o turismo. Está ampliamente reconocido que un alto nivel educativo incrementa las oportunidades de desarrollo empresarial, y podría considerarse que los empresarios con más educación tienen un proyecto de vida definido o más claro, y poseen habilidades para identificar y explotar oportunidades de negocio (ALEMANY et al., 2011), contrario a lo que podría darse en individuos con escolaridad de educación media que probablemente no cuenten con la formación necesaria para asumir los riesgos que trae aparejado emprender, pero esto no quiere decir que no puedan hacerlo.

Los equipos se conformaron inicialmente en su mayoría por poseer intereses similares entre los integrantes (45,5\%) (ver ANEXO 3-8), otros por estrategia buscando complementariedad, o 
bien por amistad o relaciones laborales anteriores. Más de la mitad de los equipos (54,5 \%) (ver ANEXO 3-9) distribuyeron los roles previamente de manera organizada, por conocimientos, habilidades o área de conocimiento de cada uno, y la mayoría continúa con la misma estructura, esto denota una buena planificación desde los inicios y son las start-ups que tienen un mejor futuro, muy diferente a las que no tienen las tareas distribuidas y todos hacen un poco de todo (dos de las doce start-ups) (ver ANEXO 3-9); estas últimas deberían comenzar a pautar un orden para saber a qué integrante recurrir en primera instancia cuando surge un problema de determinada área. La gran mayoría de estos equipos trabaja de manera remota la mayor parte del tiempo (75 \%) (ver ANEXo 3-11), algunos se reúnen cada tanto (41,7\%) (ver ANEXO 3-11) y unos pocos trabajan a diario en un mismo espacio físico (25\%) (ver ANEXO 3-11). Por lo tanto, con más razón, es fundamental tener bien distribuidas las tareas y los objetivos claros ya que la comunicación interna no es tan fluida al estar en espacios diferentes la mayor parte del tiempo.

\section{MOTIVACIONES}

Sobre la razón por la cual el entrevistado decidió comenzar a emprender, se consideraron las tres motivaciones fundamentales, descriptas en la SECCIÓN 1.1: emprender "por oportunidad", "por necesidad" y "por deseo". Es predominante la opción "Deseo" (58,3\%) y le siguen los que lo hicieron por oportunidad, es decir que todos lo hicieron por voluntad propia pero ninguno comenzó a hacerlo por una necesidad personal.

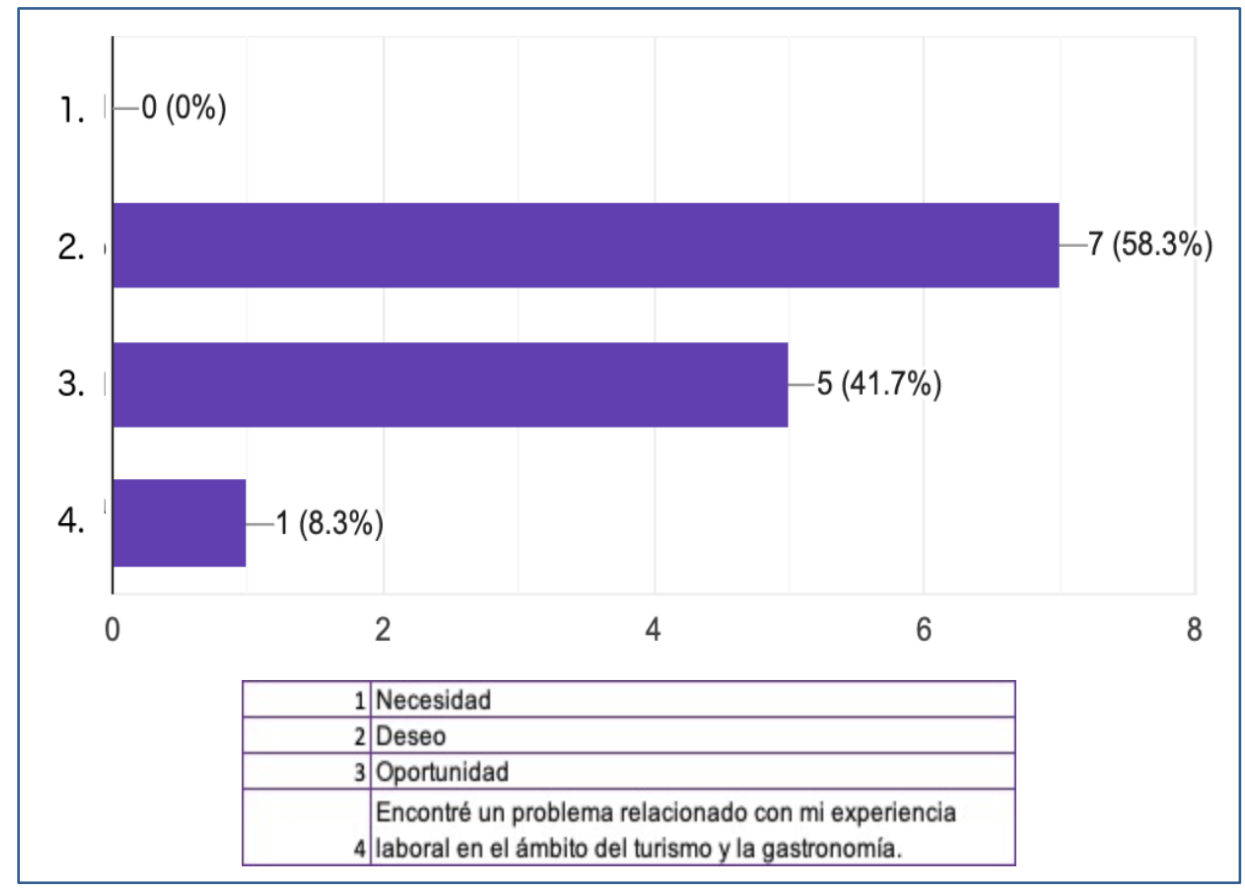

FIGURA 17

Razones para comenzar a emprender

Fuente: Elaboración propia 
Y para dar este gran salto (ver ANEXO 3-14), puede verse que hay una mayor prevalencia de factores personales en la motivación por emprender y esto tiene que ver con lo anterior, que ninguno lo hizo por necesidad. Influyó mucho la convicción del emprendedor en primer lugar, el apoyo y costumbres de la familia, deseos de ser su propio jefe (25\%) (ver ANEXo 3-14) e insatisfacción por la industria corporativa (16,7\%) (ver ANEXO 3-14). Factores de menor peso fueron "construir con libertad su futuro" y por "personalidad".

\section{DESARROLLO DEL EMPRENDIMIENTO Y PLANIFICACIÓN ESTRATÉGICA}

Analizando aspectos vinculados al modelo de negocios, los datos obtenidos revelan que todos los emprendimientos tienen un modelo de negocio bien definido, tienen en claro a quién pretenden comercializar o comercializan su producto o servicio y el $66,7 \%$ de ellos (ver ANEXO 3-16) comenta que este plan de negocios se está modificando constantemente, y esto tiene que ver, en gran parte, con la velocidad en que suceden los cambios en la industria de la tecnología. En la FIGURA 18, se puede ver que la mitad de estas start-ups tienen un modelo de negocio B2C (ver SECCIÓN 2.2), es decir que comercializan productos o servicios a consumidores finales. Tiene mucho sentido que prevalezcan dentro de la mayoría de los equipos especialistas en marketing y/o publicidad, ya que en este tipo de negocio se necesita realizar fuertes campañas para atraer el mayor volumen de usuarios/clientes posibles.

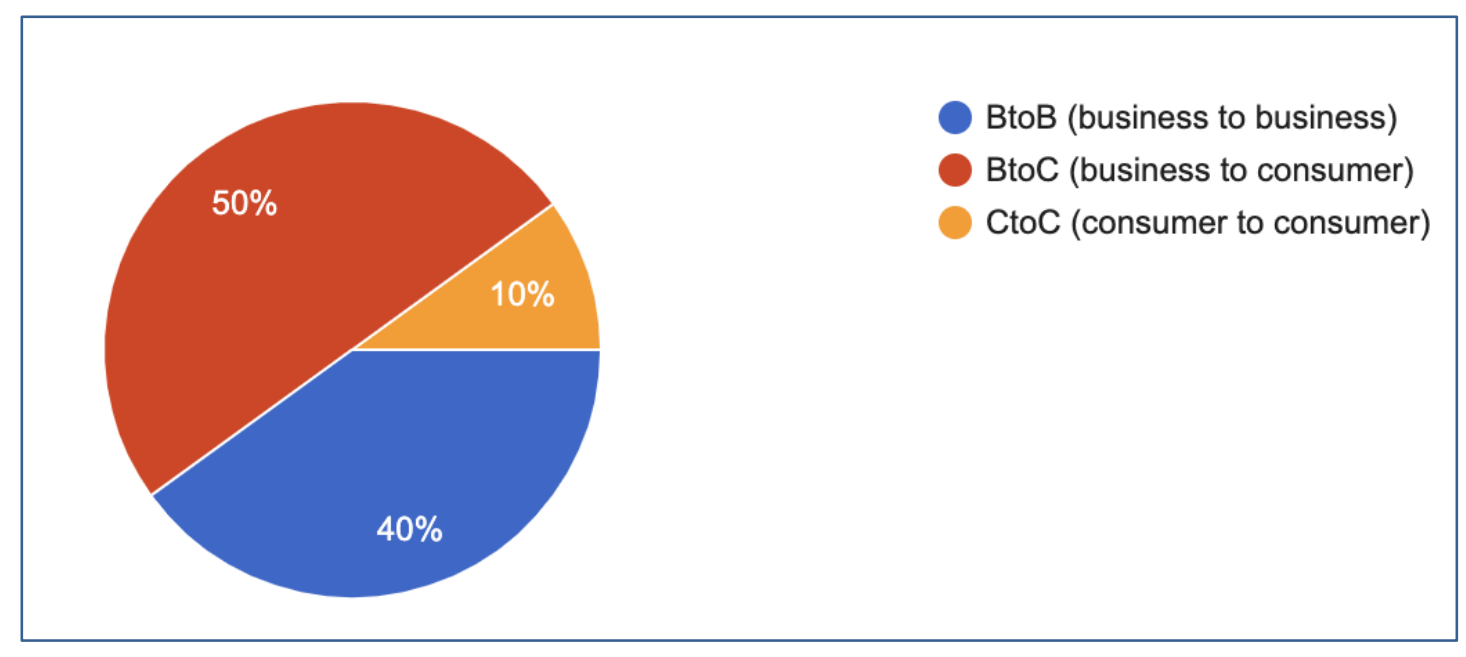

FIGURA 18

Modelo de negocios de las start-ups

Fuente: Elaboración propia

De la mitad restante, es predominante los que ofrecen su producto o servicio a otras empresas (B2B $40 \%$ ), y solo uno de los emprendimientos es una plataforma de interacción entre pares $(\mathrm{C} 2 \mathrm{C})$, puesto que se trata de una plataforma de e-commerce/e-learning. 


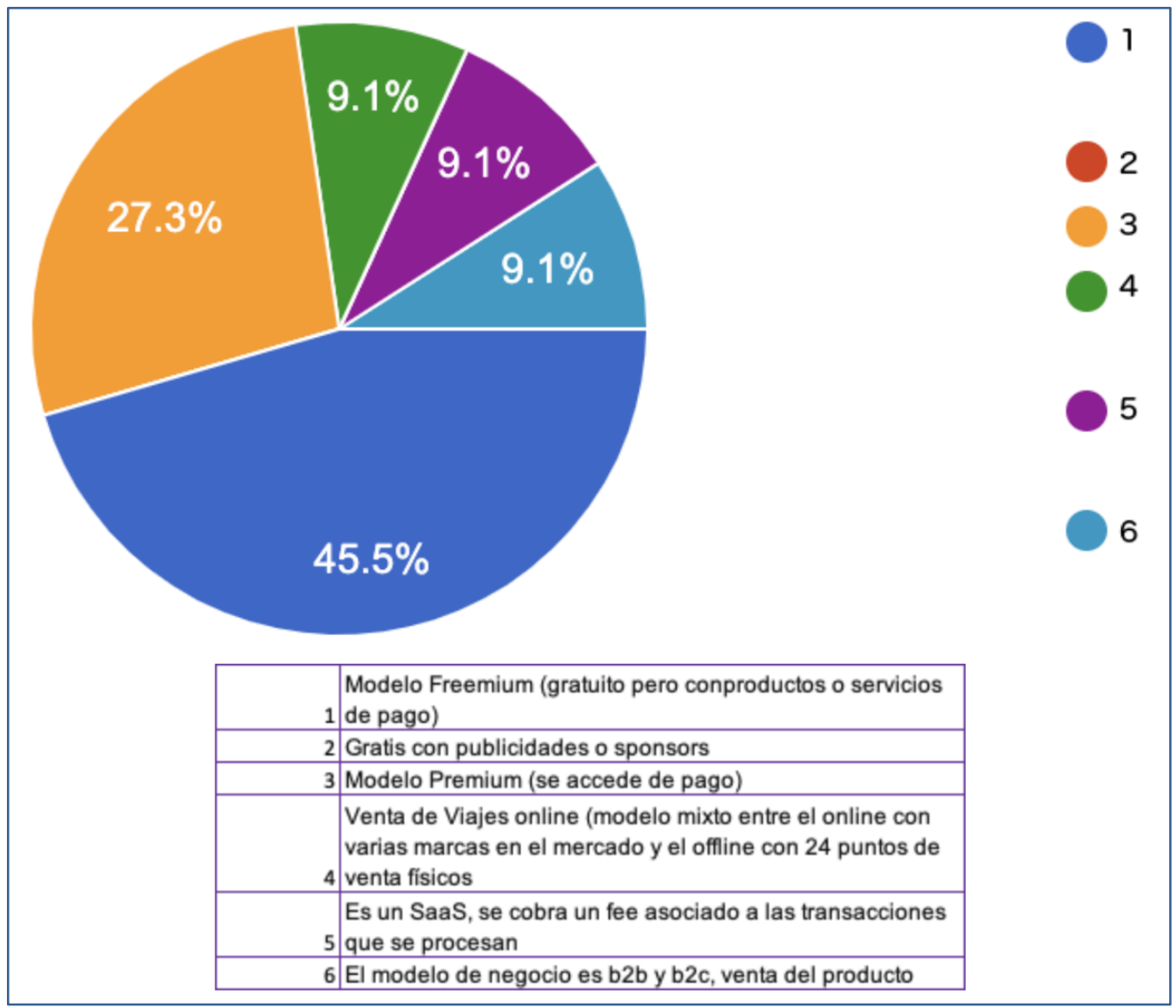

FIGURA 19

Forma de monetización de las start-ups

Fuente: Elaboración propia

De la misma forma en que todos tienen bien en claro cuál es su modelo de negocios, los resultados obtenidos relativos a la forma de monetización dejan entrever que pasa lo mismo en este caso. Todos contestaron de qué manera piensan obtener u obtienen sus ingresos, y está claro que ninguno procura "regalar" su trabajo. Esto tiene que ver con lo que dijo Ale RESNIK (EI Valle de los Tercos, 14 de marzo de 2019): "No hay nada peor que una start-up pueda hacer que regalar su trabajo o dar un descuento. Hay pocas compañías que lo hacen y son las grandes como Facebook o Google y salen de esa regla, pero si uno produce algo de valor, lo tiene que cobrar, tiene que haber un consumidor que esté dispuesto a pagar por ese valor y si no se puede encontrar ese consumidor, es porque el canal de distribución está mal o porque lo que se está ofreciendo no tiene tanto valor como uno pensaba. Si uno regala su trabajo pareciera que lo que está ofreciendo no tiene tanto valor". Muchas de las start-ups de la muestra (45,5\%), ofrecen un modelo freemium, donde inicialmente los usuarios acceden de manera gratuita, pero deben pagar si desean acceder a paquetes premium. Esto se relaciona con la etapa de crecimiento en la que se encuentran: es el momento de captar el mayor volumen de usuarios posible, y este modelo es de gran ayuda para lograr esa masividad. 
El 55,5\% restante cobra por su producto o servicio, por lo que aquí es importante que lo que están ofreciendo tenga algún atractivo o valor agregado a lo que ya existe en el mercado porque es probable que tengan muchos competidores con servicios o productos similares y algunos de ellos incluso sean gratuitos.

El siguiente interrogante incluido en la entrevista, en el que se les preguntó a los emprendedores la misión, visión y objetivos de la start-up, tenía como finalidad saber cuántos de ellos tenían esto definido, ya que es clave al iniciar un emprendimiento tener esto pautado para que sirva como guía para alcanzar lo que se plantee. Se trata de definir el por qué y para qué hacen lo que están haciendo, y a dónde quieren llegar.

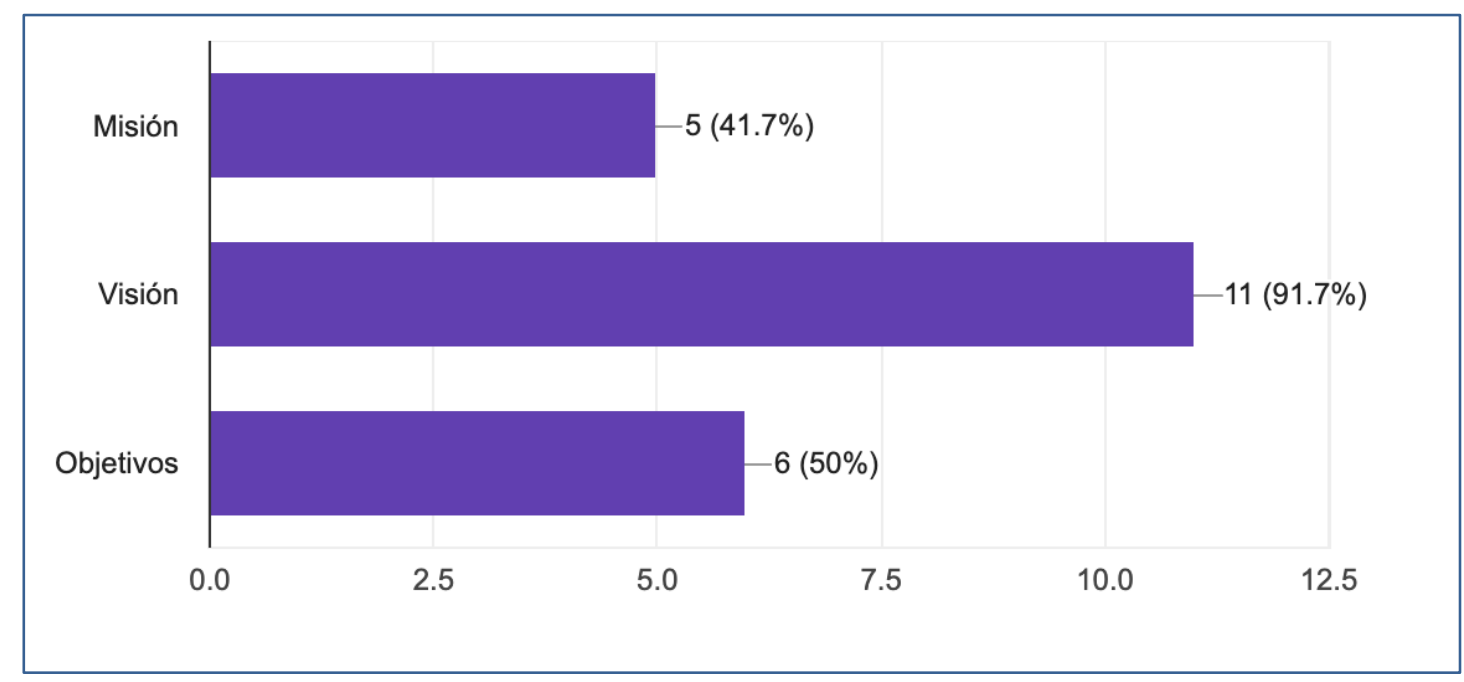

FIGURA 20

Definición de Misión, Visión y Objetivos de la start-up

Fuente: Elaboración propia

Los datos obtenidos dejaron entrever que la mayoría $(91,7 \%)$ tiene bien claro cuál es su norte, que proyectan a futuro con el emprendimiento, pero menos de la mitad $(41,7 \%)$ sabe realmente qué es lo que está haciendo en este momento, más allá de que todos parecían estar seguros del modelo de negocios planteado y la forma de monetizar el negocio, quizá se encuentran en una etapa de definición o transición, o simplemente no se tomaron el trabajo de sentarse a escribirla. Esto último no es bueno, denota desorganización, de la misma manera que lo hacía la falta de definición de los roles dentro del equipo. La mitad de las start-ups de los entrevistados tiene los objetivos claros para alcanzar esa misión y un plan estratégico diseñado (ver ANEXO 3-21), esto quiere decir que la otra mitad no está seguro de cómo alcanzar la meta planteada, o se planteó una meta irreal o inalcanzable, lo cual sería preocupante. Porque no es que una visión sea muy grande o disruptiva el problema, todo lo contrario, el problema reside en que no estén planteados los lineamientos y estrategias para lograr alcanzarla. 


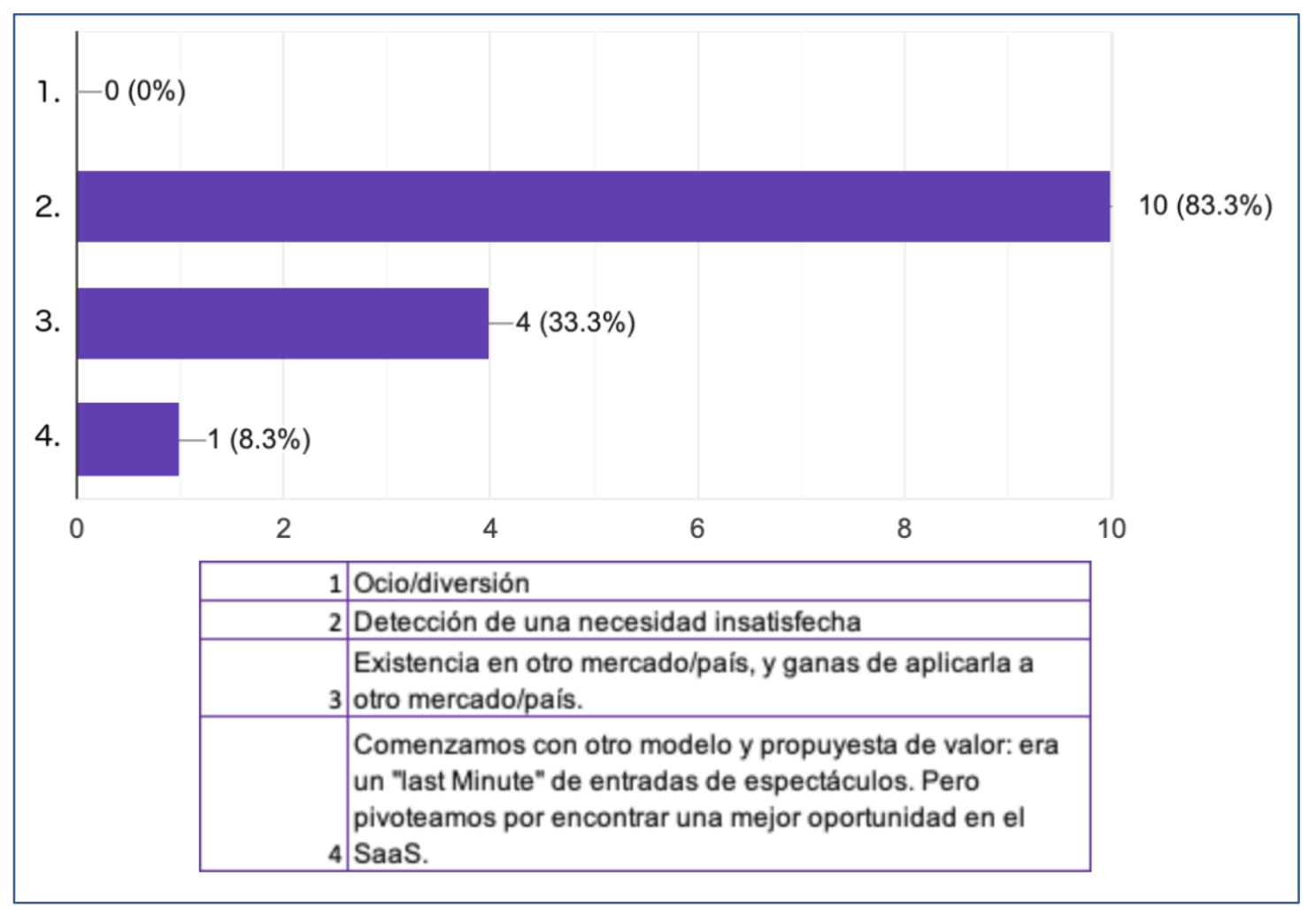

FIGURA 21

Surgimiento de la idea de negocios

Fuente: Elaboración propia

Las respuestas a la pregunta de selección múltiple de cómo fue que surgió la idea de negocio connotan una fuerte tendencia a haberse manifestado a partir de detectar una necesidad insatisfecha, algunas en un mercado específico, o en el país en general, sabiendo de la existencia de soluciones en otros países o mercados que están funcionando. Este concepto en el mundo de las start-ups se denomina copycat y se refiere a "una nueva empresa que se basa en el modelo de negocio de una empresa de otro país" (RÖßLER, 2011).

La mitad de las ideas se modificaron parcialmente y la mitad por completo, ninguna se mantuvo como se pensó originalmente. En el 83,3 \% de los casos hubo un análisis de factibilidad o de mercado previo para validar la idea, y se trata de las mismas start-ups que ya lanzaron su producto/servicio y cuentan con sus primeros clientes/usuarios. De ellas, dos esperaron a tener el producto terminado para lanzar, el resto, lo hizo primero con el mínimo producto viable (ANEXO 3-23), de manera tal de obtener un feedback temprano de los usuarios o clientes, tanto como para realizar una segunda validación de la idea, como para ajustar lo que se está ofreciendo con los comentarios obtenidos. La información obtenida respecto a cómo captaron cada uno de los emprendimientos a sus usuarios dejó entrever que un 55,5\% de ellos lo hicieron de boca en boca, por opiniones o recomendaciones de otros que ya conocían el producto/servicio. Por esto es que es muy importante aportar valor al público que lo consume, ofrecer seguridad, confianza, dar lugar para que compartan su opinión para también generar confiabilidad en otros posibles clientes, y además escuchar sus necesidades, para intentar 
satisfacerlas en la medida de lo posible y lograr una retención de los usuarios que ya se obtuvieron. Un $44,4 \%$ obtuvo sus clientes a través de publicidades o comunicados en medios digitales (SEO, SEM, Facebook entre otros), y la misma proporción de start-ups dijeron que fue gracias a contactos. Pocos fueron los clientes que llegaron a partir de medios no digitales (radio, televisión, llamadas en frío, folletería, etc.)

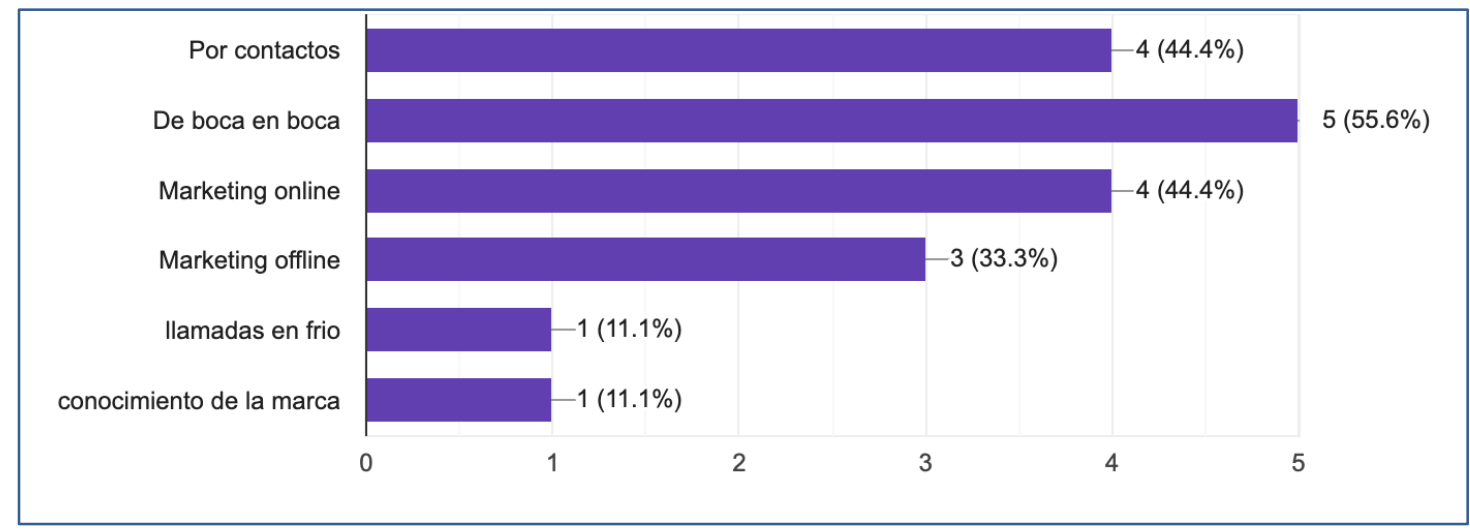

FIGURA 22

Vías de obtención de clientes/usuarios

Fuente: Elaboración propia

Una start-up no puede considerarse aislada de su entorno, ya que todo el contexto es clave para definir las estrategias y estructura interna de la compañía. De las doce entrevistas, solo uno de los emprendimientos no tiene competidores, esto puede suceder por varias cuestiones:

1. No tiene competidores directos, pero no están considerando a los competidores indirectos.

2. El producto/servicio no resulta ser tan novedoso, por lo que puede haber habido otros intentos de realizarlo pero abandonaron al no tener éxito.

3. El producto/servicio resulta ser tan novedoso que el público no está listo para adoptarlo, por lo que pueden enfrentar problemas de timing (ver SECCIÓN 1.6).

4. El producto/servicio logra satisfacer una necesidad que hasta ahora no estaba siendo cubierta o nadie había logrado antes desarrollarlo de la manera adecuada. En este caso es fundamental la velocidad con que se desarrolla el emprendimiento, para lograr llegar primero.

El resto de los emprendimientos tienen todos competencia, ya sea directa o indirecta, y la tienen bien identificada. La siguiente nube de palabras sintetiza de manera gráfica qué rol ocupan y cómo influyen los competidores en las start-ups relevadas: 


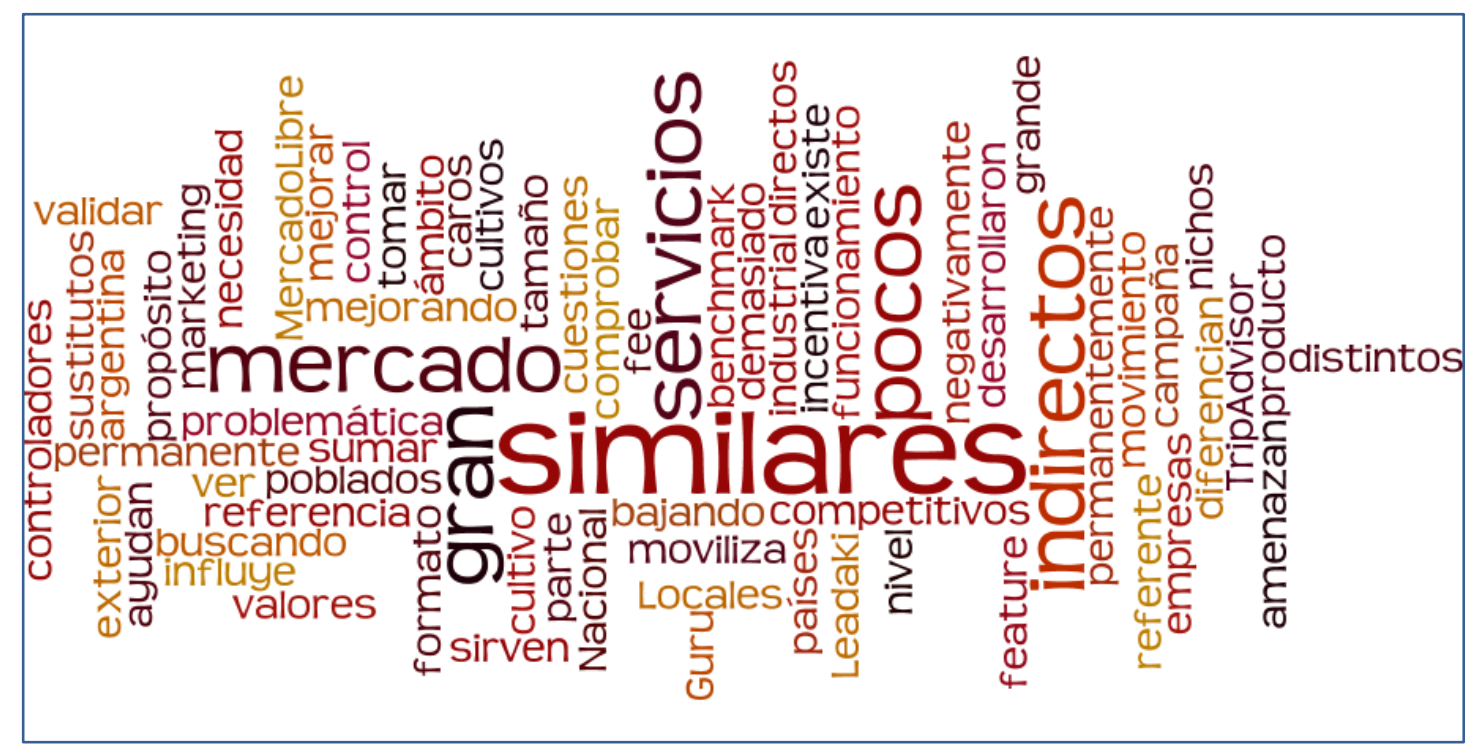

FIGURA 23

Rol e influencia de la competencia

Fuente: Elaboración propia

En la nube se distingue que hay muchos emprendimientos con competidores que ofrecen productos o servicios similares, y otros tantos con competidores indirectos. Estos últimos satisfacen las mismas necesidades pero de forma diferente, con productos o servicios sustitutos, o en mercados o nichos distintos. La competencia en algunos casos sirvió para validar la idea, como benchmarking o punto de referencia, como incentivo para mejorar de manera constante, como dijo Alec OXENFORD (La Nación Más, 16 de septiembre de 2015), "Io único importante es estar siempre un poquito delante de la competencia". De las start-ups con competidores directos, se enfrentan a competencias locales, pero que por ahora no son amenazas, por estar poco desarrollados o publicitados algunos, por tener menor calidad, nivel o tamaño, o simplemente porque aún hay lugar para nuevos competidores en el mercado ya que no está saturado. En cuanto a la competencia del exterior, algunos se enfrentan a los gigantes como Mercado Libre, "que amenazan con tomar el control de gran parte del mercado" (MARINO, ver ANEXO 2-1), y otros corren con ventaja competitiva en cuestión de costos, como es el caso de Culbot, que diseña aparatos para monitorear cultivos.

\section{FACTORES INTERNOS DE ÉXITO Y FRACASO}

Esta sección se centra en las características intrínsecas de los emprendedores entrevistados, es decir, el perfil del emprendedor, sus conocimientos, habilidades y aptitudes, así como también en la postura que presentan frente al éxito y al fracaso.

Teniendo en cuenta lo expuesto anteriormente sobre la educación, los emprendedores con un alto nivel de escolaridad, como se da en la mayoría de la muestra, tienen las ideas mucho más claras y un proyecto de vida definido de acuerdo a la formación que han recibido, la cual generalmente los perfila a emprender sus objetivos en un área relativa a ella. El análisis de los 
datos obtenidos (ANEXO 3-28) dejó entrever que casi en el $60 \%$ de los casos la educación, estudios, experiencia y conocimientos previos fueron claves para los entrevistados a la hora de comenzar con su emprendimiento. En cuatro de los casos (33,3\%), la formación profesional les sirvió de ayuda pero no fue un factor determinante, y solo uno de los emprendedores manifestó que no le sirvió de nada. Es el caso de Alan Yusim, quien estudió licenciatura en Informática, y su emprendimiento está relacionado al marketing audiovisual, un rubro totalmente diferente, más allá de que allí es quien se encarga del SEO, esto es, de la optimización de los sitios y anuncios para mejorar su aparición en los resultados de los motores de búsqueda, y esta tarea tiene que ver con la informática.

Respecto a las características inherentes al perfil del emprendedor, la que más se destaca es la "pasión" para emprender. "Nada nace sin pasión. La pasión se entiende como el motor del proyecto y la capacidad de 'seducir' a los diferentes actores (externos e internos) necesarios para el desarrollo de la empresa" (DURAND, 1999).

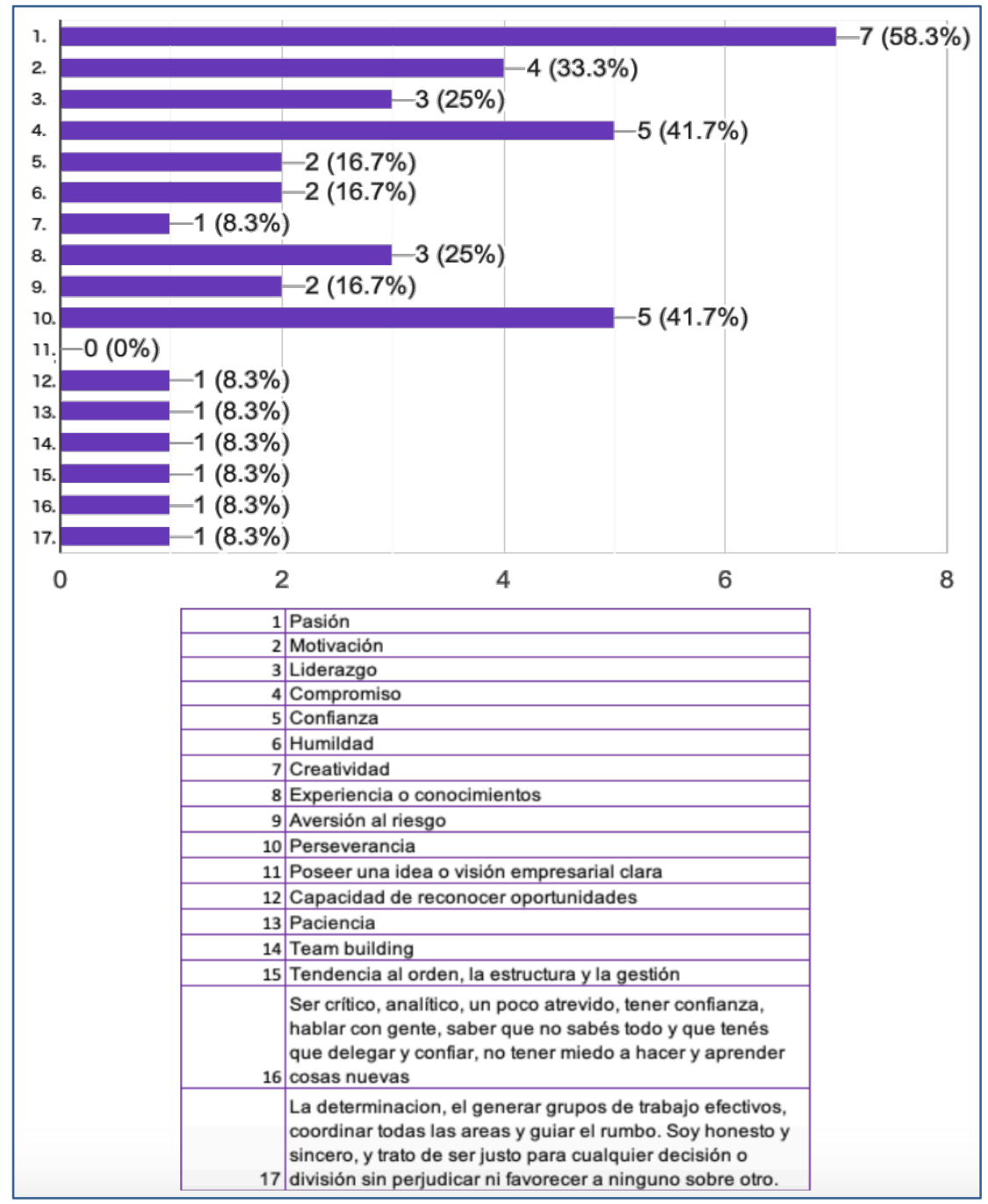

FIGURA 24

Competencias destacadas y de mayor influencia en emprendedores

Fuente: Elaboración propia 
La perseverancia también juega un papel fundamental, en un camino largo y con muchos obstáculos como los que transita una start-up, que no deben afectar al emprendedor ni impedir que siga adelante, al contrario, debe demostrar constancia, superación de las frustraciones y problemas para poder cumplir los objetivos, con la visión como único horizonte. En el mismo podio se encuentra el compromiso, la capacidad de fijar objetivos, planificar, asumir responsabilidades y cumplirlas. La motivación, "un conjunto de fuerzas que impulsan, dirigen y mantienen cierta conducta" (HITT et al., 2003), es también un rasgo importante en un emprendedor donde el motor es el deseo de crear y mantener un emprendimiento propio. "En general, los individuos que emprenden motivados por una situación de desempleo podrían no tener suficientes habilidades, preparación o experiencia para crear y desarrollar un emprendimiento" (MESSINA \& HOCHSZTAIN, 2015). No tener aversión al riesgo, ser realista, ser humilde, tener confianza en sí mismo, convicción en lo que se está haciendo y determinación para lograrlo, poseer una idea o visión empresarial clara, son algunas de las características que también es deseable que tenga un emprendedor (ver ANEXO 3-30).

Como cierre de esta sección, se indagó sobre la postura de los entrevistados frente al fracaso y sobre la percepción que tienen sobre alcanzar el éxito en su start-up. Respecto al fracaso, como buenos emprendedores todos coincidieron en que es parte del camino hacia el éxito y que sirve como aprendizaje (FIGURA 25). Como dijo Martín MIGOYA, CEO de Globant (\#Juevesdelnspiración, 12 de agosto de 2018): "Hay que sacarle dramatismo al fracaso (...) Es parte de la religión del emprendedor fracasar, pero hay que levantarse y empezar de nuevo".

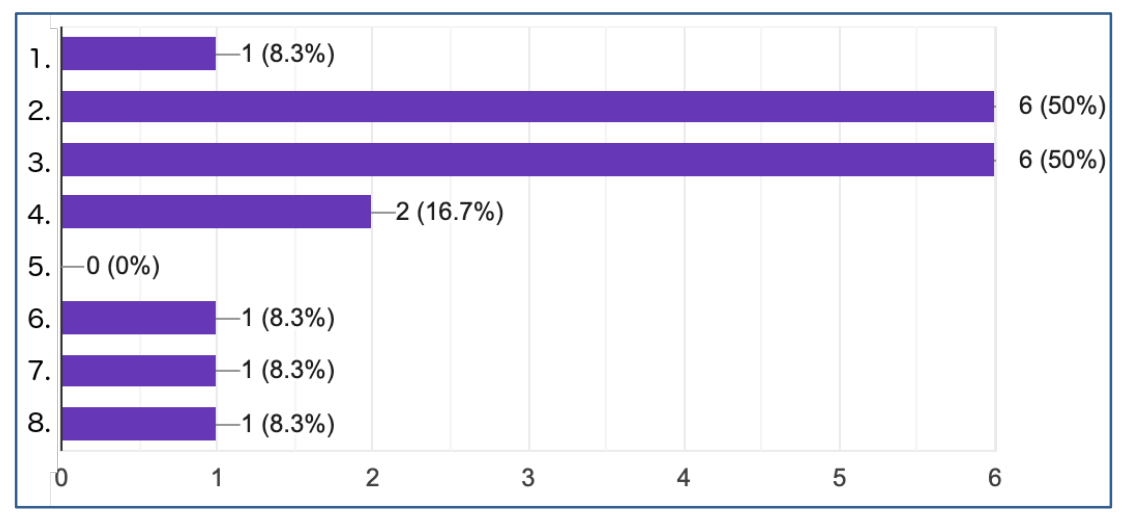

\begin{tabular}{|r|l|}
\hline 1 & Esta muy mitificado \\
\hline 2 & Es parte del camino hacia el éxito \\
\hline 3 & Sirve como aprendizaje \\
\hline 4 & Genera temor \\
\hline 5 & No hay lugar para el fracaso \\
\hline 6 & Prefiero evitarlo. Jaja \\
\hline 7 & $\begin{array}{l}\text { Seguir trabajando de lo mismo en un emprendimiento con } \\
\text { el mismo tamaño después de 10 años. }\end{array}$ \\
\hline 8 & Rendirse en el primero, segundo, tercero, cuarto, quinto... \\
\hline
\end{tabular}

FIGURA 25

Percepción del fracaso en el contexto de una start-up

Fuente: Elaboración propia 
En lo que concierne a la percepción que tienen los emprendedores del éxito, los resultados (ver ANEXO 3-32) evidencian que el término está fuertemente relacionado con el logro de resultados, como la escalabilidad, la sostenibilidad en el tiempo, la generación de valor en los usuarios/consumidores, y no tanto el proceso, es decir, la definición de estrategias y metas, de un plan de negocios y de su puesta en acción. La sostenibilidad en el tiempo es considerada en el presente trabajo de tesis como una característica clave que debe poseer una start-up para lograr el éxito (MEYER \& ZUCKER, 1989), y en cuanto a la escalabilidad, ya sea regional o global, como se vio en la SECCIÓN 1.3 es fundamental si se requiere atraer financiamiento externo. Respecto a la generación de valor, es fundamental ya que es lo que va a hacer que la start-up se diferencie de su competencia.

\section{FACTORES EXTERNOS DE ÉXITO Y FRACASO}

Al analizar el entorno de la start-up, se puede apreciar que el entorno familiar, la sociedad, las normas culturales influyeron en mayor o menor medida en la decisión de emprender de los emprendedores de la muestra (50 \% lo afirmó rotundamente y 33,3 \% respondió "Tal Vez") (ver ANEXO 3-33). A continuación, se detalla cómo fue que influyeron en los casos que respondieron de manera positiva, a partir del análisis de la siguiente nube de palabras:

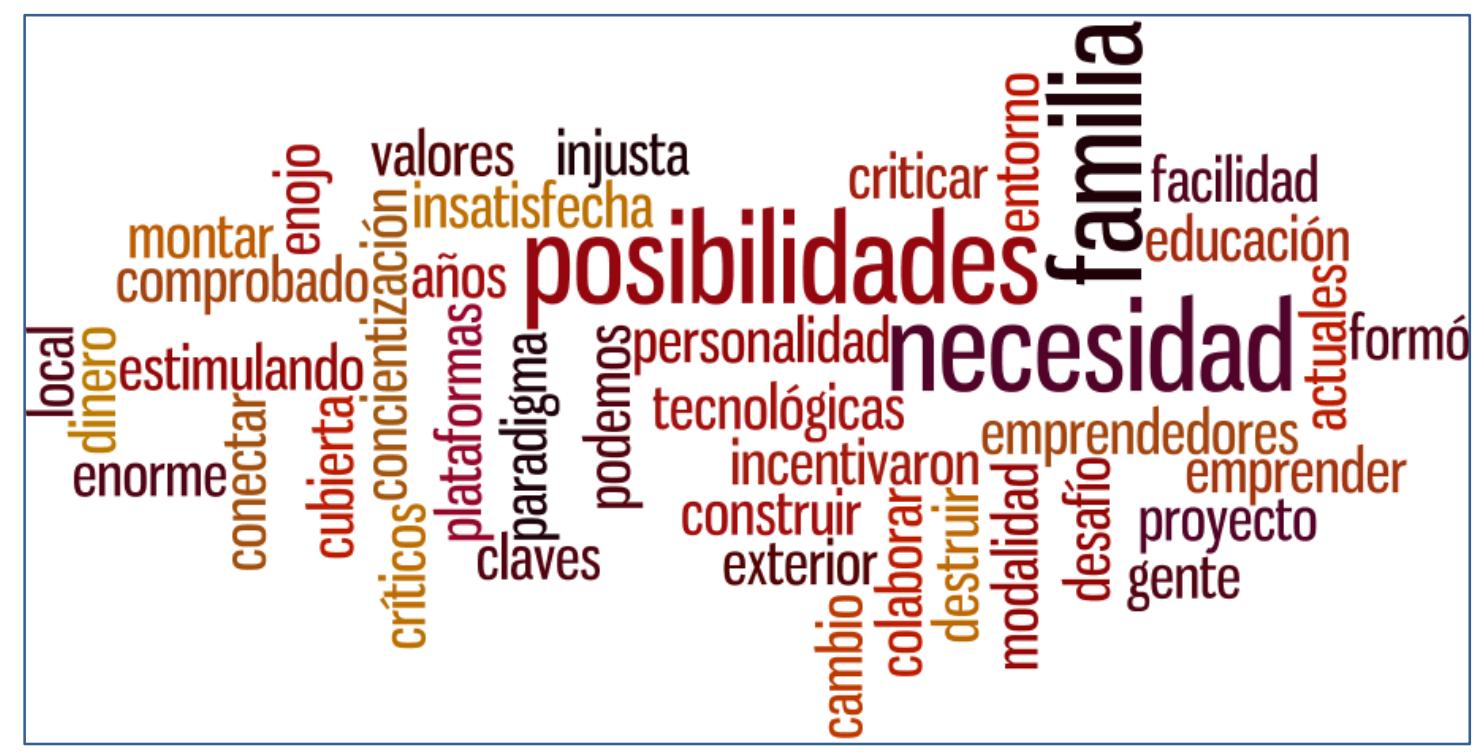

FIGURA 26

Influencia del entorno, la sociedad y/o las normas culturales sobre la decisión de emprender

Fuente: Elaboración propia

Como se puede ver, la familia del emprendedor ocupa un rol importante, es quien le trasmite valores, lo incentiva, protege, y muchas veces apoya económicamente para lanzarse a emprender. Pertenecer a un entorno familiar positivo, con espíritu emprendedor en ciertas ocasiones, es lo que los motivó a comenzar un proyecto propio con optimismo hacia el futuro. 
Este carácter emprendedor hereditario representa una gran ventaja, al contar con una referencia real de cómo la familia ha montado su emprendimiento, y sacar provecho de las experiencias tanto positivas como negativas que les hayan acontecido. "La motivación para emprender es mayor si la actividad emprendedora es aceptada socialmente y la función emprendedora es valorada y admirada" (AlEMANy et al., 2011). La sociedad y las normas culturales influyeron también en la decisión de emprender de algunos de los emprendedores examinados. En uno de los casos fue por una insatisfacción de las costumbres de la sociedad a la hora de beneficiarse con la crítica no constructiva, lo que lo llevó a querer cambiar el paradigma y concientizar con nuevos hábitos (Positrip) (ver ANEXO 2-1), y en otro caso fue una necesidad insatisfecha en el país que se halla cubierta en el exterior, la que influyó en su decisión de emprender (Topic) (ver ANEXO 2-12).

Adentrándonos en los factores que influyen en el emprendedurismo en Argentina, se puede apreciar que hay opiniones bastante opuestas sobre si el país propicia los emprendimientos. $\mathrm{Si}$ bien una mayoría respondió que no era propicio (58,8\%), muchos respondieron que sí lo era $(33,3 \%)$. Poniendo foco en los que respondieron afirmativamente, se trata en dos de los casos, de emprendimientos firmemente consolidados, con un modelo de negocios bien definido y funcionando, Babel Viajes (ANEXO 2-2), que posee franquicias en muchas partes del país, y AccessHoy (ANEXO 2-3), que ya opera hace años, tiene gran fidelización de clientes, y además atiende al mercado de Chile, por lo que parece no afectarles las reglas que instaura nuestro país. El tercer caso es Culbot (ANEXO 2-12) que ofrece un producto novedoso, que en Argentina no tiene competidores directos que estén bien desarrollados, y por otro lado obtiene financiamiento de inversores extranjeros, por lo tanto ni el contexto económico y político, ni la falta que hay en nuestro país de acceso a financiamiento, le afecta de manera drástica, esto último se puede confirmar con la respuesta a la pregunta 38 de la entrevista, ya que se trató del único caso que respondió que al emprendimiento no le afectaba a la situación actual del país (ANEXO 2-12.38). El resto de los emprendimientos, expresaron que sí les afecta: 50 \% respondió que les afecta parcialmente y $41,7 \%$ que les afecta por completo.

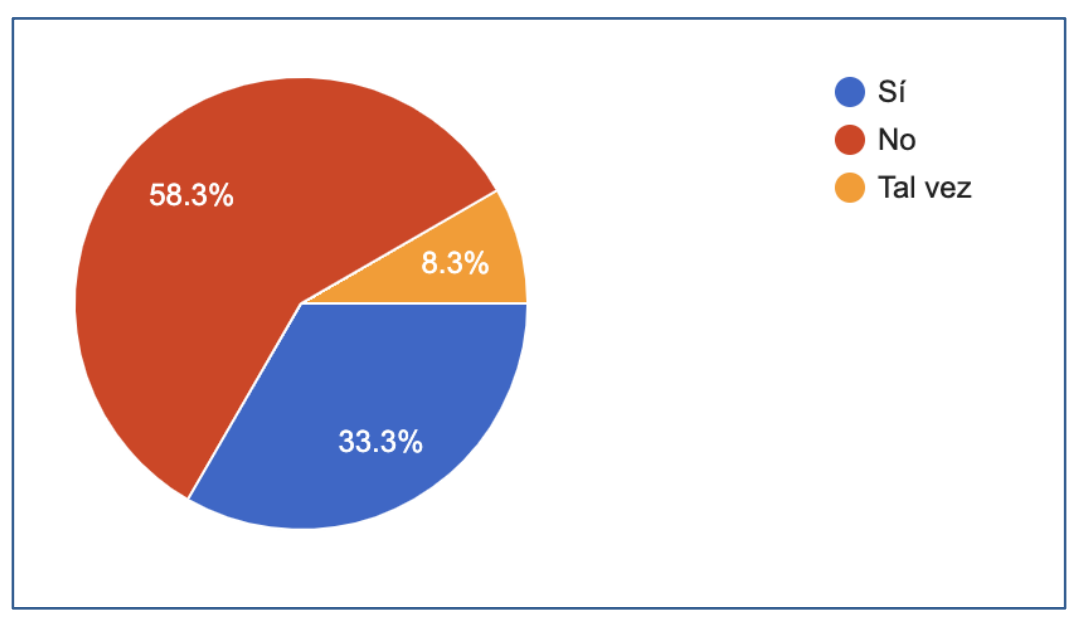

FIGURA 27

¿Considerás a Argentina un país propicio para emprender?

Fuente: Elaboración propia 
Analicemos entonces este punto con más detalle, según las ventajas y desventajas que encuentran los emprendedores en residir en este país (ver ANEXO 3-36 y 3-38). Como ventaja principal, destacaron que los cambios constantes debido a la economía inestable del país generan una gran habilidad de adaptación. Buen nivel de educación y grandes talentos, también son grandes ventajas que tiene nuestro país, como se dijo en la SECCIÓN 3.2, los empresarios de Argentina se destacan por ser innovadores, y por confiar en sus habilidades y conocimiento para comenzar nuevas empresas. Otro atractivo para este tipo de emprendimientos es que la industria de la tecnología es un nicho que todavía no está explotado, por lo que existen infinitas oportunidades para introducirse en el mercado.

Un alto nivel impositivo, dificultad de acceder a financiamiento y una economía inestable fueron las principales desventajas en este país para poder emprender que manifestaron los entrevistados. Particularmente, la Encuesta Nacional de Expertos GEM evidencia que "la falta de capital de riesgo y un estado de derecho claro, las cargas regulatorias y un entorno político y económico difícil son los principales desafíos a los cuales los empresarios deben enfrentarse y superar", y está fuertemente alineado con las respuestas obtenidas en la entrevista. Los cambios constantes, más allá de generar una actitud positiva en los emprendedores argentinos, que es la de saber adaptarse fácilmente a estas variaciones del mercado, es una gran desventaja que tiene el país, como bien dijo Alec OXENFORD, creador de OLX (STARTUPS WAY, 6 de julio de 2015), "la gimnasia que tiene que tener la gente para adaptarse a todo ese tipo de cambios es enorme, y si bien estamos acostumbrados, el resto del mundo no funciona con ese tipo de inestabilidad". OXENFORD subraya que esta es la principal diferencia que tiene nuestro país respecto del resto del mundo, todos estos cambios hacen que sea casi imposible armar compañías sustentables y que triunfen a nivel mundial, porque la estructura interna necesaria para un escenario es totalmente diferente a la necesaria para el escenario que le sigue. Los compañías de tecnología que lograron tener éxito y triunfar en el exterior fue porque no funcionaban en Argentina, sino que el equipo estaba pero el mercado era global, "ninguna de estas compañías hubiera logrado lo que logró si el resto del mundo también hubiese sido tan inestable" (STARTUPS WAY, 6 de julio de 2015).

En en ámbito concerniente a los recursos e infraestructura requerida para llevar adelante la start-up, al 58,3\% de los entrevistados (ANEXO 3-39) no les fue dificultoso conseguir lo que necesitaban. La mayoría fue creciendo con los recursos que tenía disponibles, y buscando a medida que lo necesitaban, de manera orgánica, en principio con ahorros y luego reinvirtiendo los ingresos. En esta línea, siete de los doce emprendedores entrevistados no recibieron ningún tipo de financiamiento externo, el resto consiguió apoyo económico de familia y amigos, ayuda de aceleradoras e incubadoras y en uno de los casos una inversión extranjera. 


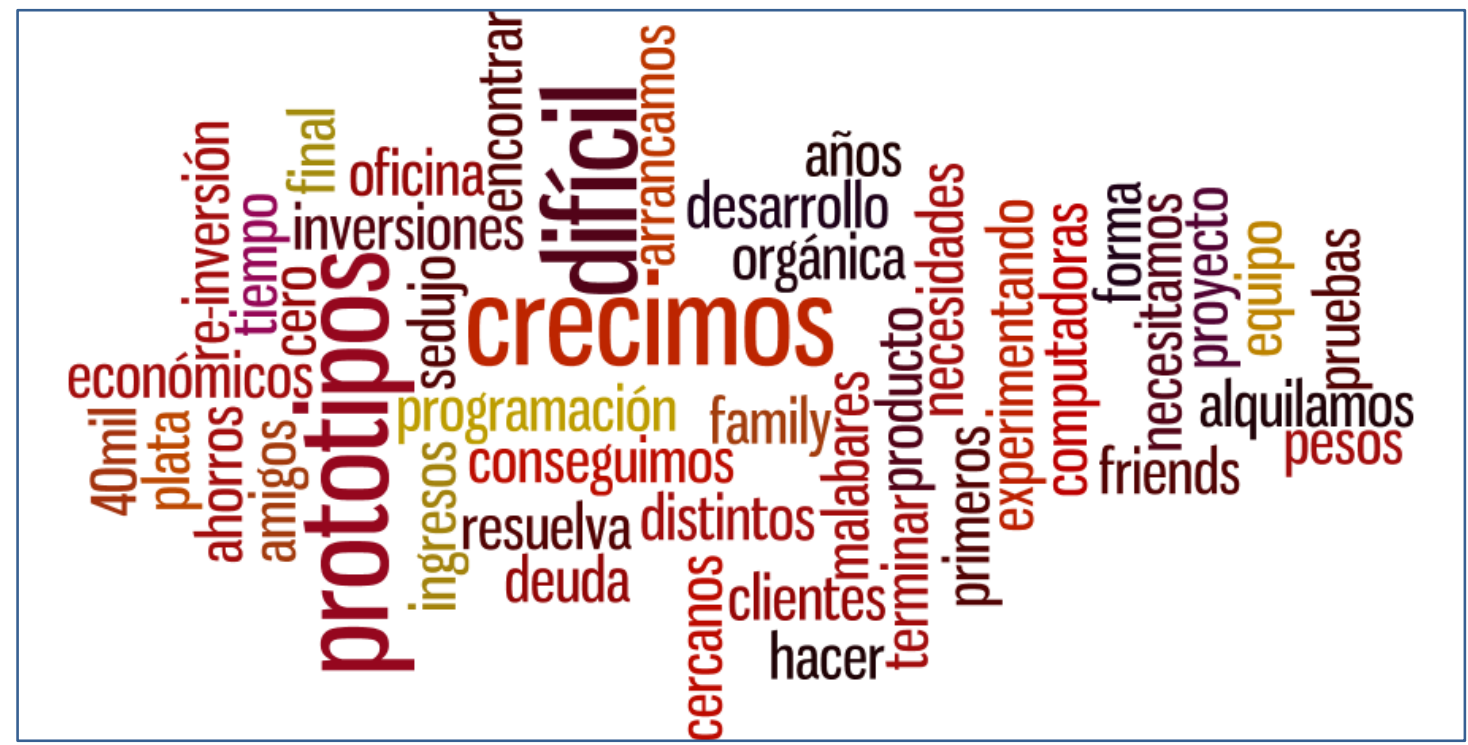

FIGURA 28

Acceso a recursos e infraestructura

Fuente: Elaboración propia

Considerando las respuestas obtenidas, el $41,7 \%$ restante expuso que les resultó más complicado acceder a lo que necesitaban, y concuerda con que implicó mucho trabajo de búsqueda, insistencia y perseverancia pero que al final consiguieron lo que buscaban.

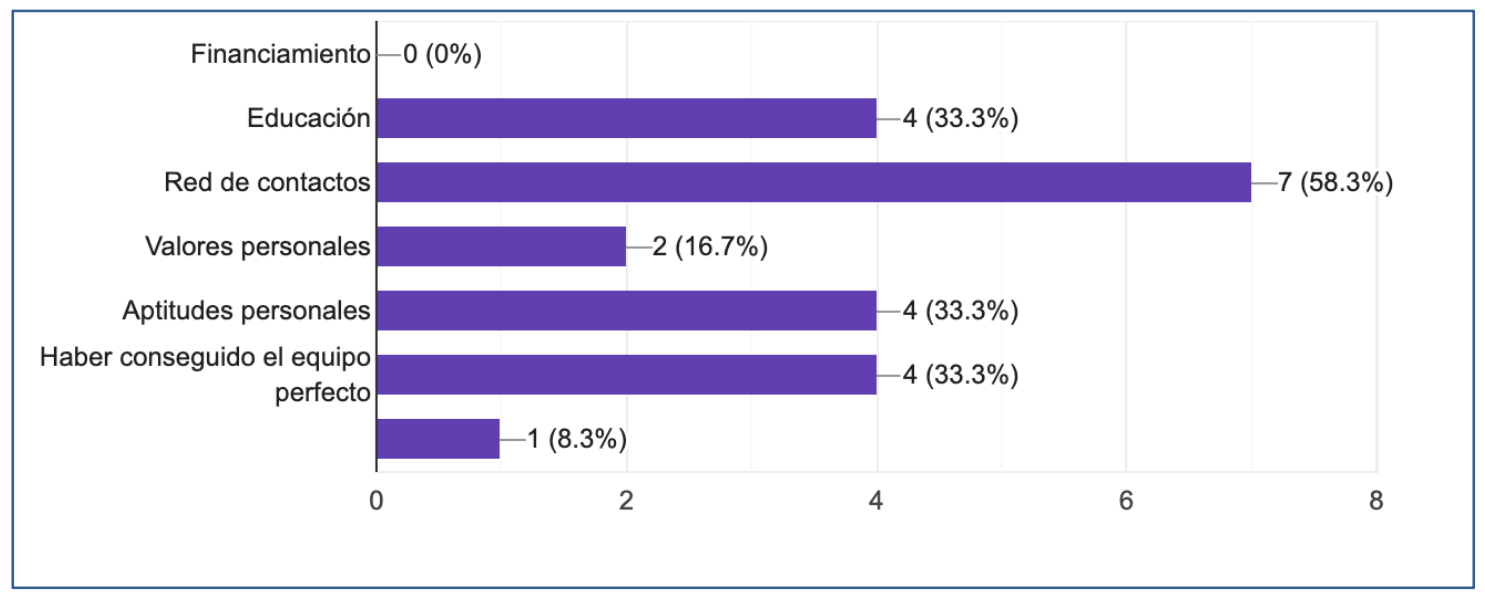

FIGURA 29

Herramientas habilitadoras para comenzar a emprender

Fuente: Elaboración propia

En lo que atañe a las herramientas que promovieron la actividad emprendedora, se logra evidenciar que desarrollar amistades y relaciones para construir una buena red de contactos es el factor más importante que el emprendedor debe considerar si quiere tener éxito en su 
emprendimiento. Las aceleradoras cuentan con una gran red de contactos que proporcionan a los emprendedores que entran en sus programas y les sirven de gran ayuda. Las redes son muy valiosas a la hora de querer conseguir financiamiento externo, y más aún en Silicon Valley. Según Santiago TEMPONE, co-fundador de Skyloom (EI Valle de los Tercos, 28 de marzo de 2019), "se puede tener suerte y encontrar fácil a la persona, y sino perseverar, y con el tiempo se llega a las personas adecuadas". La educación, como se vio anteriormente, también es una herramienta poderosa, así como resulta ser el hecho de conformar un buen equipo. Domingo GUERRA (EI Valle de los Tercos, 17 de enero de 2019) concuerda con que el equipo es clave, "ya que por más de que quieras y puedas hacer todo solo, no es posible, y hay gente más inteligente y capacitada que puede ayudarte". A esto Alec OXENFORD (Startups Way, 6 de julio de 2015) añade: "Messi es un buen ejemplo, es el mejor jugador del mundo y es hiper humilde, lo adoran y todo el equipo entero está organizado detrás de él (...) Messi no podría hacer lo que hace si no le pasaran la pelota". Por otra parte alega que la mayoría de los inversores lo que miran antes que nada es el equipo, asumen que la oportunidad y el contexto puede cambiar pero si el equipo es bueno "le encuentra la vuelta y cambia de plan". En el equipo buscan viveza, entendimiento de lo que quieren hacer, mucha pasión, y que sean confiables.

Por último, para cerrar la entrevista, se incluyó una pregunta para conocer la opinión de los entrevistados sobre las oportunidades que tiene la mujer a la hora de emprender, frente a las que tiene el hombre.

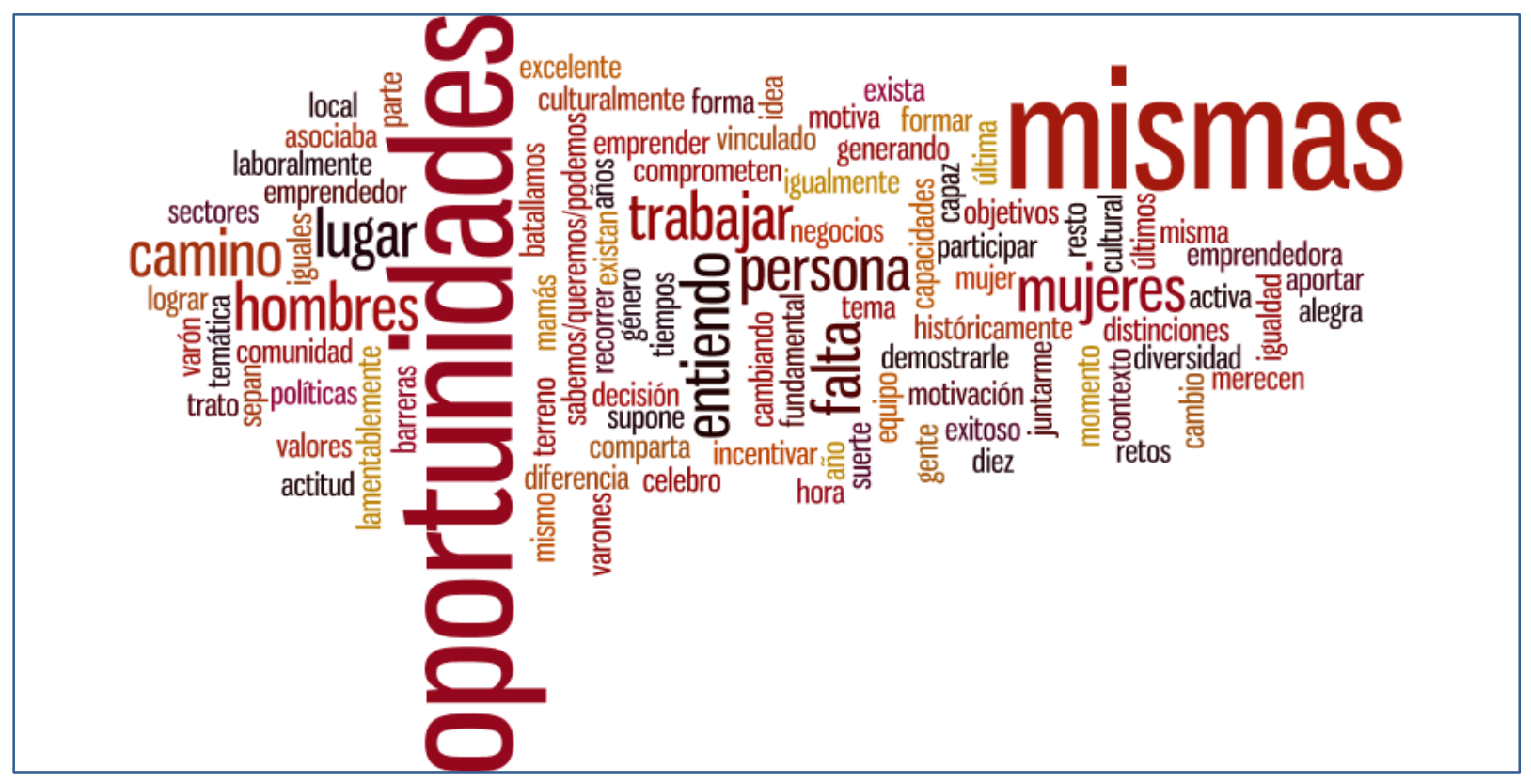

FIGURA 30

Igualdad de género en el ámbito emprendedor

Fuente: Elaboración propia

Si bien la mitad de los entrevistados no reconoce que haya desigualdad de género, es algo que históricamente sucede y aún continúa sucediendo, aunque pueden tener dicha postura por 
no considerar en ellos mismos actitudes discriminatorias. Los mecanismos de discriminación sexual han ido variando a lo largo del tiempo, pero los principales han sido, según BORDERíAS (1987), las normas legales y la construcción social e ideológica de los roles y los estereotipos de género, que han orientado la participación de las mujeres en el mercado de trabajo hacia lugares específicos.

Tradicionalmente se consideró a la tecnología y al uso de la computadora como una actividad masculina (SALANOVA SORIA et al., 2002). "Hay un tema cultural donde entiendo que a la mujer no se le han presentado las mismas oportunidades. Históricamente se asociaba más a un 'emprendedor exitoso' con un varón. Creo que en los últimos tiempos eso está cambiando y realmente me alegra" (Marino, ANEXO 2-1.43). En esta línea, WAJCMAN (1991) hace hincapié en que la prevaleciente fuerza o tendencia de la identificación entre tecnología y hombría, no es debida a una diferencia sexual biológica, sino que es el resultado de la construcción cultural e histórica del género. Por su parte, HORNIG (1992), en su estudio exploratorio de la relación entre el género y percepciones de riesgo y beneficio, concluye que las mujeres asocian más riesgo y menos beneficio a los desarrollos científicos y tecnológicos.

Es por esta misma cuestión que las mujeres participan menos del aprendizaje de las nuevas tecnologías, tienen con menos frecuencia una computadora y menos conocimientos relacionados con la informática que los hombres (ECCLES, 1994). En Argentina, "solo el $8 \%$ de las mujeres estudian carreras como Ingeniería en Sistemas o Desarrollo de Software" (LICO, 2018). Virginia FAY de Tiendup (ANEXO 2-9.43) afirma que en el país "no hay políticas de estado que nos igualen laboralmente con los hombres y culturalmente aún batallamos para demostrarle al resto (y a nosotras) que sabemos/queremos/podemos".

De todos modos, esto es algo que está cambiando en la actualidad, de hecho se están propiciando nuevas políticas en pos de la igualdad de género. En octubre de 2018, el gobierno argentino firmó un acuerdo con las empresas digitales de mayor peso en el país, en pos de promover un crecimiento económico inclusivo con enfoque de género que consiste en favorecer la inserción y la continuidad laboral de las mujeres, ampliar derechos y promover un nuevo modelo de cuidado que equipare responsabilidades entre mujeres y hombres (LICO, 2018). Entre los hombres entrevistados, estas fueron algunas de las respuestas que se alinean a la perspectiva de cambio: "No tienen las mismas oportunidades. Pero tenemos que lograr que sí las tengan!" (Diego Balan, AccesHoy, ANEXo 2-3.43); "No, pero entre todos (casi) los hombres estamos generando el contexto para que no existan barreras de género" (Leonardo Gimenez, Go4Click, ANEXO 2-4.43); "Por suerte, creo que van en camino de igualdad de oportunidades" (Mario Alza, Intriper, ANEXO 2-10.43).

Hoy, más empoderadas que nunca, debemos luchar para derribar estos viejos paradigmas y prejuicios que están instalados en la sociedad, ha llegado nuestro tiempo y la tecnología debe convertirse en nuestra gran aliada para acelerar este futuro de igualdad. 


\section{ANÁLISIS DE PODCASTS Y ENTREVISTAS PÚBLICAS}

El estudio de este conjunto de resultados se basa en el análisis interno de cada uno de los contenidos recolectados, utilizando el método de frecuencia de aparición de palabras recurrentes dentro de las entrevistas, para intentar cuantificar de alguna manera toda la información cualitativa. Con esta técnica, no es el estilo de lo expuesto en ellas lo que se pretende analizar, sino las ideas expresadas, siendo el sentido de las palabras lo que intenta cuantificarse.

Para el análisis, se elaboró la siguiente nube semántica de palabras:

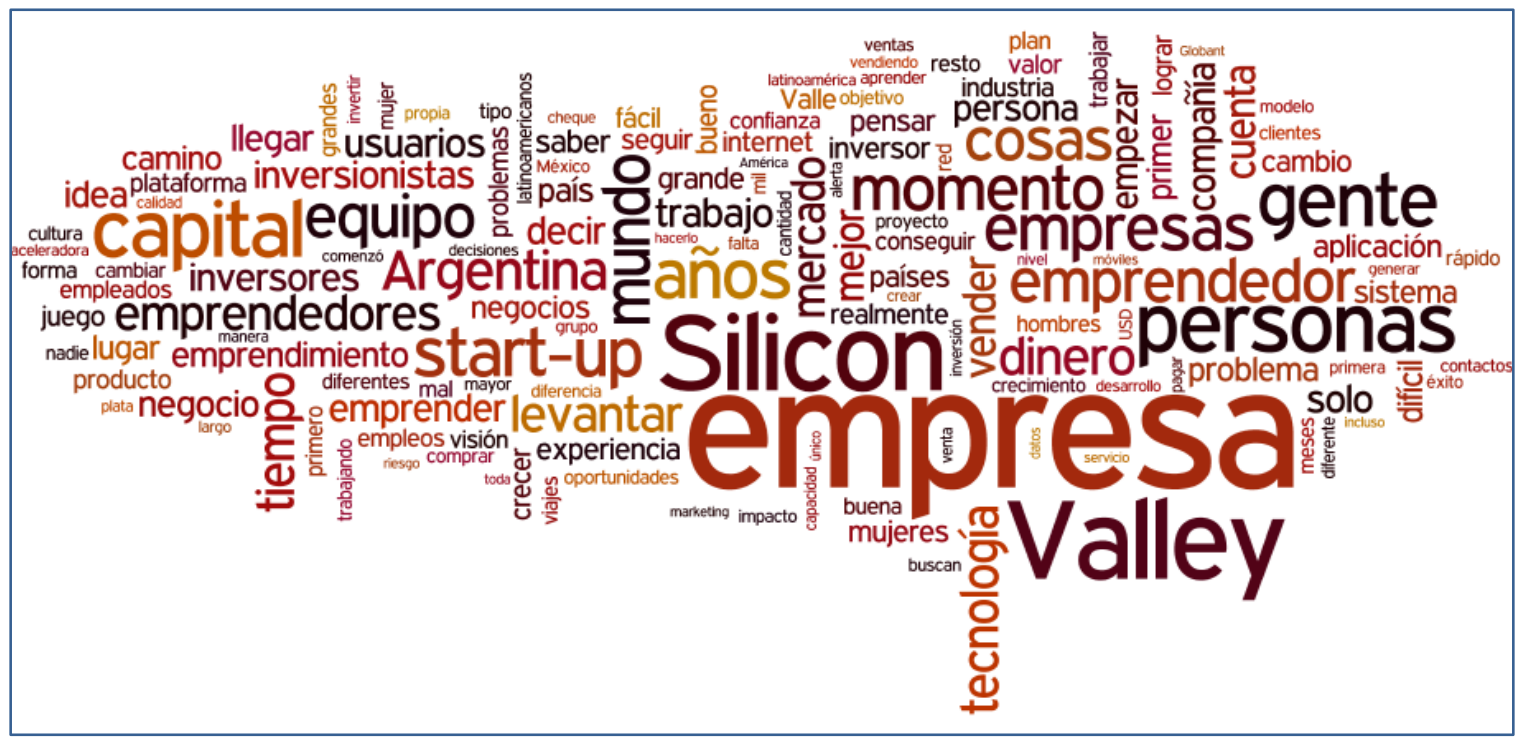

FIGURA 31

Nube semántica de palabras

Fuente: Elaboración propia

Para lograr este resultado, se debió inicialmente realizar un primer tratamiento de datos a partir del listado de términos proporcionado por la herramienta de software Textalyser. El software permite eliminar elementos lingüísticos sin valor referencial según el lenguaje del texto ingresado (preposiciones, artículos, etc.) y, además, permite excluir las palabras que no se desean contemplar para el análisis. En este caso, se eliminaron todas las formas verbales de los verbos ser, estar, querer, pasar, tener, deber, ir y hacer. Asimismo, se eliminaron las palabras que denotaban opinión: cree, piensa, opina, considera, etc. Por otro lado, se eliminaron todas las ocurrencias de adjetivos y adverbios de cantidad (mucho, muchos, poco, muy, casi, prácticamente, cada, más, menos) así como los de tiempo (actualmente, actualidad, hoy, ahora, siempre, luego, nunca, después, año, hora, vez, veces etc.) y espacio (allí, aquí, etc.). Tras este proceso de depuración de contenido, se procedió a crear la nube de tags mostrada en la FIGURA 
31 y a realizar el análisis e identificación de conceptos clave, siguiendo el modelo de inferencia inductivo, clasificando los conceptos en categorías que emergen del propio resultado, haciendo una reconstrucción de las partes para darles significado. Para lograrlo, se utilizó la técnica de mind mapping, "una poderosa técnica gráfica que aprovecha toda la gama de capacidades corticales y pone en marcha el auténtico potencial del cerebro (...) es una expresión gráfica que, con las muchas conexiones que se establecen, refleja el pensamiento irradiante, imaginativo y estructurado al mismo tiempo" (MUÑOz GonzÁlez et al., 2011), facilitando la asociación de los conceptos, y la representación de todas las ideas de forma organizada. La herramienta de software utilizada en este caso, también de carácter gratuito, se denomina text2mindmap. Se escogió como palabra clave central el concepto de start-up, y alrededor de ella se estructuraron el resto de los conceptos, y sus relaciones. 


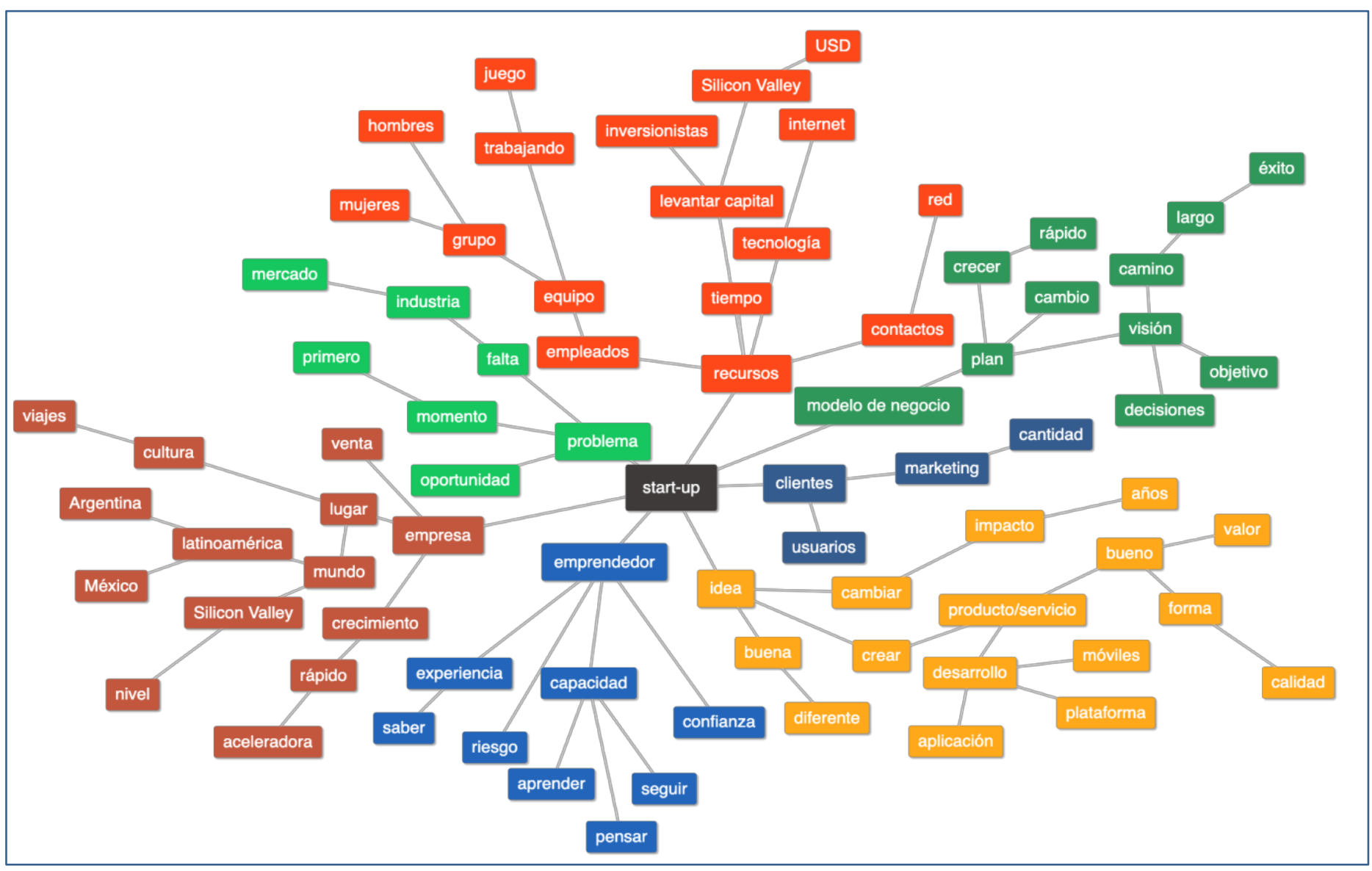

FIGURA 32

Mapa de conocimientos (sobre FIGURA 31) 
Las categorías y subcategorías que se desprenden de la palabra central tienen que ver con todos los factores involucrados durante el ciclo de vida de una start-up, desde que se detecta la problemática, ya sea por oportunidad, por una necesidad o faltante en el mercado o la industria, el surgimiento de la idea, su implementación y todos los recursos que esto implica, la definición del modelo de negocios, y todo el camino recorrido hasta obtener los primeros clientes/usuarios, luego buscar volumen, y seguir creciendo hasta el punto en que se vende la empresa o sale a la bolsa.

A continuación, se analizarán cada una de las categorías que se desprenden del eje del mapa de conocimientos:

Emprendedor: Comenzamos por esta categoría ya que el emprendedor es quien da inicio a todo el proceso. Las competencias más importantes que debe tener un emprendedor según los contenidos analizados son: confianza en sí mismo, saber tomar riesgos, ser racional, tener experiencia y capacidad de aprendizaje y de pensar en grande, $y$, sobre todo, de seguir luchando a pesar de lo que pase (perseverancia).

Problema: puede surgir de una necesidad personal como es la falta de empleo, o de la detección de una oportunidad ya sea de explotar un nicho que no ha sido explotado o de satisfacer una necesidad en alguna industria o mercado. Es importante el momento en que se detecta, siempre es mejor ser el primero en dar la solución, después puede ser demasiado tarde, y si es antes puede ser que la sociedad o el mercado no esté preparado para el cambio a introducir. "En la industria de la tecnología, todo lo que respecta a dispositivos móviles es nuevo y es un terreno fértil para emprendedores" (DEL RIO, 16 de diciembre de 2015).

$\square$ Idea: una idea además de ser buena, debe ser diferente a lo que ya existe, debe promover algún tipo de cambio, e intentar generar un impacto en los futuros usuarios/clientes, y si también se trata de un negocio que puede ser sostenible en el tiempo mucho mejor. Es importante saber reconocer cuando una idea no funciona, y saber pivotar, no hay que enamorarse nunca de las ideas. Para esto, se debe desarrollar el mínimo producto o servicio para poder salir a probarlo y obtener feedback temprano de los usuarios o clientes. Es fundamental que el desarrollo (aplicación web o móvil, plataforma, artefacto tecnológico, etc.) sea de calidad (forma), y que además de satisfacer una necesidad, agregue algún tipo de valor al quienes lo utilicen.

Recursos: son muchos los recursos necesarios a la hora de montar una start-up, y puede que unos sean más indispensables que otros dependiendo la etapa en que se encuentre.

Equipo: algo en lo que coincidieron la mayoría de los entrevistados, es que el equipo es clave, es un desafío armar un buen equipo, y que se conforme de personas que sean "Primero buena gente, después, inteligente" como dijo Alec OXENFORD (Startups Way, 6 de julio de 2015), e intentar lograr la mayor confianza, y comunicación interna posible.

El papel de la mujer: los equipos en el ámbito de la tecnología están históricamente conformados por mayoría de hombres. "Hay una realidad, hace diez años, no había tantas mujeres que estudiaran sistemas, y es por eso que tampoco hoy hay tantas profesionales 
mujeres en ese rubro" (EI Valle de los Tercos, marzo de 2018). El segundo problema, según Rocío MEDINA, es la diferencia salarial entre personas con las mismas capacidades y expertise pero distinto sexo, y el tercero es que muchos hombres aún no son conscientes de qué es discriminación y qué no lo es.

Red de contactos: es tan importante como tener un buen equipo, poder llegar a la persona justa con la mínima cantidad de grados de separación.

Tecnología: siempre se debe estar a la vanguardia en este aspecto, e incorporar nuevas tecnologías cuando exista la oportunidad. Si además de todo, se logra que todas las tecnologías utilizadas sean de desarrollo propio para no depender de terceros muchísimo mejor.

Tiempo: este recurso es sagrado, más en esta industria, donde avanza todo tan rápido. Como se explicó anteriormente en la categoría "Problema", "muchas veces lanzar un producto que está bien a tiempo, es mucho mejor que lanzar el producto perfecto después" (Startups Way, 6 de julio de 2015). Hay que intentar optimizar el uso de este recurso lo máximo posible.

Capital: este recurso está relacionado con todos los anteriores, para levantar capital, se requiere de tiempo y del desarrollo de relaciones humanas, los contactos a través de los cuales se llega a el/los inversionistas tienen mucho que ver. Asimismo, para poder levantar capital, es necesario tener un producto/servicio sólido y estar seguros de que funciona, no solo una buena idea. Particularmente, y es algo en lo que todos los entrevistados coincidieron, si se quiere levantar capital en Silicon Valley, es fundamental tener la empresa allí.

Clientes/Usuarios: son los que escriben las reglas del juego, quienes pueden hacer que el producto o servicio fracase con sus críticas, o ponerlo en un pedestal. Los clientes son cada vez más exigentes, y es fundamental atender a sus necesidades, retroalimentarse continuamente con su feedback y así conseguir retenerlos y que se mantengan activos. Las acciones de marketing juegan un papel fundamental, lograr escalabilidad en cantidad de usuarios orgánicos en el menor tiempo posible, es una de las premisas de este tipo de empresas, ya sea de forma gratuita o de pago.

Modelo de negocio: es importante tener un modelo de negocios definido más allá de que vaya cambiando por la velocidad de los cambios en el entorno. "Uno tiene un plan de negocios, pero por más planes y cálculos que se hagan, en una start-up nada funciona como lo planeado" (EI Valle de los Tercos, 17 de enero de 2019). De todas formas, es la visión a futuro la que guía el camino, sobre la que se define la estrategia y los objetivos, y todas las decisiones que se vayan tomando a lo largo del trayecto van a estar ligadas a ella. "Todo lo que consigue un emprendedor, es por la visión" (El Valle de los Tercos, septiembre de 2018). La visión de una start-up puede llevarla al éxito, así como también al fracaso. El emprendedor debe tener la habilidad de cambiar el plan cuando el mismo no esté funcionando (pivot).

Empresa: es importante a la hora de instalarse en algún lugar, analizar todas las posibilidades y los mercados, según la visión de negocio que se tenga. Por ejemplo, las cuatro empresas que son unicornios de Argentina, todas tienen su equipo de tecnología en Argentina, pero su negocio está fuera del país, al menos así nacieron la mayoría, algunas como OLX se instalaron en el mercado argentino luego de varios años de que el negocio funcionara en otros países. Argentina tiene recursos de primer nivel y, a diferencia de Silicon Valley, son mucho más 
económicos. En el contexto de Latinoamérica, Argentina está muy bien posicionada, de los nueve unicornios que existen en la región, como ya se mencionó, cuatro son argentinos, dos de Chile, dos de México y dos de Brasil. Nuestro país se caracteriza por tener muy buenos talentos, pero tiene la desventaja de sus cambios constantes en la economía. México tiene buena visibilidad en Estados Unidos por su cercanía. Es muy difícil para los latinos levantar capital en Silicon Valley y más si se trata de una mujer (EI Valle de los Tercos, 14 de marzo de 2019). Como se dijo anteriormente, ayuda mucho el hecho de tener la empresa radicada allí, pero no necesariamente todo el equipo, basta con que esté la parte de negocios, el equipo puede estar distribuido en cualquier parte del mundo. Lo que nos falta a los latinoamericanos es más regionalismo, quien mira desde afuera no ve a Latinoamérica como un todo, ve países aislados. "Hay que empezar a intentar hablar de ella como un todo, no tener conflictos internos, es decir, los latinoamericanos deben unirse más para triunfar en la industria tech, no solo para atraer salidas sino también inversiones" (EI Valle de los Tercos, julio de 2018). Las aceleradoras son actores que aparecieron en escena hace muy poco tiempo, y ayudan a la start-up a agilizar su crecimiento, proporcionando desde contactos, mentorías, espacio de trabajo, y muchos otros servicios que le son de utilidad. 
Las start-ups de tecnología son un componente importante para el desarrollo económico y social del país por su alto impacto en empleos de nueva generación, demandantes de personal de alta capacitación. Pero existe una realidad, y es que nueve de cada diez start-ups fracasan, y no logran superar sus primeros años de vida. Por esta razón, en el presente estudio se indagó tanto en los factores, características y prácticas que hacen al impulso del crecimiento y desarrollo de este tipo de empresas como a la existencia de factores limitantes para ello, particularmente en entornos económicos complejos como el argentino.

Buscando información cualitativa de fuentes que fueran valiosas por el tipo de aporte que pudieran proporcionar, se entrevistó a doce emprendedores tecnológicos bajo la figura de opinantes calificados; entre ellos, integrantes del programa Usina de Ideas de la Facultad de Ciencias Económicas de la UNLP y miembros del Polo IT de la ciudad de La Plata. Asimismo, la investigación se apoyó fuertemente en un análisis de detalle de documentación pública relacionada a la temática, hallada tanto en entrevistas públicas de canales de noticias, como en canales de YouTube y podcasts de emprendedurismo, a fin de contar con un insumo adicional de información cualitativa que al mismo tiempo "triangulara" con lo provisto por los opinantes calificados. Por otra parte, y con el objetivo de contextualizar el análisis a la realidad del escenario económico argentino, se analizaron los principales casos de éxito de start-ups de tecnología del país, quienes comparten el importante logro de haber alcanzado una valuación de más de mil millones de dólares en su capitalización. Se trata en estos casos de los cuatro unicornios argentinos: Mercado Libre, Globant, Despegar y OLX.

El análisis de toda la información disponible como resultado de la investigación permite entonces plantear las conclusiones que se presentan a continuación, en dos secciones: una primera para responder al primer objetivo específico planteado y una segunda para el segundo de esos objetivos. Con el cumplimiento de ambos objetivos específicos, se da entonces cumplimiento al objetivo general de la presente investigación.

Conclusiones referidas al objetivo específico de Identificar factores, características y prácticas que hacen al fomento del crecimiento y desarrollo de start-ups de tecnología, en general y también en un ámbito específico como es el escenario económico argentino:

Los factores intrínsecos a todo emprendedor, como lo son la pasión, la perseverancia y el compromiso, son de los requisitos más relevantes que debe reunir la persona para poder emprender.

Resultan igualmente trascendentes cuestiones relacionadas con la organización y que son comunes en general a todo tipo de empresas, como la capacidad de fijar objetivos, saber planificar, asumir responsabilidades y cumplirlas.

La capacidad de mantener la motivación y una clara actitud de propensión a asumir riesgos es también una característica muy valorada para el emprendedurismo; máxime en entornos económicos muy complejos como el argentino. En la misma línea, los emprendedores 
destacan que si bien nunca son deseados, los fracasos o los pasos en falso en un proceso de crecimiento de una start-up son "bienvenidos" en el sentido de que aportan experiencia y knowhow importantes de cara al futuro.

Aparece como característica a considerar las cuestiones de género. El sector tecnológico se ha considerado siempre como un sector muy dominado por hombres, en virtud de lo cual las mujeres aún mantienen limitaciones que aquellos no poseen como para desarrollar sus carreras profesionales dentro de empresas. Sin embargo, surge del análisis que se perciben opiniones en el sentido de que "algo está cambiando", y las mujeres son cada vez más piezas claves en la conducción y en la responsabilidad por el éxito de las empresas.

$\square \quad$ El azar juega un papel importante en el crecimiento y desarrollo de start-ups tecnológicas, sobre todo en un escenario económico como el argentino, en el que muchas veces a los emprendedores les resulta casi imposible predecir el comportamiento futuro de variables de alto impacto para el desempeño de sus start-ups. De lo relevado, surge la opinión obvia de que lo azaroso no se puede prever, pero también la coincidente de que no debe descartarse su consideración en todo momento.

$\square \quad$ El nivel de educación que hayan recibido quienes emprenden en start-ups tecnológicas es algo que también resulta clave. El estudio realizado no es explicativo y por lo tanto no fue propuesto el comprobarlo, pero es prudente plantear la premisa de que existe una fuerte relación entre quienes emprenden en forma racional y pueden llegar a alcanzar algún grado de éxito, y el nivel de habilidad técnica distintiva y capacitación general que puedan haber obtenido en sus etapas de formación como profesionales del sector.

$\square$ Se destaca en el estudio como una de las motivaciones principales del emprendedor el deseo de independizarse y de ser "su propio jefe". Habitualmente, en los primeros esfuerzos reciben el apoyo de amigos y familiares, en la forma de las primeras inversiones o bien con conocimientos específicos para fundar la empresa o simplemente el apoyo emocional para darle fuerza en la práctica de emprender.

Como otro punto de motivación se destaca también el sentido de la oportunidad; es decir, el percibir en el mercado una oportunidad que solo el emprendedor ve o bien solo él cree conocer la forma de explotar esa oportunidad percibida e implementarla y llevarla a la práctica. Muchas veces la oportunidad consiste en implementar en el mercado nacional una idea ya explotada y probada en otro mercado.

Destacan los emprendedores la importancia de armar un equipo de trabajo con ciertas características esenciales. Así, resulta importante armar un equipo con gente de intereses similares, complementarios, que tengan una visión en conjunto sobre las cuestiones que hacen a la base del negocio de la start-up. La organización de los roles de cada uno de los integrantes del equipo según sus habilidades, experiencia o área de conocimiento es muy importante, para tener siempre un referente en cada área a quien acudir.

Siguiendo la línea de las prácticas que hacen a la organización interna, se presenta como fundamental una gestión empresarial eficiente, planteando desde los primeros momentos una clara visión a futuro, y contando con un plan estratégico bien definido como para alcanzarla; pero al mismo tiempo con la flexibilidad necesaria como para adaptarlo según los cambios del 
entorno, y más aún en la industria de tecnología, en la que la velocidad de los cambios es característica saliente, y aun más dentro de un escenario como el argentino, siempre tan impredecible en cuanto al comportamiento de sus variables económicas.

Asimismo, se presenta como sustancial una cultura empresarial auténtica y comunicable, así como también una propuesta de valor realista y sostenible en el tiempo. Y para esto último, se destaca particularmente la propuesta de "monetización" de las ideas esenciales a partir de las cuales se crea la start-up; esto es, en qué forma se van a generar los "primeros ingresos" que permitan poner en marcha la empresa con la requerida solidez como para que puedan seguir funcionando.

$\square \quad$ Otra práctica habitual que se destaca como esencial es la de estar permanentemente leyendo la realidad del mercado, y prediciendo el comportamiento de las fuerzas competitivas. Saber por dónde van los avances tecnológicos, los movimientos de los competidores, las conformaciones de todas ofertas, etc., resulta imprescindible para poder mantener una startup en funcionamiento y con perspectiva de desarrollo.

Se destaca también como otra práctica muy valorada la capacidad de conocer el timing justo para el lanzamiento de una idea o un producto, o para el reacondicionamiento de la oferta de la start-up. En entornos tan cambiantes algunas start-ups pueden pecar de falta de innovación de productos o procesos y llegar siempre tarde al mercado; o por el contrario también pecar por "demasiado innovadoras", lanzando productos o servicios excesivamente disruptivos y para los que la demanda puede no encontrarse aún preparada para recibirlos. Para manejar esta cuestión del "tiempo ideal", los emprenderores recomiendan lanzar primero un producto o servicio básico que pueda ser "testeado" por la demanda, y luego aprovechar ese feedback para conocer su potencial y en dónde están las vías para poder ir enriqueciéndolo.

Lograr escalabilidad y alcanzar la sostenibilidad en el tiempo, en conjunto con la generación de valor en los usuarios/clientes resulta ser una característica saliente destacada por los emprendedores para tener éxito con una start-up. Lo mencionan como el momento en que el proyecto ha logrado la madurez suficiente para hacerse viable y sostenible en el tiempo. Cuando el emprendimiento está emergiendo, en su etapa inicial, son los amigos y familia los que ayudan aportando capital, y fomentan en la mayoría de los casos a tomar la decisión de emprender. Cuando se alcanza escalabilidad y sostenibilidad, es el proyecto start-up por sí mismo el que ya es una empresa válida, posicionada y actor competitivo en el escenario del sector de que se trate.

Presentadas las conclusiones referidas al primer objetivo específico, se presentan ahora las relacionadas con el segundo de estos objetivos; esto es, con Analizar la existencia de factores limitantes al crecimiento y desarrollo de start-ups, precisamente por estar inmersas en un escenario económico como el argentino:

Para el crecimiento y desarrollo de empresas start-ups es muy importante poder acceder a programas de aceleradoras de negocios, en los que además de lograrse una visión global del negocio, se brinde la posibilidad de establecer contactos e influencias, que son fundamentales a la hora de inaugurar rondas de capitalización. Ahora bien, en el contexto 
argentino no resulta sencillo para una start-up acceder a este tipo de aceleradoras, las que por su parte no se encuentran lo suficiente desarrolladas en nuestro país. Por lo tanto, el insuficiente desarrollo de aceleradoras y la consecuente dificultad para acceder a ellas es un factor limitante muy importante para emprendedores que quieran desarrollar sus start-ups tecnológicas.

Para poder levantar capital en Silicon Valley, por ejemplo, o en un entorno similar, proclive a fomentar el crecimiento y desarrollo de empresas tecnológicas, es importante tener un producto/servicio que funcione, tener tracción de usuarios, una red de contactos y una empresa consolidada en esos mismos entornos. Pues bien, llegar a acceder a allí desde escenarios como el argentino no es fácil, ya que éste le presenta a las empresas incipientes muchas dificultades y muchas limitaciones en sus inicios. Cuando se logra llegar, al emprendedor argentino se lo valora por su muy alta capacidad para saber afrontar dificultades y circunstancias cambiantes; pero el poder "dar el paso" y llegar, según lo obtenido de la información relevada, no parece ser un camino sencillo.

Ampliando la consideración al escenario latinoamericano, se nota que la falta de regionalismo entre los escenarios de los distintos países impiden a los inversores internacionales ver otra cosa que no sean experiencias puntuales de empresas incipientes en países aislados. Desde otra perspectiva, los inversores no ven a Latinoamérica como una región en conjunto sino que les llegan oportunidades de inversión del continente en forma de casos o iniciativas aisladas.

$\square$ De la información relevada surgen además cuestiones de género, porque a las dificultades para emprender y para obtener capital típicas de un escenario como el argentino, se le suman nuevos impedimentos si quien emprende resulta ser una mujer, si la "cara" de la oportunidad de inversión es una mujer. En esos casos, se muestra cierta resistencia mayor a invertir que de si de un hombre se tratase, o bien aparecen exigencias adicionales en los procesos de análisis de la oportunidad de inversión de que se trate.

$\square$ Factores que hacen las condiciones generales del escenario local y que afectan por igual a cualquier tipo de emprendimiento, sea o no de tecnología, afectan de igual modo a las startups tecnológicas. Así, la alta presión impositiva, la dificultad para mantener "reglas de juego" claras a lo largo del tiempo, la "burocratización" del proceso para crear nuevas empresas, o lo inestable de las condiciones de la macroeconomía, son algunas de las cuestiones que también dificultan y limitan el crecimiento y desarrollo de start-ups tecnológicas.

$\square \quad$ Los factores limitantes del escenario local se muestran claros en el análisis de casos de éxito de la industria. Todos los casos de éxito que se iniciaron como experiencias locales son de start-ups que pudieron crecer y desarrollarse "desde Argentina para el mundo"; esto es, rápidamente pudieron hacer el pasaje desde una empresa "argentina" a una con visión global y rápidamente conectada con escenarios económicos de países centrales. 
La investigación de start-ups de tecnología es todavía muy escasa y esta investigación fue apenas un trabajo exploratorio para comenzar a adentrarse en el mundo de este tipo de emprendimientos, y así conocer cuáles son los factores que pueden llegar a potenciar su éxito, pero está limitado a la muestra tomada. Las investigaciones futuras deben utilizar datos más extensos del área y comparar el resultado con los resultados de estas investigaciones. El método cuantitativo para verificar estos hallazgos de investigación también será útil.

Sería sumamente provechoso dejar de trabajar la temática como generalidad y comenzar a tratarla por vertical, probando hallazgos previos con diferentes implicaciones como:

$\square \quad$ Una investigación sobre un mercado determinado.

$\square \quad$ Una investigación sobre un modelo de negocio particular o una industria determinada.

- Una investigación que trate exclusivamente cuestiones de inversión y alta escalabilidad.

$\square \quad$ Un estudio sobre la relación entre el género y las posibilidades de éxito en una start-up. 
AhUJA, R., Michelis, T., WALKER, M., \& WeISSBUCH, M. (2007). Teen perceptions of disclosure in buzz marketing. Journal of Consumer Marketing, 24(3), 151-159.

Alemany, L., Álvarez, C., Planellas, M \& Urbano, D. (2011). Libro blanco de la cultura emprendedora en España. Fundación Príncipe de Girona. Barcelona: ESADE.

Almus, M. (2002). What characterizes a fast-growing firm? Applied Economics, 34, 14971508.

ARGENTINA STARTUPS. Angel List [Sitio web].<https://angel.co/argentina>

AscúA, R. (2009). La importancia del proceso emprendedor en la Argentina post-crisis 2002 y las asimetrías en la evaluación de factores influyentes en el financiamiento de empresas jóvenes. Comisión Económica para América Latina y el Caribe (CEPAL).

Asón Toca, José M. \& Santamaría Renedo, Alicia S. C. G. (2012). 100 Buenas Prácticas en emprendimiento universitario. NETbibLO, 1, 15-17.

AUtIO, E., \& KAURANEN, I. (1994). Technologist-entrepreneurs versus non-entrepreneurial technologists: analysis of motivational triggering factors. Entrepreneurship \& Regional Development, 6 (4), 315-328.

AZPIAZU, D., \& BASUALDO, E. (2000). Las pymes y la industria argentina. Potencialidades de crecimiento y empleo. Buenos Aires: FLACSO.

Baraona Pohl, E., \& NAJera Reyes, C. (2018). El peso de Bitcoin. ARQ (Santiago), 98, 32-43.

BBVA. (2014). Reinventar la empresa en la era digital. Open Mind, 144.

BILL, A. (2015). La disciplina de emprender: 24 pasos para lanzar una startup exitosa. LID Editorial.

Blanco, CARLOS (2014). Fases de inversión en una startup. Recuperado de <https://carlosblanco.com/2014/11/13/fases-de-inversion-en-una-startup/>

BLANK, S. (2013). Manual del Emprendedor. México: Gestión 2000.

BORDERÍAS, C. (1987). Un nuevo enfoque metodológico para el estudio de la discriminación sexual en el mercado de trabajo. Madrid: Instituto de la mujer. El trabajo de las mujeres, pp. 21-42.

BossI, J. (2018, febrero 10). ¿Sabías que Mercado Libre también nació en un garaje?, CNN. Recuperado de <https://cnnespanol.cnn.com/video/mercado-libre-nacio-en-ungaraje-mercado-sur-bossi-intv-galperin/>

BRUNET, L. (2004). El clima de trabajo en las organizaciones: definición diagnóstica y consecuencias. México: Trillas.

CABIEDES, LuIS M. (2016). Dicen que soy un inversor con el que se gana mucho dinero. Emprendedores. Recuperado de <http://www.emprendedores.es/casos-de-exito/luis- 
martin-cabiedes>

CARLAND, J., HoY, F., Boulton, W., \& Jo ANn C. CARLAND. (1984). Differentiating Entrepreneurs from Small Business Owners: A Conceptualization. The Academy of Management Review, 9(2), 354-359.

CARson, D., Cromie, S., McGowan, P., \& Hill, J. (1995). Marketing and Entrepreneurship in $S M E^{\prime}$ 's. London: Prentice Hall.

CASTILLO, V., RIVAS, D., Rojo, S. \& ROTONDO, S. (2006) La creación de nuevas empresas durante la etapa post-convertibilidad (2003-2005): impacto sobre el empleo asalariado registrado. Ministerio de Trabajo, Empleo y Seguridad Social, AAEP.

CATALANO, S. (2018, diciembre 4). Marcos Galperin: "Si no reformamos nuestro marco laboral será muy difícil salir adelante", Infobae. Recuperado de <https://www.infobae.com/economia/finanzas-y-negocios/2018/12/04/marcosgalperin-si-no-reformamos-nuestro-marco-laboral-sera-muy-dificil-salir-adelante/>

CB INSIGHTS (2018). The Top 20 Reasons Startups Fail. Recuperado de <https://www.cbinsights.com/research/startup-failure-reasons-top/>

CHEN, ANDREW (2012). Growth Hacker is the new VP Marketing. Recuperado de <http://andrewchen.co/how-to-be-a-growth-hacker-an-airbnbcraigslist-case-study/>

CIRIACO, A., \& RIO, C., \& SANTAMARíA, R. (2003). ¿ ¿Tienen los inversores habilidades de selección? Resultados con fondos de inversión. Revista de Economía Aplicada, XI(32), 51-75.

CODER FM (2018, agosto). ¿Cómo superar los fracasos y seguir con tu emprendimiento? [Audio en podcast]. Recuperado de <https://open.spotify.com/episode/2j9819eU258HzRNycUc95k?si=LBpN7a7QVuy_iPwoFMdWw>

CODER FM (2018, agosto). ¿Cómo emprender en Argentina? con Claudio Sanchez de Sky Teddy [Audio en podcast]. Recuperado de <https://open.spotify.com/episode/5xiVPCrzXAsiyVW7pAyJ8G?si=e713PhlsRt6lH1QC $x E C O z A>$

D'AVINo, M., De Simone, V., IANNucCI, M., \& SCHIRALDI, M. (2015). Guidelines for e-Startup Promotion Strategy. Journal of Technology Management \& Innovation, 10(1), 1-16.

DE LA VEGA, A. (2017). Glovo y The Crowd Angel protagonizan el primer exit del equity crowdfunding en España. Recuperado de $<$ http://blog.thecrowdangel.com/blog/glovo-protagoniza-primer-exit-del-equitycrowdfunding-espana/>

Del RIO, J. (2015, diciembre 16). Roberto Souviron: “Creo que en los negocios hay mucho de suerte", La Nación. Recuperado de <https://www.lanacion.com.ar/economia/roberto-souviron-creo-que-en-losnegocios-hay-mucho-de-suerte-nid1854793>

Dolader Retamal, C., Bel Roig, J., \& Muñoz TAPia, J. L. (s.f.). La blockchain: fundamentos, aplicaciones y relación con otras tecnologías disruptivas. Universitat Politécnica de Catalunya, 33-40. 
DRUCKER, P. F. (1993). Innovation and entrepreneurship. Harper Business.

DURAND, T. (1999). El perfil y las habilidades del empresario. Madrid: IE Business School.

DyE, R. (2000). The Buzz on Buzz. Harvard Business Review, 139-146. Recuperado de <https://hbr.org/2000/11/the-buzz-on-buzz>

ECCLES, J. S. (1994). Understanding Women's Educational And Occupational Choices: Applying the Eccles et al. Model of Achievement-Related Choices. Psychology of Women Quarterly, 18(4), 585-609.

El Valle de los Tercos (2019, marzo 28). Santiago Tempone, cofundador de Skyloom: Cómo convertir tu empresa en una startup de Silicon Valley [Audio en podcast]. Recuperado de

<https://open.spotify.com/episode/2ZRzagQO5DxyTmlkUbbOU6?si=LE221iYYT0G5ET hqoiHxPg >

EI Valle de los Tercos (2019, marzo 14). Martha Hernández, fundadora de madeBOS: Cambiar el mundo de verdad no es fácil en Silicon Valley [Audio en podcast]. Recuperado de $<$ https://open.spotify.com/episode/2FGTGbN6hu47lu1pV70c0h?si=2EcJPMEVSPG5PzAYs8-Sg>

El Valle de los Tercos (2019, febrero 28). Ale Resnik, emprendedor, fundador de Beepi y Belong: Qué es fracasar en Silicon Valley [Audio en podcast]. Recuperado de <https://open.spotify.com/episode/7sGMyaFJKHfMk1m0ozQFXR?si=Ot4WtCMR4qImRF7P2qmog>

El Valle de los Tercos (2019, enero 17). Domingo Guerra, fundador de Appthority: Un emprendedor latinoamericano que vendió su startup en Silicon Valley [Audio en podcast]. Recuperado de $<$ https://open.spotify.com/episode/4Uh5XwTiy8uyHtmesHP9LT?si=9dBVx4kNTbuaf4 9nY_pKzQ >

El Valle de los Tercos (2018, agosto). Gonzalo Juárez, Sebastián Juárez, eTips: Los emprendedores argentinos anti Silicon Valley [Audio en podcast]. Recuperado de $<$ https://open.spotify.com/episode/5IFqlpsopvKslqtHPeEuLP?si=_HVKNPT5Seaqmg8 mf6NMZg >

El Valle de los Tercos (2018, julio). Alejandro Cantú, fundador de SkyAlert: Silicon Valley te acelera... iy cómo! [Audio en podcast]. Recuperado de <https://open.spotify.com/episode/6p9nEyw9AJjHpeNd2KhYZU?si=kO3RkFacTNe0l5V4IRj1A>

El Valle de los Tercos (2018, septiembre). Lecciones de una start-up de alto crecimiento en Silicon Valley: Hernán Jaramillo, VP de Desarrollo de Negocios, Just (ex Hampton Creek) [Audio en podcast]. Recuperado de <https://open.spotify.com/episode/32BapBHYMjBD93WndaNJTw?si=y7xx94ZPQiC69 PpR_LLddw>

El Valle de los Tercos (2018, marzo). Rocío Medina, fundadora de Latinas in Tech: ¿Silicon Valley es tan machista como parece? [Audio en podcast]. Recuperado de <https://open.spotify.com/episode/789Dlyh2EPj5N519ul6MXs?si=ag9Ra7EBRzWyhX- 
jVMxmDg>

El Valle de los Tercos (2018, febrero). Leonardo Shapiro, fundador de Airbanq, Ultapay, TiendaKit y más: El hombre que llegaba demasiado temprano a la innovación [Audio en podcast]. Recuperado de <https://open.spotify.com/episode/0yhwHrQz7Brdfv3rnU6g1X?si=7vA3VEmTjGvTCgFzDLq4A>

EI Valle de los Tercos (2018, julio). Jonathan Nelson, Hackers and Founders: Silicon Valley es racista y lo dice un gringo [Audio en podcast]. Recuperado de $<$ https://open.spotify.com/episode/2le1Hgnkm1vW4k5tKTTE80?si=oObfOzLQWezRJPXQEIOA>

EMPREAR BUSINESS ANGelS (2015). ¿Por qué hoy en día las start-ups crecen más rápido? Recuperado de <http://businessangels.emprear.org.ar/blog/por-que-hoy-en-dia-lasstartups-crecen-mas-rapido>

ENDEAVOR (2013). Cómo son y qué quieren las emprendedoras de alto impacto. Recuperado de <http://www.endeavor.org.ar/como-son-y-que-quieren-las-emprendedoras-dealto-impacto/>

ESPARRAGOZA, L. (2016). Blockchain, el Internet de las Cosas y la Cuarta Revolución Industrial. Recuperado de <https://www.criptonoticias.com/opinion/blockchain-internet-cosascuarta-revolucion-industrial/>

ESTENSSORO, M. E. (2017). Argentina innovadora. Buenos Aires: Sudamericana.

EsteR, P. (2017, 01). Innovation and Startups in Silicon Valley: An Ecosystem Approach. En Accelerators in Silicon Valley, Amsterdam University Press, pp. 37-62.

ESTER, P. (2017, 02). Silicon Valley: The DNA of an Entrepreneurial Region. En Accelerators in Silicon Valley. Amsterdam University Press, pp. 21-36.

FleisCH, Elgar; WeInBERger, M. \& WORTMANN, F. (2014). Business Models and the Internet of Things. Bosch Internet of Things \& Services Lab. Recuperado de <http://www.iotlab.ch/wp-content/uploads/2014/11/EN_Bosch-Lab-White-Paper-GM-im-IOT1_3.pdf>

FREIRE, A. (2004). Pasión por emprender: de la idea a la cruda realidad. Buenos Aires: Aguilar.

Frese, M., \& RAUCH, A. (2014). The Psychology of Entrepreneurship. Annual Review of Organizational Psychology and Organizational Behavior, 1, 413-438.

Fried, J. \& Heinemeier Hansson, D. (2010). Rework. Random House Lcc Us, 1, pp. 10-11.

GalluP, A. M. (2007). Entrepreneurship Survey of the EU (25 Member States), United States, Iceland and Norway. Brussels. The Gallup Organization, Flash EB Series (192). Recuperado

<http://ec.europa.eu/commfrontoffice/publicopinion/flash/fl_192_sum_en.pdf>

GARBULSKY, GERRY (2017, agosto 2). "Inicios de Despegar.com I Roby Souviron I INNOVATION DAY 2017", Amigos de la Universidad de Tel Aviv en Argentina [Video en youtube]. Recuperado de <https://www.youtube.com/watch?v=w1u7Lt8fpUE> 
GarCía Fuentes, M. (2013). Hacia el emprendimiento de alto impacto. Entrepreneur. Recuperado de <https://www.entrepreneur.com/article/266218>

GHEMAWAT, P. (1999). Strategy and the business landscape: text and cases. Addison-Wesley.

Gómez Gras, J. M., Mira Solves, I., \& Martínez MateO, J. (2012). Actividad Emprendedora en la Comunidad Valenciana. Informe GEM 2011-2012: Global Entrepreneurship Monitor. Universidad Miguel Hernández, p. 51.

GRAHAM, PAUL (2012). Want to start a Startup? Recuperado de $<$ http://www.paulgraham.com/growth.html>

Gross, B. (2015). The single biggest reason why start-up's succeed. TedTalks (TED2015). Recuperado de $<$ https://www.ted.com/talks/bill_gross_the_single_biggest_reason_why_startups_su cceed>

HeRnÁndez-Puértolas Pavía, Á. (2018, marzo 26). Estrategia de salida en las Startups. Recuperado de <http://net-craman.com/blog/estrategia-de-salida-en-las-startups/>

HeRnández SAMPIERI et. al. (2014). Metodología de la investigación. Buenos Aires: McGraw Hill.

HitT, M. L.; Stewart Black, J. \& PoRTeR, L. (2003). Administración. Pearson.

HORNIG, S. (1992) Gender differences in responses to news about Science and Technology. Science, Technology, \& Human Values, 17(4), 532-542.

HowelL, S., \& ROCHA ARMADA, M. (1998). Investor timing behavior under imperfect timing information in the factor model. RAC-Revista de Administração Contemporânea, 2 (2), 7-21.

JURVETSON, STEVE (2000). What exactly is Viral Marketing?. Red Herring, 110-111. Recuperado de $<$ https://bit.ly/2Hhv9Kx>

KANTIS, H. (2004). Desarrollo Emprendedor. América Latina y la experiencia internacional. Banco Interamericano de Desarrollo (IADB) y Fundes Internacional, 2.

KANTIS, H.; ANGelelLI, P. \& GATTO, F. (2000). Nuevos emprendimientos y emprendedores en Argentina: ¿de qué depende su creación y supervivencia? Universidad Nacional de Córdoba, Memorias de la 5a. Reunión Anual de la Red PyMEs Mercosur.

KATZ, J. (1984). Book Reviews. Work and Occupations, 11(4), 500-504.

KorunKa, C.; Kessler, A.; Frank, H.; LUeger, M.; (2011). Conditions for growth in one-person startups: A longitudinal study spanning eight years. Psicothema, 23, 446-452. Recuperado de <http://www.redalyc.org/articulo.oa?id=72718925017>

KREAUS, S., HARMS, R., \& FINK, M. (2010). Entrepreneurial marketing: moving beyond marketing in new ventures. International Journal of Entrepreneurship and Innovation Management, 11(1), 19-34.

La Nación Más (2015, septiembre 16). ¿Cómo llegó OLX a ser una de las 5 empresas de internet más exitosas de la India? [Video en youtube]. Recuperado de $<$ https://www.youtube.com/watch?v=JiGZER54Cok> 
LeE, Alleen (2013). Welcome To The Unicorn Club: Learning From Billion-Dollar Startups. TechCrunch. AOL. Recuperado de <https://techcrunch.com/2013/11/02/welcome-tothe-unicorn-club/>

LEVINSON, J. \& LEVINSON, J. (2011). The best of guerilla marketing: Guerilla Marketing remix. USA: Entrepreneur Press.

LEVINSON, JAY CONRAD. (2007). Guerrilla Marketing: Easy and Inexpensive strategies for making big profits from your small business. New York: Houghton Mifflin Company. Recuperado de $<$ https://bit.ly/2HkKRVs $>$

LICO, M. (2018, octubre 16). El Gobierno de la Ciudad de Buenos Aires y Empresas Tech por la igualdad de género en el mercado de trabajo. Recuperado de $<$ https://geekpopsite.wordpress.com/2018/10/16/el-gobierno-de-la-ciudad-debuenos-aires-y-empresas-tech-por-la-igualdad-de-genero-en-el-mercado-detrabajo/>

LONGOBARDI, M. (2018, noviembre 11). Galperín: "El marco laboral argentino es terriblemente anticuado", CNN. Recuperado de <https://cnnespanol.cnn.com/video/argentinamarcos-galperin-marco-laboral-argentino-anticuado-mercadolibre-dialogolongobardi/>

Matallín SÁEZ, J. C. \& Fernández Izquierdo, M. A. (1999). Análisis de la performance a través del estilo del fondo de inversión. Revista Española de Financiación y Contabilidad, XXVIII (99), 413-442.

Messina, M. \& HochszTAIN, E. (2015). Factores de éxito de un emprendimiento: Un estudio exploratorio con base en Técnicas de Data Mining. Tec Empresarial, 9(1), 31-40.

MEYER, M. \& ZUCKER, L. (1989). Permanently failing organizations. Newbury Park, CA: Sage Publications.

MigliAZZO, OsCAR ANDRÉs (2017). Por qué son importantes los emprendimientos en la generación de empleo. La Voz. Recuperado de $<$ http://www.lavoz.com.ar/opinion/por-que-son-importantes-los-emprendimientosen-la-generacion-de-empleo>

MINER, J. B. (1997-1). A psychological typology of successful entrepreneurs. Quorum Books.

MINER, J. B. (1997-2). The expanded horizon for achieving entrepreneurial success. Organizational Dynamics, 25(3), 54-67.

MOHR, J. \& SPEKMAN, R. (1994). Characteristics of partnership success: Partnership attributes, communication behavior, and conflict resolution techniques. Strategic Management Journal, 15(2), 135-152.

MontoyA, D. M. (2015). Startups: tendencias en América Latina y su potencialidad para el crecimiento empresarial. Contexto, 4, 7-20.

MorRIS, M. H., SCHINDEHUTtE, M. S., \& LAFORGE, R. W. (2002). Entrepreneurial marketing: a construct for integrating emerging entrepreneurship and marketing perspectives. Journal of Marketing Theory and Practice, 10(4), 1-19. 
MUNROE, T. \& WESTWIND, M. (2009). What makes Silicon Valley tick? The Ecology of Innovation at Work. Nova Vista Publishing.

Muñoz González, J. \& Ontoria Peña, A., \& Molina-Rubio, A. (2011). El mapa mental, un organizador gráfico como estrategia didáctica para la construcción del conocimiento. Magis. Revista Internacional de Investigación en Educación, 3(6), 343-361.

Musso, R. \& ECHECOPAR, G. (2012). El Valle de la Muerte. Amazon.com. Recuperado el de <http://altair.elo.utfsm.cl/uploads/pdf/Musso2012_cortesia_para_ELO_USM.pdf>

ObSeRVATORIo ViRTuAl de TRANSFERENCIA de TeCnOlogía (OVTT). Empresas de base tecnológica. Recuperado de <https://www.ovtt.org/empresa-base-tecnologica>

Periodista Digital, Economía de la vida. (2014). Startups: pequeñas empresas con grandes ideas. Recuperado de <http://www.periodistadigital.com/economia-de-lavida/finanzas/2014/10/14/startups-pequenas-empresas-grandes-ideas-googlebusiness-angels-facebook-twitter.shtml>

PhelpS, J., LeWIS,R., MobILIO, L.,PeRry, D., \& RAMAN,N. (2004). Viral Marketing or Electronic Word-of-Mouth Advertising: Examining Consumer Responses and Motivations to Pass Along Email. Journal of Advertising Research, 44(4), 333-348.

PORTER, M. E. (1980). Competitive strategy: techniques for analyzing industries and competitors. New York: The Free Press.

PROPTECH LATAM. (2018, agosto 10). Consejos de un emprendedor de alma [Video en youtube]. Recuperado de <https://www.youtube.com/watch?v=Cb4SL26m4KE >

RANDS, K. (2018, julio 31). 5 top blockchain trends of 2018. Recuperado de <https://www.cio.com/article/3294225/5-top-blockchain-trends-of-2018.html>

Redacción MDZ. (2019, mayo 21). Una startup se transformó en el quinto "unicornio" argentino. Recuperado de <https://www.mdzol.com/amp/dinero/una-startup-setransformo-en-el-quinto-unicornio-argentino-20190521-29084.html>

RIES, E. (2012). El método Lean Startup: Cómo crear empresas de éxito utilizando la innovación continua. Barcelona: Deusto.

RIVKIN, J. \& PORTER, M. E. (2012). What Business Should Do to Restore U.S. Competitiveness. Fortune, 166(7).

RÖßLER, A. (2011). Sourcing Start-up Success: Towards a Model of Successful Intercultural Transfer and Adaption. Íntegra, 90.

ROGERS, E. M. (1995). Diffusion of innovations. New York: Free Press.

Salanova Soria, M., Grau, R. \& Peiró, J. M. (2001). Nuevas tecnologías y formación continua en la empresa: un estudio psicosocial. Universitat Jaume I, pp. 210-213.

SCHUMPETER, J. (1942). Capitalismo, socialismo y democracia. Folio, 118-124.

SEGURA, R. (2006). Innovación, Empresario y Destrucción Creativa. Una lectura de Schumpeter como teórico de la modernidad. Universidad Nacional de General Sarmiento, Instituto de Industria, p. 10. 
SMALl Business TREnds (2019). STARTUP STATISTICS - The Numbers You Need to Know. Recuperado de <https://smallbiztrends.com/2019/03/startup-statistics-smallbusiness.html>

SOLANO FERNÁNDEZ, I., \& SÁNCHEZ VERA, M. (2010). Aprendiendo en cualquier lugar: el podcast educativo. Pixel-Bit. Revista de Medios y Educación, 36, 125-139.

Startups Way (2015, julio 6). Alec Oxenford (Entrevista parte 1) [Video en youtube]. Recuperado de <https://www.youtube.com/watch?v=RuM9BOrBxgE>

Startups Way (2015, julio 6). Alec Oxenford (Entrevista parte 2) [Video en youtube]. Recuperado de <https://www.youtube.com/watch?v=YcVqluPK40k>

STOKES, D. (2002). Entrepreneurial Marketing in the Public Sector:The Lessons of Headteachers as Entrepreneurs. Journal of Marketing Management, 18(3/4), 397-414.

TALEB, NASSIM. (2013). Antifrágil: Las cosas que se benefician del desorden. Madrid: Paidós.

Teten, D., Abdelfattah, A., Bremer, K., \& Buslig, G. (2013). The Lower-Risk Startup: How Venture Capitalists Increase the Odds of Startup Success. The Journal of Private Equity, 16(2), 7-19. Recuperado de <http://www.jstor.org/stable/43503741>

The Crowd Angel (2018). Cómo se obtiene rentabilidad invirtiendo en startups. Recuperado de $\quad<$ http://blog.thecrowdangel.com/blog/obtener-rentabilidad-invirtiendo-enstartups/>

The Nielsen Company (2009). Nielsen BuzzMetrics, The Global Measurement Standard in Consumer-Generated Media. Recuperado de <https://bit.ly/2GIsZT8>

THIEL, Peter (2014). Zero to One. New York: Crown Business.

VARELA, R., \& BEDOYA, O. (2006). Modelo conceptual de desarrollo empresarial basado en competencias. Estudios Gerenciales, 22(100), 21-47.

WAJCMAN, J. (1991). Feminism confronts technology. Polity Press.

MORIANO, J., PALACÍ, F. \& MORAleS, J. (2006). Adaptación y validación en España de la escala de autoeficacia emprendedora. Revista de Psicología Social, 21(1), 35-50.

WATTS, D. \& PERETTI, J. (2007). Viral Marketing for the Real World. Harvard Business Review. 1-2. Recuperado de <https://hbr.org/2007/05/viral-marketing-for-the-real-world >

WESTHEAD, P. \& COWLING, M. (1995). Employment change in independent owner-managed high-technology firms in Great Britain. Small Business Economics, 7(2), 111-140.

ZILBER, S. N., \& BRAZ DE ARAúJo, J. (2012). Small Companies Innovations in Emerging Countries: E-Business Adoption and its Business Model. Journal of Technology Management \& Innovation, 7(2), 102-116.

\#Juevesdelnspiración. (2018, agosto 12). ¿Qué es el éxito? Usina de Ideas UNLP [Video en youtube]. Recuperado de <https://www.youtube.com/watch?v=_ORi-hsaZ-I>

\#Juevesdelnspiración. (2018, agosto 12). Martín Migoya, CEO de Globant - 1er Parte, Usina de Ideas UNLP [Video en youtube]. Recuperado de 
$<$ https://www.youtube.com/watch?v=_ORi-hsaZ-I>

\#Juevesdelnspiración. (2018, agosto 12). Martín Migoya, CEO de Globant - 2da Parte, Usina de Ideas UNLP [Video en youtube]. Recuperado de <https://www.youtube.com/watch?v=nfLgUr3y6m4\&t=18s>

\#Juevesdelnspiración. (2018, agosto 12). Martín Migoya, CEO de Globant - 3er Parte, Usina de Ideas UNLP [Video en youtube]. Recuperado de $<$ https://www.youtube.com/watch?v=mUUENXJwPil> 


\section{ANEXOS}

\section{ANEXo 1: MODELO DE ENTREVISTA A EMPRENDEDORES}

Datos del emprendedor y del emprendimiento

1. ¿Cómo se llama tu start-up?

2. ¿Qué es lo que ofrece?

1. Producto

2. Servicio

3. ¿De qué se trata?

4. ¿Tiene página web o redes sociales? En caso afirmativo indicar los links de acceso.

5. ¿Desde cuándo comenzaste con el emprendimiento?

1. Hace menos de 1 año

2. Entre 1 y 2 años atrás

3. Entre 2 y 3 años atrás

4. Entre 3 y 4 años atrás

5. Entre 4 y 5 años atrás

6. Hace más de cinco años

6. ¿Qué puesto o funciones cumplís dentro de la start-up?

1. CEO/Director Ejecutivo

2. $\mathrm{COO} /$ Director General

3. $\mathrm{CMO} /$ Director de Marketing

4. CFO/Director Financiero

5. CCO/Director de Comunicaciones

6. $\mathrm{ClO} / \mathrm{CTO} /$ Director de Sistemas 

7. Desarrollador
8. Diseñador gráfico
9. Otro...

\section{Datos del equipo emprendedor}

7. ¿Quiénes conforman el equipo? Indicar nombre de cada integrante, profesión o área de conocimiento, cargo y edad.

8. ¿Cómo fue que se asociaron?

1. Amistad

2. Estrategia

3. Intereses similares

4. Otro...

9. ¿Cómo distribuyeron las responsabilidades de cada uno?

1. No están distribuidas, todos hacen un poco de todo

2. Se distribuyeron naturalmente según lo que hacía cada uno

3. Hubo una distribución pautada previamente, por conocimientos/habilidades/área de experiencia de cada uno

4. Otro...

10. ¿Se mantiene la misma estructura hoy en día?

1. Sí

2. No

11. ¿Trabajan de manera remota o in situ?

1. Remota

2. In situ

3. Ambas

\section{Motivaciones}

12. ¿Cuáles fueron las razones por las que decidiste emprender? 

1. Necesidad
2. Deseo
3. Oportunidad
4. Otro...

13. ¿Qué te dio ánimo en dar el salto a emprender?

1. Insatisfacción por la industria corporativa

2. Deseo de ser tu propio jefe/a

3. Convicción

4. Costumbres familiares

5. Otro...

\section{Desarrollo del emprendimiento y planificación estratégica}

14. ¿Tiene el emprendimiento un modelo de negocios definido? En caso afirmativo, ¿de qué tipo es?

1. $\quad$ B2B (business to business)

2. $\quad$ B2C (business to consumer)

3. $\mathrm{C} 2 \mathrm{C}$ (consumer to consumer)

15. ¿Cuál es la forma de monetización?

1. Modelo Freemium (gratuito pero con productos o servicios de pago)

2. Gratis con publicidades o sponsors

3. Modelo Premium (se accede de pago)

4. Otro...

16. ¿Siempre fue el mismo o tuvo modificaciones?

1. Se mantiene el mismo modelo desde el principio

2. Tuvo modificaciones pero ya no

3. Constantemente se está modificando

17. ¿Cuál es su misión, visión y objetivos? 
18. ¿Cómo fue que surgió la idea?

1. Ocio/diversión

2. Detección de una necesidad insatisfecha

3. Existencia en otro mercado/país, y ganas de aplicarla a otro mercado/país

4. Otro...

19. ¿Se mantuvo tal como se les ocurrió? ¿O fue modificándose?

1. Se mantuvo

2. Se modificó parcialmente

3. Se modificó por completo

20. ¿Se hizo algún análisis de factibilidad o análisis de mercado previo?

1. Sí

2. No

21. ¿Hay un plan estratégico diseñado?

1. Sí

2. No

22. ¿Ya se lanzó el producto/servicio?

1. Sí

2. No

23. Si es así, ¿̇se hizo primero con un producto mínimo viable?

1. Sí, lanzamos lo antes posible con un PMV

2. No, esperamos a tener todo el producto terminado

24. ¿El emprendimiento tiene clientes?

1. Sí

2. No 
25. En caso afirmativo, ¿cómo los obtuvo?

1. Por contactos

2. De boca en boca

3. Marketing online

4. Marketing offline

5. Otro...

26. ¿Tiene competidores?

1. Sí

2. No

27. En caso afirmativo, ¿qué rol ocupan y cómo influye en la start-up?

\section{Factores internos de éxito y fracaso}

28. ¿Tu educación, estudios, experiencia y conocimientos previos fueron relevantes a la hora de lanzarte a emprender?

1. Sí, fue clave

2. No

3. Algo, pero no tanto

29. ¿Cuáles son los atributos como emprendedor y como persona que destacás en vos, y cuáles tuvieron mayor influencia a la hora de hacer crecer tu start-up? Marcá una o más opciones:
1. Pasión
2. Motivación
3. Liderazgo
4. Compromiso
5. Confianza
6. Humildad
7. Creatividad
8. Experiencia o conocimientos
9. Aversión al riesgo
10. Perseverancia 
11. Poseer una idea o visión empresarial clara

12. Capacidad de reconocer oportunidades

13. Otro...

30. ¿Cuál creés que es la cualidad más importante que un emprendedor debe tener para lograr su objetivo? Marcá una opción:

1. Pasión

2. Motivación

3. Liderazgo

4. Compromiso

5. Confianza

6. Humildad

7. Creatividad

8. Experiencia o conocimientos

9. Aversión al riesgo

10. Perseverancia

11. Poseer una idea o visión empresarial clara

12. Capacidad de reconocer oportunidades

13. Otro...

31. ¿Cómo percibís el fracaso en el contexto de una start-up? Marcá una o más opciones

1. Está muy mitificado

2. Es parte del camino hacia el éxito

3. Sirve como aprendizaje

4. Genera temor

5. No hay lugar para el fracaso

6. Otro...

32. ¿Cuándo considerarías que tu start-up ha tenido éxito? Marcá una o más opciones

1. Cuando se haya podido devolver toda la inversión recibida

2. Cuando tiene metas y estrategias establecidas

3. Cuando se estén realizando acciones estratégicas para obtener el resultado deseado 
4. Cuando pueda ser sostenible en el tiempo

5. Cuando haya resuelto la necesidad insatisfecha

6. Cuando logre rentabilidad

7. Cuando logre una ventaja competitiva en el mercado

8. Cuando se logre la retención del $100 \%$ de los usuarios/clientes

9. Cuando logre escalabilidad

10. Cuando pueda salir a la bolsa

11. Otro...

\section{Factores externos de éxito y fracaso}

33. ¿Creés que tu entorno, la sociedad y/o las normas culturales influyeron en la decisión de emprender?
1. $\quad$ Sí
2. No
3. Tal vez

34. En caso afirmativo, ¿̇cómo fue que influyeron?

35. ¿Considerás a Argentina un país propicio para emprender?

1. Sí

2. No

3. Tal vez

36. ¿Qué ventajas encontrás en residir en este país? Marcá una o más opciones:

1. Buen nivel de educación/grandes talentos

2. Genera la habilidad de adaptarse a cambios constantes

3. La industria de la tecnología es un nicho que no está explotado

4. El gobierno apoya el emprendedurismo con programas y/o financiamiento

5. Falta de legislación y regulaciones en la industria de la tecnología

6. Otro...

37. ¿Y desventajas ? Marcá una o más opciones: 
1. Falta de recursos

2. Falta de programas de apoyo al emprendedurismo

3. Dificultad de acceder a financiamiento

4. Cambios constantes

5. Nivel de educación bajo

6. Falta de legislación y regulaciones en la industria de la tecnología

7. Economía inestable

8. Alto nivel impositivo

9. Otro...

38. ¿Cómo vive la start-up la situación actual del país?

1. No le afecta

2. Le afecta parcialmente

3. Le afecta por completo

39. ¿Cómo accedieron a los recursos e infraestructura necesaria? ¿Fue dificultoso conseguir lo que necesitaban?

40. ¿Recibieron algún tipo de financiamiento o ayuda externa? ¿Accedieron a algún programa de financiamiento o aceleración?

1. Sí

2. No

41. En caso afirmativo, ¿de institución/es pública/s o privada/s?

1. Pública

2. Privada

3. Aporte de familia y amigos (FFF)

42. ¿Cuál/es considerás que fue/ron las herramientas que te ayudaron a llegar donde estás hoy? Marcá una o más opciones:

1. Financiamiento

2. Educación

3. Red de contactos 
4. Valores personales

5. Aptitudes personales

6. Haber conseguido el equipo perfecto

7. Otro...

43. ¿Qué opinás sobre las las mujeres emprendedoras? ¿Pensás que tienen las mismas oportunidades que los hombres a la hora de emprender? 


\section{ANEXO 2: RESULTADOS DE LAS ENTREVISTAS A EMPRENDEDORES}

\section{ENTREVISTA № 1}

Entrevistado: PACHI MARINO

\section{Datos del emprendedor y del emprendimiento}

1. ¿Cómo se llama tu start-up?

Positrip

2. ¿Qué es lo que ofrece?

1. Producto

2. Servicio $\mathrm{X}$

3. ¿De qué se trata?

Es una red social para que los viajeros puedan atesorar sus viajes y obtener info útil y confiable en un ámbito positivo.

4. ¿Tiene página web o redes sociales? En caso afirmativo indicar los links de acceso.

$\square$ positrip.com

$\square \quad$ Facebook.com/Positrip

口Instagram:@positrip

5. ¿Desde cuándo comenzaste con el emprendimiento?

1. Hace menos de 1 año

2. Entre 1 y 2 años atrás

3. Entre 2 y 3 años atrás

4. Entre 3 y 4 años atrás $X$

5. Entre 4 y 5 años atrás

6. Hace más de cinco años

6. ¿Qué puesto o funciones cumplís dentro de la start-up?

1. CEO/Director Ejecutivo $\mathrm{X}$ 
2. COO/Director General

3. $\mathrm{CMO} /$ Director de Marketing

4. CFO/Director Financiero

5. CCO/Director de Comunicaciones

6. $\mathrm{ClO} / \mathrm{CTO} /$ Director de Sistemas

7. Desarrollador

8. Diseñador gráfico

9. Otro...

\section{Datos del equipo emprendedor}

7. ¿Quiénes conforman el equipo? Indicar nombre de cada integrante, profesión o área de conocimiento, cargo y edad.

- Pachi Marino: Administración - CEO - M - 41

ㄱicolás Villarreal: Diseño - Design Manager - M - 41

$\square$ Tercerizamos el desarrollo con el equipo de QwertySoft

8. ¿Cómo fue que se asociaron?

1. Amistad X

2. Estrategia

3. Intereses similares

4. Otro...

9. ¿Cómo distribuyeron las responsabilidades de cada uno?

1. No están distribuidas, todos hacen un poco de todo

2. Se distribuyeron naturalmente según lo que hacia cada uno

3. Hubo una distribución pautada previamente, por conocimientos/habilidades/área de experiencia de cada uno $X$

4. Otro...

10. ¿Se mantiene la misma estructura hoy en día?

1. Sí X

2. No 
11. ¿Trabajan de manera remota o in situ?

1. Remota $X$

2. In situ

3. Ambas

\section{Motivaciones}

12. ¿Cuáles fueron las razones por las que decidiste emprender?

1. Necesidad

2. Deseo

3. Oportunidad

4. Otro... X Encontré un problema relacionado con mi experiencia laboral en el ámbito del turismo y la gastronomía.

13. ¿Qué te dio ánimo en dar el salto a emprender?

1. Insatisfacción por la industria corporativa

2. Deseo de ser tu propio jefe/a

3. Convicción $\mathrm{X}$

4. Costumbres familiares

5. Otro...

\section{Desarrollo del emprendimiento y planificación estratégica}

14. ¿Tiene el emprendimiento un modelo de negocios definido? En caso afirmativo, ¿de qué tipo es?

1. $B 2 B$ (business to business) $X$

2. $\quad B 2 C$ (business to consumer) $\mathrm{X}$

3. $\mathrm{C} 2 \mathrm{C}$ (consumer to consumer)

15. ¿Cual es la forma de monetización?

1. Modelo Freemium (gratuito pero con productos o servicios de pago) $\mathrm{X}$

2. Gratis con publicidades o sponsors 
3. Modelo Premium (se accede de pago)

4. Otro...

16. ¿Siempre fue el mismo o tuvo modificaciones?

1. Se mantiene el mismo modelo desde el principio

2. Tuvo modificaciones pero ya no

3. Constantemente se está modificando $X$

17. ¿Cuál es su misión, visión y objetivos?

- Misión: Trabajamos sobre el derecho que tienen las personas de recibir información relacionada justa y confiable generando una integración positiva entre los viajeros y los establecimientos comerciales.

$\square$ Visión: si te gusta viajar, queremos que nos pienses como primera opción y que podamos brindarte información útil, confiable y positiva.

Objetivos 2019:

○ obtener u\$sd 100.000 y con ello

○ alcanzar 819.500 usuarios viajeros

○ alcanzar 1000 establecimientos premium.

18. ¿Cómo fue que surgió la idea?

1. Ocio/diversión

2. Detección de una necesidad insatisfecha $\mathbf{X}$

3. Existencia en otro mercado/país, y ganas de aplicarla a otro mercado/país.

4. Otro...

19. ¿Se mantuvo tal como se les ocurrió? ¿O fue modificándose?

1. Se mantuvo

2. Se modificó parcialmente $\mathbf{X}$

3. Se modificó por completo

20. ¿Se hizo algún análisis de factibilidad o análisis de mercado previo?

1. Sí X

2. No 
21. ¿Hay un plan estratégico diseñado?

1. Sí

2. No X

22. ¿Ya se lanzó el producto/servicio?

1. Sí $X$

2. No

23. Si es así, ¿se hizo primero con un producto mínimo viable?

1. Sí, lanzamos lo antes posible con un PMV X

2. No, esperamos a tener todo el producto terminado

24. ¿El emprendimiento tiene clientes?

1. Sí $X$

2. No

25. En caso afirmativo, ¿cómo los obtuvo?

1. Por contactos $\mathrm{X}$

2. De boca en boca $X$

3. Marketing online $X$

4. Marketing offline $X$

5. Otro...

26. ¿Tiene competidores?

1. Sí X

2. No

27. En caso afirmativo, ¿qué rol ocupan y cómo influye en la start-up?

Hay competidores que hacen cosas muy similares en otros países, que nos sirven de referencia y ayudan a comprobar que la problemática existe. 
Luego está TripAdvisor, como gran referente en el ámbito, con quien nos diferencian cuestiones que van más allá del formato y funcionamiento, y tienen que ver con los valores y el propósito que a nosotros nos moviliza.

\section{Factores internos de éxito y fracaso}

28. ¿Tu educación, estudios, experiencia y conocimientos previos fueron relevantes a la hora de lanzarte a emprender?

1. Sí, fue clave $\mathbf{X}$

2. No

3. Algo, pero no tanto

29. ¿Cuáles son los atributos como emprendedor y como persona que destacás en vos, y cuáles tuvieron mayor influencia a la hora de hacer crecer tu start-up? Marcá una o más opciones:

1. Pasión $\mathrm{X}$

2. Motivación

3. Liderazgo

4. Compromiso $\mathrm{X}$

5. Confianza

6. Humildad

7. Creatividad

8. Experiencia o conocimientos $\mathrm{X}$

9. Aversión al riesgo

10. Perseverancia

11. Poseer una idea o visión empresarial clara

12. Capacidad de reconocer oportunidades

13. Otro... X Paciencia

30. ¿Cuál creés que es la cualidad más importante que un emprendedor debe tener para lograr su objetivo? Marcá una opción:

1. Pasión

2. Motivación

3. Liderazgo

4. Compromiso 
5. Confianza

6. Humildad

7. Creatividad

8. Experiencia o conocimientos

9. Aversión al riesgo

10. Perseverancia

11. Poseer una idea o visión empresarial clara

12. Capacidad de reconocer oportunidades

13. Otro... X Paciencia

31. ¿Cómo percibís el fracaso en el contexto de una start-up? Marcá una o más opciones:

1. Está muy mitificado

2. Es parte del camino hacia el éxito

3. Sirve como aprendizaje

4. Genera temor

5. No hay lugar para el fracaso

6. Otro... X Prefiero evitarlo. Jaja

32. ¿Cuándo considerarías que tu start-up ha tenido éxito? Marcá una o más opciones:

1. Cuando se haya podido devolver toda la inversión recibida

2. Cuando tiene metas y estrategias establecidas

3. Cuando se estén realizando acciones estratégicas para obtener el resultado deseado

4. Cuando la misma pueda ser sostenible en el tiempo

5. Cuando haya resuelto la necesidad insatisfecha $X$

6. Cuando logre rentabilidad

7. Cuando logre una ventaja competitiva en el mercado

8. Cuando se logre la retención del $100 \%$ de los usuarios/clientes

9. Cuando logre escalabilidad

10. Cuando pueda salir a la bolsa

11. Otro...

Factores externos de éxito y fracaso 
33. ¿Creés que tu entorno, la sociedad y/o las normas culturales influyeron en la decisión de emprender?

1. Sí X

2. No

3. Tal vez

34. En caso afirmativo, ¿cómo fue que influyeron?

Hallo muy injusta la modalidad que comenzó hace unos diez años, donde todos podemos ser críticos de todo con una facilidad enorme. Y cuando está comprobado a que a mayor enojo, más posibilidades de criticar en las plataformas tecnológicas actuales, estas hacen dinero estimulando a la gente destruir, por sobre construir. Quiero colaborar en esa concientización y en el cambio de paradigma.

35. ¿Considerás a Argentina un país propicio para emprender?

1. Sí

2. No X

3. Tal vez

36. ¿Qué ventajas encontrás en residir en este país? Marcá una o más opciones:

1. Buen nivel de educación/Grandes talentos X

2. Genera la habilidad de adaptarse a cambios constantes

3. La industria de la tecnología es un nicho que no está explotado

4. El gobierno apoya el emprendedurismo con programas y/o financiamiento

5. Falta de legislación y regulaciones en la industria de la tecnología

6. Otro...

37. ¿Y desventajas ? Marcá una o más opciones:

1. Falta de recursos

2. Falta de programas de apoyo al emprendedurismo

3. Dificultad de acceder a financiamiento $X$

4. Cambios constantes

5. Nivel de educación bajo

6. Falta de legislación y regulaciones en la industria de la tecnología 
7. Economía inestable $X$

8. Alto nivel impositivo

9. Otro... X Inflación, competitividad y egos entre emprendedores

38. ¿Cómo vive la start-up la situación actual del país?

1. No le afecta

2. Le afecta parcialmente

3. Le afecta por completo $\mathrm{X}$

39. ¿Cómo accedieron a los recursos e infraestructura necesaria? ¿Fue dificultoso conseguir lo que necesitaban?

Sí, fue y es dificultoso. Con mucho trabajo.

40. ¿Recibieron algún tipo de financiamiento o ayuda externa? ¿Accedieron a algún programa de financiamiento o aceleración?
1. Sí X
2. No

41. En caso afirmativo, ¿de institución/es pública/s o privada/s?

1. Pública

2. Privada

3. Aporte de familia y amigos (FFF) $\mathrm{X}$

42. ¿Cuál/es considerás que fue/ron las herramientas que te ayudaron a llegar donde estás hoy? Marcá una o más opciones:

1. Financiamiento

2. Educación

3. Red de contactos

4. Valores personales

5. Aptitudes personales

6. Haber conseguido el equipo perfecto $X$

7. Otro... 
43. ¿Qué opinás sobre las las mujeres emprendedoras? ¿Pensás que tienen las mismas oportunidades que los hombres a la hora de emprender?

Personalmente no hago distinciones entre varones y mujeres al momento de trabajar en equipo. Trato de juntarme con gente capaz con la cual comparta valores.

Igualmente entiendo, por estar vinculado a la temática emprendedora hace ya más de diez años, que hay un tema cultural donde entiendo que a la mujer no se le han presentado las mismas oportunidades. Históricamente se asociaba más a un "emprendedor exitoso" con un varón. Creo que en los últimos tiempos eso está cambiando y realmente me alegra.

\section{ENTREVISTA № 2}

Entrevistado: Diego MAUMUS

\section{Datos del emprendedor y del emprendimiento}

1. ¿Cómo se llama tu start-up?

Babel Viajes

2. ¿Qué es lo que ofrece?

1. Producto

2. Servicio $\mathrm{X}$

3. ¿De qué se trata?

Agencia de viajes especializada en destinos exóticos.

4. ¿Tiene página web o redes sociales? En caso afirmativo indicar los links de acceso.

口 www.babelviajes.com.ar

ㄴttps://www.facebook.com/babelviajes/

5. ¿Desde cuándo comenzaste con el emprendimiento?

1. Hace menos de 1 año

2. Entre 1 y 2 años atrás

3. Entre 2 y 3 años atrás

4. Entre 3 y 4 años atrás

5. Entre 4 y 5 años atrás 
6. Hace más de cinco años $\mathrm{X}$

6. ¿Qué puesto o funciones cumplís dentro de la start-up?

1. CEO/Director Ejecutivo $\mathrm{X}$

2. COO/Director General

3. $\mathrm{CMO} /$ Director de Marketing

4. CFO/Director Financiero

5. CCO/Director de Comunicaciones

6. $\mathrm{ClO} / \mathrm{CTO} /$ Director de Sistemas

7. Desarrollador

8. Diseñador gráfico

9. Otro...

\section{Datos del equipo emprendedor}

7. ¿Quiénes conforman el equipo? Indicar nombre de cada integrante, profesión o área de conocimiento, cargo y edad.

En total son quince personas en la oficina central (Coronel Pringles) y ochenta repartidas entre veinticuatro puntos de venta repartidos en siete provincias.

8. ¿Cómo fue que se asociaron?

1. Amistad

2. Estrategia

3. Intereses similares

4. Otro... X Si bien es una S.A. en mi caso soy el responsable de la empresa, trabajamos bajo un sistema de franquicias.

9. ¿Cómo distribuyeron las responsabilidades de cada uno?

1. No están distribuidas, todos hacen un poco de todo

2. Se distribuyeron naturalmente según lo que hacia cada uno

3. Hubo una distribución pautada previamente, por conocimientos/habilidades/área de experiencia de cada uno

4. Otro... 
10. ¿Se mantiene la misma estructura hoy en día?

1. Sí

2. No X

11. ¿Trabajan de manera remota o in situ?

1. Remota

2. In situ

3. Ambas $\mathbf{X}$

\section{Motivaciones}

12. ¿Cuáles fueron las razones por las que decidiste emprender?

1. Necesidad

2. Deseo $X$

3. Oportunidad

4. Otro...

13. ¿Qué te dio ánimo en dar el salto a emprender?

1. Insatisfacción por la industria corporativa

2. Deseo de ser tu propio jefe/a $X$

3. Convicción

4. Costumbres familiares

5. Otro...

\section{Desarrollo del emprendimiento y planificación estratégica}

14. ¿'Tiene el emprendimiento un modelo de negocios definido? En caso afirmativo, ¿de qué tipo es?

1. $\quad$ B2B (business to business)

2. $\quad B 2 C$ (business to consumer) $\mathrm{X}$

3. $\mathrm{C} 2 \mathrm{C}$ (consumer to consumer)

15. ¿Cuál es la forma de monetización?

1. Modelo Freemium (gratuito pero con productos o servicios de pago) 
2. Gratis con publicidades o sponsors

3. Modelo Premium (se accede de pago)

4. Otro... X Venta de viajes online (modelo mixto entre el online con varias marcas en el mercado y el offline con veinticuatro puntos de venta físicos).

16. ¿Siempre fue el mismo o tuvo modificaciones?

1. Se mantiene el mismo modelo desde el principio

2. Tuvo modificaciones pero ya no

3. Constantemente se está modificando $X$

\section{7. ¿Cuál es su misión, visión y objetivos?}

www.babelviajes.com es un portal web dedicado a la comercialización de servicios turísticos en Argentina y el Mundo. El mismo se encuentra registrado desde hace varios años, siendo una de las primeras Empresas de Viajes y Turismo en poseer la extensión tur.ar bajo el dominio web www.babelviajes.tur.ar, certificando de este modo nuestra solvencia e idoneidad bajo los parámetros de la Cancillería Argentina y la Entidad Registrante en nic.ar y estando habilitados por el Ministerio de Turismo de la Nación con el nombre de Babel Empresa de Viajes y Turismo bajo el Legajo № 15.667. Babel Viajes es propiedad de Babel Travel \& Business S.A. CUIT: 3071404971-9.

Somos miembros activos de la AAMF (Asociación de Marcas y Franquicias) y la AAVYT (Asociación Argentina de Agencias de Viajes y Turismo de la República Argentina).

Nuestros clientes están respaldados por un sólido grupo humano, distribuidos en las distintas sucursales y franquicias de Babel Viajes que se encuentran dentro de nuestro país. Todo nuestro personal trabaja día a día para la correcta prestación de los servicios turísticos ofrecidos, atendiendo a la premisa PRECIO = CALIDAD asegurando de esta manera la plena satisfacción de nuestros clientes.

Promovemos un alto grado de especialización lo cual nos permite brindar un servicio de excelencia potenciando una de nuestras ventajas comparativas, el ser una de las Agencias de Viajes con mayor cantidad de sucursales operativas en el país.

Visión

Ser la Agencia de Viajes № 1 en Ventas en Argentina, imponiendo nuestra marca como un signo distintivo en la prestación de servicios turísticos integrales.

Misión

Nuestra misión es ofrecer servicios turísticos integrales orientados a los distintos mercados (tanto nacional como internacional), alcanzando la más amplia cobertura geográfica a nivel nacional y atendiendo a las necesidades de nuestros clientes. 
A través de nuestros representantes locales, sucursales y franquicias, situados en distintos puntos del país, usted encontrará la mejor atención para la concreción de viajes turísticos y empresariales, provista por especialistas idóneos en turismo.

\section{Estrategia}

Segmentar los mercados y lograr el mayor grado de eficiencia en la captación y atención de de cada uno de ellos, utilizando distintos canales de comunicación y aprovechando las innovaciones tecnológicas disponibles.

Innovar en la zonificación estratégica del mercado, prestando nuestros servicios a través de sucursales propias, franquicias o de representantes locales, constituyéndonos en la Empresa de Viajes y Turismo de mayor presencia física a nivel nacional.

Proveer a nuestros clientes un amplio abanico de posibilidades a la hora de elegir su próximo viaje, brindando el mejor precio y teniendo en cuenta la relación COSTO = BENEFICIO.

Lograr un grado de especialización en Destinos Específicos a fin de lograr una atención diferencial y especializada en determinados nichos de mercado.

18. ¿Cómo fue que surgió la idea?

1. Ocio/diversión

2. Detección de una necesidad insatisfecha

3. Existencia en otro mercado/país, y ganas de aplicarla a otro mercado/país $\mathbf{X}$

4. Otro...

19. ¿Se mantuvo tal como se les ocurrió? ¿O fue modificándose?

1. Se mantuvo

2. Se modificó parcialmente

3. Se modificó por completo $X$

20. ¿Se hizo algún análisis de factibilidad o análisis de mercado previo?

1. Sí

2. No X

21. ¿Hay un plan estratégico diseñado?

1. Sí

2. No X 
22. ¿YYa se lanzó el producto/servicio?

1. Sí $X$

2. No

23. Si es así, ¿se hizo primero con un producto mínimo viable?

1. Sí, lanzamos lo antes posible con un PMV

2. No, esperamos a tener todo el producto terminado $X$

24. ¿El emprendimiento tiene clientes?

1. Sí X

2. No

25. En caso afirmativo, ¿cómo los obtuvo?

1. Por contactos

2. De boca en boca

3. Marketing online $\mathbf{X}$

4. Marketing offline

5. Otro...

26. ¿Tiene competidores?

1. Sí X

2. No

27. En caso afirmativo, ¿qué rol ocupan y cómo influye en la start-up?

\section{Factores internos de éxito y fracaso}

28. ¿Tu educación, estudios, experiencia y conocimientos previos fueron relevantes a la hora de lanzarte a emprender?

1. Sí, fue clave $\mathrm{X}$

2. No

3. Algo, pero no tanto 
29. ¿Cuáles son los atributos como emprendedor y como persona que destacás en vos, y cuáles tuvieron mayor influencia a la hora de hacer crecer tu start-up? Marcá una o más opciones:

1. Pasión $\mathrm{X}$

2. Motivación

3. Liderazgo

4. Compromiso

5. Confianza

6. Humildad

7. Creatividad

8. Experiencia o conocimientos

9. Aversión al riesgo

10. Perseverancia

11. Poseer una idea o visión empresarial clara

12. Capacidad de reconocer oportunidades

13. Otro...

30. ¿Cuál creés que es la cualidad más importante que un emprendedor debe tener para lograr su objetivo? Marcá una opción:

1. Pasión

2. Motivación

3. Liderazgo

4. Compromiso

5. Confianza

6. Humildad

7. Creatividad

8. Experiencia o conocimientos

9. Aversión al riesgo

10. Perseverancia

11. Poseer una idea o visión empresarial clara

12. Capacidad de reconocer oportunidades

13. Otro... 
31. ¿Cómo percibís el fracaso en el contexto de una start-up? Marcá una o más opciones:

1. Está muy mitificado $\mathrm{X}$

2. Es parte del camino hacia el éxito

3. Sirve como aprendizaje

4. Genera temor

5. No hay lugar para el fracaso

6. Otro...

32. ¿Cuándo considerarías que tu start-up ha tenido éxito? Marcá una o más opciones:

1. Cuando se haya podido devolver toda la inversión recibida

2. Cuando tiene metas y estrategias establecidas

3. Cuando se estén realizando acciones estratégicas para obtener el resultado deseado

4. Cuando la misma pueda ser sostenible en el tiempo

5. Cuando haya resuelto la necesidad insatisfecha

6. Cuando logre rentabilidad

7. Cuando logre una ventaja competitiva en el mercado

8. Cuando se logre la retención del $100 \%$ de los usuarios/clientes

9. Cuando logre escalabilidad

10. Cuando pueda salir a la bolsa

11. Otro...

\section{Factores externos de éxito y fracaso}

33. ¿Creés que tu entorno, la sociedad y/o las normas culturales influyeron en la decisión de emprender?
1. Sí
2. No
3. Tal vez $\mathrm{X}$

34. En caso afirmativo, ¿cómo fue que influyeron? 
35. ¿Considerás a Argentina un país propicio para emprender?

1. Sí $X$

2. No

3. Tal vez

36. ¿Qué ventajas encontrás en residir en este país? Marcá una o más opciones:

1. Buen nivel de educación/Grandes talentos

2. Genera la habilidad de adaptarse a cambios constantes $X$

3. La industria de la tecnología es un nicho que no está explotado

4. El gobierno apoya el emprendedurismo con programas y/o financiamiento

5. Falta de legislación y regulaciones en la industria de la tecnología

6. Otro...

37. ¿Y desventajas ? Marcá una o más opciones:

1. Falta de recursos

2. Falta de programas de apoyo al emprendedurismo

3. Dificultad de acceder a financiamiento

4. Cambios constantes

5. Nivel de educación bajo

6. Falta de legislación y regulaciones en la industria de la tecnología

7. Economía inestable

8. Alto nivel impositivo $\mathrm{X}$

9. Otro...

38. ¿Cómo vive la start-up la situación actual del país?

1. No le afecta

2. Le afecta parcialmente $X$

3. Le afecta por completo

39. ¿Cómo accedieron a los recursos e infraestructura necesaria? ¿Fue dificultoso conseguir lo que necesitaban?

Fuimos creciendo de manera paulatina a medida que necesitábamos recursos. 
40. ¿Recibieron algún tipo de financiamiento o ayuda externa? ¿Accedieron a algún programa de financiamiento o aceleración?

1. Sí

2. No X

41. En caso afirmativo, ¿de institución/es pública/s o privada/s?

1. Pública

2. Privada

3. Aporte de familia y amigos (FFF)

42. ¿Cuál/es considerás que fue/ron las herramientas que te ayudaron a llegar donde estás hoy? Marcá una o más opciones:

1. Financiamiento

2. Educación

3. Red de contactos

4. Valores personales

5. Aptitudes personales $X$

6. Haber conseguido el equipo perfecto

7. Otro...

43. ¿Qué opinás sobre las las mujeres emprendedoras? ¿Pensás que tienen las mismas oportunidades que los hombres a la hora de emprender?

Sí, tienen las mismas oportunidades a la hora de tomar la decisión de emprender.

\section{ENTREVISTA № 3}

Entrevistado: DIEGO BALAN

Datos del emprendedor y del emprendimiento

1. ¿Cómo se llama tu start-up?

AccessHoy

2. ¿Qué es lo que ofrece? 

1. Producto $\mathrm{X}$
2. Servicio

3. ¿De qué se trata?

El producto es un SaaS (Software as a Service) de ticketing. Es un software basado en la nube para que productores de espectáculos, organizadores de eventos, dueños de teatros y espacios culturales, cines, museos y equipos de fútbol, manejen integralmente todo el flujo de difusión de los eventos, venta de entradas, control de accesos y reporting.

4. ¿'Tiene página web o redes sociales? En caso afirmativo indicar los links de acceso.

$\square \quad$ www.accesshoy.com

5. ¿Desde cuándo comenzaste con el emprendimiento?

1. Hace menos de 1 año

2. Entre 1 y 2 años atrás

3. Entre 2 y 3 años atrás

4. Entre 3 y 4 años atrás $X$

5. Entre 4 y 5 años atrás

6. Hace más de cinco años

6. ¿Qué puesto o funciones cumplís dentro de la start-up?

1. CEO/Director Ejecutivo $\mathrm{X}$

2. COO/Director General

3. $\mathrm{CMO} /$ Director de Marketing

4. CFO/Director Financiero

5. $\mathrm{CCO} /$ Director de Comunicaciones

6. $\mathrm{ClO} / \mathrm{CTO} /$ Director de Sistemas

7. Desarrollador

8. Diseñador gráfico

9. Otro...

Datos del equipo emprendedor 
7. ¿Quiénes conforman el equipo? Indicar nombre de cada integrante, profesión o área de conocimiento, cargo y edad.

$\square \quad$ Tomy Lucadamo (CTO - Masculino - 34)

$\square \quad$ Diego Balan (CEO - Masculino -36

- Alejandro Güerri (CMO - Masculino - 40)

ㄴ. Leandro Giovinazzi (Diseño - Masculino - 35)

8. ¿Cómo fue que se asociaron?

1. Amistad

2. Estrategia

3. Intereses similares $\mathrm{X}$

4. Otro...

9. ¿Cómo distribuyeron las responsabilidades de cada uno?

1. No están distribuidas, todos hacen un poco de todo

2. Se distribuyeron naturalmente según lo que hacia cada uno $X$

3. Hubo una distribución pautada previamente, por conocimientos/habilidades/área de experiencia de cada uno

4. Otro...

10. ¿Se mantiene la misma estructura hoy en día?

1. Sí X

2. No

11. ¿Trabajan de manera remota o in situ?

1. Remota

2. In situ

3. Ambas $\mathrm{X}$

\section{Motivaciones}

12. ¿Cuáles fueron las razones por las que decidiste emprender?

1. Necesidad 

2. Deseo
3. Oportunidad $\mathrm{X}$
4. Otro...

13. ¿Qué te dio ánimo en dar el salto a emprender?

1. Insatisfacción por la industria corporativa

2. Deseo de ser tu propio jefe/a

3. Convicción

4. Costumbres familiares $X$

5. Otro...

\section{Desarrollo del emprendimiento y planificación estratégica}

14. ¿Tiene el emprendimiento un modelo de negocios definido? En caso afirmativo, ¿de qué tipo es?
1. $\quad \mathrm{B} 2 \mathrm{~B}$ (business to business) $\mathrm{X}$
2. B2C (business to consumer)
3. $\mathrm{C} 2 \mathrm{C}$ (consumer to consumer)

15. ¿Cuál es la forma de monetización?

1. Modelo Freemium (gratuito pero con productos o servicios de pago)

2. Gratis con publicidades o sponsors

3. Modelo Premium (se accede de pago)

4. Otro... X Es un SaaS, se cobra un fee asociado a las transacciones que se procesan.

16. ¿Siempre fue el mismo o tuvo modificaciones?

1. Se mantiene el mismo modelo desde el principio

2. Tuvo modificaciones pero ya no $\mathrm{X}$

3. Constantemente se está modificando

17. ¿Cuál es su misión, visión y objetivos?

$\square$ Misión: Ser el software número 1 de Latinoamérica para vender eventos de todo tipo. 
Visión: Facilitarle todo el proceso a productores y organizadores de eventos para que creen experiencias geniales.

18. ¿Cómo fue que surgió la idea?

1. Ocio/diversión

2. Detección de una necesidad insatisfecha

3. Existencia en otro mercado/país, y ganas de aplicarla a otro mercado/país.

4. Otro... X Comenzamos con otro modelo y propuesta de valor: era un "last minute" de entradas de espectáculos. Pero pivoteamos por encontrar una mejor oportunidad en el SaaS.

19. ¿Se mantuvo tal como se les ocurrió? ¿O fue modificándose?

1. Se mantuvo

2. Se modificó parcialmente $X$

3. Se modificó por completo

20. ¿Se hizo algún análisis de factibilidad o análisis de mercado previo?

1. Sí X

2. No

21. ¿Hay un plan estratégico diseñado?

1. Sí X

2. No

22. ¿Ya se lanzó el producto/servicio?

1. Sí X

2. No

23. Si es así, ¿̇e hizo primero con un producto mínimo viable?

1. Sí, lanzamos lo antes posible con un PMV X

2. No, esperamos a tener todo el producto terminado

24. ¿El emprendimiento tiene clientes? 

1. Sí $X$
2. No

25. En caso afirmativo, ¿cómo los obtuvo?

1. Por contactos $\mathrm{X}$

2. De boca en boca

3. Marketing online $\mathbf{X}$

4. Marketing offline

5. Otro...

26. ¿Tiene competidores?

1. Sí $X$

2. No

27. En caso afirmativo, ¿qué rol ocupan y cómo influye en la start-up?

La competencia nos hace estar en permanente movimiento, mejorando permanentemente el producto, bajando el fee para ser competitivos y buscando nichos que no estén poblados.

\section{Factores internos de éxito y fracaso}

28. ¿Tu educación, estudios, experiencia y conocimientos previos fueron relevantes a la hora de lanzarte a emprender?

1. Sí, fue clave $\mathbf{X}$

2. No

3. Algo, pero no tanto

29. ¿Cuáles son los atributos como emprendedor y como persona que destacás en vos, y cuáles tuvieron mayor influencia a la hora de hacer crecer tu start-up? Marcá una o más opciones:

1. Pasión

2. Motivación $X$

3. Liderazgo $\mathrm{X}$

4. Compromiso

5. Confianza 

6. Humildad
7. Creatividad
8. Experiencia o conocimientos
9. Aversión al riesgo
10. Perseverancia $\mathbf{X}$
11. Poseer una idea o visión empresarial clara
12. Capacidad de reconocer oportunidades
13. Otro... X Team building

30. ¿Cuál creés que es la cualidad más importante que un emprendedor debe tener para lograr su objetivo? Marcá una opción:
1. Pasión
2. Motivación
3. Liderazgo
4. Compromiso
5. Confianza
6. Humildad
7. Creatividad

8. Experiencia o conocimientos

9. Aversión al riesgo

10. Perseverancia

11. Poseer una idea o visión empresarial clara $X$

12. Capacidad de reconocer oportunidades

13. Otro...

31. ¿Cómo percibís el fracaso en el contexto de una start-up? Marcá una o más opciones:

1. Está muy mitificado

2. Es parte del camino hacia el éxito

3. Sirve como aprendizaje $\mathbf{X}$

4. Genera temor

5. No hay lugar para el fracaso

6. Otro... 
32. ¿Cuándo considerarías que tu start-up ha tenido éxito? Marcá una o más opciones:

1. Cuando se haya podido devolver toda la inversión recibida

2. Cuando tiene metas y estrategias establecidas

3. Cuando se estén realizando acciones estratégicas para obtener el resultado deseado

4. Cuando la misma pueda ser sostenible en el tiempo

5. Cuando haya resuelto la necesidad insatisfecha

6. Cuando logre rentabilidad

7. Cuando logre una ventaja competitiva en el mercado

8. Cuando se logre la retención del $100 \%$ de los usuarios/clientes

9. Cuando logre escalabilidad $\mathrm{X}$

10. Cuando pueda salir a la bolsa

11. Otro...

\section{Factores externos de éxito y fracaso}

33. ¿Creés que tu entorno, la sociedad y/o las normas culturales influyeron en la decisión de emprender?
1. Sí X
2. No
3. Tal vez

34. En caso afirmativo, ¿cómo fue que influyeron?

Todos emprendedores en mi familia.

35. ¿Considerás a Argentina un país propicio para emprender?

1. Sí X

2. No

3. Tal vez

36. ¿Qué ventajas encontrás en residir en este país? Marcá una o más opciones:

1. Buen nivel de educación/Grandes talentos

2. Genera la habilidad de adaptarse a cambios constantes $\mathbf{X}$ 
3. La industria de la tecnología es un nicho que no está explotado

4. El gobierno apoya el emprendedurismo con programas y/o financiamiento

5. Falta de legislación y regulaciones en la industria de la tecnología

6. Otro...

37. ¿Y desventajas ? Marcá una o más opciones:

1. Falta de recursos

2. Falta de programas de apoyo al emprendedurismo

3. Dificultad de acceder a financiamiento

4. Cambios constantes

5. Nivel de educación bajo

6. Falta de legislación y regulaciones en la industria de la tecnología

7. Economía inestable $X$

8. Alto nivel impositivo

9. Otro...

38. ¿Cómo vive la start-up la situación actual del país?

1. No le afecta

2. Le afecta parcialmente $\mathbf{X}$

3. Le afecta por completo

39. ¿Cómo accedieron a los recursos e infraestructura necesaria? ¿Fue dificultoso conseguir lo que necesitaban?

Tuvimos rápidamente apoyo de aceleradoras e incubadoras.

40. ¿Recibieron algún tipo de financiamiento o ayuda externa? ¿Accedieron a algún programa de financiamiento o aceleración?

1. Sí X

2. No

41. En caso afirmativo, ¿de institución/es pública/s o privada/s?

1. Pública 
2. Privada $\mathrm{X}$

3. Aporte de familia y amigos (FFF)

42. ¿Cuál/es considerás que fue/ron las herramientas que te ayudaron a llegar donde estás hoy? Marcá una o más opciones:

1. Financiamiento

2. Educación

3. Red de contactos

4. Valores personales

5. Aptitudes personales $\mathrm{X}$

6. Haber conseguido el equipo perfecto

7. Otro...

43. ¿Qué opinás sobre las las mujeres emprendedoras? ¿Pensás que tienen las mismas oportunidades que los hombres a la hora de emprender?

No tienen las mismas oportunidades. Pero tenemos que lograr que sí las tengan!

\section{ENTREVISTA № 4}

Entrevistado: LEONARDO GIMENEZ

Datos del emprendedor y del emprendimiento

1. ¿Cómo se llama tu start-up?

Go4Clic

2. ¿Qué es lo que ofrece?

1. Producto $\mathrm{X}$

2. Servicio

3. ¿De qué se trata?

Plataforma de E-Learning. 
4. ¿Tiene página web o redes sociales? En caso afirmativo indicar los links de acceso.

Instagram/Linkedln/ Facebook

5. ¿Desde cuándo comenzaste con el emprendimiento?

1. Hace menos de 1 año $X$

2. Entre 1 y 2 años atrás

3. Entre 2 y 3 años atrás

4. Entre 3 y 4 años atrás

5. Entre 4 y 5 años atrás

6. Hace más de cinco años

6. ¿Qué puesto o funciones cumplís dentro de la start-up?

1. CEO/Director Ejecutivo $\mathrm{X}$

2. COO/Director General

3. $\mathrm{CMO} /$ Director de Marketing

4. CFO/Director Financiero

5. $\mathrm{CCO} /$ Director de Comunicaciones

6. $\mathrm{ClO} / \mathrm{CTO} /$ Director de Sistemas

7. Desarrollador

8. Diseñador gráfico

9. Otro...

\section{Datos del equipo emprendedor}

7. ¿Quiénes conforman el equipo? Indicar nombre de cada integrante, profesión o área de conocimiento, cargo y edad.

ㅁ Esteban Zozaya - CTO - Lic. en Sistemas

口 Alina Martinez - CPO - Publicista

․ Mauro Gallardo - CFO - Contador

$\square$ Leonardo Giménez - CEO - Lic. en ADM, Coach y Cand a Mg Ed a distancia

8. ¿Cómo fue que se asociaron?

1. Amistad 
2. Estrategia

3. Intereses similares

4. Otro... X Propuesta del CEO, para aportar conocimiento y experiencia al proyecto. Mis socios ya habían trabajado con plataformas de e-learning.

9. ¿Cómo distribuyeron las responsabilidades de cada uno?

1. No están distribuidas, todos hacen un poco de todo

2. Se distribuyeron naturalmente según lo que hacia cada uno

3. Hubo una distribución pautada previamente, por conocimientos/habilidades/área de experiencia de cada uno $X$

4. Otro...

10. ¿Se mantiene la misma estructura hoy en día?

1. Sí X

2. No

11. ¿Trabajan de manera remota $o$ in situ?

1. Remota

2. In situ

3. Ambas $\mathbf{X}$

\section{Motivaciones}

12. ¿Cuáles fueron las razones por las que decidiste emprender?

1. Necesidad

2. Deseo $X$

3. Oportunidad

4. Otro...

13. ¿Qué te dio ánimo en dar el salto a emprender?

1. Insatisfacción por la industria corporativa

2. Deseo de ser tu propio jefe/a

3. Convicción 

4. Costumbres familiares
5. Otro... X Construir con libertad mi futuro.

\section{Desarrollo del emprendimiento y planificación estratégica}

14. ¿Tiene el emprendimiento un modelo de negocios definido? En caso afirmativo, ¿de qué tipo es?

1. $\mathrm{B} 2 \mathrm{~B}$ (business to business) $\mathrm{X}$

2. B2C (business to consumer)

3. $\mathrm{C} 2 \mathrm{C}$ (consumer to consumer)

15. ¿Cuál es la forma de monetización?

1. Modelo Freemium (gratuito pero con productos o servicios de pago) $\mathbf{X}$

2. Gratis con publicidades o sponsors

3. Modelo Premium (se accede de pago)

4. Otro...

16. ¿Siempre fue el mismo o tuvo modificaciones?

1. Se mantiene el mismo modelo desde el principio

2. Tuvo modificaciones pero ya no

3. Constantemente se está modificando $\mathrm{X}$

17. ¿Cuál es su misión, visión y objetivos?

- Visión/Misión ACERCAR EL CONOCIMIENTO A CADA RINCÓN DEL PLANETA

$\square$ Objetivos:

- Lanzamiento en La Plata, a través de la red de contactos

- Lanzamiento en CABA a través de Wayra

- Lanzamiento en España (Telefónica)

18. ¿Cómo fue que surgió la idea?

1. Ocio/diversión

2. Detección de una necesidad insatisfecha $\mathbf{X}$

3. Existencia en otro mercado/país, y ganas de aplicarla a otro mercado/país 
4. Otro...

19. ¿Se mantuvo tal como se les ocurrió? ¿O fue modificándose?

1. Se mantuvo

2. Se modificó parcialmente $X$

3. Se modificó por completo

20. ¿Se hizo algún análisis de factibilidad o análisis de mercado previo?

1. Sí $X$

2. No

21. ¿Hay un plan estratégico diseñado?

1. Sí $X$

2. No

22. ¿Ya se lanzó el producto/servicio?

1. Sí $X$

2. No

23. Si es así, ¿̇se hizo primero con un producto mínimo viable?

1. Sí, lanzamos lo antes posible con un PMV X

2. No, esperamos a tener todo el producto terminado

24. ¿El emprendimiento tiene clientes?

1. Sí

2. No X

25. En caso afirmativo, ¿cómo los obtuvo?

1. Por contactos

2. De boca en boca

3. Marketing online

4. Marketing offline 
5. Otro...

26. ¿Tiene competidores?

1. Sí $X$

2. No

27. En caso afirmativo, ¿qué rol ocupan y cómo influye en la start-up?

Tiene +10 competidores directos $y+25$ indirectos.

\section{Factores internos de éxito y fracaso}

28. ¿Tu educación, estudios, experiencia y conocimientos previos fueron relevantes a la hora de lanzarte a emprender?

1. Sí, fue clave $\mathbf{X}$

2. No

3. Algo, pero no tanto

29. ¿Cuáles son los atributos como emprendedor y como persona que destacás en vos, y cuáles tuvieron mayor influencia a la hora de hacer crecer tu start-up? Marcá una o más opciones:

1. Pasión

2. Motivación

3. Liderazgo

4. Compromiso

5. Confianza X

6. Humildad

7. Creatividad

8. Experiencia o conocimientos

9. Aversión al riesgo

10. Perseverancia $X$

11. Poseer una idea o visión empresarial clara

12. Capacidad de reconocer oportunidades

13. Otro... 
30. ¿Cuál creés que es la cualidad más importante que un emprendedor debe tener para lograr su objetivo? Marcá una opción:

1. Pasión

2. Motivación

3. Liderazgo

4. Compromiso

5. Confianza X

6. Humildad

7. Creatividad

8. Experiencia o conocimientos

9. Aversión al riesgo

10. Perseverancia

11. Poseer una idea o visión empresarial clara

12. Capacidad de reconocer oportunidades

13. Otro...

31. ¿Cómo percibis el fracaso en el contexto de una start-up? Marcá una o más opciones:

1. Está muy mitificado

2. Es parte del camino hacia el éxito $X$

3. Sirve como aprendizaje $\mathbf{X}$

4. Genera temor

5. No hay lugar para el fracaso

6. Otro...

32. ¿Cuándo considerarías que tu start-up ha tenido éxito? Marcá una o más opciones:

1. Cuando se haya podido devolver toda la inversión recibida

2. Cuando tiene metas y estrategias establecidas

3. Cuando se estén realizando acciones estratégicas para obtener el resultado deseado

4. Cuando la misma pueda ser sostenible en el tiempo

5. Cuando haya resuelto la necesidad insatisfecha

6. Cuando logre rentabilidad

7. Cuando logre una ventaja competitiva en el mercado 
8. Cuando se logre la retención del $100 \%$ de los usuarios/clientes

9. Cuando logre escalabilidad

10. Cuando pueda salir a la bolsa

11. Otro... X Cuando empieza a ser valioso para otros, cuando mejora las posibilidades de los demás y se apropian de la idea (deja de ser del promotor original).

\section{Factores externos de éxito y fracaso}

33. ¿Creés que tu entorno, la sociedad y/o las normas culturales influyeron en la decisión de emprender?
1. Sí $X$
2. No
3. Tal vez

34. En caso afirmativo, ¿cómo fue que influyeron?

Mi entorno me formó (familia, educación, etc.) la personalidad, y los valores claves para emprender. Luego el desafío es conectar con esas posibilidades y montar un proyecto sobre eso.

35. ¿Considerás a Argentina un país propicio para emprender?

1. Sí

2. No X

3. Tal vez

36. ¿Qué ventajas encontrás en residir en este país? Marcá una o más opciones:

1. Buen nivel de educación/Grandes talentos

2. Genera la habilidad de adaptarse a cambios constantes

3. La industria de la tecnología es un nicho que no está explotado

4. El gobierno apoya el emprendedurismo con programas y/o financiamiento

5. Falta de legislación y regulaciones en la industria de la tecnología

6. Otro...

37. ¿Y desventajas ? Marcá una o más opciones:

1. Falta de recursos

2. Falta de programas de apoyo al emprendedurismo 
3. Dificultad de acceder a financiamiento $X$

4. Cambios constantes

5. Nivel de educación bajo

6. Falta de legislación y regulaciones en la industria de la tecnología

7. Economía inestable

8. Alto nivel impositivo

9. Otro...

38. ¿Cómo vive la start-up la situación actual del país?

1. No le afecta

2. Le afecta parcialmente

3. Le afecta por completo $\mathrm{X}$

39. ¿Cómo accedieron a los recursos e infraestructura necesaria? ¿Fue dificultoso conseguir lo que necesitaban?

A través de trabajar, pedir, aplicar, insistir.

40. ¿Recibieron algún tipo de financiamiento o ayuda externa? ¿Accedieron a algún programa de financiamiento o aceleración?
1. Sí X
2. No

41. En caso afirmativo, ¿de institución/es pública/s o privada/s?

1. Pública $X$

2. Privada

3. Aporte de familia y amigos (FFF)

42. ¿Cuál/es considerás que fue/ron las herramientas que te ayudaron a llegar donde estás hoy? Marcá una o más opciones:

1. Financiamiento

2. Educación

3. Red de contactos $\mathrm{X}$

4. Valores personales 

5. Aptitudes personales
6. Haber conseguido el equipo perfecto
7. Otro...

43. ¿Qué opinás sobre las las mujeres emprendedoras? ¿Pensás que tienen las mismas oportunidades que los hombres a la hora de emprender?

No, pero entre todos (casi) los hombres estamos generando el contexto para que no existan barreras de género.

\section{ENTREVISTA № 5}

Entrevistado: ALAN YUSIM

Datos del emprendedor y del emprendimiento

1. ¿Cómo se llama tu start-up?

Mipublicidad.com.ar

2. ¿Qué es lo que ofrece?

1. Producto

2. Servicio $\mathrm{X}$

3. ¿De qué se trata?

Audio\&visual marketing.

4. ¿Tiene página web o redes sociales? En caso afirmativo indicar los links de acceso.

$\square$ https://www.facebook.com/mipublicidadface/

5. ¿Desde cuándo comenzaste con el emprendimiento?

1. Hace menos de 1 año

2. Entre 1 y 2 años atrás $X$

3. Entre 2 y 3 años atrás

4. Entre 3 y 4 años atrás

5. Entre 4 y 5 años atrás 
6. Hace más de cinco años

6. ¿Qué puesto o funciones cumplís dentro de la start-up?

1. CEO/Director Ejecutivo $\mathrm{X}$

2. COO/Director General

3. $\mathrm{CMO} /$ Director de Marketing

4. CFO/Director Financiero

5. CCO/Director de Comunicaciones

6. $\mathrm{ClO} / \mathrm{CTO} /$ Director de Sistemas

7. Desarrollador

8. Diseñador gráfico

9. Otro...

\section{Datos del equipo emprendedor}

7. ¿Quiénes conforman el equipo? Indicar nombre de cada integrante, profesión o área de conocimiento, cargo y edad.

Lucas, locutor del ISER

Alan, SEO

Melany, asesora de ventas

Agustín, licenciado en Comunicación

8. ¿Cómo fue que se asociaron?

1. Amistad

2. Estrategia

3. Intereses similares

4. Otro...

9. ¿Cómo distribuyeron las responsabilidades de cada uno?

1. No están distribuidas, todos hacen un poco de todo

2. Se distribuyeron naturalmente según lo que hacía cada uno

3. Hubo una distribución pautada previamente, por conocimientos/habilidades/área de experiencia de cada uno $X$ 
4. Otro...

10. ¿Se mantiene la misma estructura hoy en día?

1. Sí X

2. No

11. ¿Trabajan de manera remota o in situ?

1. Remota

2. In situ

3. Ambas $\mathbf{X}$

\section{Motivaciones}

12. ¿Cuáles fueron las razones por las que decidiste emprender?

1. Necesidad

2. Deseo $X$

3. Oportunidad

4. Otro...

13. ¿Qué te dio ánimo en dar el salto a emprender?

1. Insatisfacción por la industria corporativa

2. Deseo de ser tu propio jefe/a

3. Convicción $\mathrm{X}$

4. Costumbres familiares

5. Otro... X Personalidad

\section{Desarrollo del emprendimiento y planificación estratégica}

14. ¿Tiene el emprendimiento un modelo de negocios definido? En caso afirmativo, ¿de qué tipo es?

1. $B 2 B$ (business to business) $X$

2. $\mathrm{B} 2 \mathrm{C}$ (business to consumer)

3. $\mathrm{C} 2 \mathrm{C}$ (consumer to consumer) 
15. ¿Cuál es la forma de monetización?

1. Modelo Freemium (gratuito pero con productos o servicios de pago)

2. Gratis con publicidades o sponsors

3. Modelo Premium (se accede de pago) $\mathrm{X}$

4. Otro...

16. ¿Siempre fue el mismo o tuvo modificaciones?

1. Se mantiene el mismo modelo desde el principio

2. Tuvo modificaciones pero ya no

3. Constantemente se está modificando $X$

17. ¿Cuál es su misión, visión y objetivos?

Llevar a un nivel VIP a quienes no pueden llegar.

18. ¿Cómo fue que surgió la idea?

1. Ocio/diversión

2. Detección de una necesidad insatisfecha $\mathbf{X}$

3. Existencia en otro mercado/país, y ganas de aplicarla a otro mercado/país.

4. Otro...

19. ¿Se mantuvo tal como se les ocurrió? ¿O fue modificándose?

1. Se mantuvo

2. Se modificó parcialmente

3. Se modificó por completo $\mathrm{X}$

20. ¿Se hizo algún análisis de factibilidad o análisis de mercado previo?

1. Sí

2. No X

21. ¿Hay un plan estratégico diseñado?

1. Sí

2. No X 
22. ¿Ya se lanzó el producto/servicio?

1. Sí X

2. No

23. Si es así, ¿se hizo primero con un producto mínimo viable?

1. Sí, lanzamos lo antes posible con un PMV X

2. No, esperamos a tener todo el producto terminado

24. ¿El emprendimiento tiene clientes?

1. Sí $X$

2. No

25. En caso afirmativo, ¿cómo los obtuvo?

1. Por contactos

2. De boca en boca

3. Marketing online

4. Marketing offline

5. Otro...

26. ¿Tiene competidores?

1. Sí X

2. No

27. En caso afirmativo, ¿qué rol ocupan y cómo influye en la start-up?

Son distintos.

\section{Factores internos de éxito y fracaso}

28. ¿Tu educación, estudios, experiencia y conocimientos previos fueron relevantes a la hora de lanzarte a emprender?

1. Sí, fue clave

2. No X

3. Algo, pero no tanto 
29. ¿Cuáles son los atributos como emprendedor y como persona que destacás en vos, y cuáles tuvieron mayor influencia a la hora de hacer crecer tu start-up? Marcá una o más opciones:

1. Pasión $\mathrm{X}$

2. Motivación

3. Liderazgo $\mathrm{X}$

4. Compromiso $\mathrm{X}$

5. Confianza

6. Humildad $X$

7. Creatividad

8. Experiencia o conocimientos

9. Aversión al riesgo

10. Perseverancia

11. Poseer una idea o visión empresarial clara

12. Capacidad de reconocer oportunidades

13. Otro...

30. ¿Cuál creés que es la cualidad más importante que un emprendedor debe tener para lograr su objetivo? Marcá una opción:

1. Pasión $\mathbf{X}$

2. Motivación

3. Liderazgo

4. Compromiso

5. Confianza

6. Humildad

7. Creatividad

8. Experiencia o conocimientos

9. Aversión al riesgo

10. Perseverancia

11. Poseer una idea o visión empresarial clara

12. Capacidad de reconocer oportunidades

13. Otro... 
31. ¿Cómo percibís el fracaso en el contexto de una start-up? Marcá una o más opciones:

1. Está muy mitificado

2. Es parte del camino hacia el éxito $X$

3. Sirve como aprendizaje

4. Genera temor $\mathbf{X}$

5. No hay lugar para el fracaso

6. Otro...

32. ¿Cuándo considerarías que tu start-up ha tenido éxito? Marcá una o más opciones

1. Cuando se haya podido devolver toda la inversión recibida $X$

2. Cuando tiene metas y estrategias establecidas

3. Cuando se estén realizando acciones estratégicas para obtener el resultado deseado

4. Cuando la misma pueda ser sostenible en el tiempo $\mathrm{X}$

5. Cuando haya resuelto la necesidad insatisfecha

6. Cuando logre rentabilidad

7. Cuando logre una ventaja competitiva en el mercado

8. Cuando se logre la retención del $100 \%$ de los usuarios/clientes

9. Cuando logre escalabilidad

10. Cuando pueda salir a la bolsa

11. Otro...

\section{Factores externos de éxito y fracaso}

33. ¿Creés que tu entorno, la sociedad y/o las normas culturales influyeron en la decisión de emprender?

1. Sí

2. No X

3. Tal vez

34. En caso afirmativo, ¿cómo fue que influyeron? 
35. ¿Considerás a Argentina un país propicio para emprender?

1. Sí

2. No

3. Tal vez $\mathrm{X}$

36. ¿Qué ventajas encontrás en residir en este país? Marcá una o más opciones:

1. Buen nivel de educación/Grandes talentos

2. Genera la habilidad de adaptarse a cambios constantes

3. La industria de la tecnología es un nicho que no está explotado $X$

4. El gobierno apoya el emprendedurismo con programas y/o financiamiento

5. Falta de legislación y regulaciones en la industria de la tecnología

6. Otro...

37. ¿Y desventajas ? Marcá una o más opciones:

1. Falta de recursos $\mathrm{X}$

2. Falta de programas de apoyo al emprendedurismo

3. Dificultad de acceder a financiamiento $X$

4. Cambios constantes $\mathrm{X}$

5. Nivel de educación bajo $\mathrm{X}$

6. Falta de legislación y regulaciones en la industria de la tecnología

7. Economía inestable $X$

8. Alto nivel impositivo $\mathrm{X}$

9. Otro...

38. ¿Cómo vive la start-up la situación actual del país?

1. No le afecta

2. Le afecta parcialmente

3. Le afecta por completo $\mathrm{X}$

39. ¿Cómo accedieron a los recursos e infraestructura necesaria? ¿Fue dificultoso conseguir lo que necesitaban?

Sí. 
40. ¿Recibieron algún tipo de financiamiento o ayuda externa? ¿Accedieron a algún programa de financiamiento o aceleración?
1. Sí
2. No X

41. En caso afirmativo, ¿de institución/es pública/s o privada/s?

1. Pública

2. Privada

3. Aporte de familia y amigos (FFF)

42. ¿Cuál/es considerás que fue/ron las herramientas que te ayudaron a llegar donde estás hoy? Marcá una o más opciones:

1. Financiamiento

2. Educación

3. Red de contactos

4. Valores personales $\mathrm{X}$

5. Aptitudes personales $X$

6. Haber conseguido el equipo perfecto

7. Otro...

43. ¿Qué opinás sobre las las mujeres emprendedoras? ¿Pensás que tienen las mismas oportunidades que los hombres a la hora de emprender?

Sí.

\section{ENTREVISTA No 6}

Entrevistado: TOMÁs EsPósITO

Datos del emprendedor y del emprendimiento

1. ¿Cómo se llama tu start-up?

Está Reservado. 
2. ¿Qué es lo que ofrece?

1. Producto

2. Servicio $\mathrm{X}$

3. ¿De qué se trata?

Una plataforma digital de reservas. "Si se puede reservar, EstáReservado".

4. ¿Tiene página web o redes sociales? En caso afirmativo indicar los links de acceso.

No.

5. ¿Desde cuándo comenzaste con el emprendimiento?

1. Hace menos de 1 año

2. Entre 1 y 2 años atrás

3. Entre 2 y 3 años atrás $X$

4. Entre 3 y 4 años atrás

5. Entre 4 y 5 años atrás

6. Hace más de cinco años

6. ¿Qué puesto o funciones cumplís dentro de la start-up?

1. CEO/Director Ejecutivo $\mathrm{X}$

2. COO/Director General $\mathrm{X}$

3. $\mathrm{CMO} /$ Director de Marketing

4. CFO/Director Financiero

5. $\mathrm{CCO} /$ Director de Comunicaciones

6. $\mathrm{ClO} / \mathrm{CTO} /$ Director de Sistemas

7. Desarrollador

8. Diseñador gráfico

9. Otro...

\section{Datos del equipo emprendedor}

7. ¿Quiénes conforman el equipo? Indicar nombre de cada integrante, profesión o área de conocimiento, cargo y edad. 
- Tomás Espósito (estudiante), Marketing y Comunicación; hombre; 21 años.

․ Martín Gutiérrez, Lic en Administración; Finanzas; hombre; 43 años.

8. ¿Cómo fue que se asociaron?

1. Amistad

2. Estrategia $\mathrm{X}$

3. Intereses similares $\mathrm{X}$

4. Otro...

9. ¿Cómo distribuyeron las responsabilidades de cada uno?

1. No están distribuidas, todos hacen un poco de todo $X$

2. Se distribuyeron naturalmente según lo que hacia cada uno

3. Hubo una distribución pautada previamente, por conocimientos/habilidades/área de experiencia de cada uno

4. Otro...

10. ¿Se mantiene la misma estructura hoy en día?

1. Sí X

2. No

11. ¿Trabajan de manera remota o in situ?

1. Remota $\mathbf{X}$

2. In situ

3. Ambas

\section{Motivaciones}

12. ¿Cuáles fueron las razones por las que decidiste emprender?

1. Necesidad

2. Deseo $X$

3. Oportunidad

4. Otro... 
13. ¿Qué te dio ánimo en dar el salto a emprender?

1. Insatisfacción por la industria corporativa

2. Deseo de ser tu propio jefe/a

3. Convicción $\mathrm{X}$

4. Costumbres familiares

5. Otro...

\section{Desarrollo del emprendimiento y planificación estratégica}

14. ¿Tiene el emprendimiento un modelo de negocios definido? En caso afirmativo, ¿de qué tipo es?

1. $\quad$ B2B (business to business)

2. $\mathrm{B} 2 \mathrm{C}$ (business to consumer) $\mathrm{X}$

3. $\mathrm{C} 2 \mathrm{C}$ (consumer to consumer)

15. ¿Cuál es la forma de monetización?

1. Modelo Freemium (gratuito pero con productos o servicios de pago) $\mathbf{X}$

2. Gratis con publicidades o sponsors

3. Modelo Premium (se accede de pago)

4. Otro...

16. ¿Siempre fue el mismo o tuvo modificaciones?

1. Se mantiene el mismo modelo desde el principio

2. Tuvo modificaciones pero ya no

3. Constantemente se está modificando $\mathrm{X}$

17. ¿Cuál es su misión, visión y objetivos?

Ser la plataforma número 1 de reservas pequeñas de LATAM.

18. ¿Cómo fue que surgió la idea?

1. Ocio/diversión

2. Detección de una necesidad insatisfecha $X$

3. Existencia en otro mercado/país, y ganas de aplicarla a otro mercado/país. 
4. Otro...

19. ¿Se mantuvo tal como se les ocurrió? ¿O fue modificándose?

1. Se mantuvo

2. Se modificó parcialmente $X$

3. Se modificó por completo

20. ¿Se hizo algún análisis de factibilidad o análisis de mercado previo?

1. Sí $X$

2. No

21. ¿Hay un plan estratégico diseñado?

1. Sí $X$

2. No

22. ¿Ya se lanzó el producto/servicio?

1. Sí

2. No X

23. Si es así, ¿̇se hizo primero con un producto mínimo viable?

1. Sí, lanzamos lo antes posible con un PMV X

2. No, esperamos a tener todo el producto terminado

24. ¿El emprendimiento tiene clientes?

1. Sí X

2. No

25. En caso afirmativo, ¿cómo los obtuvo?

1. Por contactos $\mathbf{X}$

2. De boca en boca

3. Marketing online

4. Marketing offline 
5. Otro...

26. ¿Tiene competidores?

1. Sí $X$

2. No

27. En caso afirmativo, ¿qué rol ocupan y cómo influye en la start-up?

Son competidores indirectos. De servicios sustitutos.

\section{Factores internos de éxito y fracaso}

28. ¿Tu educación, estudios, experiencia y conocimientos previos fueron relevantes a la hora de lanzarte a emprender?

1. Sí, fue clave

2. No

3. Algo, pero no tanto $\mathrm{X}$

29. ¿Cuáles son los atributos como emprendedor y como persona que destacás en vos, y cuales tuvieron mayor influencia a la hora de hacer crecer tu start-up? Marcá una o más opciones:

1. Pasión $\mathrm{X}$

2. Motivación $\mathrm{X}$

3. Liderazgo

4. Compromiso $\mathrm{X}$

5. Confianza

6. Humildad

7. Creatividad $\mathrm{X}$

8. Experiencia o conocimientos

9. Aversión al riesgo

10. Perseverancia

11. Poseer una idea o visión empresarial clara

12. Capacidad de reconocer oportunidades $\mathbf{X}$

13. Otro... 
30. ¿Cuál creés que es la cualidad más importante que un emprendedor debe tener para lograr su objetivo? Marcá una opción:

1. Pasión

2. Motivación

3. Liderazgo

4. Compromiso

5. Confianza

6. Humildad

7. Creatividad

8. Experiencia o conocimientos

9. Aversión al riesgo

10. Perseverancia

11. Poseer una idea o visión empresarial clara

12. Capacidad de reconocer oportunidades

13. Otro... X Contactos

31. ¿Cómo percibís el fracaso en el contexto de una start-up? Marcá una o más opciones:

1. Está muy mitificado

2. Es parte del camino hacia el éxito $X$

3. Sirve como aprendizaje $\mathbf{X}$

4. Genera temor

5. No hay lugar para el fracaso

6. Otro...

32. ¿Cuándo considerarías que tu start-up ha tenido éxito? Marcá una o más opciones:

1. Cuando se haya podido devolver toda la inversión recibida

2. Cuando tiene metas y estrategias establecidas

3. Cuando se estén realizando acciones estratégicas para obtener el resultado deseado

4. Cuando la misma pueda ser sostenible en el tiempo

5. Cuando haya resuelto la necesidad insatisfecha

6. Cuando logre rentabilidad

7. Cuando logre una ventaja competitiva en el mercado 
8. Cuando se logre la retención del $100 \%$ de los usuarios/clientes

9. Cuando logre escalabilidad $\mathrm{X}$

10. Cuando pueda salir a la bolsa

11. Otro...

\section{Factores externos de éxito y fracaso}

33. ¿Creés que tu entorno, la sociedad y/o las normas culturales influyeron en la decisión de emprender?
1. Sí
2. No $X$
3. Tal vez

34. En caso afirmativo, ¿cómo fue que influyeron?

35. ¿Considerás a Argentina un país propicio para emprender?

1. Sí

2. No $\mathrm{X}$

3. Tal vez

36. ¿Qué ventajas encontrás en residir en este país? Marcá una o más opciones:

1. Buen nivel de educación/Grandes talentos

2. Genera la habilidad de adaptarse a cambios constantes $\mathbf{X}$

3. La industria de la tecnología es un nicho que no está explotado

4. El gobierno apoya el emprendedurismo con programas y/o financiamiento

5. Falta de legislación y regulaciones en la industria de la tecnología

6. Otro...

37. ¿Y desventajas ? Marcá una o más opciones:

1. Falta de recursos $\mathrm{X}$

2. Falta de programas de apoyo al emprendedurismo

3. Dificultad de acceder a financiamiento

4. Cambios constantes 
5. Nivel de educación bajo

6. Falta de legislación y regulaciones en la industria de la tecnología

7. Economía inestable

8. Alto nivel impositivo $X$

9. Otro...

38. ¿Cómo vive la start-up la situación actual del país?

1. No le afecta

2. Le afecta parcialmente $X$

3. Le afecta por completo

39. ¿Cómo accedieron a los recursos e infraestructura necesaria? ¿Fue dificultoso conseguir lo que necesitaban?

Sí. Estuvimos mucho tiempo hasta que conseguimos las inversiones. Fue muy difícil encontrar al equipo de programación que resuelva todas nuestras necesidades.

40. ¿Recibieron algún tipo de financiamiento o ayuda externa? ¿Accedieron a algún programa de financiamiento o aceleración?
1. Sí $X$
2. No

41. En caso afirmativo, ¿de institución/es pública/s o privada/s?

1. Pública

2. Privada $X$

3. Aporte de familia y amigos (FFF)

42. ¿Cuál/es considerás que fue/ron las herramientas que te ayudaron a llegar donde estás hoy? Marcá una o más opciones:

1. Financiamiento

2. Educación

3. Red de contactos $\mathbf{X}$

4. Valores personales

5. Aptitudes personales 
6. Haber conseguido el equipo perfecto

7. Otro...

43. ¿Qué opinás sobre las las mujeres emprendedoras? ¿Pensás que tienen las mismas oportunidades que los hombres a la hora de emprender?

Sí, la misma. Se comprometen mucho más!

\section{ENTREVISTA № 7}

Entrevistado: PABLO BALDOMÁ JONES

\section{Datos del emprendedor y del emprendimiento}

1. ¿Cómo se llama tu start-up?

Celerative.

2. ¿Qué es lo que ofrece?

1. Producto $\mathrm{X}$

2. Servicio

3. ¿De qué se trata?

Hire Manage Pulse.

4. ¿Tiene página web o redes sociales? En caso afirmativo indicar los links de acceso. @celerative

5. ¿Desde cuándo comenzaste con el emprendimiento?

1. Hace menos de 1 año

2. Entre 1 y 2 años atrás

3. Entre 2 y 3 años atrás

4. Entre 3 y 4 años atrás

5. Entre 4 y 5 años atrás

6. Hace más de cinco años $X$ 
6. ¿Qué puesto o funciones cumplís dentro de la start-up?

1. CEO/Director Ejecutivo $\mathrm{X}$

2. COO/Director General

3. $\mathrm{CMO} /$ Director de Marketing

4. CFO/Director Financiero

5. CCO/Director de Comunicaciones

6. $\mathrm{ClO} / \mathrm{CTO} /$ Director de Sistemas

7. Desarrollador

8. Diseñador gráfico

9. Otro...

\section{Datos del equipo emprendedor}

7. ¿Quiénes conforman el equipo? Indicar nombre de cada integrante, profesión o área de conocimiento, cargo y edad.

Equipo de 10 personas del producto, 2 co CEOs, COO, CTO VP Sales.

8. ¿Cómo fue que se asociaron?

1. Amistad

2. Estrategia

3. Intereses similares $\mathbf{X}$

4. Otro...

9. ¿Cómo distribuyeron las responsabilidades de cada uno?

1. No están distribuidas, todos hacen un poco de todo

2. Se distribuyeron naturalmente según lo que hacia cada uno

3. Hubo una distribución pautada previamente, por conocimientos/habilidades/área de experiencia de cada uno $X$

4. Otro...

10. ¿Se mantiene la misma estructura hoy en día?

1. Sí 
2. No X

11. ¿Trabajan de manera remota o in situ?

1. Remota X

2. In situ

3. Ambas

\section{Motivaciones}

12. ¿Cuáles fueron las razones por las que decidiste emprender?

1. Necesidad

2. Deseo

3. Oportunidad $\mathrm{X}$

4. Otro...

13. ¿Qué te dio ánimo en dar el salto a emprender?

1. Insatisfacción por la industria corporativa

2. Deseo de ser tu propio jefe/a

3. Convicción $\mathrm{X}$

4. Costumbres familiares $X$

5. Otro...

\section{Desarrollo del emprendimiento y planificación estratégica}

14. ¿'Tiene el emprendimiento un modelo de negocios definido? En caso afirmativo, ¿de qué tipo es?

1. $\mathrm{B} 2 \mathrm{~B}$ (business to business) $\mathrm{X}$

2. $\quad \mathrm{B} 2 \mathrm{C}$ (business to consumer)

3. $\mathrm{C} 2 \mathrm{C}$ (consumer to consumer)

15. ¿Cuál es la forma de monetización?

1. Modelo Freemium (gratuito pero con productos o servicios de pago) $\mathrm{X}$

2. Gratis con publicidades o sponsors

3. Modelo Premium (se accede de pago) 
4. Otro...

16. ¿Siempre fue el mismo o tuvo modificaciones?

1. Se mantiene el mismo modelo desde el principio

2. Tuvo modificaciones pero ya no

3. Constantemente se está modificando $X$

17. ¿Cuál es su misión, visión y objetivos?

Hacer que equipos trabajen bien en forma remota.

18. ¿Cómo fue que surgió la idea?

1. Ocio/diversión

2. Detección de una necesidad insatisfecha $\mathbf{X}$

3. Existencia en otro mercado/país, y ganas de aplicarla a otro mercado/país.

4. Otro...

19. ¿Se mantuvo tal como se les ocurrió? ¿O fue modificándose?

1. Se mantuvo

2. Se modificó parcialmente

3. Se modificó por completo $X$

20. ¿Se hizo algún análisis de factibilidad o análisis de mercado previo?

1. Sí X

2. No

21. ¿Hay un plan estratégico diseñado?

1. Sí X

2. No

22. ¿Ya se lanzó el producto/servicio?

1. Sí $X$

2. No 
23. Si es así, ¿¿se hizo primero con un producto mínimo viable?

1. Sí, lanzamos lo antes posible con un PMV X

2. No, esperamos a tener todo el producto terminado

24. ¿El emprendimiento tiene clientes?

1. Sí $X$

2. No

25. En caso afirmativo, ¿cómo los obtuvo?

1. Por contactos

2. De boca en boca $\mathbf{X}$

3. Marketing online

4. Marketing offline

5. Otro...

26. ¿Tiene competidores?

1. Sí X

2. No

27. En caso afirmativo, ¿qué rol ocupan y cómo influye en la start-up?

Los competidores son benchmark para algunos feature y para validar la necesidad.

\section{Factores internos de éxito y fracaso}

28. ¿Tu educación, estudios, experiencia y conocimientos previos fueron relevantes a la hora de lanzarte a emprender?

1. Sí, fue clave

2. No

3. Algo, pero no tanto $\mathrm{X}$

29. ¿Cuáles son los atributos como emprendedor y como persona que destacás en vos, y cuáles tuvieron mayor influencia a la hora de hacer crecer tu start-up? Marcá una o más opciones: 
1. Pasión $\mathbf{X}$

2. Motivación

3. Liderazgo $\mathrm{X}$

4. Compromiso $\mathrm{X}$

5. Confianza

6. Humildad

7. Creatividad

8. Experiencia o conocimientos $\mathrm{X}$

9. Aversión al riesgo $X$

10. Perseverancia

11. Poseer una idea o visión empresarial clara

12. Capacidad de reconocer oportunidades

13. Otro...

30. ¿Cuál creés que es la cualidad más importante que un emprendedor debe tener para lograr su objetivo? Marcá una opción:

1. Pasión

2. Motivación

3. Liderazgo

4. Compromiso

5. Confianza

6. Humildad

7. Creatividad

8. Experiencia o conocimientos

9. Aversión al riesgo $X$

10. Perseverancia

11. Poseer una idea o visión empresarial clara

12. Capacidad de reconocer oportunidades

13. Otro...

31. ¿Cómo percibís el fracaso en el contexto de una start-up? Marcá una o más opciones:

1. Está muy mitificado 
2. Es parte del camino hacia el éxito

3. Sirve como aprendizaje $\mathbf{X}$

4. Genera temor $\mathbf{X}$

5. No hay lugar para el fracaso

6. Otro...

32. ¿Cuándo considerarías que tu start-up ha tenido éxito? Marcá una o más opciones:

1. Cuando se haya podido devolver toda la inversión recibida

2. Cuando tiene metas y estrategias establecidas

3. Cuando se estén realizando acciones estratégicas para obtener el resultado deseado

4. Cuando la misma pueda ser sostenible en el tiempo $X$

5. Cuando haya resuelto la necesidad insatisfecha

6. Cuando logre rentabilidad

7. Cuando logre una ventaja competitiva en el mercado $X$

8. Cuando se logre la retención del $100 \%$ de los usuarios/clientes

9. Cuando logre escalabilidad $X$

10. Cuando pueda salir a la bolsa

11. Otro...

\section{Factores externos de éxito y fracaso}

33. ¿Creés que tu entorno, la sociedad y/o las normas culturales influyeron en la decisión de emprender?
1. Sí $\mathrm{X}$
2. No
3. Tal vez

34. En caso afirmativo, ¿cómo fue que influyeron?

35. ¿Considerás a Argentina un país propicio para emprender?

1. Sí

2. No X

3. Tal vez 
36. ¿Qué ventajas encontrás en residir en este país? Marcá una o más opciones:

1. Buen nivel de educación/Grandes talentos

2. Genera la habilidad de adaptarse a cambios constantes $X$

3. La industria de la tecnología es un nicho que no está explotado

4. El gobierno apoya el emprendedurismo con programas y/o financiamiento

5. Falta de legislación y regulaciones en la industria de la tecnología

6. Otro...

37. ¿Y desventajas ? Marcá una o más opciones:

1. Falta de recursos $\mathbf{X}$

2. Falta de programas de apoyo al emprendedurismo $X$

3. Dificultad de acceder a financiamiento $X$

4. Cambios constantes $\mathrm{X}$

5. Nivel de educación bajo

6. Falta de legislación y regulaciones en la industria de la tecnología

7. Economía inestable $X$

8. Alto nivel impositivo $X$

9. Otro...

38. ¿Cómo vive la start-up la situación actual del país?

1. No le afecta

2. Le afecta parcialmente $X$

3. Le afecta por completo

39. ¿Cómo accedieron a los recursos e infraestructura necesaria? ¿Fue dificultoso conseguir lo que necesitaban?

Sí.

40. ¿Recibieron algún tipo de financiamiento o ayuda externa? ¿Accedieron a algún programa de financiamiento o aceleración?

1. Sí 
2. No X

41. En caso afirmativo, ¿de institución/es pública/s o privada/s?

1. Pública

2. Privada

3. Aporte de familia y amigos (FFF)

42. ¿Cuál/es considerás que fue/ron las herramientas que te ayudaron a llegar donde estás hoy? Marcá una o más opciones:

1. Financiamiento

2. Educación

3. Red de contactos $X$

4. Valores personales

5. Aptitudes personales

6. Haber conseguido el equipo perfecto $X$

7. Otro...

43. ¿Qué opinás sobre las las mujeres emprendedoras? ¿Pensás que tienen las mismas oportunidades que los hombres a la hora de emprender? 


\section{ENTREVISTA № 8}

Entrevistado: JULIÁN CHOMICKI

\section{Datos del emprendedor y del emprendimiento}

1. ¿Cómo se llama tu start-up?

Sherlock.

2. ¿Qué es lo que ofrece?

1. Producto

2. Servicio $X$

3. ¿De qué se trata?

Terminal financiera para personas que invierten en la bolsa argentina.

4. ¿Tiene página web o redes sociales? En caso afirmativo indicar los links de acceso.

$\square \quad \underline{\text { www.sherlockfinanzas.com.ar }}$

5. ¿Desde cuándo comenzaste con el emprendimiento?

1. Hace menos de 1 año

2. Entre 1 y 2 años atrás

3. Entre 2 y 3 años atrás

4. Entre 3 y 4 años atrás $X$

5. Entre 4 y 5 años atrás

6. Hace más de cinco años

6. ¿Qué puesto o funciones cumplís dentro de la start-up?

1. CEO/Director Ejecutivo $X$

2. COO/Director General

3. $\mathrm{CMO} /$ Director de Marketing

4. $\mathrm{CFO} /$ Director Financiero

5. CCO/Director de Comunicaciones

6. $\mathrm{ClO} / \mathrm{CTO} /$ Director de Sistemas 

7. Desarrollador
8. Diseñador gráfico
9. Otro...

\section{Datos del equipo emprendedor}

7. ¿Quiénes conforman el equipo? Indicar nombre de cada integrante, profesión o área de conocimiento, cargo y edad.

Cristian, 29, analista sistemas, hombre, encargado backend.

口 Pablo, 34, analista sistemas, hombre, encargado frontend.
8. ¿Cómo fue que se asociaron?
1. Amistad
2. Estrategia
3. Intereses similares $\mathrm{X}$
4. Otro...

9. ¿Cómo distribuyeron las responsabilidades de cada uno?

1. No están distribuidas, todos hacen un poco de todo

2. Se distribuyeron naturalmente según lo que hacía cada uno $X$

3. Hubo una distribución pautada previamente, por conocimientos/habilidades/área de experiencia de cada uno

4. Otro...

10. ¿Se mantiene la misma estructura hoy en día?

1. Sí X

2. No

11. ¿Trabajan de manera remota o in situ?

1. Remota $\mathrm{X}$

2. In situ

3. Ambas 


\section{Motivaciones}

12. ¿Cuáles fueron las razones por las que decidiste emprender?

1. Necesidad

2. Deseo

3. Oportunidad $\mathrm{X}$

4. Otro...

13. ¿Qué te dio ánimo en dar el salto a emprender?

1. Insatisfacción por la industria corporativa

2. Deseo de ser tu propio jefe/a

3. Convicción

4. Costumbres familiares

5. Otro... X El hecho de que mi familia me haya apoyado

\section{Desarrollo del emprendimiento y planificación estratégica}

14. ¿Tiene el emprendimiento un modelo de negocios definido? En caso afirmativo, ¿de qué tipo es?

1. $\quad$ B2B (business to business)

2. $\mathrm{B} 2 \mathrm{C}$ (business to consumer) $\mathrm{X}$

3. $\mathrm{C} 2 \mathrm{C}$ (consumer to consumer)

15. ¿Cuál es la forma de monetización?

1. Modelo Freemium (gratuito pero con productos o servicios de pago) $\mathbf{X}$

2. Gratis con publicidades o sponsors

3. Modelo Premium (se accede de pago)

4. Otro...

16. ¿Siempre fue el mismo o tuvo modificaciones?

1. Se mantiene el mismo modelo desde el principio $\mathbf{X}$

2. Tuvo modificaciones pero ya no

3. Constantemente se está modificando 
17. ¿Cuál es su misión, visión y objetivos?

Democratizar el acceso al mercado de capitales.

18. ¿Cómo fue que surgió la idea?

1. Ocio/diversión

2. Detección de una necesidad insatisfecha $\mathbf{X}$

3. Existencia en otro mercado/país, y ganas de aplicarla a otro mercado/país $\mathbf{X}$

4. Otro...

19. ¿Se mantuvo tal como se les ocurrió? ¿O fue modificándose?

1. Se mantuvo

2. Se modificó parcialmente $\mathbf{X}$

3. Se modificó por completo

20. ¿Se hizo algún análisis de factibilidad o análisis de mercado previo?

1. Sí $\mathrm{X}$

2. No

21. ¿Hay un plan estratégico diseñado?

1. Sí X

2. No

22. ¿Ya se lanzó el producto/servicio?

1. Sí X

2. No

23. Si es así, ¿¿se hizo primero con un producto mínimo viable?

1. Sí, lanzamos lo antes posible con un PMV

2. No, esperamos a tener todo el producto terminado $\mathrm{X}$

24. ¿El emprendimiento tiene clientes?

1. Sí X 
2. No

25. En caso afirmativo, ¿cómo los obtuvo?

1. Por contactos

2. De boca en boca $\mathrm{X}$

3. Marketing online

4. Marketing offline

5. Otro...

26. ¿Tiene competidores?

1. Sí $X$

2. No

27. En caso afirmativo, ¿qué rol ocupan y cómo influye en la start-up?

Nos incentiva a mejorar.

\section{Factores internos de éxito y fracaso}

28. ¿Tu educación, estudios, experiencia y conocimientos previos fueron relevantes a la hora de lanzarte a emprender?

1. Sí, fue clave $\mathbf{X}$

2. No

3. Algo, pero no tanto

29. ¿Cuáles son los atributos como emprendedor y como persona que destacás en vos, y cuáles tuvieron mayor influencia a la hora de hacer crecer tu start-up? Marcá una o más opciones:

1. Pasión $\mathbf{X}$

2. Motivación $\mathrm{X}$

3. Liderazgo

4. Compromiso

5. Confianza

6. Humildad

7. Creatividad 
8. Experiencia o conocimientos $\mathrm{X}$

9. Aversión al riesgo

10. Perseverancia $\mathbf{X}$

11. Poseer una idea o visión empresarial clara

12. Capacidad de reconocer oportunidades

13. Otro...

30. ¿Cuál creés que es la cualidad más importante que un emprendedor debe tener para lograr su objetivo? Marcá una opción:

1. Pasión

2. Motivación

3. Liderazgo

4. Compromiso

5. Confianza

6. Humildad

7. Creatividad

8. Experiencia o conocimientos

9. Aversión al riesgo

10. Perseverancia

11. Poseer una idea o visión empresarial clara

12. Capacidad de reconocer oportunidades

13. Otro...

31. ¿Cómo percibís el fracaso en el contexto de una start-up? Marcá una o más opciones:

1. Está muy mitificado

2. Es parte del camino hacia el éxito $X$

3. Sirve como aprendizaje

4. Genera temor

5. No hay lugar para el fracaso

6. Otro...

32. ¿Cuándo considerarías que tu start-up ha tenido éxito? Marcá una o más opciones: 
1. Cuando se haya podido devolver toda la inversión recibida

2. Cuando tiene metas y estrategias establecidas

3. Cuando se estén realizando acciones estratégicas para obtener el resultado deseado

4. Cuando la misma pueda ser sostenible en el tiempo $X$

5. Cuando haya resuelto la necesidad insatisfecha

6. Cuando logre rentabilidad $\mathrm{X}$

7. Cuando logre una ventaja competitiva en el mercado

8. Cuando se logre la retención del $100 \%$ de los usuarios/clientes

9. Cuando logre escalabilidad

10. Cuando pueda salir a la bolsa

11. Otro...

\section{Factores externos de éxito y fracaso}

33. ¿Creés que tu entorno, la sociedad y/o las normas culturales influyeron en la decisión de emprender?

1. Sí X

2. No

3. Tal vez

34. En caso afirmativo, ¿cómo fue que influyeron?

Me incentivaron a hacerlo.

35. ¿Considerás a Argentina un país propicio para emprender?

1. Sí

2. No X

3. Tal vez

36. ¿Qué ventajas encontrás en residir en este país? Marcá una o más opciones:

1. Buen nivel de educación/Grandes talentos

2. Genera la habilidad de adaptarse a cambios constantes

3. La industria de la tecnología es un nicho que no está explotado $\mathrm{X}$

4. El gobierno apoya el emprendedurismo con programas y/o financiamiento 
5. Falta de legislación y regulaciones en la industria de la tecnología

6. Otro...

37. ¿Y desventajas ? Marcá una o más opciones:

1. Falta de recursos

2. Falta de programas de apoyo al emprendedurismo

3. Dificultad de acceder a financiamiento

4. Cambios constantes $\mathrm{X}$

5. Nivel de educación bajo

6. Falta de legislación y regulaciones en la industria de la tecnología

7. Economía inestable $\mathrm{X}$

8. Alto nivel impositivo $X$

9. Otro...

38. ¿Cómo vive la start-up la situación actual del país?

1. No le afecta

2. Le afecta parcialmente $\mathrm{X}$

3. Le afecta por completo

39. ¿Cómo accedieron a los recursos e infraestructura necesaria? ¿Fue dificultoso conseguir lo que necesitaban?

Friends \& Family.

40. ¿Recibieron algún tipo de financiamiento o ayuda externa? ¿Accedieron a algún programa de financiamiento o aceleración?

1. Sí

2. No X

41. En caso afirmativo, ¿de institución/es pública/s o privada/s?

1. Pública

2. Privada

3. Aporte de familia y amigos (FFF) $X$ 
42. ¿Cuál/es considerás que fue/ron las herramientas que te ayudaron a llegar donde estás hoy? Marcá una o más opciones:

1. Financiamiento

2. Educación $\mathrm{X}$

3. Red de contactos $\mathbf{X}$

4. Valores personales

5. Aptitudes personales

6. Haber conseguido el equipo perfecto

7. Otro...

43. ¿Qué opinás sobre las las mujeres emprendedoras? ¿Pensás que tienen las mismas oportunidades que los hombres a la hora de emprender?

No tengo idea.

\section{ENTREVISTA № 9}

Entrevistado: VIRGINIA FAY

\section{Datos del emprendedor y del emprendimiento}

1. ¿Cómo se llama tu start-up?

Tiendup.

2. ¿Qué es lo que ofrece?

1. Producto $X$

2. Servicio

3. ¿De qué se trata?

Plataforma de e-commerce/e-learning.

4. ¿Tiene página web o redes sociales? En caso afirmativo indicar los links de acceso.

$\square$ https://tiendup.com/ 
5. ¿Desde cuándo comenzaste con el emprendimiento?

1. Hace menos de 1 año

2. Entre 1 y 2 años atrás

3. Entre 2 y 3 años atrás

4. Entre 3 y 4 años atrás

5. Entre 4 y 5 años atrás $X$

6. Hace más de cinco años

6. ¿Qué puesto o funciones cumplís dentro de la start-up?

1. CEO/Director Ejecutivo

2. COO/Director General

3. $\mathrm{CMO}$ /Director de Marketing $\mathrm{X}$

4. CFO/Director Financiero

5. CCO/Director de Comunicaciones

6. $\mathrm{ClO} / \mathrm{CTO} /$ Director de Sistemas

7. Desarrollador

8. Diseñador gráfico

9. Otro... X Nuevos negocios

\section{Datos del equipo emprendedor}

7. ¿Quiénes conforman el equipo? Indicar nombre de cada integrante, profesión o área de conocimiento, cargo y edad.

ㅁarío Santandrea (31 años) - Director

$\square \quad$ Eugenia Chielli (28 años) - CTO

$\square \quad$ Mariano Planter (34 años) - Co-director

$\square \quad$ Virginia Fay (36 años) - Marketing y nuevos negocios

8. ¿Cómo fue que se asociaron?

1. Amistad

2. Estrategia

3. Intereses similares 
4. Otro... X Darío, Euge y Marian trabajaron juntos muchos años en una empresa y comenzaron a trabajar en este proyecto. En el año 2015 nos conocimos en el Seminario de Emprendedores de la FCE y completamos el equipo de 4 socixs que somos hoy.

9. ¿Cómo distribuyeron las responsabilidades de cada uno?

1. No están distribuidas, todos hacen un poco de todo

2. Se distribuyeron naturalmente según lo que hacía cada uno

3. Hubo una distribución pautada previamente, por conocimientos/habilidades/área de experiencia de cada uno $\mathrm{X}$

4. Otro...

10. ¿Se mantiene la misma estructura hoy en día?

1. Sí X

2. No

11. ¿Trabajan de manera remota $o$ in situ?

1. Remota

2. In situ X

3. Ambas

\section{Motivaciones}

12. ¿Cuáles fueron las razones por las que decidiste emprender?

1. Necesidad

2. Deseo $X$

3. Oportunidad

4. Otro...

13. ¿Qué te dio ánimo en dar el salto a emprender?

1. Insatisfacción por la industria corporativa $\mathrm{X}$

2. Deseo de ser tu propio jefe/a

3. Convicción

4. Costumbres familiares

5. Otro... X Encontrar un proyecto que me motiva mucho y me desafía todo el tiempo. 


\section{Desarrollo del emprendimiento y planificación estratégica}

14. ¿Tiene el emprendimiento un modelo de negocios definido? En caso afirmativo, ¿de qué tipo es?

1. $\quad$ B2B (business to business)

2. $\quad B 2 C$ (business to consumer)

3. $\mathrm{C} 2 \mathrm{C}$ (consumer to consumer) $\mathrm{X}$

15. ¿Cuál es la forma de monetización?

1. Modelo Freemium (gratuito pero con productos o servicios de pago)

2. Gratis con publicidades o sponsors

3. Modelo Premium (se accede de pago) $\mathrm{X}$

4. Otro...

16. ¿Siempre fue el mismo o tuvo modificaciones?

1. Se mantiene el mismo modelo desde el principio

2. Tuvo modificaciones pero ya no

3. Constantemente se está modificando $X$

17. ¿Cuál es su misión, visión y objetivos?

Usamos el método de gestión OKR: nuestro objetivo principal es escalar.

18. ¿Cómo fue que surgió la idea?

1. Ocio/diversión

2. Detección de una necesidad insatisfecha $\mathbf{X}$

3. Existencia en otro mercado/país, y ganas de aplicarla a otro mercado/país

4. Otro...

19. ¿Se mantuvo tal como se les ocurrió? ¿O fue modificándose?

1. Se mantuvo

2. Se modificó parcialmente

3. Se modificó por completo 
20. ¿Se hizo algún análisis de factibilidad o análisis de mercado previo?

1. Sí $X$

2. No

21. ¿Hay un plan estratégico diseñado?

1. Sí X

2. No

22. ¿Ya se lanzó el producto/servicio?

1. Sí X

2. No

23. Si es así, ¿¿se hizo primero con un producto mínimo viable?

1. Sí, lanzamos lo antes posible con un PMV

2. No, esperamos a tener todo el producto terminado

24. ¿El emprendimiento tiene clientes?

1. Sí X

2. No

25. En caso afirmativo, ¿cómo los obtuvo?

1. Por contactos

2. De boca en boca $\mathbf{X}$

3. Marketing online

4. Marketing offline

5. Otro... X Llamadas en frío.

26. ¿Tiene competidores?

1. Sí

2. No X 
27. En caso afirmativo, ¿qué rol ocupan y cómo influye en la start-up?

\section{Factores internos de éxito y fracaso}

28. ¿¿Tu educación, estudios, experiencia y conocimientos previos fueron relevantes a la hora de lanzarte a emprender?

1. Sí, fue clave $\mathrm{X}$

2. No

3. Algo, pero no tanto

29. ¿Cuáles son los atributos como emprendedor y como persona que destacás en vos, y cuáles tuvieron mayor influencia a la hora de hacer crecer tu start-up? Marcá una o más opciones:

1. Pasión

2. Motivación

3. Liderazgo

4. Compromiso

5. Confianza

6. Humildad

7. Creatividad

8. Experiencia o conocimientos

9. Aversión al riesgo

10. Perseverancia

11. Poseer una idea o visión empresarial clara

12. Capacidad de reconocer oportunidades

13. Otro... X Tendencia al orden, la estructura y la gestión.

30. ¿Cuál creés que es la cualidad más importante que un emprendedor debe tener para lograr su objetivo? Marcá una opción:
1. Pasión
2. Motivación
3. Liderazgo
4. Compromiso
5. Confianza 
6. Humildad

7. Creatividad

8. Experiencia o conocimientos

9. Aversión al riesgo

10. Perseverancia

11. Poseer una idea o visión empresarial clara

12. Capacidad de reconocer oportunidades

13. Otro... X Ser realista.

31. ¿Cómo percibís el fracaso en el contexto de una start-up? Marcá una o más opciones:

1. Está muy mitificado

2. Es parte del camino hacia el éxito

3. Sirve como aprendizaje

4. Genera temor

5. No hay lugar para el fracaso

6. Otro... X Seguir trabajando de lo mismo en un emprendimiento con el mismo tamaño después de diez años.

32. ¿Cuándo considerarías que tu start-up ha tenido éxito? Marcá una o más opciones:

1. Cuando se haya podido devolver toda la inversión recibida

2. Cuando tiene metas y estrategias establecidas

3. Cuando se estén realizando acciones estratégicas para obtener el resultado deseado

4. Cuando la misma pueda ser sostenible en el tiempo

5. Cuando haya resuelto la necesidad insatisfecha

6. Cuando logre rentabilidad

7. Cuando logre una ventaja competitiva en el mercado

8. Cuando se logre la retención del $100 \%$ de los usuarios/clientes

9. Cuando logre escalabilidad

10. Cuando pueda salir a la bolsa

11. Otro... X Cuando funcione sin nosotros. 


\section{Factores externos de éxito y fracaso}

33. ¿Creés que tu entorno, la sociedad y/o las normas culturales influyeron en la decisión de emprender?
1. Sí
2. No
3. Tal vez $\mathrm{X}$

34. En caso afirmativo, ¿cómo fue que influyeron?

35. ¿Considerás a Argentina un país propicio para emprender?

1. Sí

2. NoX

3. Tal vez

36. ¿Qué ventajas encontrás en residir en este país? Marcá una o más opciones:

1. Buen nivel de educación/Grandes talentos

2. Genera la habilidad de adaptarse a cambios constantes

3. La industria de la tecnología es un nicho que no está explotado

4. El gobierno apoya el emprendedurismo con programas y/o financiamiento

5. Falta de legislación y regulaciones en la industria de la tecnología

6. Otro... X Tenés que pensar MUCHO qué estás haciendo.

37. ¿Y desventajas ? Marcá una o más opciones:

1. Falta de recursos

2. Falta de programas de apoyo al emprendedurismo $X$

3. Dificultad de acceder a financiamiento $X$

4. Cambios constantes

5. Nivel de educación bajo

6. Falta de legislación y regulaciones en la industria de la tecnología X

7. Economía inestable

8. Alto nivel impositivo $X$

9. Otro... 
38. ¿Cómo vive la start-up la situación actual del país?

1. No le afecta

2. Le afecta parcialmente

3. Le afecta por completo $\mathrm{X}$

39. ¿Cómo accedieron a los recursos e infraestructura necesaria? ¿Fue dificultoso conseguir lo que necesitaban?

Durante los primeros dos años no necesitamos más que nuestras computadoras. Luego crecimos y alquilamos nuestra oficina actual. No fue difícil porque lo hicimos de a poco y de forma orgánica.

40. ¿Recibieron algún tipo de financiamiento o ayuda externa? ¿Accedieron a algún programa de financiamiento o aceleración?

1. Sí

2. No X

41. En caso afirmativo, ¿de institución/es pública/s o privada/s?

1. Pública

2. Privada

3. Aporte de familia y amigos (FFF)

42. ¿Cuál/es considerás que fue/ron las herramientas que te ayudaron a llegar donde estás hoy? Marcá una o más opciones:

1. Financiamiento

2. Educación $\mathrm{X}$

3. Red de contactos $\mathbf{X}$

4. Valores personales

5. Aptitudes personales

6. Haber conseguido el equipo perfecto

7. Otro...

43. ¿Qué opinás sobre las las mujeres emprendedoras? ¿Pensás que tienen las mismas oportunidades que los hombres a la hora de emprender? 
No. No creo que tengamos las mismas oportunidades en ningún terreno. Para nosotras siquiera trabajar supone otros retos y las que somos mamás, más aún. No hay políticas de Estado que nos igualen laboralmente con los hombres y culturalmente aún batallamos para demostrarle al resto ( $y$ a nosotras) que sabemos/queremos/podemos.

Me parece excelente esta última pregunta, celebro! De hecho, uno de mis objetivos este año es participar de forma activa en la comunidad de negocios local para aportar más diversidad e incentivar a otras mujeres a hacer lo mismo. Me parece fundamental y me motiva mucho formar parte de ese cambio.

\section{ENTREVISTA № 10}

Entrevistado: MARIO AlZA

\section{Datos del emprendedor y del emprendimiento}

1. ¿Cómo se llama tu start-up?

Intriper.

2. ¿Qué es lo que ofrece?

1. Producto

2. Servicio $\mathrm{X}$

3. ¿De qué se trata?

Medio, agencia de marketing online y productora asociada a viajes.

4. ¿Tiene página web o redes sociales? En caso afirmativo indicar los links de acceso.

$\square \quad$ https://intriper.com

5. ¿Desde cuándo comenzaste con el emprendimiento?

1. Hace menos de 1 año

2. Entre 1 y 2 años atrás

3. Entre 2 y 3 años atrás

4. Entre 3 y 4 años atrás

5. Entre 4 y 5 años atrás $X$ 
6. Hace más de cinco años

6. ¿Qué puesto o funciones cumplís dentro de la start-up?

1. CEO/Director Ejecutivo

2. COO/Director General

3. $\mathrm{CMO} /$ Director de Marketing

4. CFO/Director Financiero

5. CCO/Director de Comunicaciones

6. $\mathrm{ClO} / \mathrm{CTO} /$ Director de Sistemas

7. Desarrollador

8. Diseñador gráfico

9. Otro... X Director creativo.

\section{Datos del equipo emprendedor}

7. ¿Quiénes conforman el equipo? Indicar nombre de cada integrante, profesión o área de conocimiento, cargo y edad.

Mario Alza, lic. turismo, marketing.

Equipo de 10 personas: marketing, video editor, diseño gráfico, editores, ilustradores, redactores.

8. ¿Cómo fue que se asociaron?

1. Amistad

2. Estrategia

3. Intereses similares

4. Otro... X Nos conocíamos de otro trabajo.

9. ¿Cómo distribuyeron las responsabilidades de cada uno?

1. No están distribuidas, todos hacen un poco de todo

2. Se distribuyeron naturalmente según lo que hacía cada uno

3. Hubo una distribución pautada previamente, por conocimientos/habilidades/área de experiencia de cada uno $X$

4. Otro... 
10. ¿Se mantiene la misma estructura hoy en día?

1. Sí

2. No X

11. ¿Trabajan de manera remota o in situ?

1. Remota

2. In situ $\mathrm{X}$

3. Ambas

\section{Motivaciones}

12. ¿Cuáles fueron las razones por las que decidiste emprender?

1. Necesidad

2. Deseo

3. Oportunidad $\mathrm{X}$

4. Otro...

13. ¿Qué te dio ánimo en dar el salto a emprender?

1. Insatisfacción por la industria corporativa

2. Deseo de ser tu propio jefe/a

3. Convicción

4. Costumbres familiares $\mathbf{X}$

5. Otro...

\section{Desarrollo del emprendimiento y planificación estratégica}

14. ¿'Tiene el emprendimiento un modelo de negocios definido? En caso afirmativo, ¿de qué tipo es?

1. $\quad$ B2B (business to business)

2. $\quad B 2 C$ (business to consumer) $\mathrm{X}$

3. $\mathrm{C} 2 \mathrm{C}$ (consumer to consumer)

15. ¿Cuál es la forma de monetización?

1. Modelo Freemium (gratuito pero con productos o servicios de pago) $\mathrm{X}$ 
2. Gratis con publicidades o sponsors

3. Modelo Premium (se accede de pago)

4. Otro...

16. ¿Siempre fue el mismo o tuvo modificaciones?

1. Se mantiene el mismo modelo desde el principio

2. Tuvo modificaciones pero ya no

3. Constantemente se está modificando $\mathrm{X}$

17. ¿Cuál es su misión, visión y objetivos?

No están escritos, pero ser uno de los medios de viajes más influyentes en LATAM.

18. ¿Cómo fue que surgió la idea?

1. Ocio/diversión

2. Detección de una necesidad insatisfecha $\mathbf{X}$

3. Existencia en otro mercado/país, y ganas de aplicarla a otro mercado/país $\mathbf{X}$

4. Otro...

19. ¿Se mantuvo tal como se les ocurrió? ¿O fue modificándose?

1. Se mantuvo

2. Se modificó parcialmente

3. Se modificó por completo

20. ¿Se hizo algún análisis de factibilidad o análisis de mercado previo?

1. Sí X

2. No

21. ¿Hay un plan estratégico diseñado?

1. Sí

2. No X

22. ¿Ya se lanzó el producto/servicio? 

1. Sí $X$
2. No

23. Sí es así, ¿¿se hizo primero con un producto mínimo viable?

1. Sí, lanzamos lo antes posible con un PMV

2. No, esperamos a tener todo el producto terminado

24. ¿El emprendimiento tiene clientes?

1. Sí X

2. No

25. En caso afirmativo, ¿cómo los obtuvo?

1. Por contactos

2. De boca en boca

3. Marketing online

4. Marketing offline $X$

5. Otro... X Conocimiento de la marca.

26. ¿Tiene competidores?

1. Sí X

2. No

27. En caso afirmativo, ¿qué rol ocupan y cómo influye en la start-up?

\section{Factores internos de éxito y fracaso}

28. ¿Tu educación, estudios, experiencia y conocimientos previos fueron relevantes a la hora de lanzarte a emprender?

1. Sí, fue clave $\mathbf{X}$

2. No

3. Algo, pero no tanto 
29. ¿Cuáles son los atributos como emprendedor y como persona que destacás en vos, y cuáles tuvieron mayor influencia a la hora de hacer crecer tu start-up? Marcá una o más opciones:

1. Pasión

2. Motivación

3. Liderazgo

4. Compromiso

5. Confianza X

6. Humildad X

7. Creatividad

8. Experiencia o conocimientos

9. Aversión al riesgo

10. Perseverancia

11. Poseer una idea o visión empresarial clara

12. Capacidad de reconocer oportunidades

13. Otro... X Ser crítico, analítico, un poco atrevido, tener confianza, hablar con gente, saber que no sabés todo y que tenés que delegar y confiar, no tener miedo a hacer y aprender cosas nuevas.

30. ¿Cuál creés que es la cualidad más importante que un emprendedor debe tener para lograr su objetivo? Marcá una opción:

1. Pasión

2. Motivación

3. Liderazgo

4. Compromiso

5. Confianza

6. Humildad

7. Creatividad

8. Experiencia o conocimientos

9. Aversión al riesgo

10. Perseverancia

11. Poseer una idea o visión empresarial clara

12. Capacidad de reconocer oportunidades 
13. Otro...

31. ¿Cómo percibís el fracaso en el contexto de una start-up? Marcá una o más opciones:

1. Está muy mitificado

2. Es parte del camino hacia el éxito

3. Sirve como aprendizaje

4. Genera temor

5. No hay lugar para el fracaso

6. Otro... X Rendirse en el primero, segundo, tercero, cuarto, quinto...

32. ¿Cuándo considerarías que tu start-up ha tenido éxito? Marcá una o más opciones:

1. Cuando se haya podido devolver toda la inversión recibida

2. Cuando tiene metas y estrategias establecidas

3. Cuando se estén realizando acciones estratégicas para obtener el resultado deseado

4. Cuando la misma pueda ser sostenible en el tiempo

5. Cuando haya resuelto la necesidad insatisfecha

6. Cuando logre rentabilidad

7. Cuando logre una ventaja competitiva en el mercado

8. Cuando se logre la retención del $100 \%$ de los usuarios/clientes

9. Cuando logre escalabilidad

10. Cuando pueda salir a la bolsa

11. Otro... X Cuando te hace feliz lo que hacés todos los días (y si podés darle trabajo a alguien, mucho más).

\section{Factores externos de éxito y fracaso}

33. ¿Creés que tu entorno, la sociedad y/o las normas culturales influyeron en la decisión de emprender?
1. Sí
2. No
3. Tal vez $\mathbf{X}$

34. En caso afirmativo, ¿cómo fue que influyeron? 
35. ¿Considerás a Argentina un país propicio para emprender?

1. Sí

2. No $X$

3. Tal vez

36. ¿Qué ventajas encontrás en residir en este país? Marcá una o más opciones:

1. Buen nivel de educación/Grandes talentos $X$

2. Genera la habilidad de adaptarse a cambios constantes

3. La industria de la tecnología es un nicho que no está explotado

4. El gobierno apoya el emprendedurismo con programas y/o financiamiento

5. Falta de legislación y regulaciones en la industria de la tecnología

6. Otro...

37. ¿Y desventajas ? Marcá una o más opciones:

1. Falta de recursos

2. Falta de programas de apoyo al emprendedurismo

3. Dificultad de acceder a financiamiento

4. Cambios constantes

5. Nivel de educación bajo

6. Falta de legislación y regulaciones en la industria de la tecnología

7. Economía inestable

8. Alto nivel impositivo

9. Otro...

38. ¿Cómo vive la start-up la situación actual del país?

1. No le afecta

2. Le afecta parcialmente $\mathbf{X}$

3. Le afecta por completo

39. ¿Cómo accedieron a los recursos e infraestructura necesaria? ¿Fue dificultoso conseguir lo que necesitaban?

Ahorros y reinversión de ingresos. 
40. ¿Recibieron algún tipo de financiamiento o ayuda externa? ¿Accedieron a algún programa de financiamiento o aceleración?

1. Sí

2. No X

41. En caso afirmativo, ¿de institución/es pública/s o privada/s?

1. Pública

2. Privada

3. Aporte de familia y amigos (FFF)

42. ¿Cuál/es considerás que fue/ron las herramientas que te ayudaron a llegar donde estás hoy? Marcá una o más opciones

1. Financiamiento

2. Educación $X$

3. Red de contactos $\mathbf{X}$

4. Valores personales

5. Aptitudes personales

6. Haber conseguido el equipo perfecto

7. Otro...

43. ¿Qué opinás sobre las las mujeres emprendedoras? ¿Pensás que tienen las mismas oportunidades que los hombres a la hora de emprender?

Por suerte, creo que van en camino de igualdad de oportunidades. Lamentablemente, en algunos sectores, falta aún recorrer camino.

\section{ENTREVISTA № 11}

Entrevistado: LEANDRO CAAMAÑO

\section{Datos del emprendedor y del emprendimiento}

1. ¿Cómo se llama tu start-up?

Culbot 
2. ¿Qué es lo que ofrece?

1. Producto $\mathrm{X}$

2. Servicio

3. ¿De qué se trata?

Es un aparato electrónico para el control y monitoreo de cultivos indoor que se controla por medio de una app, y que además detecta cuándo las plantas necesitan agua y riega automáticamente.

4. ¿Tiene página web o redes sociales? En caso afirmativo indicar los links de acceso.

$\square \quad$ www.culbot.com

$\square$ @culbot

5. ¿Desde cuándo comenzaste con el emprendimiento?

1. Hace menos de 1 año

2. Entre 1 y 2 años atrás

3. Entre 2 y 3 años atrás $X$

4. Entre 3 y 4 años atrás

5. Entre 4 y 5 años atrás

6. Hace más de cinco años

6. ¿Qué puesto o funciones cumplís dentro de la start-up?

1. CEO/Director Ejecutivo

2. COO/Director General

3. $\mathrm{CMO} /$ Director de Marketing

4. CFO/Director Financiero

5. $\mathrm{CCO} /$ Director de Comunicaciones

6. $\mathrm{ClO} / \mathrm{CTO} /$ Director de Sistemas

7. Desarrollador

8. Diseñador gráfico

9. Otro... X Líder de proyecto. 


\section{Datos del equipo emprendedor}

7. ¿Quiénes conforman el equipo? Indicar nombre de cada integrante, profesión o área de conocimiento, cargo y edad.

Leandro Caamaño, arquitecto, lider de equipo, hombre, 37 años.

$\square$ Jorge Palacio, ingeniero electrónico, hardware y encargado de software, hombre, 37 años.

- Martín Gutierrez, licenciado en administración, finanzas, contabilidad, plan de negocio, hombre, 43 años.

8. ¿Cómo fue que se asociaron?

1. Amistad

2. Estrategia $\mathrm{X}$

3. Intereses similares

4. Otro... X Leandro participó de Usina de Ideas y Martín fue mentor, luego se le propuso ser parte del equipo de trabajo, y luego incorporamos a Jorge por ser conocido desde muchos años de Leandro y sus conocimientos profesionales eran lo que estábamos necesitando.

9. ¿Cómo distribuyeron las responsabilidades de cada uno?

1. No están distribuidas, todos hacen un poco de todo

2. Se distribuyeron naturalmente según lo que hacía cada uno $X$

3. Hubo una distribución pautada previamente, por conocimientos/habilidades/área de experiencia de cada uno

4. Otro...

10. ¿Se mantiene la misma estructura hoy en día?

1. Sí X

2. No

11. ¿Trabajan de manera remota o in situ?

1. Remota

2. In situ

3. Ambas $\mathrm{X}$ 


\section{Motivaciones}

12. ¿Cuáles fueron las razones por las que decidiste emprender?

1. Necesidad

2. Deseo $X$

3. Oportunidad

4. Otro...

13. ¿Qué te dio ánimo en dar el salto a emprender?

1. Insatisfacción por la industria corporativa

2. Deseo de ser tu propio jefe/a $X$

3. Convicción

4. Costumbres familiares

5. Otro...

\section{Desarrollo del emprendimiento y planificación estratégica}

14. ¿Tiene el emprendimiento un modelo de negocios definido? En caso afirmativo, ¿de qué tipo es?

1. $\quad B 2 B$ (business to business) $\mathrm{X}$

2. $\mathrm{B} 2 \mathrm{C}$ (business to consumer) $\mathrm{X}$

3. $\mathrm{C} 2 \mathrm{C}$ (consumer to consumer)

15. ¿Cuál es la forma de monetización?

1. Modelo Freemium (gratuito pero con productos o servicios de pago)

2. Gratis con publicidades o sponsors

3. Modelo Premium (se accede de pago)

4. Otro... X El modelo de negocio es b2b y b2c, venta del producto.

16. ¿Siempre fue el mismo o tuvo modificaciones?

1. Se mantiene el mismo modelo desde el principio $\mathbf{X}$

2. Tuvo modificaciones pero ya no

3. Constantemente se está modificando 
17. ¿Cuál es su misión, visión y objetivos?

Dotar de loT a gabinetes o ambientes de cultivo indoor, pudiendo monitorear y realizar modificaciones de parámetros para el cultivo desde cualquier lugar del mundo en cualquier momento siempre y cuando se tenga acceso a internet. Queremos posicionarnos como referentes para dotar de loT a bajo costo a cualquier amante del cultivo y de manera muy simple. Nuestro objetivo es terminar el desarrollo, hacer que funcione e intentar vender la empresa para poder trabajar en otros proyectos nuevos.

18. ¿Cómo fue que surgió la idea?

1. Ocio/diversión

2. Detección de una necesidad insatisfecha $\mathbf{X}$

3. Existencia en otro mercado/país, y ganas de aplicarla a otro mercado/país

4. Otro...

19. ¿Se mantuvo tal como se les ocurrió? ¿O fue modificándose?

1. Se mantuvo

2. Se modificó parcialmente

3. Se modificó por completo $\mathrm{X}$

20. ¿Se hizo algún análisis de factibilidad o análisis de mercado previo?

1. Sí $\mathrm{X}$

2. No

21. ¿Hay un plan estratégico diseñado?

1. Sí

2. No X

22. ¿Ya se lanzó el producto/servicio?

1. Sí

2. No X

23. Si es así, ¿se hizo primero con un producto mínimo viable?

1. Sí, lanzamos lo antes posible con un PMV $\mathrm{X}$ 
2. No, esperamos a tener todo el producto terminado

24. ¿El emprendimiento tiene clientes?

1. Sí

2. No X

25. En caso afirmativo, ¿cómo los obtuvo?

1. Por contactos

2. De boca en boca

3. Marketing online

4. Marketing offline

5. Otro...

26. ¿Tiene competidores?

1. Sí $X$

2. No

27. En caso afirmativo, ¿qué rol ocupan y cómo influye en la start-up?

Hay algunos similares en Argentina que no se desarrollaron demasiado o no tienen una gran campaña de marketing. En el exterior hay algunos pocos controladores de cultivos muy caros y para el cultivo industrial.

\section{Factores internos de éxito y fracaso}

28. ¿Tu educación, estudios, experiencia y conocimientos previos fueron relevantes a la hora de lanzarte a emprender?

1. Sí, fue clave

2. No

3. Algo, pero no tanto $\mathrm{X}$

29. ¿Cuáles son los atributos como emprendedor y como persona que destacás en vos, y cuáles tuvieron mayor influencia a la hora de hacer crecer tu start-up? Marcá una o más opciones:

1. Pasión 
2. Motivación

3. Liderazgo

4. Compromiso

5. Confianza

6. Humildad

7. Creatividad

8. Experiencia o conocimientos

9. Aversión al riesgo

10. Perseverancia $\mathbf{X}$

11. Poseer una idea o visión empresarial clara

12. Capacidad de reconocer oportunidades

13. Otro... X La determinación, el generar grupos de trabajo efectivos, coordinar todas las áreas y guiar el rumbo. Soy honesto y sincero, y trato de ser justo para cualquier decisión o división sin perjudicar ni favorecer a ninguno sobre otro.

30. ¿Cuál creés que es la cualidad más importante que un emprendedor debe tener para lograr su objetivo? Marcá una opción:

1. Pasión

2. Motivación

3. Liderazgo

4. Compromiso

5. Confianza

6. Humildad

7. Creatividad

8. Experiencia o conocimientos

9. Aversión al riesgo

10. Perseverancia

11. Poseer una idea o visión empresarial clara

12. Capacidad de reconocer oportunidades

13. Otro... X Determinación, perseverancia, convicción y tener los pies sobre la tierra cuando haga falta. 
31. ¿Cómo percibís el fracaso en el contexto de una start-up? Marcá una o más opciones:

1. Esta muy mitificado

2. Es parte del camino hacia el éxito $X$

3. Sirve como aprendizaje $\mathbf{X}$

4. Genera temor

5. No hay lugar para el fracaso

6. Otro...

32. ¿Cuándo considerarías que tu start-up ha tenido éxito? Marcá una o más opciones:

1. Cuando se haya podido devolver toda la inversión recibida

2. Cuando tiene metas y estrategias establecidas

3. Cuando se estén realizando acciones estratégicas para obtener el resultado deseado

4. Cuando la misma pueda ser sostenible en el tiempo

5. Cuando haya resuelto la necesidad insatisfecha

6. Cuando logre rentabilidad

7. Cuando logre una ventaja competitiva en el mercado

8. Cuando se logre la retención del $100 \%$ de los usuarios/clientes

9. Cuando logre escalabilidad

10. Cuando pueda salir a la bolsa

11. Otro... X No creo tener éxito aún con la start-up, estamos trabajando para lograrlo, pero fue muy gratificante cuando la gente inversora me llamó para confirmarme que les interesaba el proyecto y el equipo de trabajo, y que iban a sumarse a trabajar con nosotros.

\section{Factores externos de éxito y fracaso}

33. ¿Creés que tu entorno, la sociedad y/o las normas culturales influyeron en la decisión de emprender?

1. Sí

2. No

3. Tal vez $\mathrm{X}$

34. En caso afirmativo, ¿cómo fue que influyeron? 
35. ¿Considerás a Argentina un país propicio para emprender?

1. Sí $X$

2. No

3. Tal vez

36. ¿Qué ventajas encontrás en residir en este país? Marcá una o más opciones:

1. Buen nivel de educación/Grandes talentos

2. Genera la habilidad de adaptarse a cambios constantes $X$

3. La industria de la tecnología es un nicho que no está explotado

4. El gobierno apoya el emprendedurismo con programas y/o financiamiento

5. Falta de legislación y regulaciones en la industria de la tecnología

6. Otro...

37. ¿Y desventajas ? Marcá una o más opciones:

1. Falta de recursos

2. Falta de programas de apoyo al emprendedurismo

3. Dificultad de acceder a financiamiento $X$

4. Cambios constantes

5. Nivel de educación bajo

6. Falta de legislación y regulaciones en la industria de la tecnología

7. Economía inestable

8. Alto nivel impositivo

9. Otro...

38. ¿Cómo vive la start-up la situación actual del país?

1. No le afecta $X$

2. Le afecta parcialmente

3. Le afecta por completo

39. ¿Cómo accedieron a los recursos e infraestructura necesaria? ¿Fue dificultoso conseguir lo que necesitaban? 
Arrancamos experimentando, haciendo prototipos muy económicos, y luego a tres amigos distintos les sedujo el proyecto y nos dieron 40 mil pesos cada uno, y con esa plata hicimos malabares para terminar el desarrollo y hacer pruebas y prototipos más cercanos al producto final.

40. ¿Recibieron algún tipo de financiamiento o ayuda externa? ¿Accedieron a algún programa de financiamiento o aceleración?
1. Sí X
2. No

41. En caso afirmativo, ¿de institución/es pública/s o privada/s?

1. Pública

2. Privada

3. Aporte de familia y amigos (FFF) $X$

42. ¿Cuál/es considerás que fue/ron las herramientas que te ayudaron a llegar donde estás hoy? Marcá una o más opciones:

1. Financiamiento

2. Educación

3. Red de contactos

4. Valores personales

5. Aptitudes personales

6. Haber conseguido el equipo perfecto $X$

7. Otro... X La perseverancia y confiar en el proyecto incluso cuando hubo gente que abandonó el proyecto o en un momento que estuvo medio pausado y sin avances significativos.

43. ¿Qué opinás sobre las las mujeres emprendedoras? ¿Pensás que tienen las mismas oportunidades que los hombres a la hora de emprender?

No creo que exista alguna diferencia, depende de las capacidades de la persona y la actitud. 


\section{ENTREVISTA № 12}

\section{Datos del emprendedor y del emprendimiento}

1. ¿Cómo se llama tu start-up?

Topic.

2. ¿Qué es lo que ofrece?

1. Producto

2. Servicio $X$

3. ¿De qué se trata?

Servicios de marketing digital.

4. ¿Tiene página web o redes sociales? En caso afirmativo indicar los links de acceso.

$\square \quad$ www.topic.com.ar

$\square \quad$ www.facebook.com/topicmarketing

5. ¿Desde cuándo comenzaste con el emprendimiento?

1. Hace menos de 1 año

2. Entre 1 y 2 años atrás

3. Entre 2 y 3 años atrás $X$

4. Entre 3 y 4 años atrás

5. Entre 4 y 5 años atrás

6. Hace más de cinco años

6. ¿Qué puesto o funciones cumplís dentro de la start-up?

1. CEO/Director Ejecutivo

2. $\mathrm{COO} /$ Director General

3. $\mathrm{CMO} /$ Director de Marketing

4. CFO/Director Financiero

5. $\mathrm{CCO} /$ Director de Comunicaciones 
6. $\mathrm{ClO} / \mathrm{CTO} /$ Director de Sistemas

7. Desarrollador

8. Diseñador gráfico

9. Otro... X Director Comercial.

\section{Datos del equipo emprendedor}

7. ¿Quiénes conforman el equipo? Indicar nombre de cada integrante, profesión o área de conocimiento, cargo y edad.

Enzo Chiaffitelli: Lic. en Administración.

$\square \quad$ Guido Zaina: Lic. y profesor en Multimedios.

ㄱanco Lasalvia: Publicidad.

- Emiliano Navarro: Diseño y comunicación visual.

Adriana Quispe: Marketing digital (S21).

$\square$ Belén Castro: Publicidad Mg en Marketing Internacional.

ㄱariana Bobbio: Periodista.

8. ¿Cómo fue que se asociaron?

1. Amistad X

2. Estrategia

3. Intereses similares $\mathbf{X}$

4. Otro...

9. ¿Cómo distribuyeron las responsabilidades de cada uno?

1. No están distribuidas, todos hacen un poco de todo $X$

2. Se distribuyeron naturalmente según lo que hacía cada uno

3. Hubo una distribución pautada previamente, por conocimientos/habilidades/área de experiencia de cada uno

4. Otro...

10. ¿Se mantiene la misma estructura hoy en día?

1. Sí

2. No X 
11. ¿Trabajan de manera remota o in situ?

1. Remota

2. In situ $\mathrm{X}$

3. Ambas

\section{Motivaciones}

12. ¿Cuáles fueron las razones por las que decidiste emprender?

1. Necesidad

2. Deseo $X$

3. Oportunidad $\mathrm{X}$

4. Otro...

13. ¿Qué te dio ánimo en dar el salto a emprender?

1. Insatisfacción por la industria corporativa X

2. Deseo de ser tu propio jefe/a $X$

3. Convicción $\mathrm{X}$

4. Costumbres familiares

5. Otro...

\section{Desarrollo del emprendimiento y planificación estratégica}

14. ¿Tiene el emprendimiento un modelo de negocios definido? En caso afirmativo, ¿De qué tipo es?

1. $\quad B 2 B$ (business to business) $X$

2. B2C (business to consumer)

3. $\mathrm{C} 2 \mathrm{C}$ (consumer to consumer)

15. ¿Cuál es la forma de monetización?

1. Modelo Freemium (gratuito pero con productos o servicios de pago)

2. Gratis con publicidades o sponsors

3. Modelo Premium (se accede de pago) $\mathrm{X}$

4. Otro... 
16. ¿Siempre fue el mismo o tuvo modificaciones?

1. Se mantiene el mismo modelo desde el principio $\mathbf{X}$

2. Tuvo modificaciones pero ya no

3. Constantemente se está modificando

17. ¿Cuál es su misión, visión y objetivos?

$\square$ Visión y misión: Todavía no hemos podido desarrollar una que nos quepa como organización, estamos trabajando en eso. Si quieren ofrecer ayuda, bienvenida :)

Sin buena definición, medianamente sabemos que queremos apuntar a hacer marketing digital con aplicación de tecnología, apuntado a performance (marketing de resultados).

$\square$ Objetivos: Simplemente objetivos operativos, estamos en búsqueda de la dirección.

18. ¿Cómo fue que surgió la idea?

1. Ocio/diversión

2. Detección de una necesidad insatisfecha $\mathbf{X}$

3. Existencia en otro mercado/país, y ganas de aplicarla a otro mercado/país $\mathbf{X}$

4. Otro...

19. ¿Se mantuvo tal como se les ocurrió? ¿¿ fue modificándose?

1. Se mantuvo

2. Se modificó parcialmente

3. Se modificó por completo $\mathrm{X}$

20. ¿Se hizo algún análisis de factibilidad o análisis de mercado previo?

1. Sí X

2. No

21. ¿Hay un plan estratégico diseñado?

1. Sí

2. No X 
22. ¿YYa se lanzó el producto/servicio?

1. Sí $X$

2. No

23. Si es así, ¿¿se hizo primero con un producto mínimo viable?

1. Sí, lanzamos lo antes posible con un PMV $X$

2. No, esperamos a tener todo el producto terminado

24. ¿El emprendimiento tiene clientes?

1. Sí X

2. No

25. En caso afirmativo, ¿cómo los obtuvo?

1. Por contactos $\mathrm{X}$

2. De boca en boca $X$

3. Marketing online $\mathbf{X}$

4. Marketing offline $X$

5. Otro...

26. ¿Tiene competidores?

1. Sí X

2. No

27. En caso afirmativo, ¿qué rol ocupan y cómo influye en la start-up?

L Locales: tenemos muchos con servicios similares, muy pocos con el nivel y tamaño nuestro.

$\square$ Nacional: tenemos competencia, pero el mercado es grande por lo cual no influye negativamente.

Para sumar a esto, hay empresas como Mercado Libre, Leadaki y Gurú, que amenazan con tomar el control de gran parte del mercado. 
28. ¿Tu educación, estudios, experiencia y conocimientos previos fueron relevantes a la hora de lanzarte a emprender?

1. Sí, fue clave

2. No

3. Algo, pero no tanto $\mathrm{X}$

29. ¿Cuáles son los atributos como emprendedor y como persona que destacás en vos, y cuáles tuvieron mayor influencia a la hora de hacer crecer tu start-up? Marcá una o más opciones:

1. Pasión $\mathrm{X}$

2. Motivación $\mathrm{X}$

3. Liderazgo

4. Compromiso $\mathrm{X}$

5. Confianza

6. Humildad

7. Creatividad

8. Experiencia o conocimientos

9. Aversión al riesgo $X$

10. Perseverancia $\mathbf{X}$

11. Poseer una idea o visión empresarial clara

12. Capacidad de reconocer oportunidades

13. Otro...

30. ¿Cuál creés que es la cualidad más importante que un emprendedor debe tener para lograr su objetivo? Marcá una opción:

1. Pasión

2. Motivación

3. Liderazgo

4. Compromiso

5. Confianza

6. Humildad

7. Creatividad

8. Experiencia o conocimientos 
9. Aversión al riesgo

10. Perseverancia $\mathbf{X}$

11. Poseer una idea o visión empresarial clara

12. Capacidad de reconocer oportunidades

13. Otro...

31. ¿Cómo percibís el fracaso en el contexto de una start-up? Marcá una o más opciones:

1. Está muy mitificado

2. Es parte del camino hacia el éxito $X$

3. Sirve como aprendizaje $\mathrm{X}$

4. Genera temor

5. No hay lugar para el fracaso

6. Otro...

32. ¿Cuándo considerarías que tu start-up ha tenido éxito? Marcá una o más opciones:

1. Cuando se haya podido devolver toda la inversión recibida

2. Cuando tiene metas y estrategias establecidas

3. Cuando se estén realizando acciones estratégicas para obtener el resultado deseado X

4. Cuando la misma pueda ser sostenible en el tiempo $X$

5. Cuando haya resuelto la necesidad insatisfecha

6. Cuando logre rentabilidad

7. Cuando logre una ventaja competitiva en el mercado

8. Cuando se logre la retención del $100 \%$ de los usuarios/clientes

9. Cuando logre escalabilidad $\mathrm{X}$

10. Cuando pueda salir a la bolsa

11. Otro...

Factores externos de éxito y fracaso

33. ¿Creés que tu entorno, la sociedad y/o las normas culturales influyeron en la decisión de emprender?

1. Sí X

2. No 
3. Tal vez

34. En caso afirmativo, ¿cómo fue que influyeron?

Necesidad local insatisfecha vs necesidad cubierta en el exterior.

35. ¿Considerás a Argentina un país propicio para emprender?

1. Sí X

2. No

3. Tal vez

36. ¿Qué ventajas encontrás en residir en este país? Marcá una o más opciones:

1. Buen nivel de educación/Grandes talentos

2. Genera la habilidad de adaptarse a cambios constantes

3. La industria de la tecnología es un nicho que no está explotado $\mathrm{X}$

4. El gobierno apoya el emprendedurismo con programas y/o financiamiento

5. Falta de legislación y regulaciones en la industria de la tecnología

6. Otro...

37. ¿Y desventajas ? Marcá una o más opciones:

1. Falta de recursos $\mathrm{X}$

2. Falta de programas de apoyo al emprendedurismo

3. Dificultad de acceder a financiamiento

4. Cambios constantes $\mathrm{X}$

5. Nivel de educación bajo $\mathrm{X}$

6. Falta de legislación y regulaciones en la industria de la tecnología

7. Economía inestable $X$

8. Alto nivel impositivo $X$

9. Otro... X Problemas para contratar empleados, alto riesgo.

38. ¿Cómo vive la start-up la situación actual del país?

1. No le afecta

2. Le afecta parcialmente

3. Le afecta por completo $\mathrm{X}$ 
39. ¿Cómo accedieron a los recursos e infraestructura necesaria? ¿Fue dificultoso conseguir lo que necesitaban?

Paso a paso, crecimos a partir de clientes, tuvimos y tenemos cero deuda.

40. ¿Recibieron algún tipo de financiamiento o ayuda externa? ¿Accedieron a algún programa de financiamiento o aceleración?

1. Sí

2. No X

41. En caso afirmativo, ¿de institución/es pública/s o privada/s?

1. Pública

2. Privada

3. Aporte de familia y amigos (FFF)

42. ¿Cuál/es considerás que fue/ron las herramientas que te ayudaron a llegar donde estás hoy? Marcá una o más opciones:

1. Financiamiento

2. Educación $\mathrm{X}$

3. Red de contactos $\mathbf{X}$

4. Valores personales $\mathrm{X}$

5. Aptitudes personales $X$

6. Haber conseguido el equipo perfecto $X$

7. Otro...

43. ¿Qué opinás sobre las las mujeres emprendedoras? ¿Pensás que tienen las mismas oportunidades que los hombres a la hora de emprender?

Sí y no, el lugar está, pero falta motivación a las mismas para que sepan que tienen y se merecen como cualquier otra persona ese lugar. 


\section{ANEXo 3: CLASIFICACIÓN DE RESULTADOS DE ENTREVISTAS A EMPRENDEDORES}

\section{Datos del emprendedor y del emprendimiento}

1. ¿Cómo se llama tu start-up?

\begin{tabular}{|l|}
\hline Positrip \\
\hline Babel Viajes \\
\hline AccessHoy \\
\hline Go4Clic \\
\hline Mipublicidad.com.ar \\
\hline Está Reservado \\
\hline Celerative \\
\hline Sherlock \\
\hline Tiendup \\
\hline intriper \\
\hline Culbot \\
\hline Topic \\
\hline
\end{tabular}

CUADRO 2

Start-ups de la muestra

Fuente: Elaboración propia

2. ¿Qué es lo que ofrece?

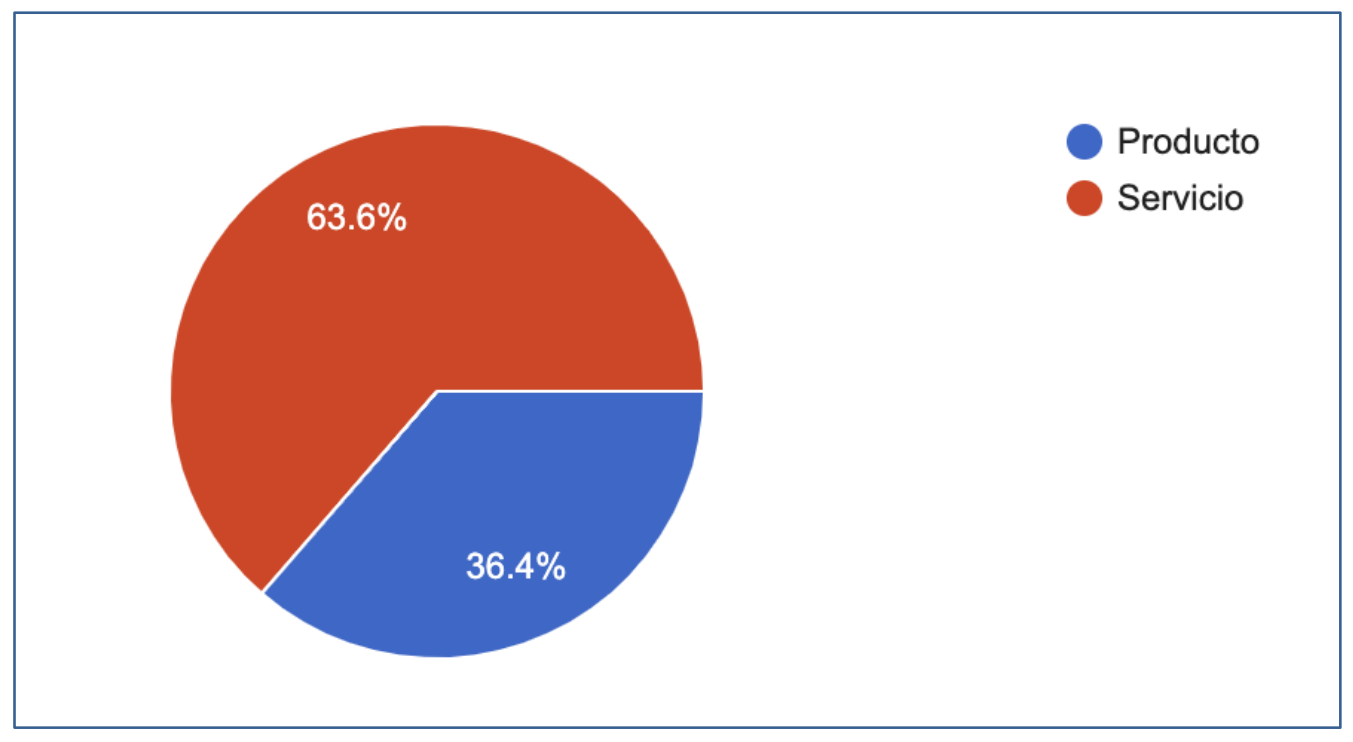

FIGURA 33

Fuente: Elaboración propia 
3. ¿De qué se trata?

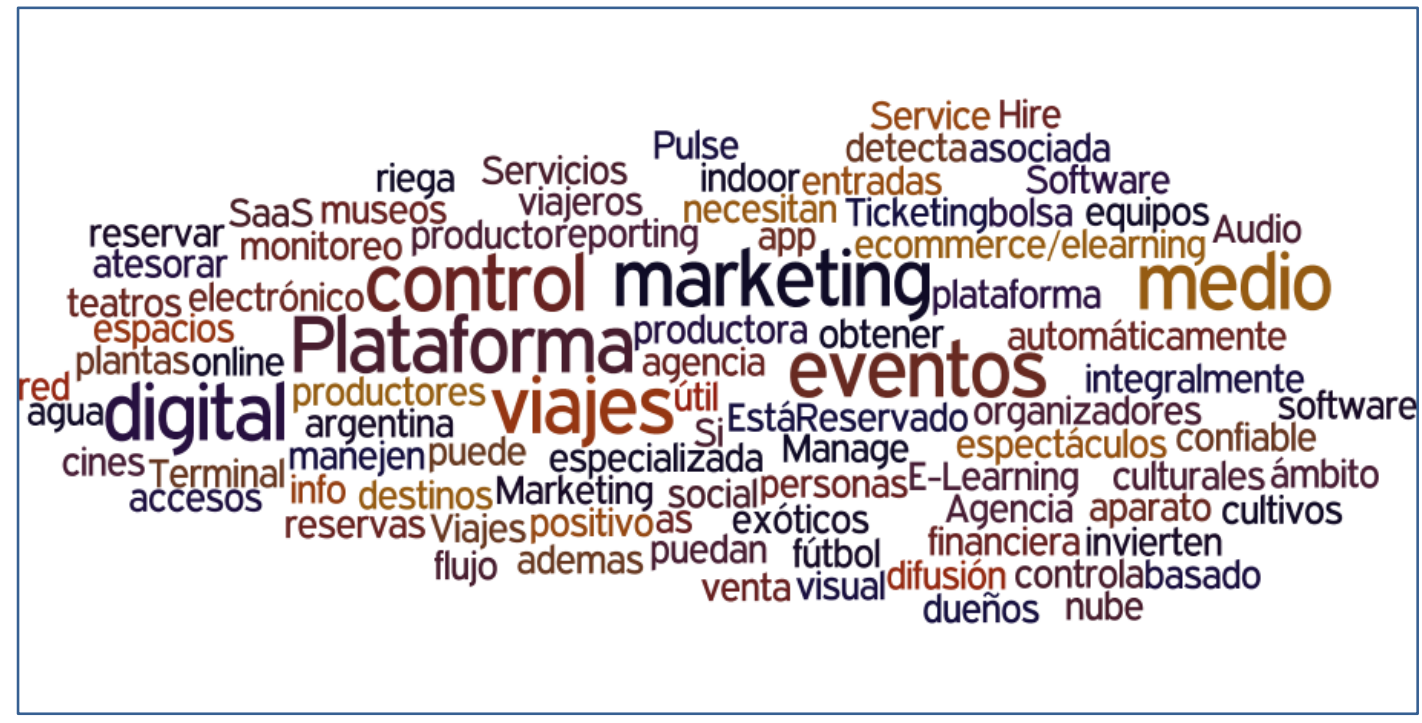

FIGURA 34

Fuente: Elaboración propia

4. ¿Tiene página web o redes sociales? En caso afirmativo indicar los links de acceso.

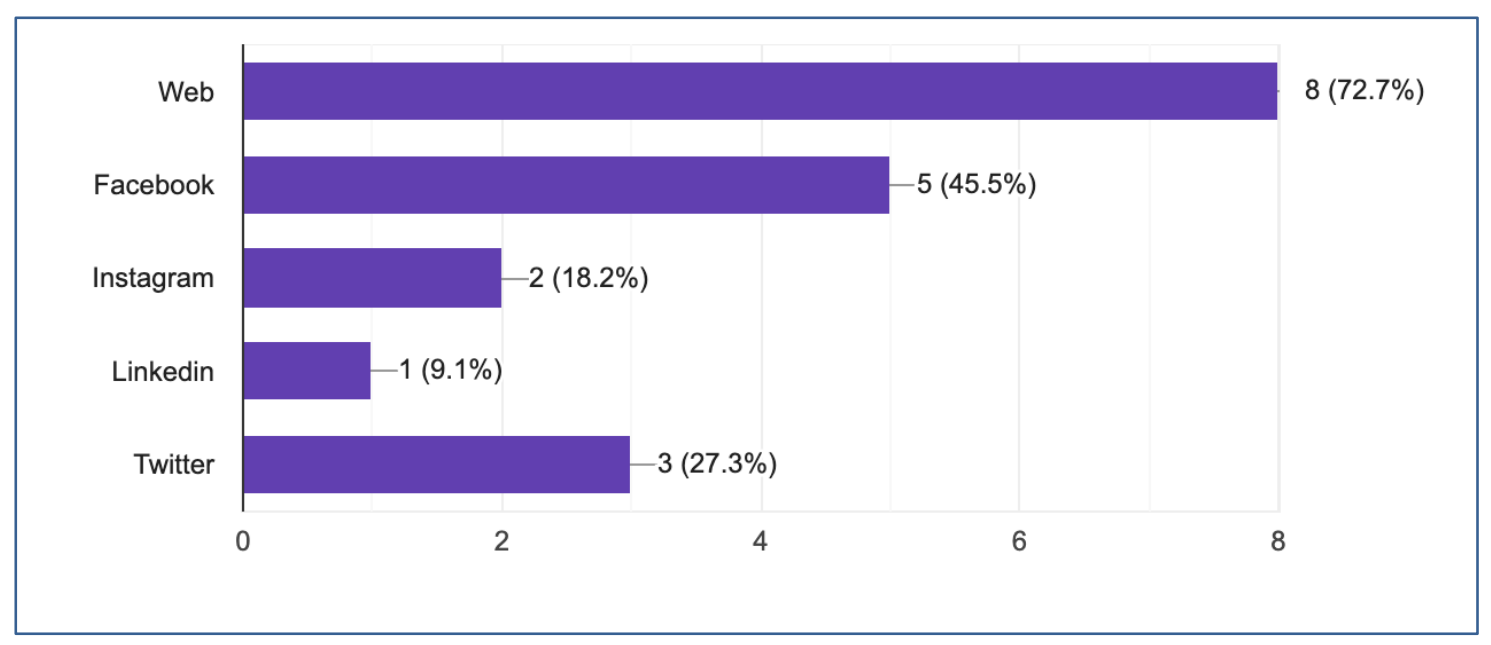

FIgURA 35

Fuente: Elaboración propia 
5. ¿Desde cuándo comenzaste con el emprendimiento?

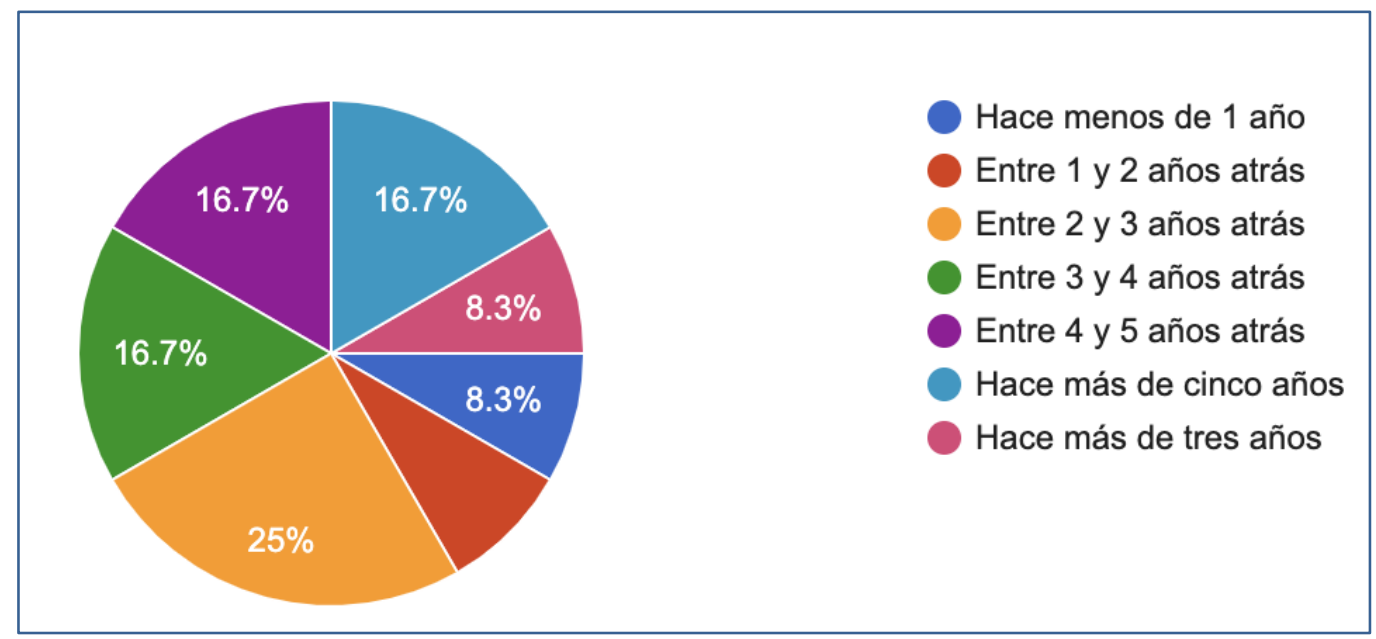

FIGURA 36

Fuente: Elaboración propia

6. ¿Qué puesto o funciones cumplís dentro de la start-up?

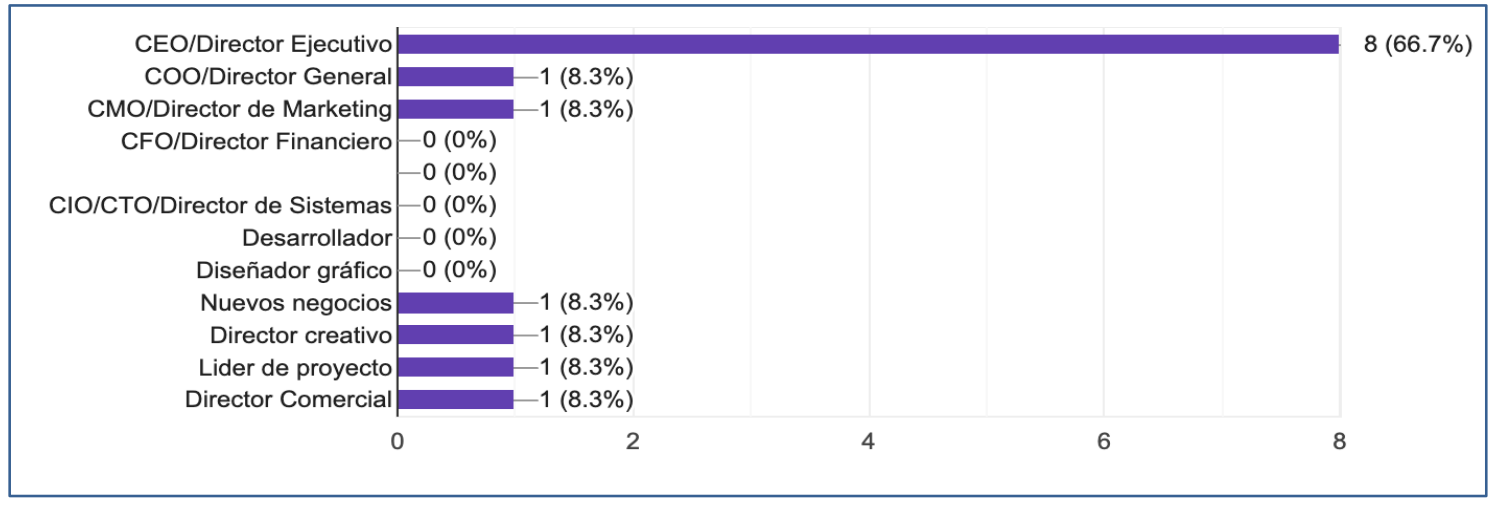

FIGURA 37

Fuente: Elaboración propia

\section{Datos del equipo emprendedor}

7. ¿Quiénes conforman el equipo? Indicar nombre de cada integrante, profesión o área de conocimiento, cargo y edad. 


\section{$\%$ de mujeres/total equipo}

11 responses

6

$5(45.5 \%)$

4

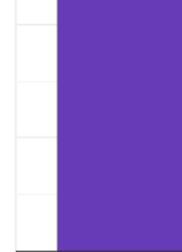

0

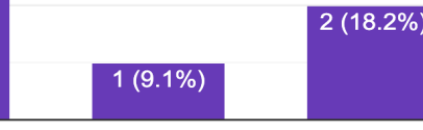

25

$1(9.1 \%)$

40
$1(9.1 \%)$

42
$1(9.1 \%)$

50

FIGURA 38

Fuente: Elaboración propia

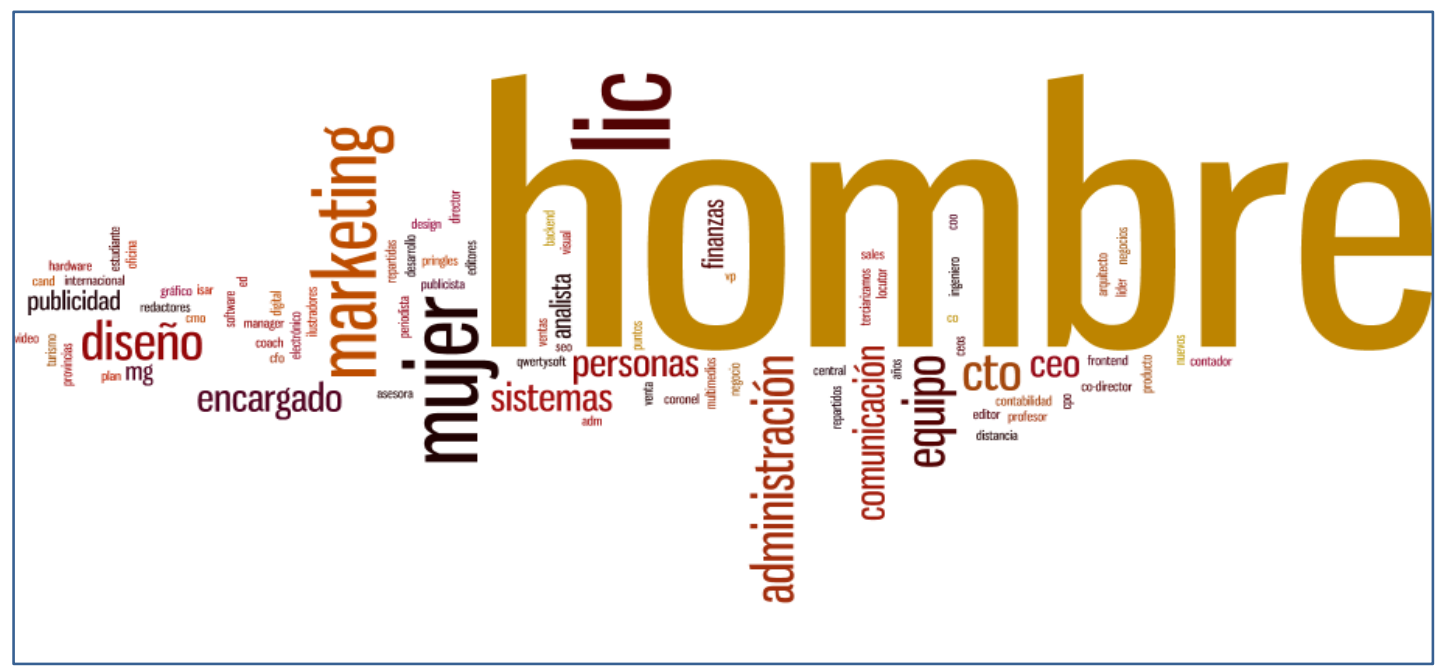

FIGURA 39

Fuente: Elaboración propia 


\section{8. ¿Cómo fue que se asociaron?}

\begin{tabular}{|l|r|r|r|}
\hline 1. & $-2(18.2 \%)$ & \\
\hline 2. & $-2(18.2 \%)$ & $5(45.5 \%)$ \\
\hline 3. & $-1(9.1 \%)$ & \\
\hline 4. & $-1(9.1 \%)$ & & \\
\hline 5. & $-1(9.1 \%)$ & & \\
\hline 6. & $-1(9.1 \%)$ & & \\
\hline 7. & $-1(9.1 \%)$ & & 5 \\
\hline 8. & 1 & 3 & 4 \\
\hline & & 2 & \\
\hline
\end{tabular}

\begin{tabular}{|r|l|}
\hline 1 & Amistad \\
\hline 2 & Estrategia \\
\hline 3 & Intereses similares \\
\hline 4 & $\begin{array}{l}\text { Si bien es una S.A. en mi caso soy el responsable de la } \\
\text { Empresa, trabajamos bajo un sistema de franquicias. }\end{array}$ \\
\hline 5 & $\begin{array}{l}\text { Propuesta del CEO, para aportar conocimiento y } \\
\text { experiencia al proyecto. Mis socios ya habian trabajado } \\
\text { con plataformas de e learning }\end{array}$ \\
\hline 6 & $\begin{array}{l}\text { Dario, Euge y Marian trabajaron justos muchos años en } \\
\text { una empresa y comenzaron a trabajar en este proyecto. En } \\
\text { el año 2015 nos conocimos en el Seminario de } \\
\text { Emprendedores de la FCE y completamos el equipo de 4 } \\
\text { socixs que somos hoy. }\end{array}$ \\
\hline 7 & nos conociamos de otro trabajo \\
\hline 8 & $\begin{array}{l}\text { Leandro participo de usina de ideas y martin fue mentor, } \\
\text { luego se le propuso ser parte del equipo de trabajo, y } \\
\text { luego incorporamos a jorge por ser conocido desde } \\
\text { muchos años de leandro y sus conocimientos } \\
\text { profesionales eran lo que estabamos necesitando }\end{array}$ \\
\hline
\end{tabular}

FIGURA 40

Fuente: Elaboración propia 
9. ¿Cómo distribuyeron las responsabilidades de cada uno?

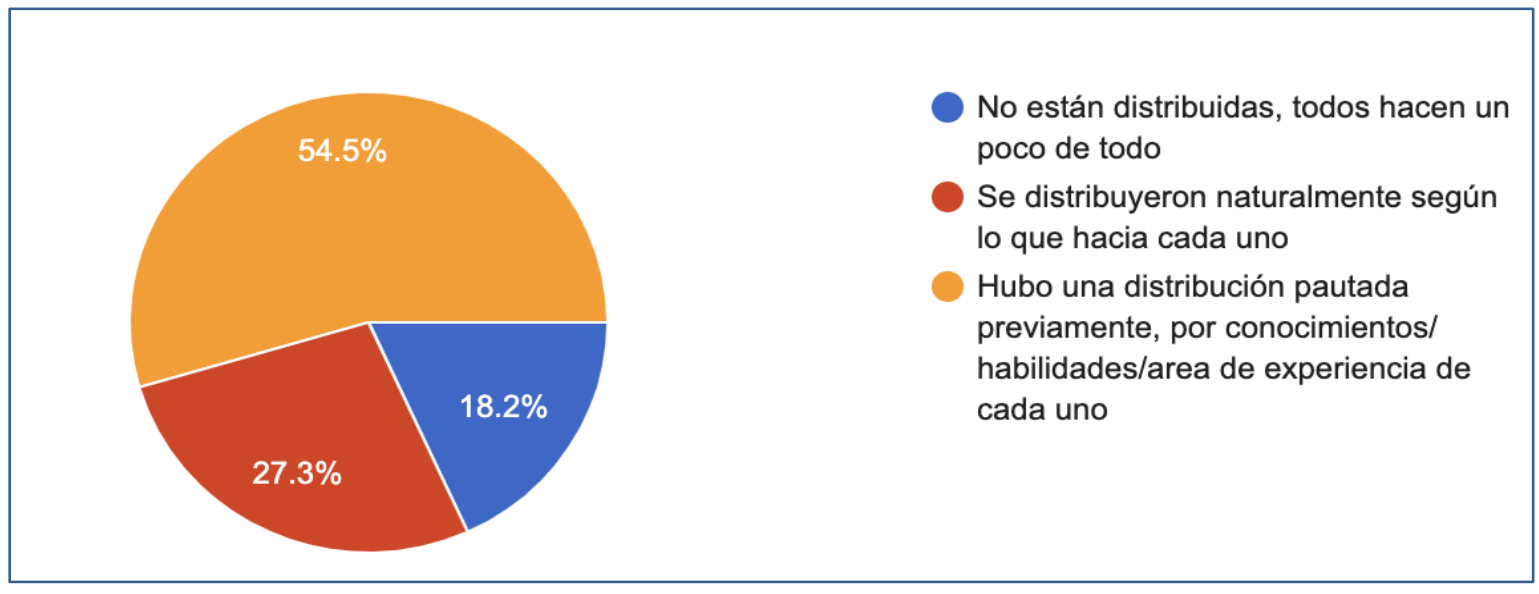

FIGURA 41

Fuente: Elaboración propia

10. ¿Se mantiene la misma estructura hoy en día?

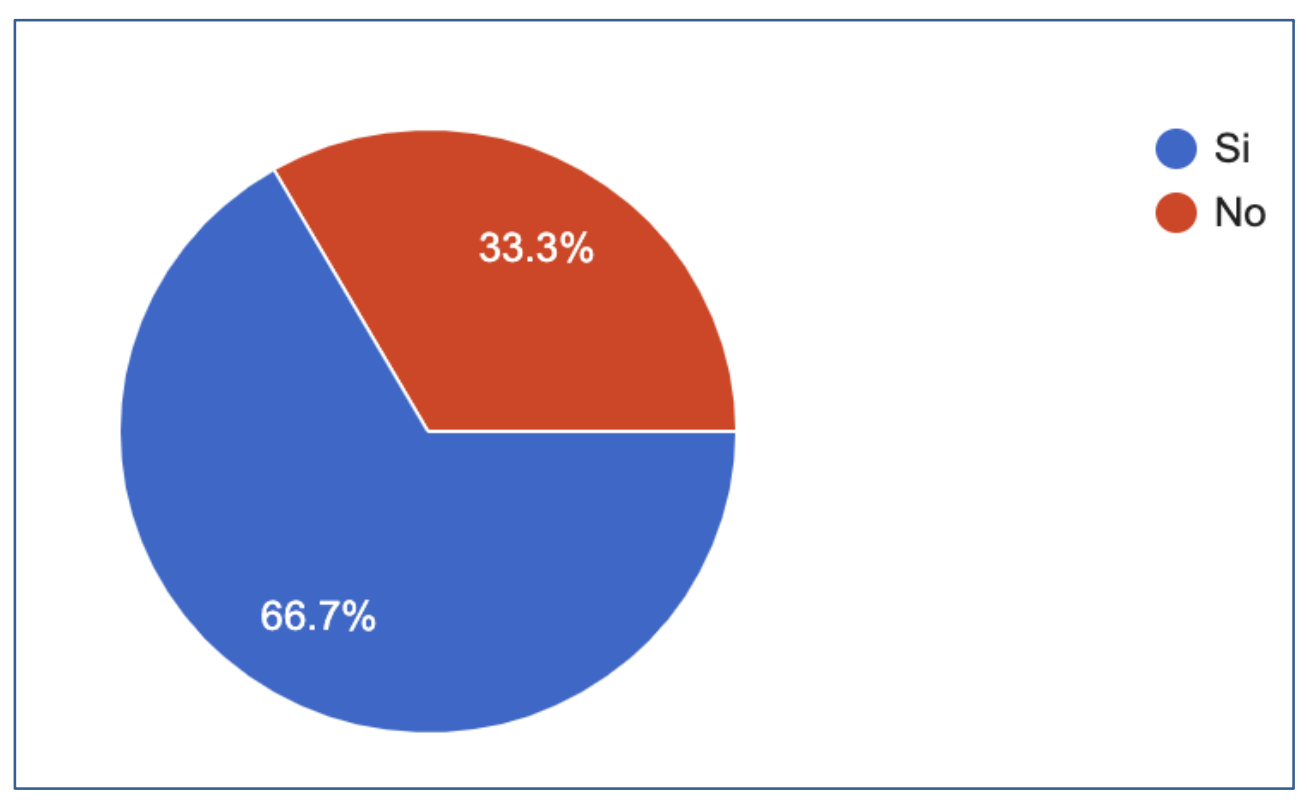

FIGURA 42

Fuente: Elaboración propia 
11. ¿Trabajan de manera remota o in situ?

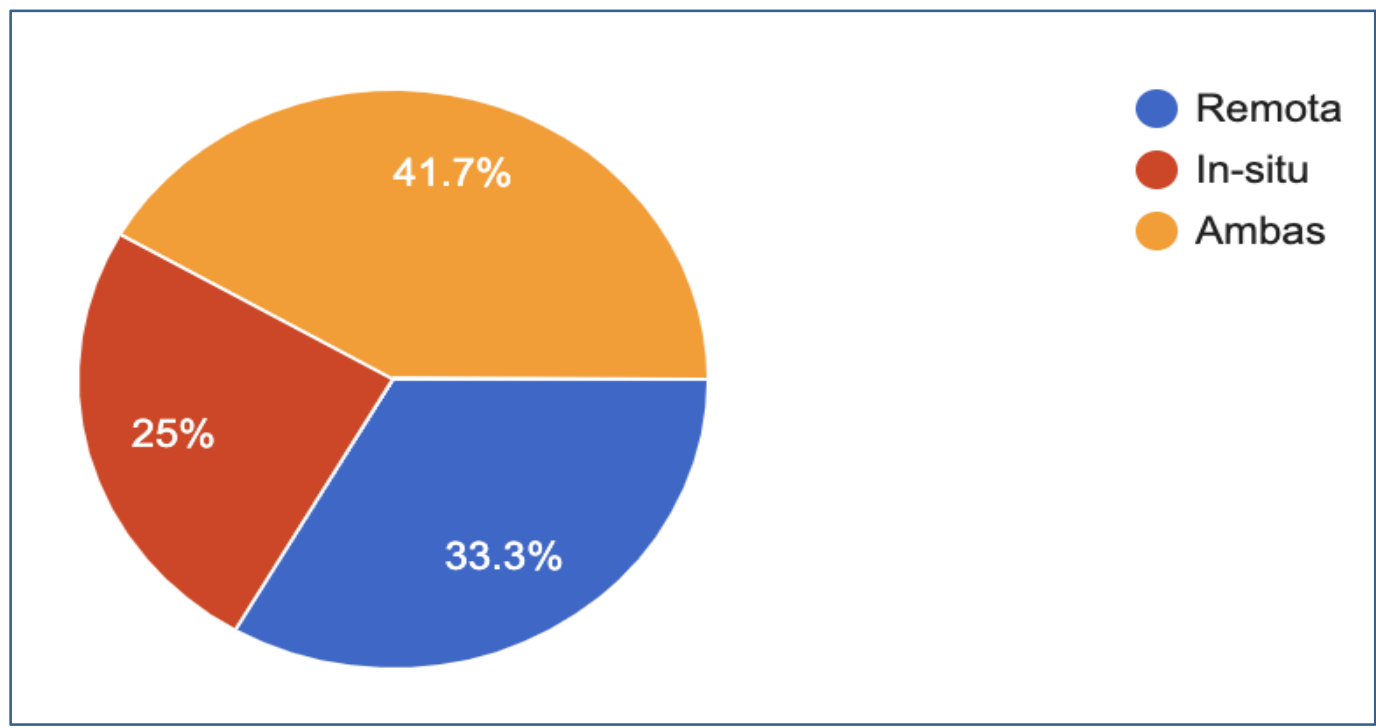

FIGURA 43

Fuente: Elaboración propia

\section{Motivaciones}

12. ¿Cuáles fueron las razones por las que decidiste emprender?

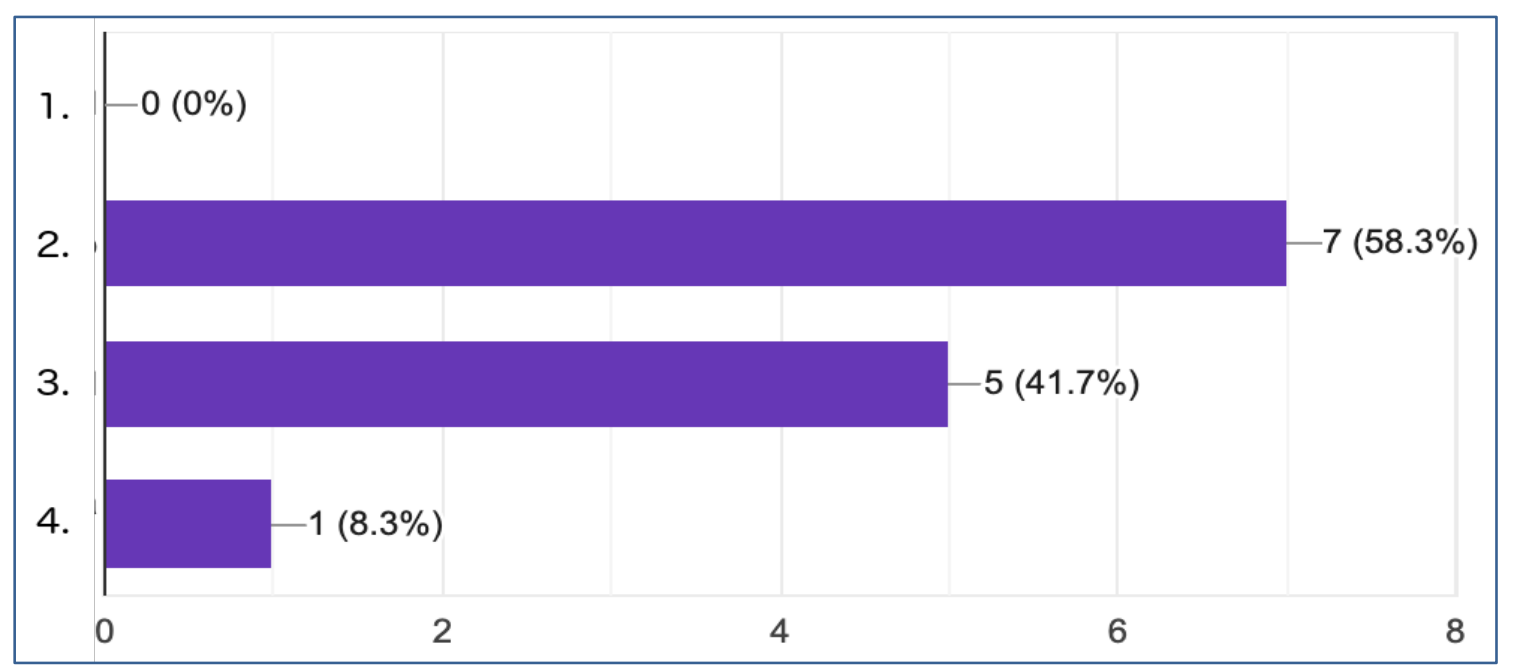

\begin{tabular}{|r|l|}
\hline 1 & Necesidad \\
\hline 2 & Deseo \\
\hline 3 & Oportunidad \\
\hline 4 & $\begin{array}{l}\text { Encontré un problema relacionado con mi experiencia } \\
\text { laboral en el ámbito del turismo y la gastronomía. }\end{array}$ \\
\hline
\end{tabular}

FIGURA 44 
13. ¿Qué te dio ánimo en dar el salto a emprender?

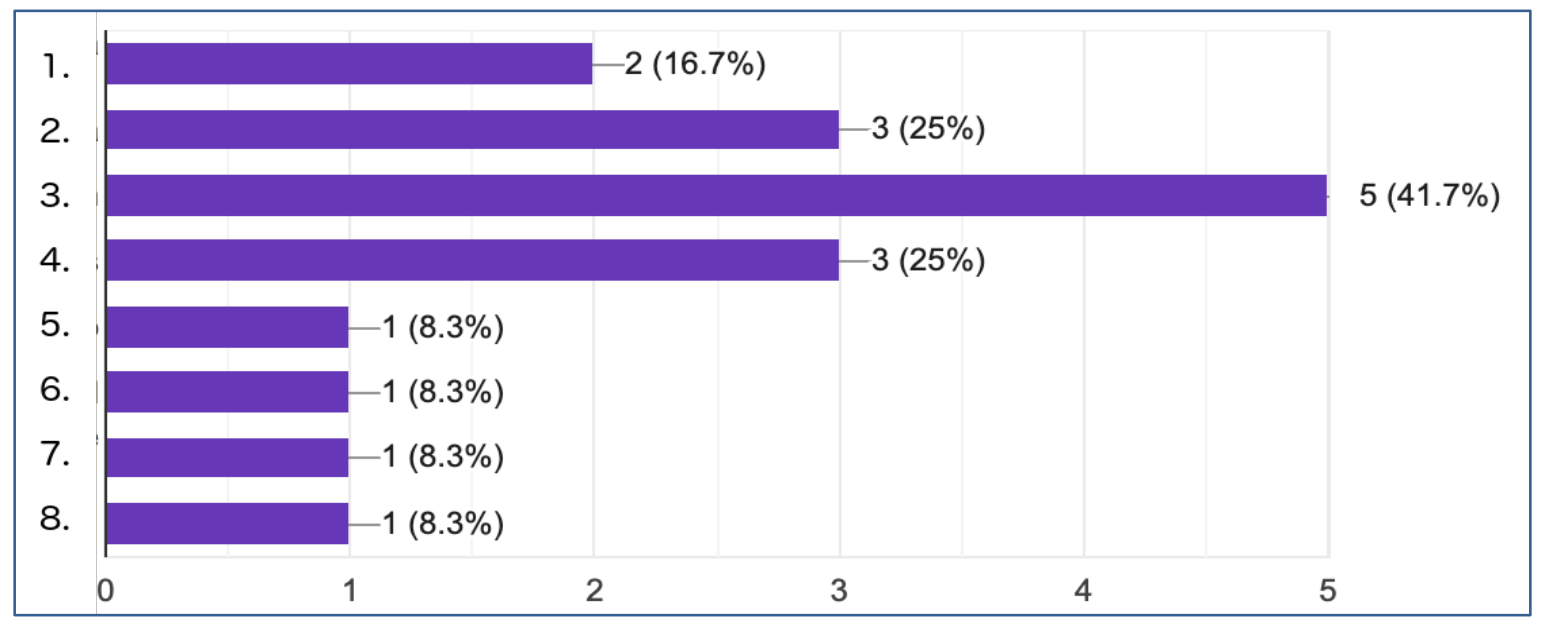

\begin{tabular}{|r|l|}
\hline 1 & Insatisfacción por la industria corporativa \\
\hline 2 & Deseo de ser tu propio jefe/a \\
\hline 3 & Oportunidad \\
\hline 4 & Convicción \\
\hline 5 & Costumbres familiares \\
\hline 6 & Construir con libertad mi futuro \\
\hline 7 & Personalidad \\
\hline 8 & El hecho de que mi familia me haya apoyado \\
\hline & $\begin{array}{l}\text { Encontrar un proyecto que me motiva mucho y me desafia } \\
\text { todo el tiempo }\end{array}$ \\
\hline
\end{tabular}

FIGURA 45

Fuente: Elaboración propia

\section{Desarrollo del emprendimiento y planificación estratégica}

14. ¿Tiene el emprendimiento un modelo de negocios definido? En caso afirmativo, ¿de qué tipo es?

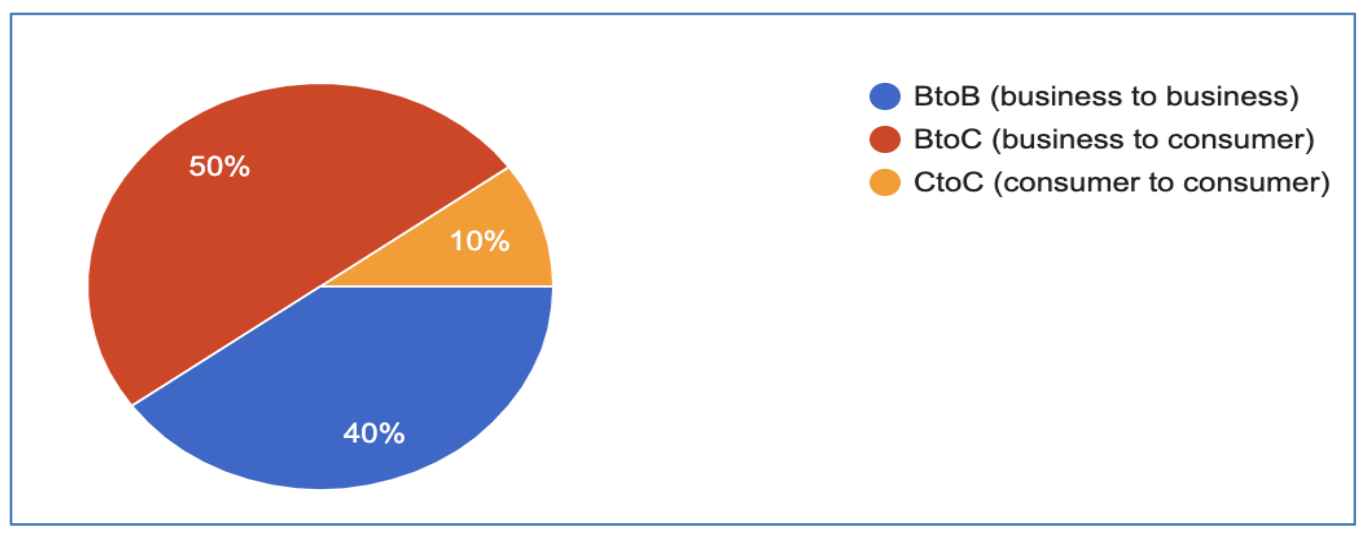

FIGURA 46

Fuente: Elaboración propia 
15. ¿Cuál es la forma de monetización?

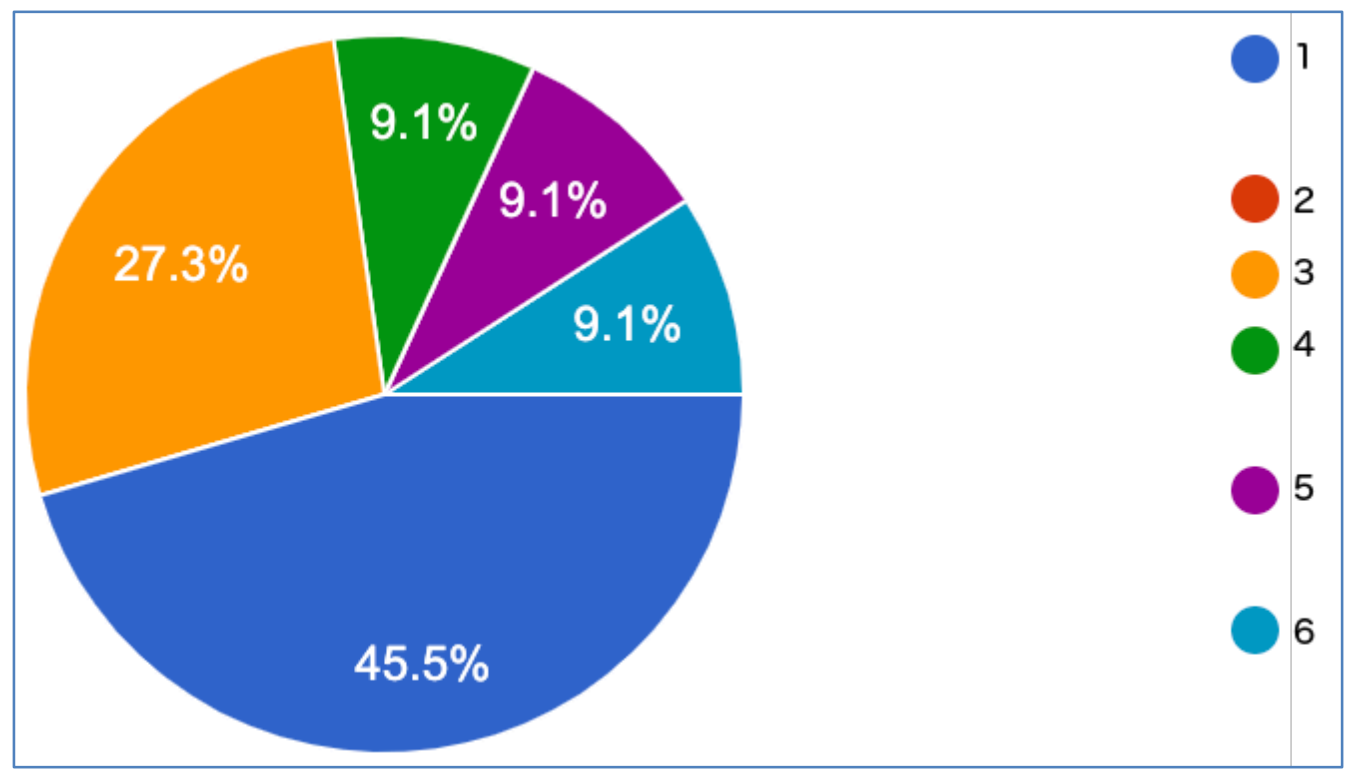

\begin{tabular}{|r|l|}
\hline 1 & $\begin{array}{l}\text { Modelo Freemium (gratuito pero conproductos o servicios } \\
\text { de pago) }\end{array}$ \\
\hline 2 & Gratis con publicidades o sponsors \\
\hline 3 & Modelo Premium (se accede de pago) \\
\hline & $\begin{array}{l}\text { Venta de Viajes online (modelo mixto entre el online con } \\
\text { varias marcas en el mercado y el offline con } 24 \text { puntos de } \\
\text { venta fisicos }\end{array}$ \\
\hline 5 & $\begin{array}{l}\text { Es un SaaS, se cobra un fee asociado a las transacciones } \\
\text { que se procesan }\end{array}$ \\
\hline 6 & El modelo de negocio es b2b y b2c, venta del producto \\
\hline
\end{tabular}

FIGURA 47

Fuente: Elaboración propia 
16. ¿Siempre fue el mismo o tuvo modificaciones?

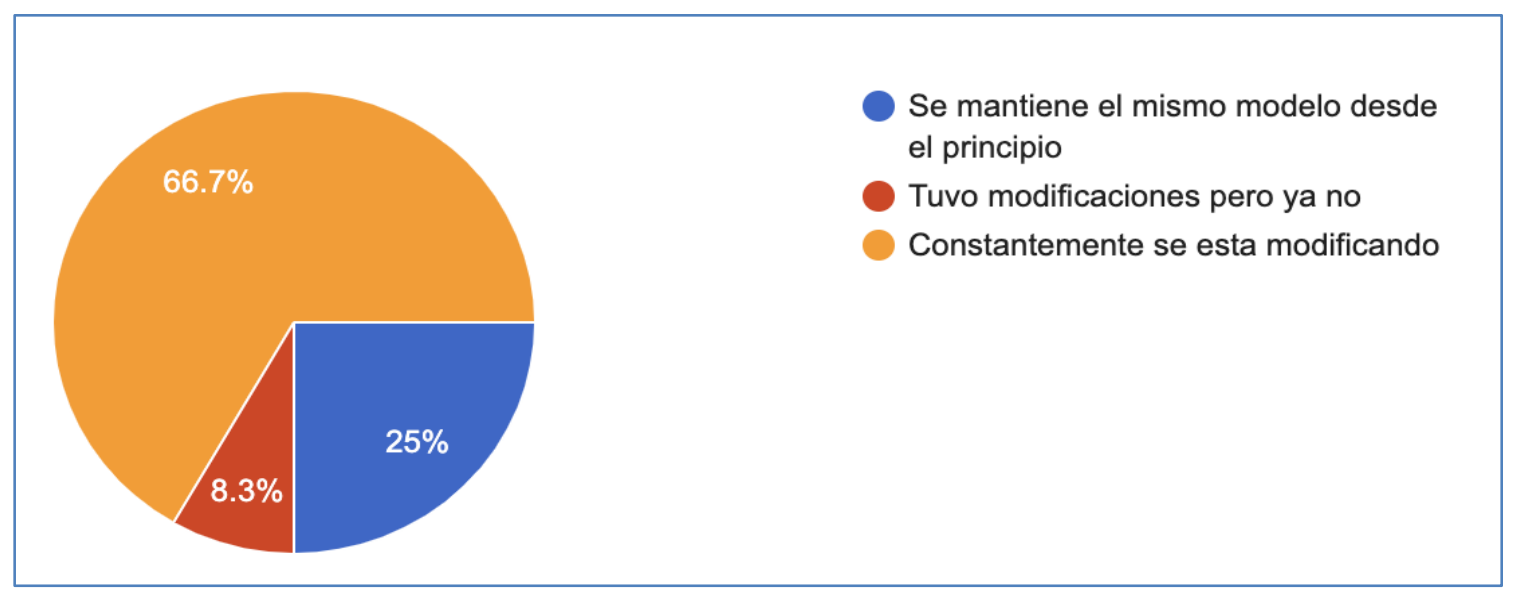

FIGURA 48

Fuente: Elaboración propia

17. ¿Cuál es su misión, visión y objetivos?

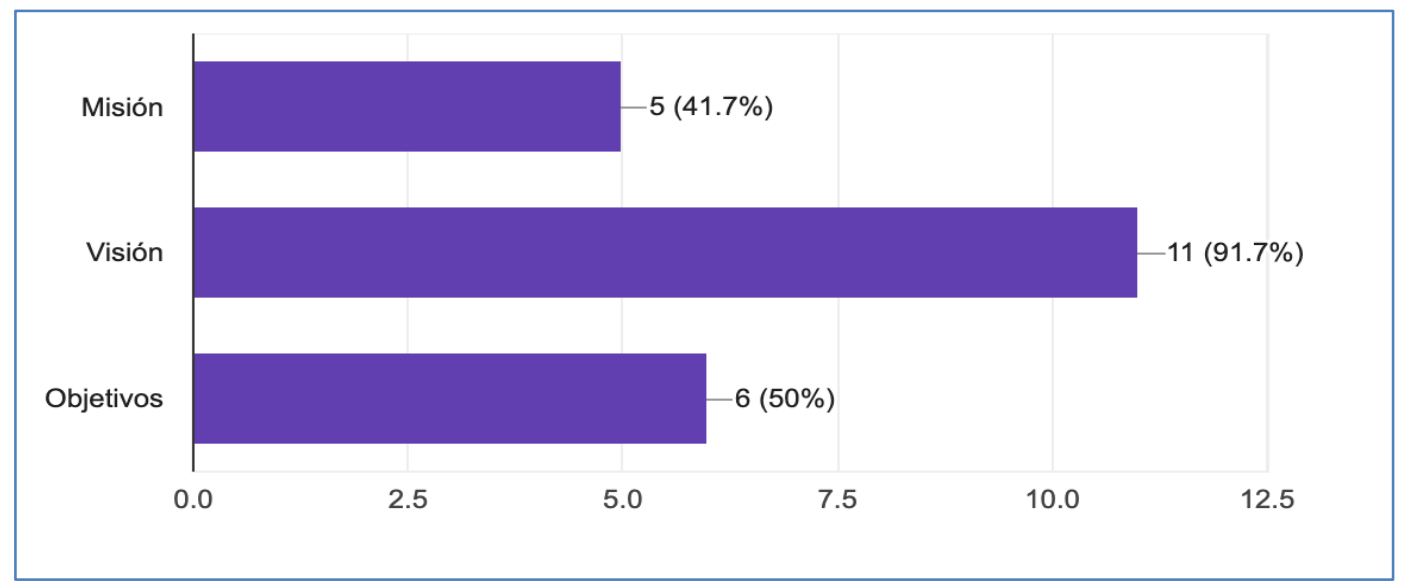

FIGURA 49

Fuente: Elaboración propia 
18. ¿Cómo fue que surgió la idea?

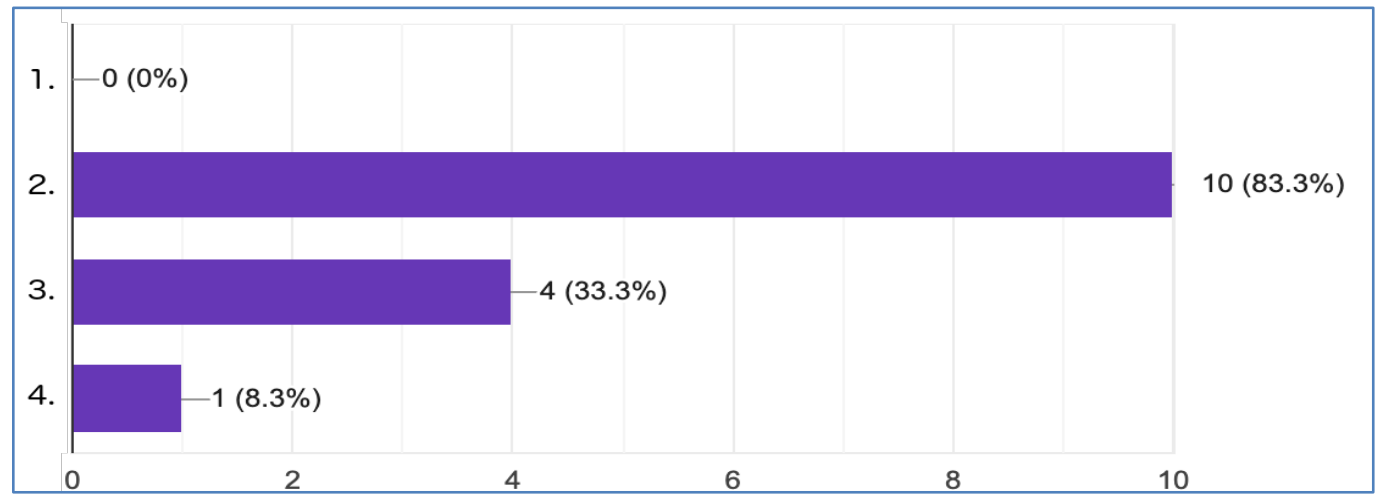

\begin{tabular}{|r|l|}
\hline 1 & Ocio/diversión \\
\hline 2 & Detección de una necesidad insatisfecha \\
\hline 3 & $\begin{array}{l}\text { Existencia en otro mercado/pais, y ganas de aplicarla a } \\
\text { otro mercado/país. }\end{array}$ \\
\hline 4 & $\begin{array}{l}\text { Comenzamos con otro modelo y propuyesta de valor: era } \\
\text { un "last Minute" de entradas de espectáculos. Pero } \\
\text { pivoteamos por encontrar una mejor oportunidad en el } \\
\text { SaaS. }\end{array}$ \\
\hline
\end{tabular}

FIGURA 50

Fuente: Elaboración propia

19. ¿Se mantuvo tal como se les ocurrió? ¿O fue modificándose?

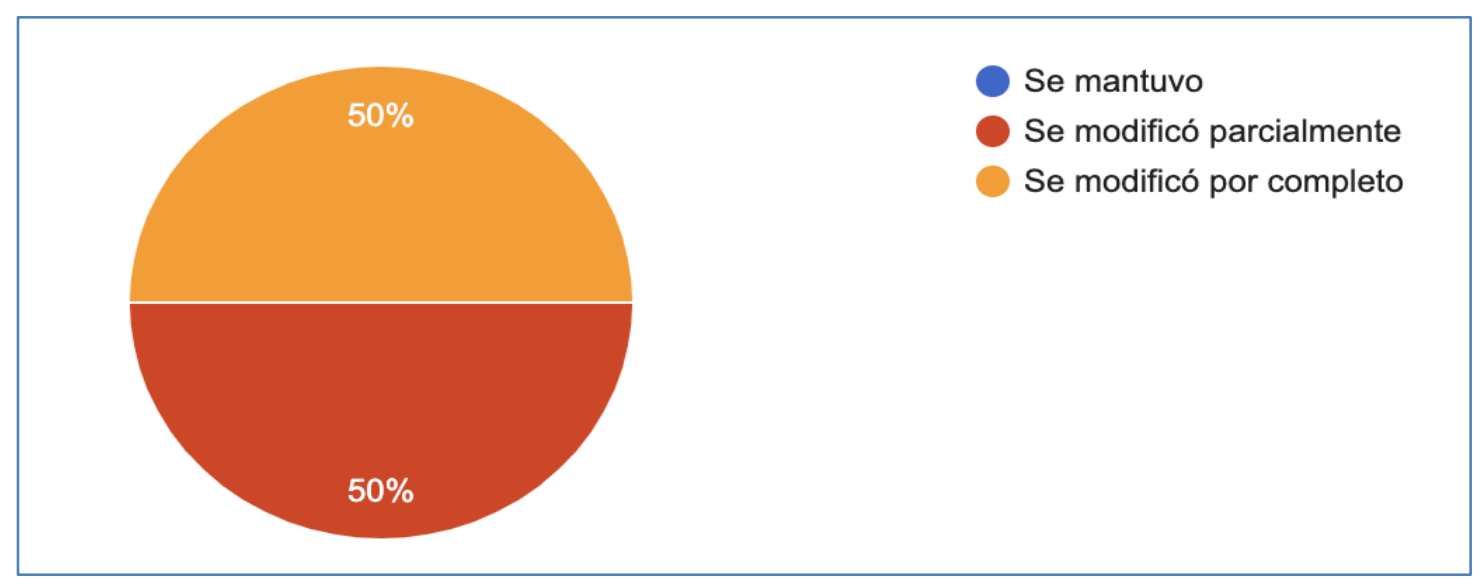

FIGURA 51

Fuente: Elaboración propia 
20. ¿Se hizo algún análisis de factibilidad o análisis de mercado previo?

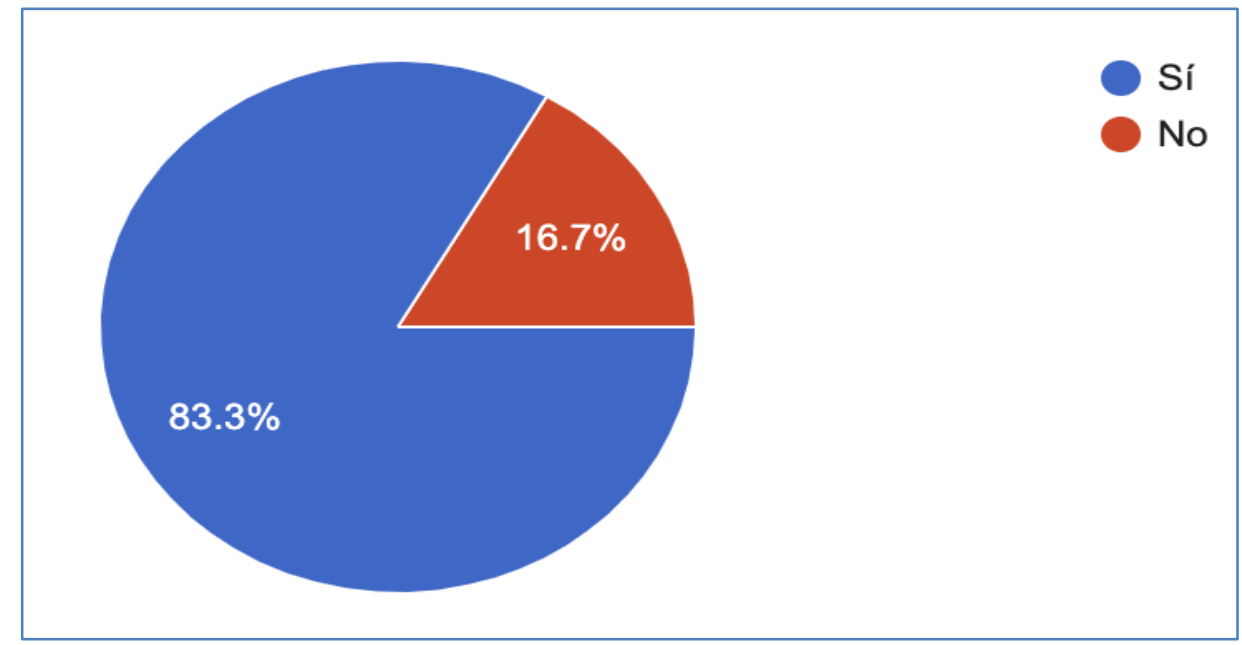

FIGURA 52

Fuente: Elaboración propia

21. ¿Hay un plan estratégico diseñado?

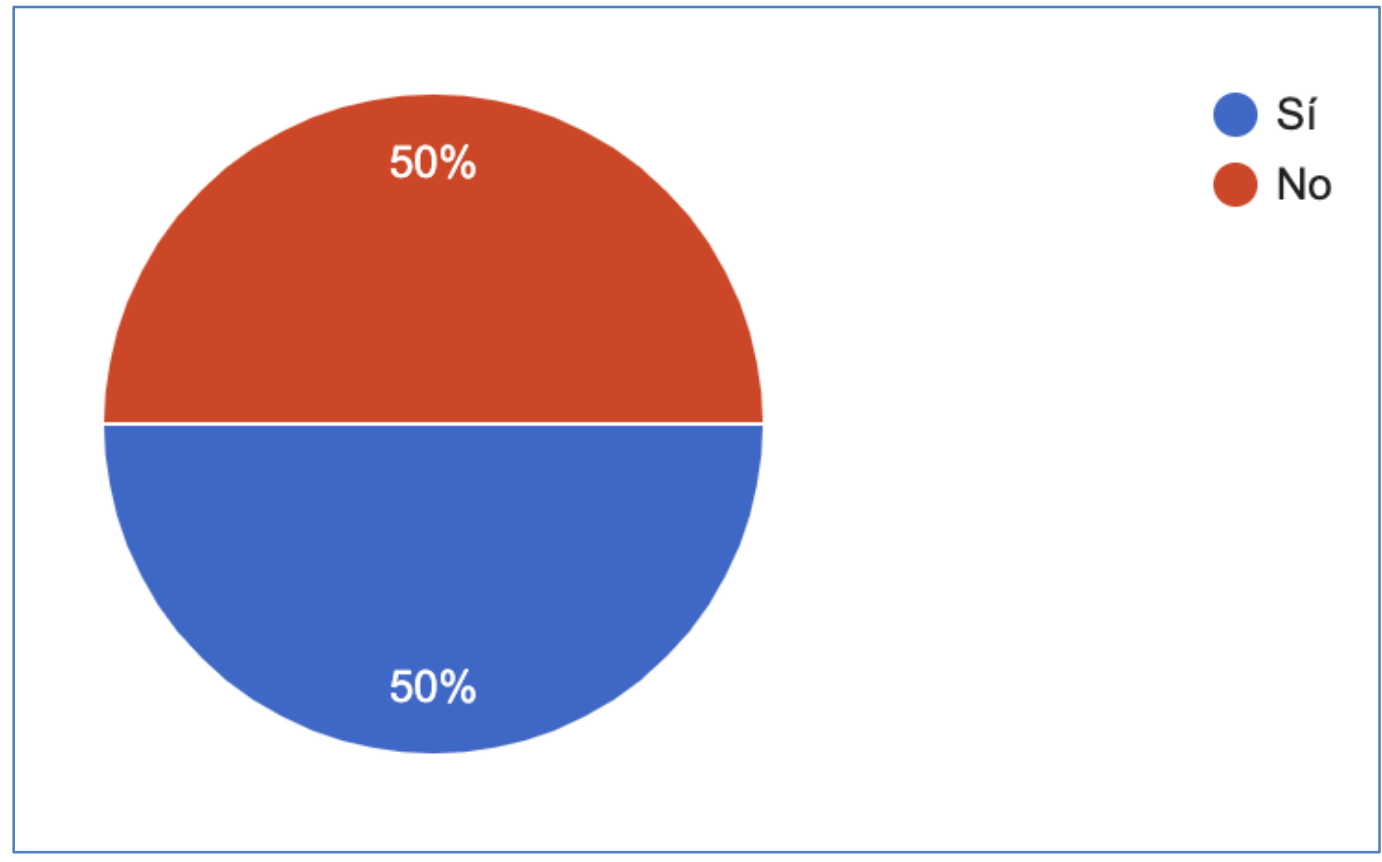

FIGURA 53

Fuente: Elaboración propia 
22. ¿Ya se lanzó el producto/servicio?

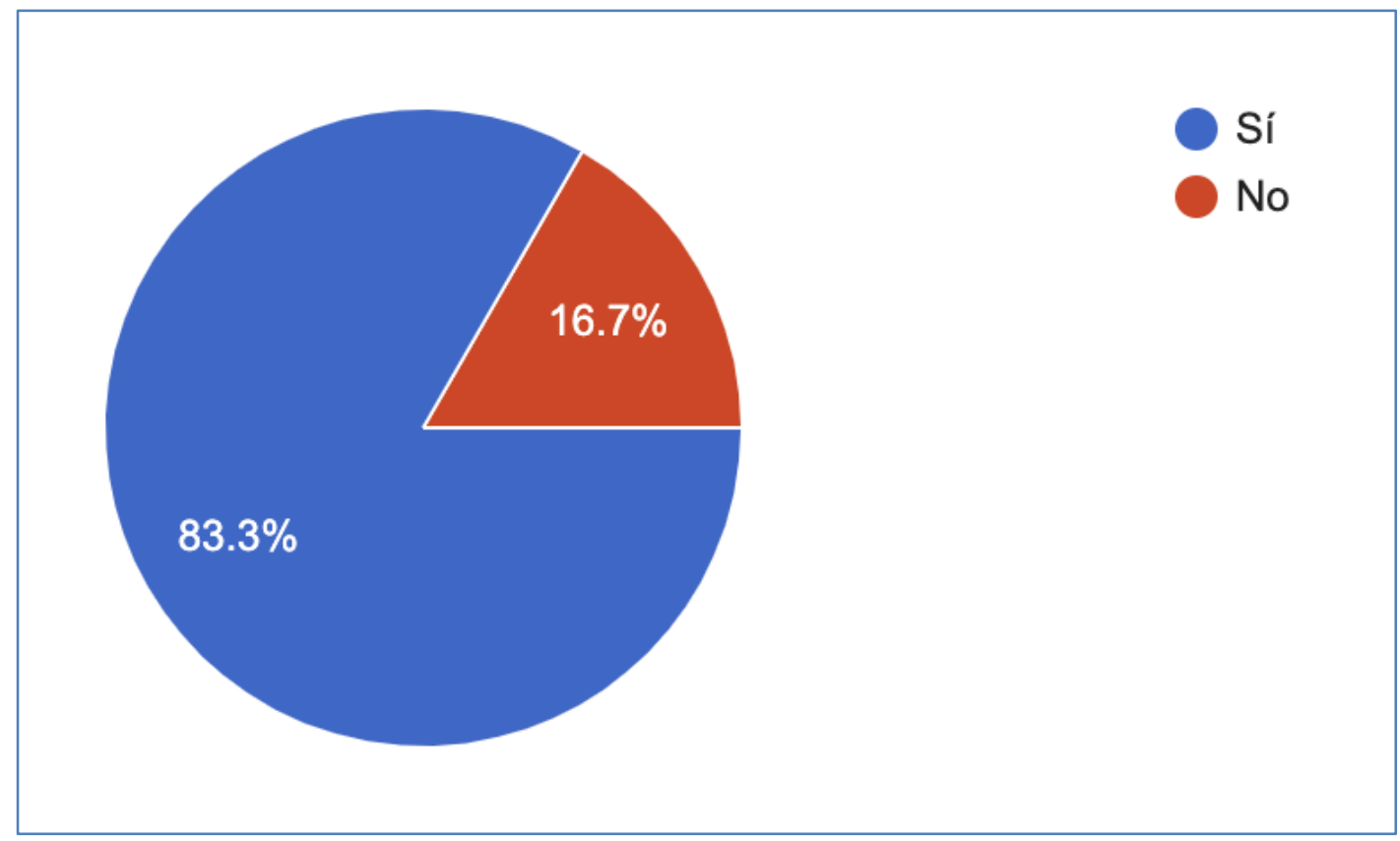

FIGURA 54

Fuente: Elaboración propia

23. Si es así, ¿se hizo primero con un producto mínimo viable?

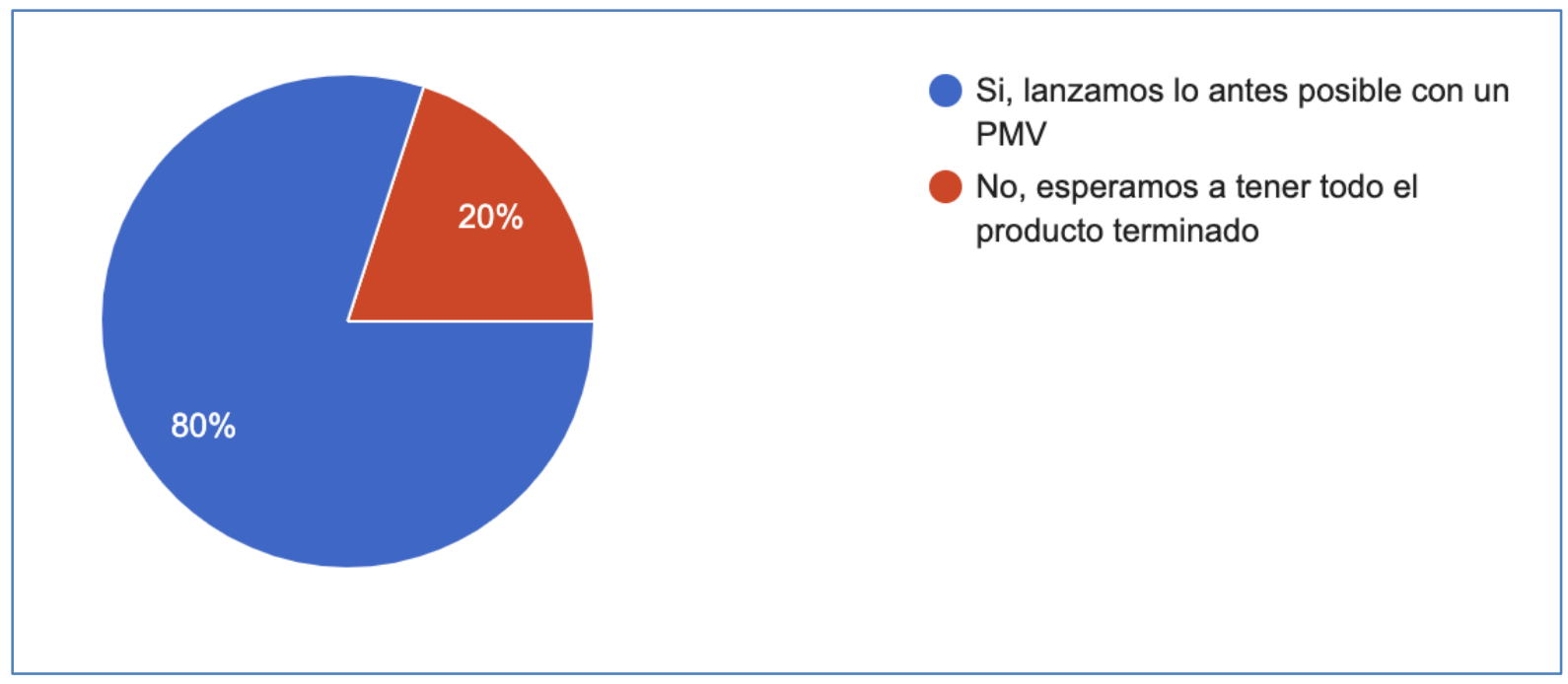

FIGURA 55

Fuente: Elaboración propia 
24. ¿El emprendimiento tiene clientes?

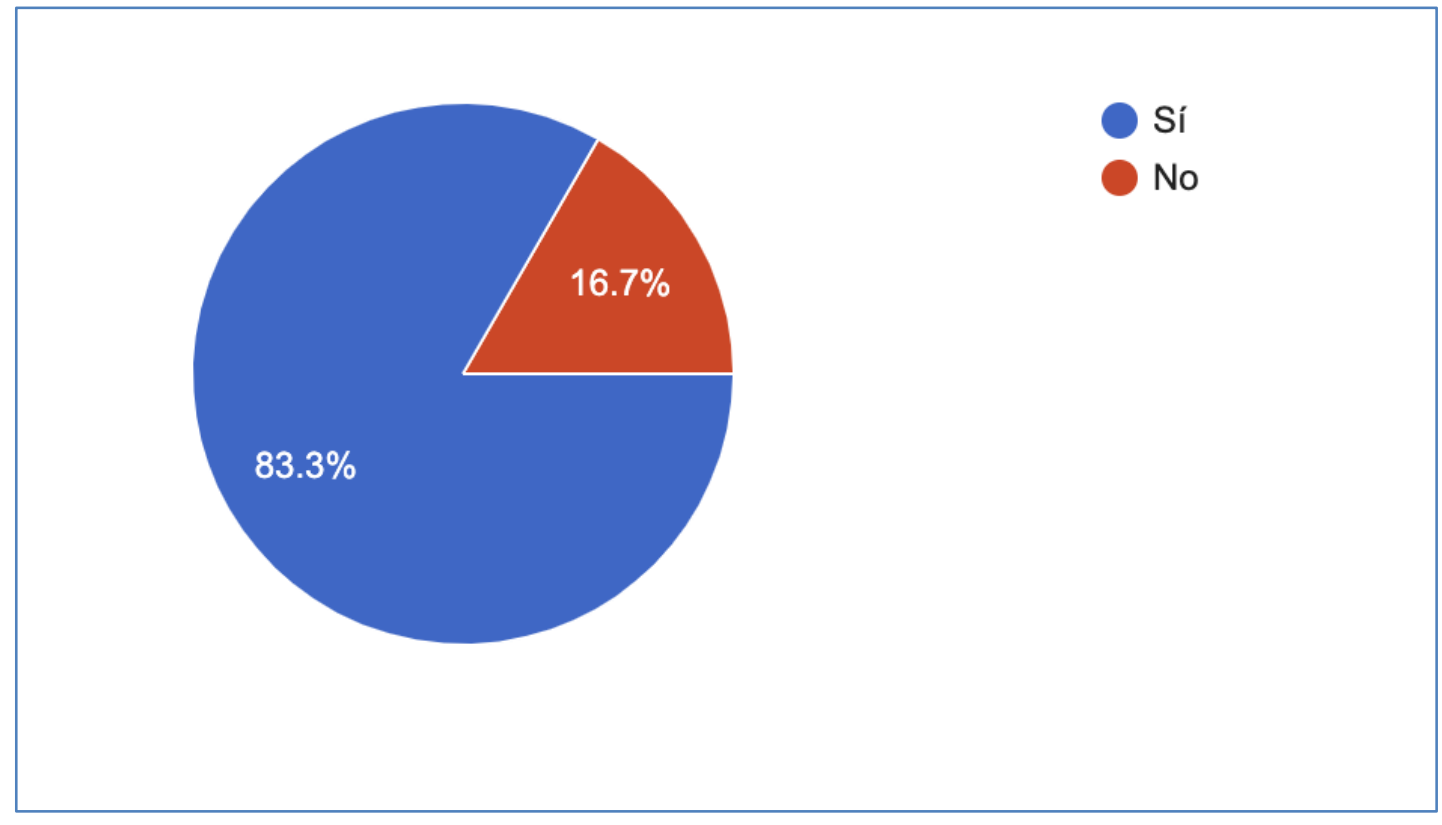

FIGURA 56

Fuente: Elaboración propia

25. En caso afirmativo, ¿cómo los obtuvo?

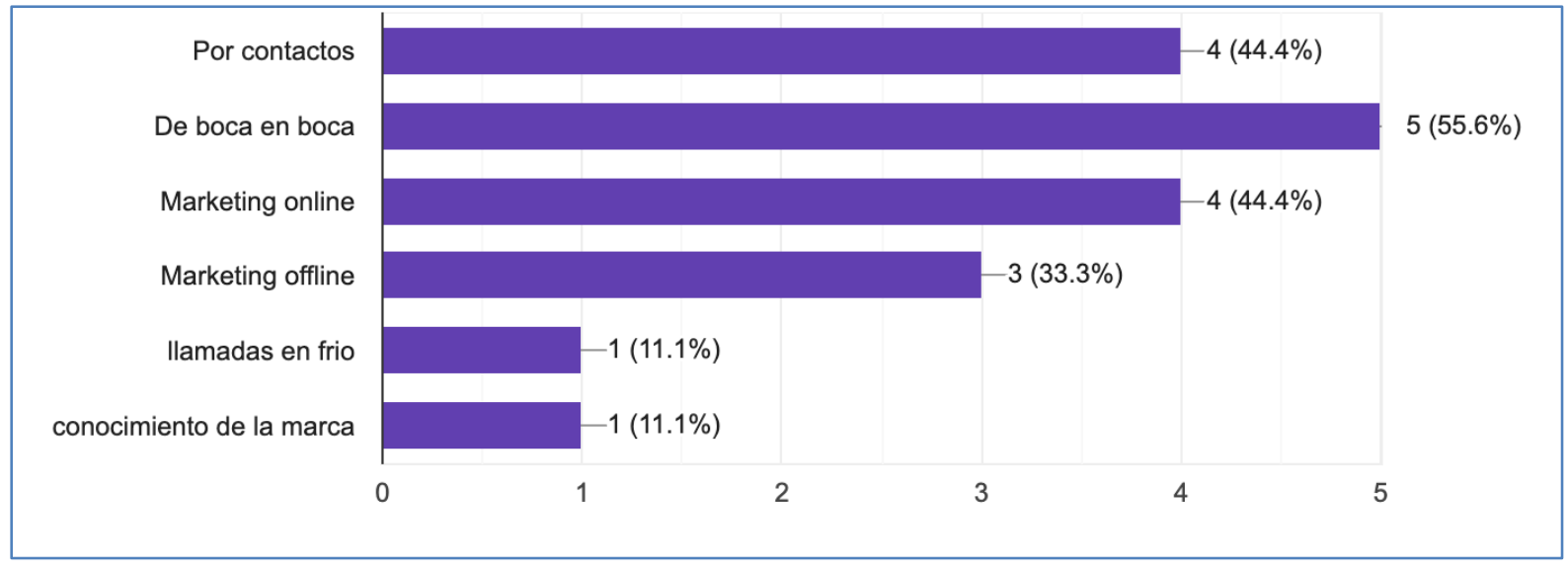

FIGURA 57

Fuente: Elaboración propia 
26. ¿Tiene competidores?

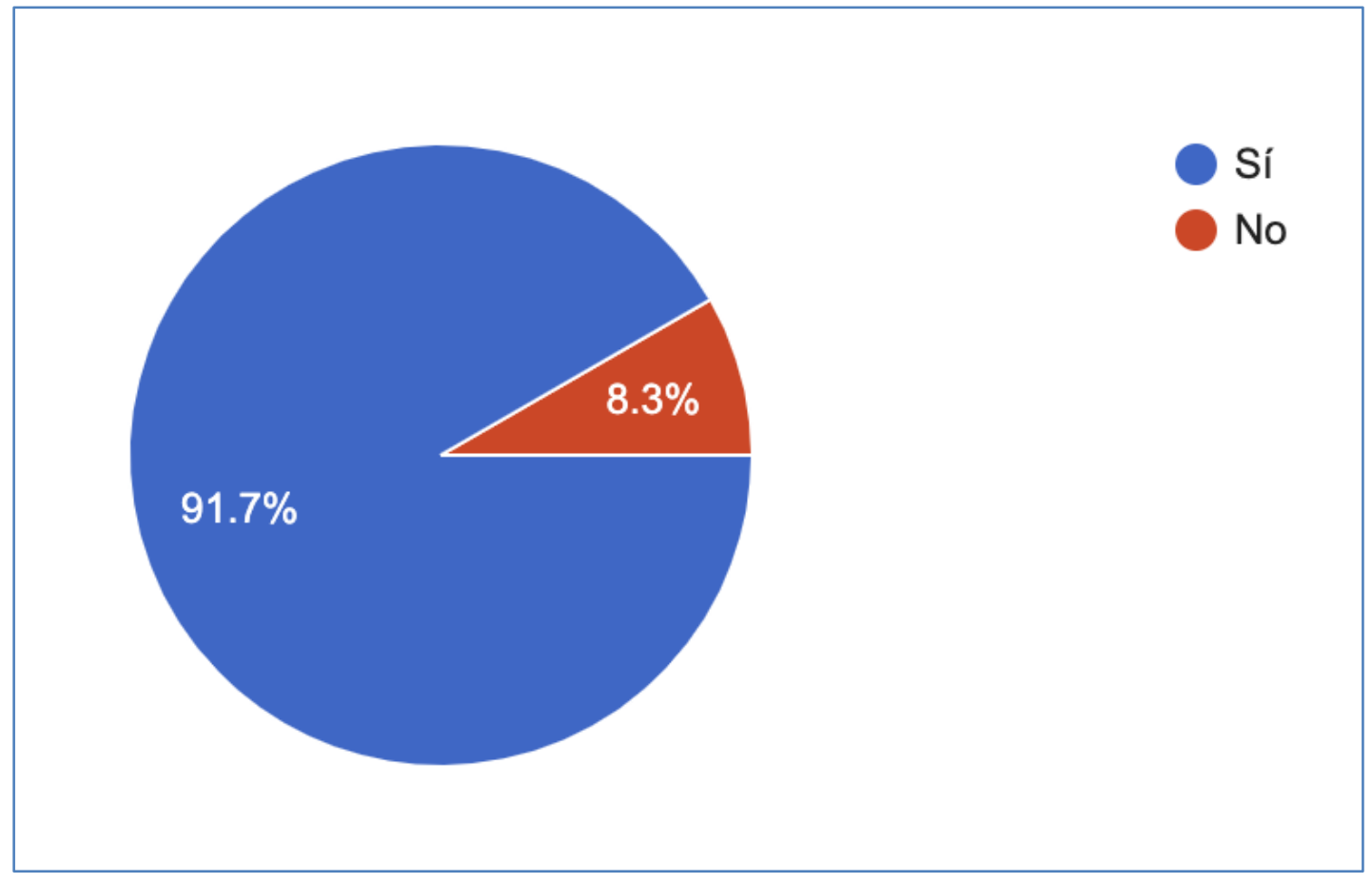

FIGURA 58

Fuente: Elaboración propia

27. En caso afirmativo, ¿qué rol ocupan y cómo influye en la start-up?

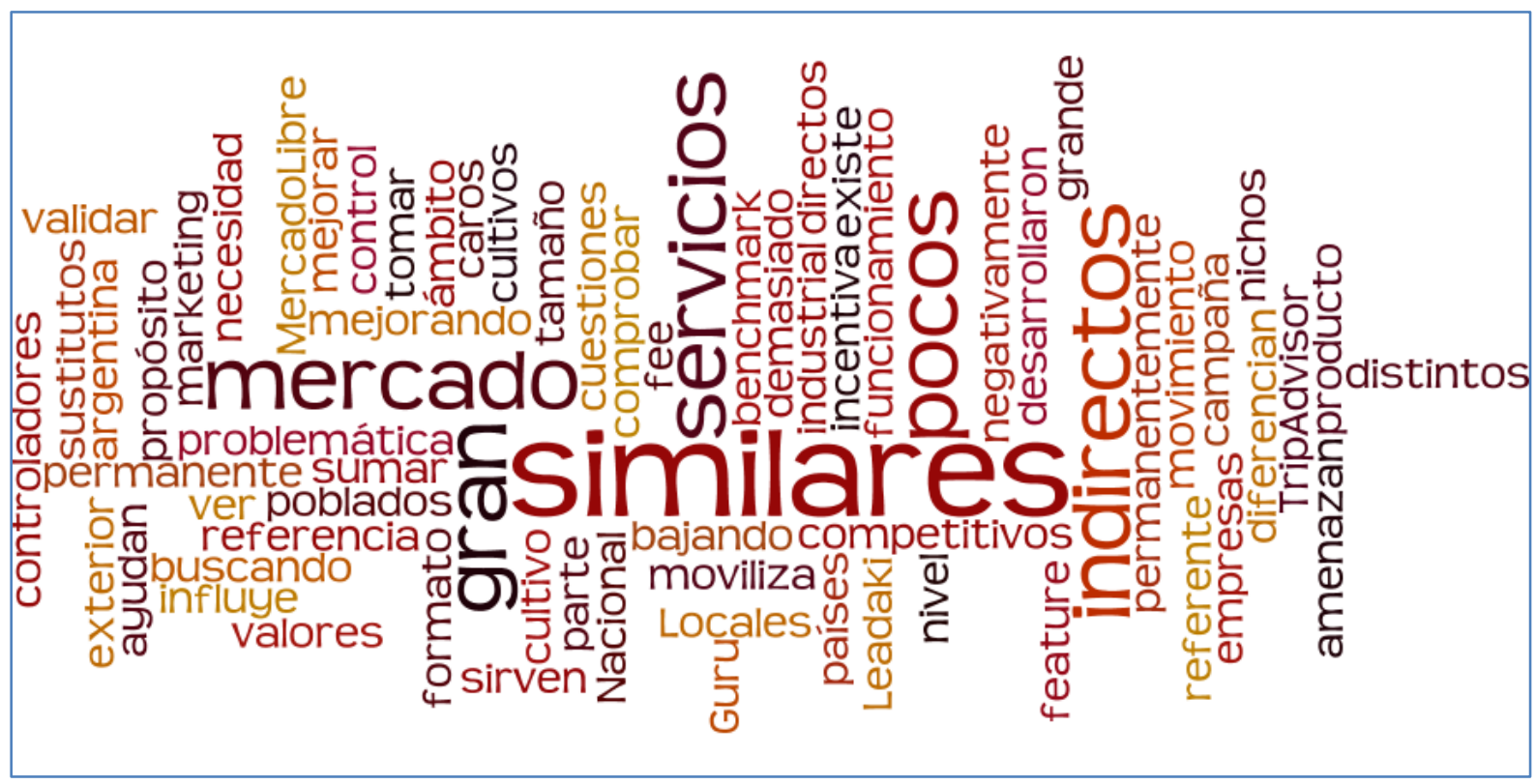

FIGURA 59 


\section{Factores internos de éxito y fracaso}

28. ¿Tu educación, estudios, experiencia y conocimientos previos fueron relevantes a la hora de lanzarte a emprender?

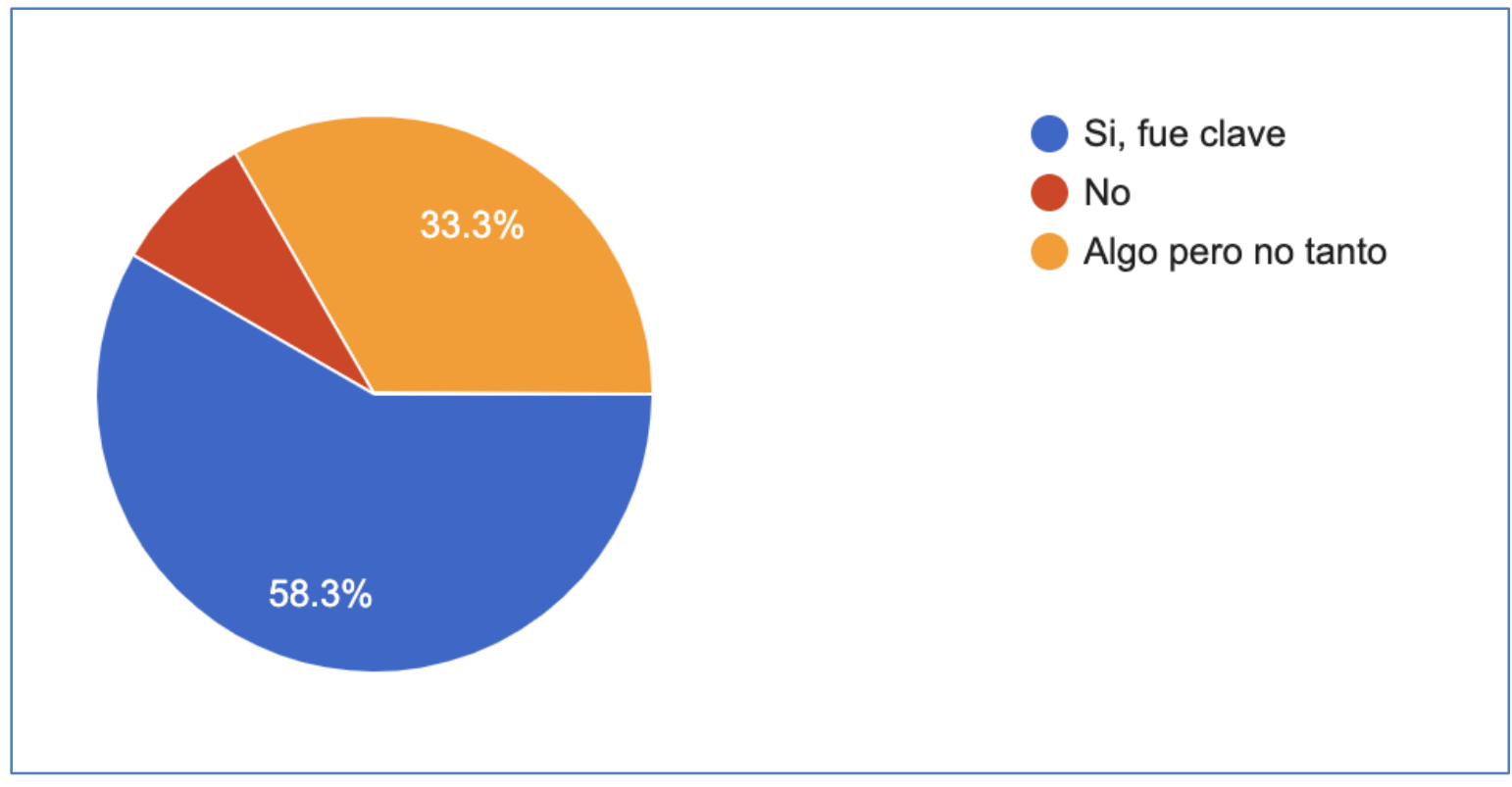

FIGURA 60

Fuente: Elaboración propia

29. ¿Cuáles son los atributos como emprendedor y como persona que destacás en vos, y cuáles tuvieron mayor influencia a la hora de hacer crecer tu start-up? Marcá una o más opciones:

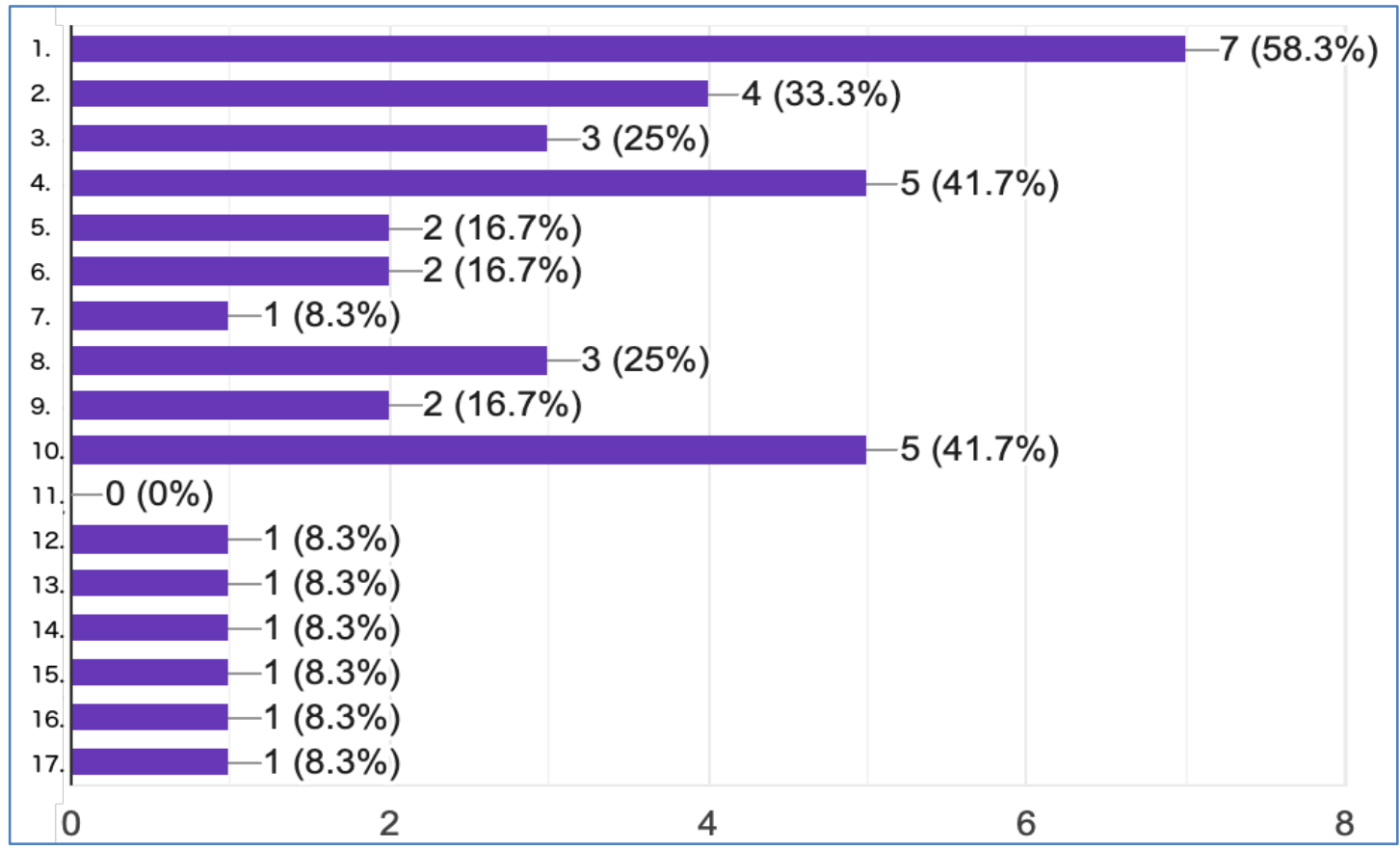




\begin{tabular}{|c|c|}
\hline 1 & Pasión \\
\hline 2 & Motivación \\
\hline 3 & Liderazgo \\
\hline 4 & Compromiso \\
\hline 5 & Confianza \\
\hline 6 & Humildad \\
\hline 7 & Creatividad \\
\hline 8 & Experiencia o conocimientos \\
\hline 9 & Aversión al riesgo \\
\hline 10 & Perseverancia \\
\hline 11 & Poseer una idea o visión empresarial clara \\
\hline 12 & Capacidad de reconocer oportunidades \\
\hline 13 & Paciencia \\
\hline 14 & Team building \\
\hline 15 & Tendencia al orden, la estructura y la gestión \\
\hline 16 & $\begin{array}{l}\text { Ser crítico, analítico, un poco atrevido, tener confianza, } \\
\text { hablar con gente, saber que no sabés todo y que tenés } \\
\text { que delegar y confiar, no tener miedo a hacer y aprender } \\
\text { cosas nuevas }\end{array}$ \\
\hline 17 & $\begin{array}{l}\text { La determinacion, el generar grupos de trabajo efectivos, } \\
\text { coordinar todas las areas y guiar el rumbo. Soy honesto y } \\
\text { sincero, y trato de ser justo para cualquier decisión o } \\
\text { división sin perjudicar ni favorecer a ninguno sobre otro. }\end{array}$ \\
\hline
\end{tabular}

FIGURA 61

Fuente: Elaboración propia

30. ¿Cuál creés que es la cualidad más importante que un emprendedor debe tener para lograr su objetivo? Marcá una opción

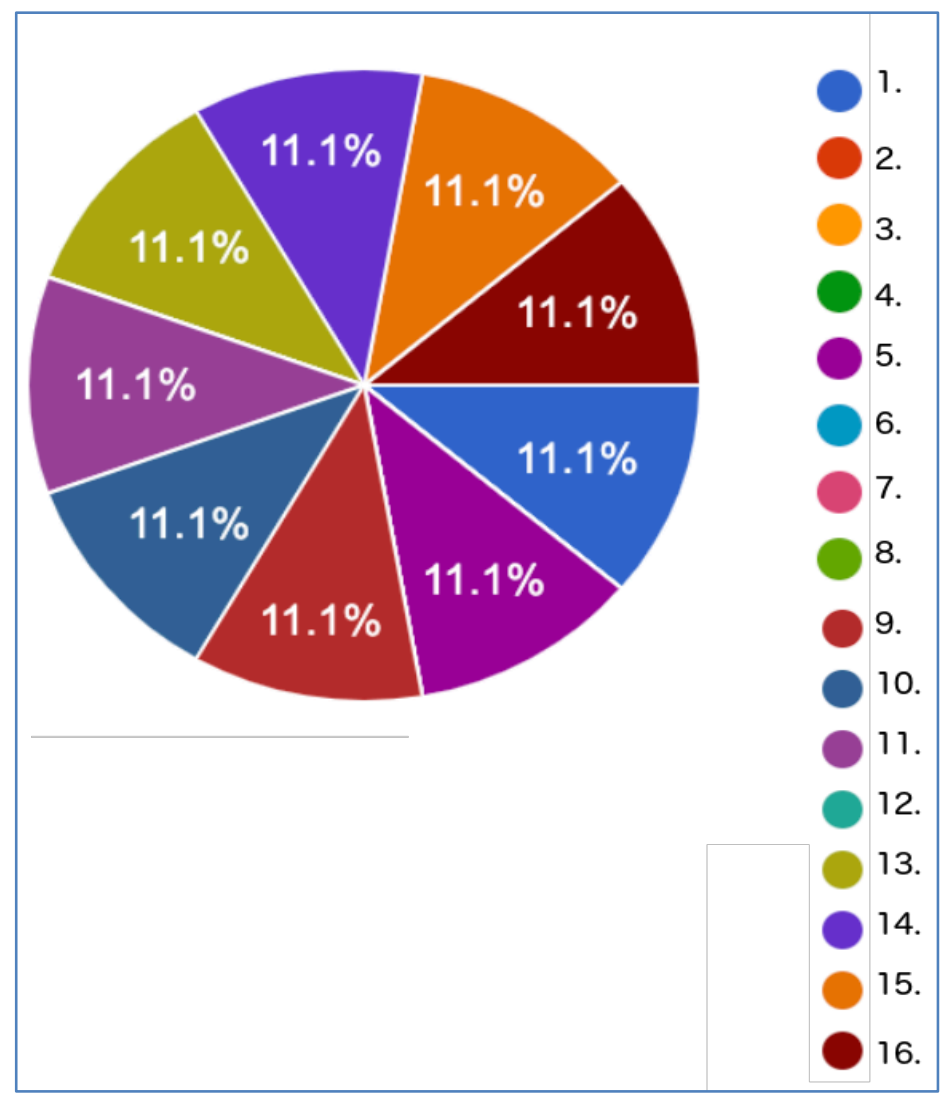




\begin{tabular}{|r|l|}
\hline 1 & Pasión \\
\hline 2 & Motivación \\
\hline 3 & Liderazgo \\
\hline 4 & Compromiso \\
\hline 5 & Confianza \\
\hline 6 & Humildad \\
\hline 7 & Creatividad \\
\hline 8 & Experiencia o conocimientos \\
\hline 9 & Aversión al riesgo \\
\hline 10 & Perseverancia \\
\hline 11 & Poseer una idea o visión empresari... \\
\hline 12 & Capacidad de reconocer oportunida... \\
\hline 13 & Paciencia \\
\hline 14 & Contactos \\
\hline 15 & Ser realista \\
\hline 16 & Determinación, perseverancia, convicción y tener los pies sobre la tierra cuando haga falta. \\
\hline
\end{tabular}

FIGURA 62

Fuente: Elaboración propia

31. ¿Cómo percibís el fracaso en el contexto de una start-up? Marcá una o más opciones

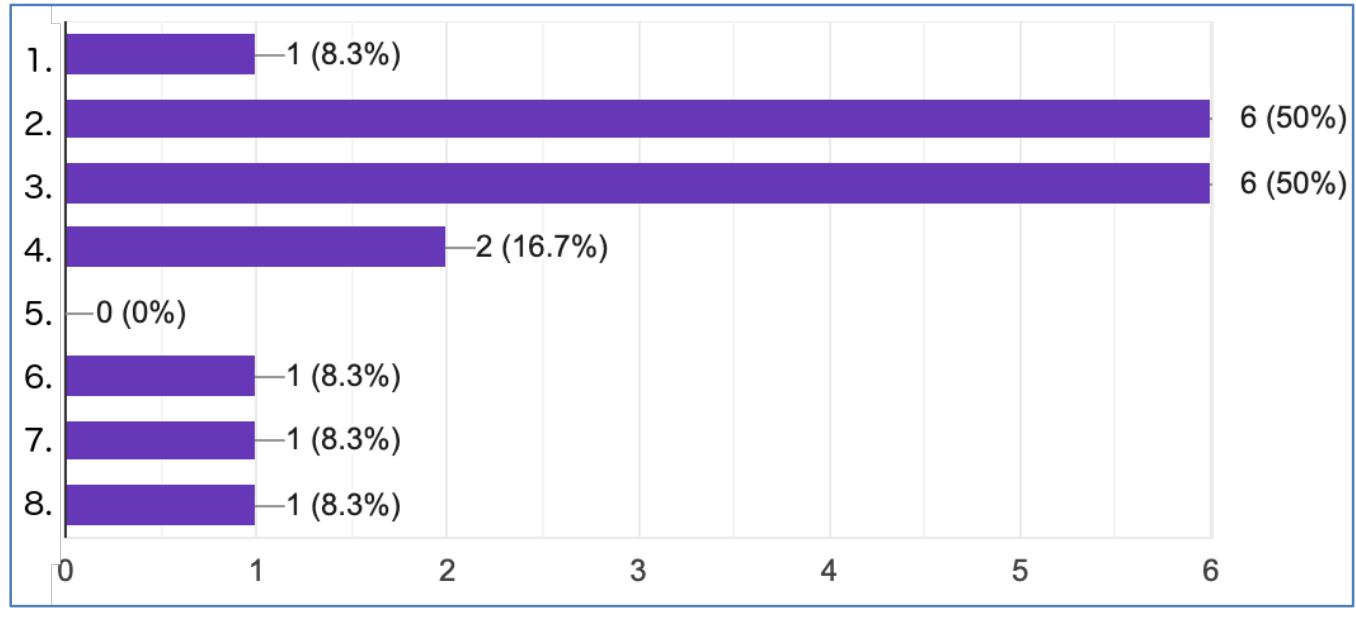

\begin{tabular}{|r|l|}
\hline 1 & Esta muy mitificado \\
\hline 2 & Es parte del camino hacia el éxito \\
\hline 3 & Sirve como aprendizaje \\
\hline 4 & Genera temor \\
\hline 5 & No hay lugar para el fracaso \\
\hline 6 & Prefiero evitarlo. Jaja \\
\hline & Seguir trabajando de lo mismo en un emprendimiento con \\
7 & el mismo tamaño después de 10 años. \\
\hline 8 & Rendirse en el primero, segundo, tercero, cuarto, quinto... \\
\hline
\end{tabular}

FIGURA 63

Fuente: Elaboración propia 
32. ¿Cuándo considerarías que tu start-up ha tenido éxito? Marcá una o más opciones:

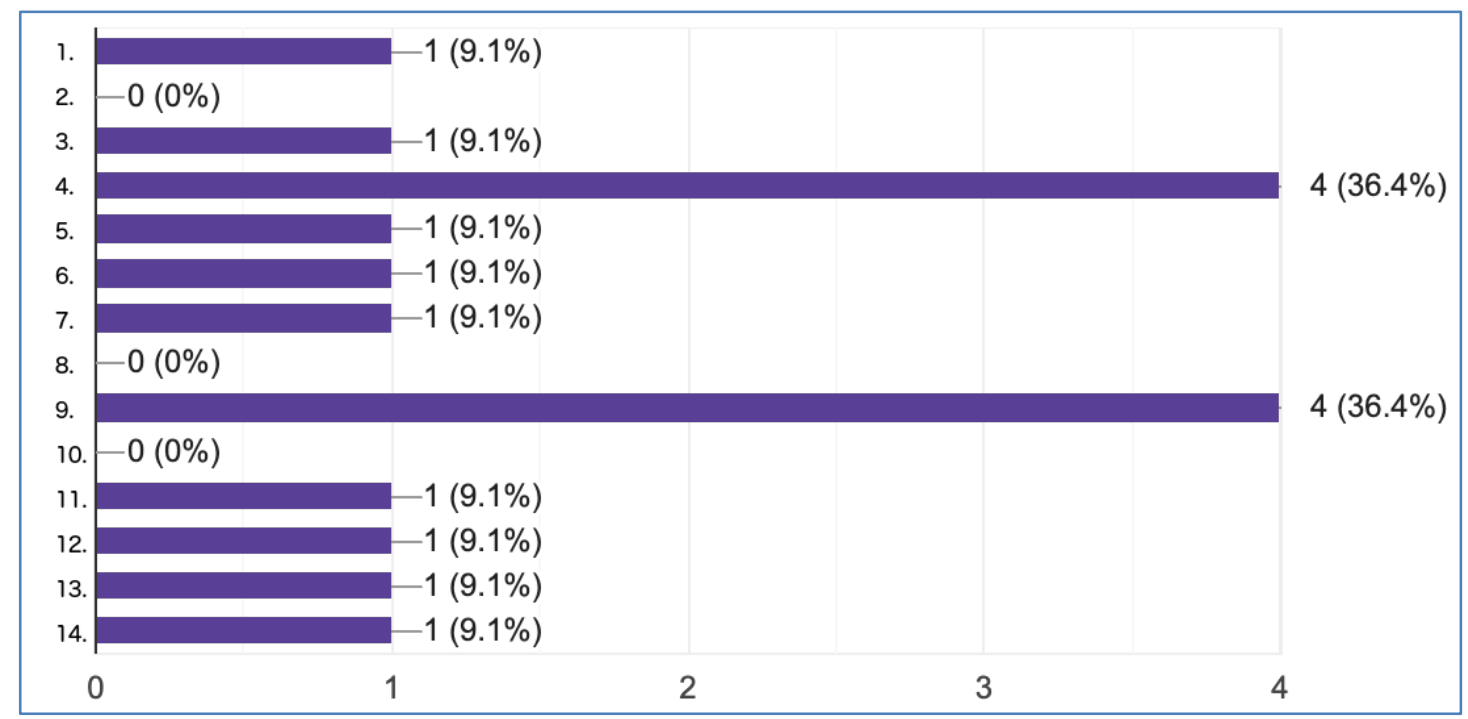

\begin{tabular}{|r|l|}
\hline 1 & Cuando se haya podido devolver toda la inversión recibida \\
\hline 2 & Cuando tiene metas y estrategias establecidas \\
\hline 3 & Cuando se estén realizando acciones estratégicas para obtener el resultado deseado \\
\hline 4 & Cuando la misma pueda ser sostenible en el tiempo \\
\hline 5 & Cuando haya resuelto la necesidad insatisfecha \\
\hline 6 & Cuando logre rentabilidad \\
\hline 7 & Cuando logre una ventaja competitiva en el mercado \\
\hline 8 & Cuando se logre la retención del 100\% de los usuarios/clientes \\
\hline 10 & Cuando logre escalabilidad \\
\hline 11 & Cuando pueda salir a la bolsa \\
\hline 12 & Cuando empieza a ser valioso para otros, cuando mejora las posibilidades de los demás idea (deja de ser del promotor original) \\
\hline 13 & $\begin{array}{l}\text { cuando te hace feliz lo que hacés todos los dias (y si podés darle trabajo a alguien, } \\
\text { mucho más) }\end{array}$ \\
\hline & $\begin{array}{l}\text { No creo tener éxito aún con la start up, estamos trabajando para lograrlo, pero fue muy } \\
\text { gratificante cuando la gente inversora me llamó para confirmarme que les interesaba el } \\
\text { proyecto y el equipo de trabajo, y que iban a sumarse a trabajar con nosotros. }\end{array}$ \\
\hline
\end{tabular}

FIGURA 64

Fuente: Elaboración propia

\section{Factores externos de éxito y fracaso}

33. ¿Creés que tu entorno, la sociedad y/o las normas culturales influyeron en la decisión de emprender? 


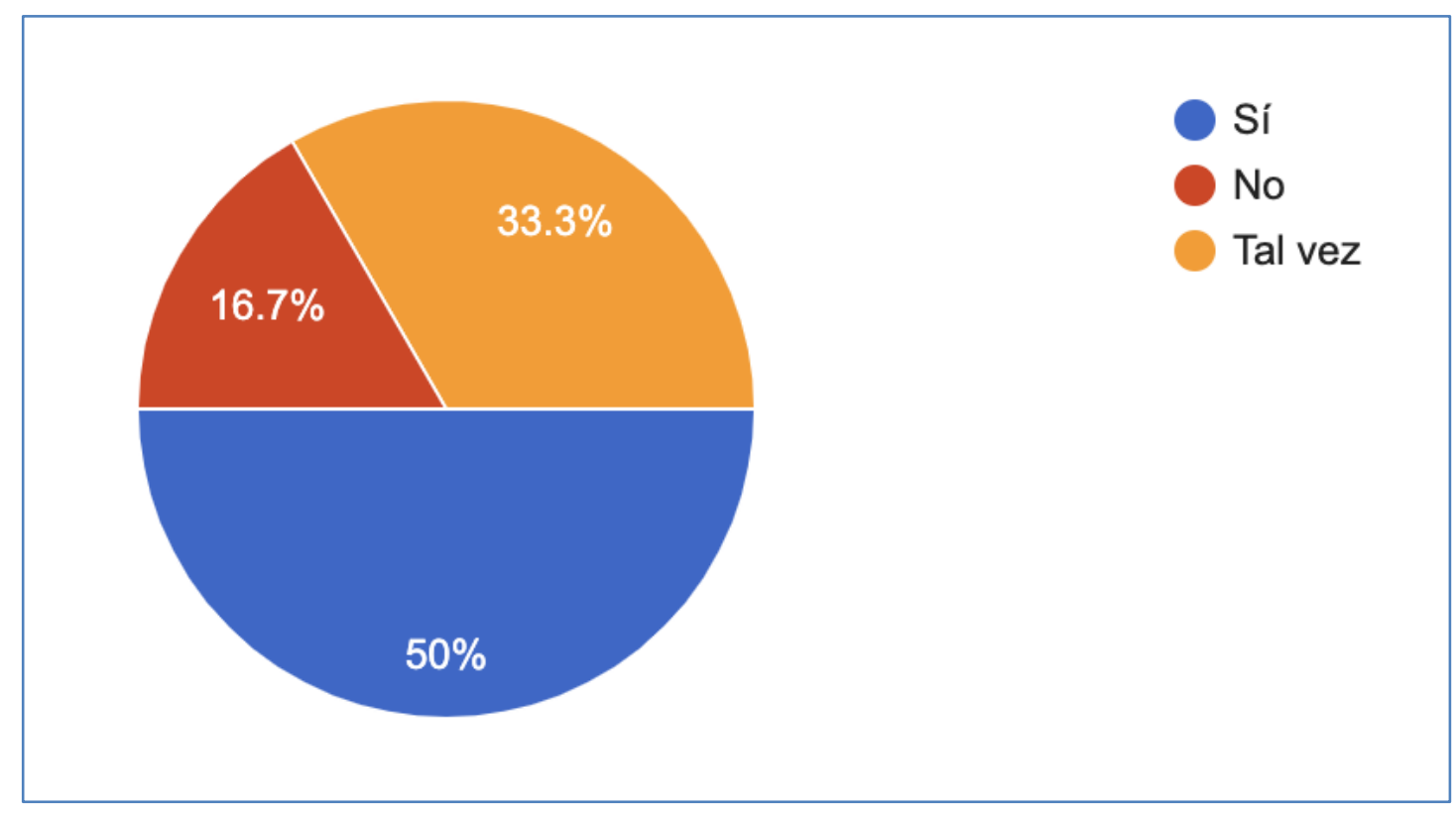

FIGURA 65

34. En caso afirmativo, ¿cómo fue que influyeron?

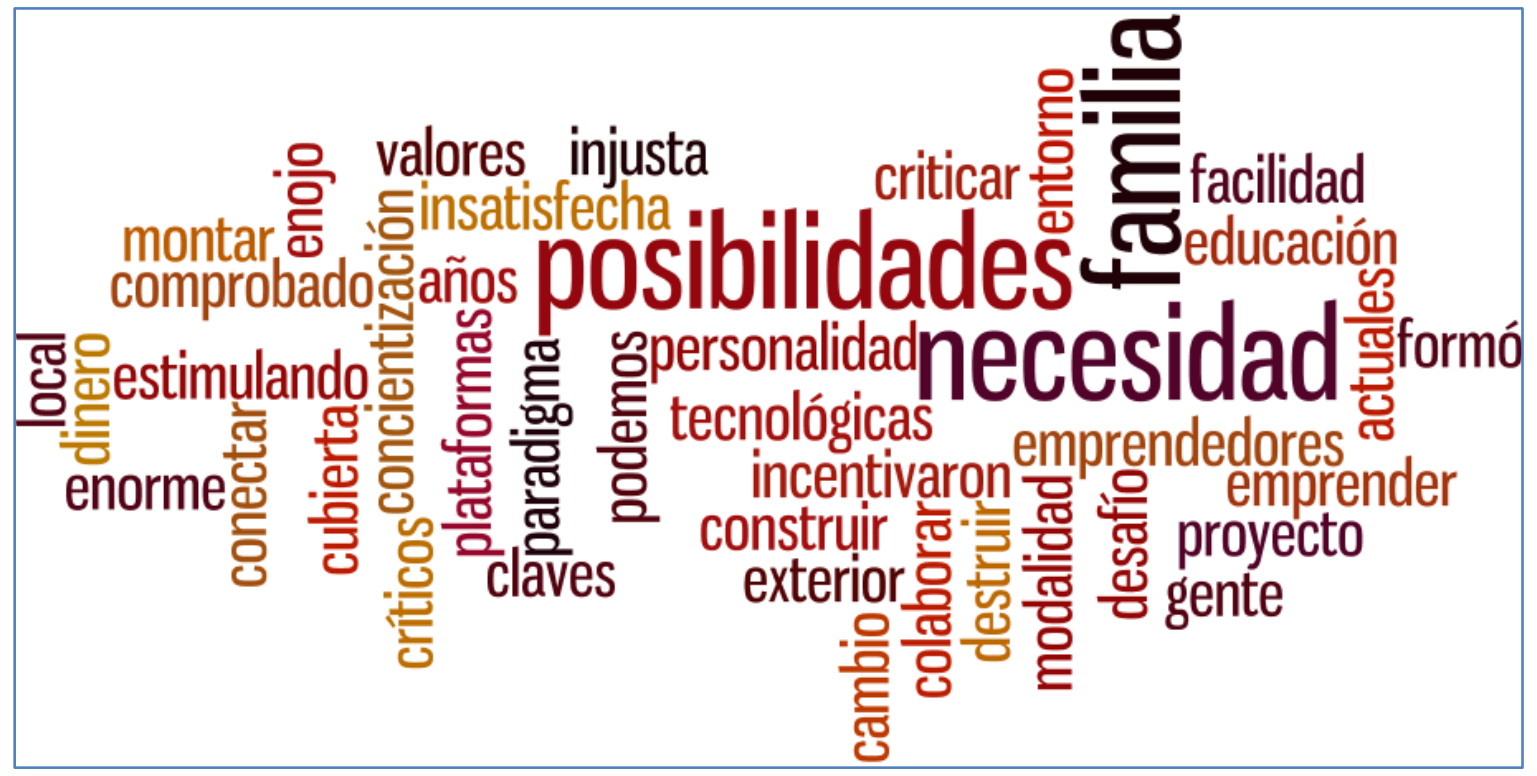

FIGURA 66

Fuente: Elaboración propia 
35. ¿Considerás a Argentina un país propicio para emprender?

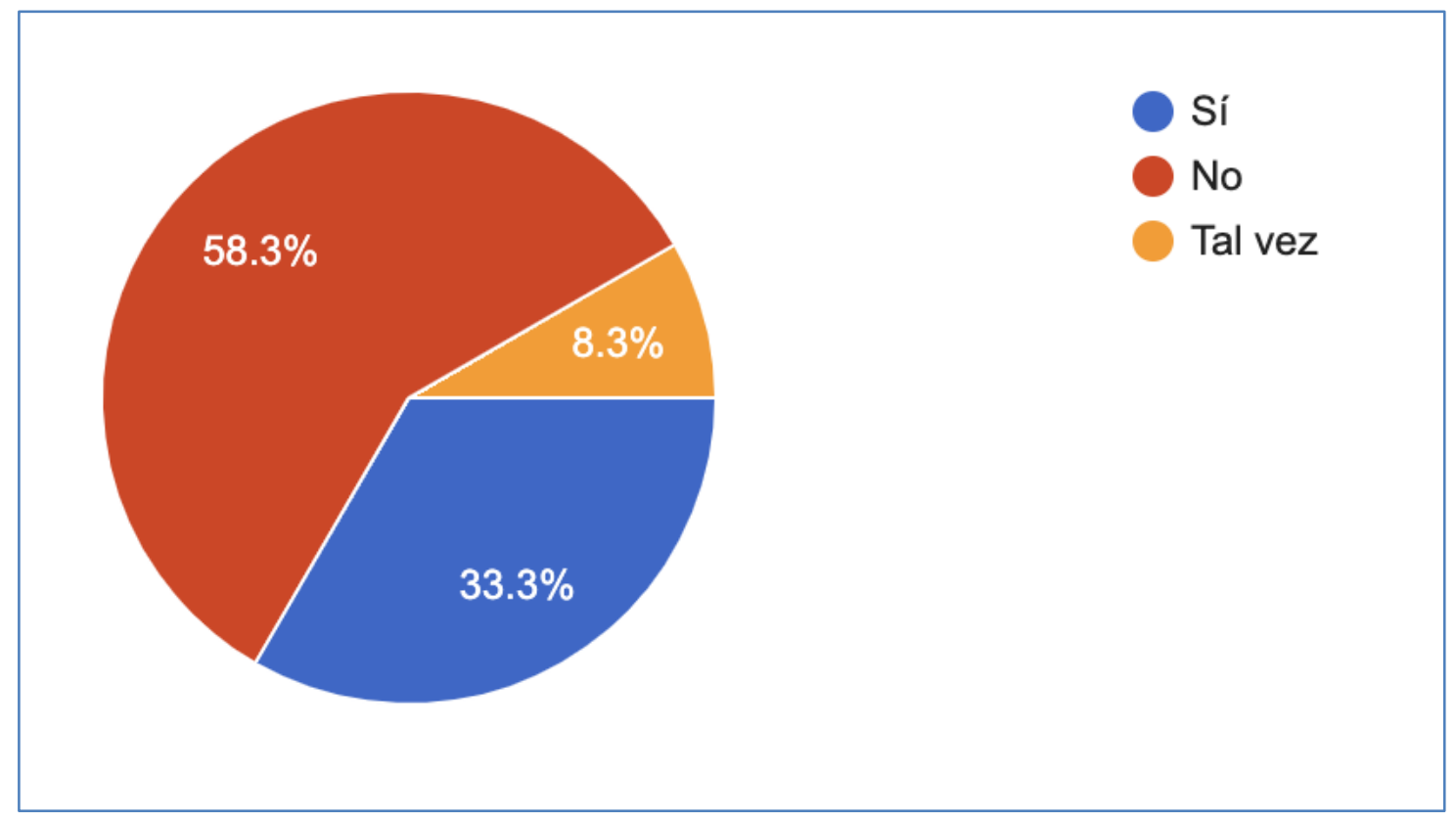

FIGURA 67

Fuente: Elaboración propia

36. ¿Qué ventajas encontrás en residir en este país? Marcá una o más opciones:

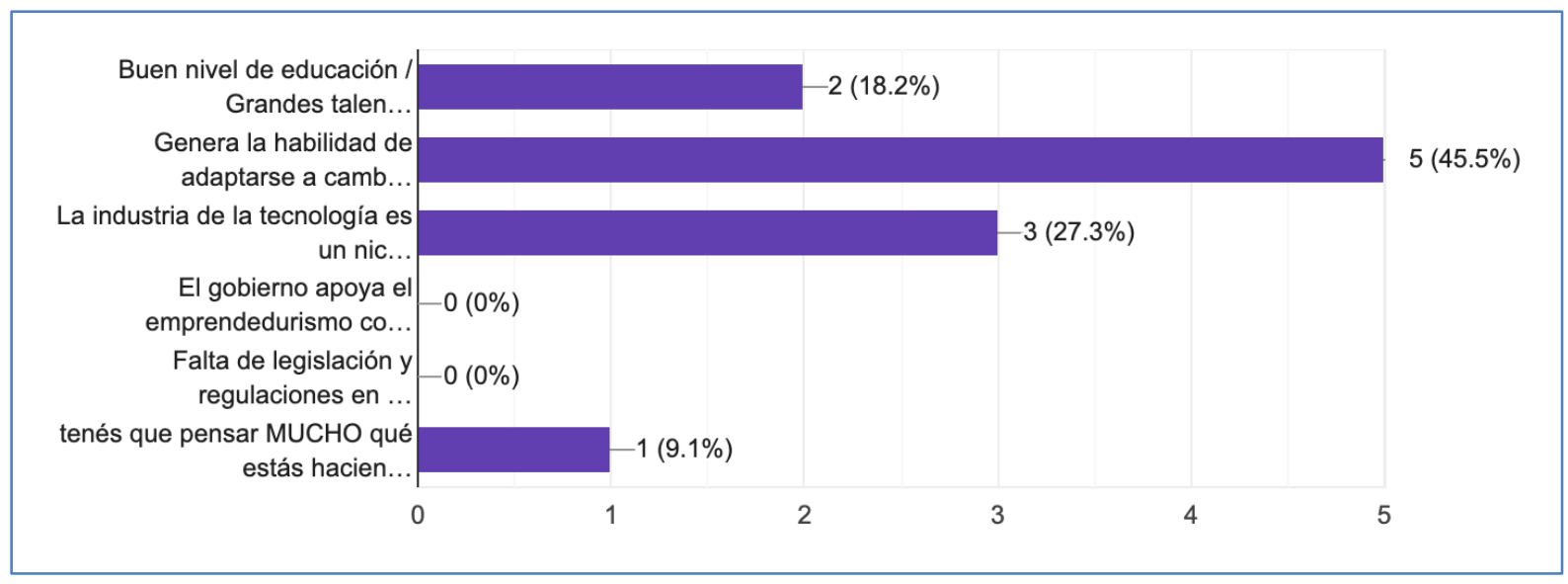

FIGURA 68

Fuente: Elaboración propia 
37. ¿YY desventajas ? Marcá una o más opciones:

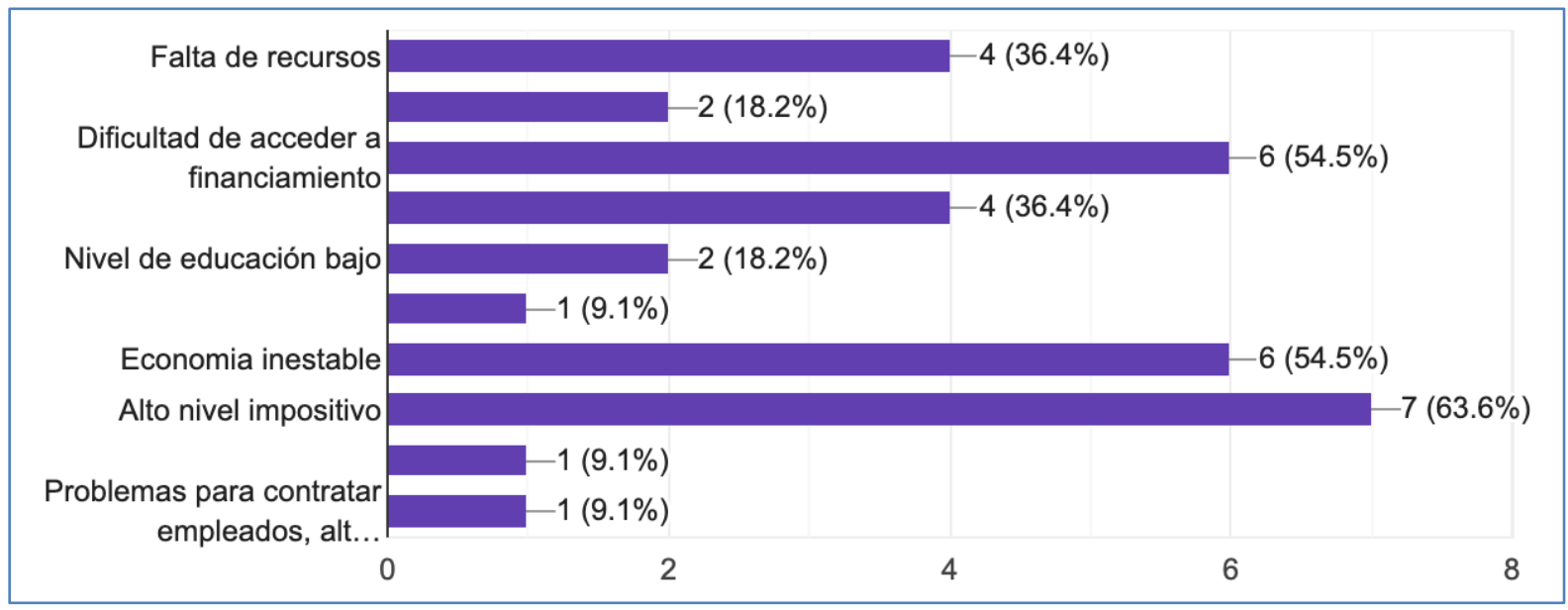

FIGURA 69

Fuente: Elaboración propia

38. ¿Cómo vive la start-up la situación actual del país?

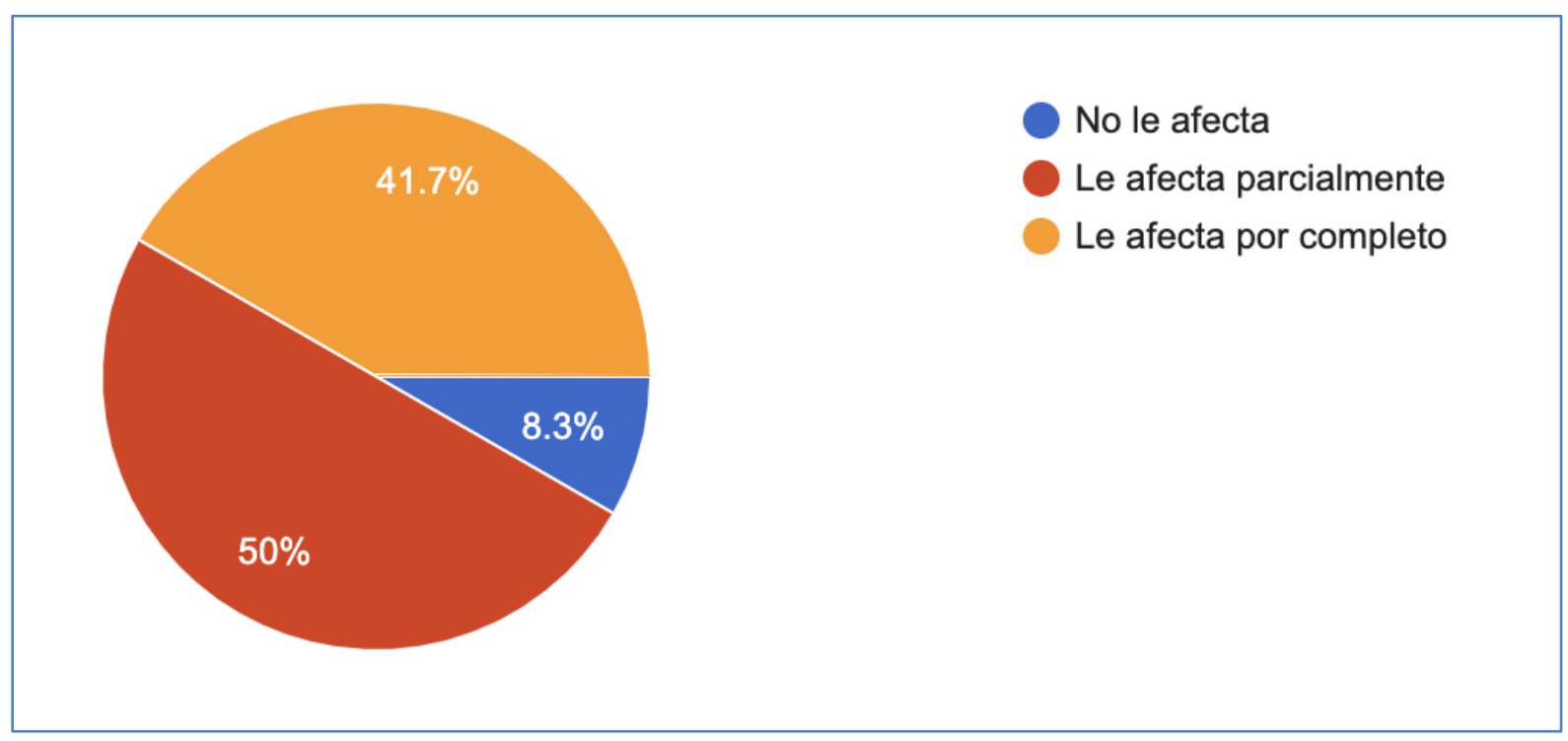

FIGURA 70

Fuente: Elaboración propia 
39. ¿Cómo accedieron a los recursos e infraestructura necesaria? ¿Fue dificultoso conseguir lo que necesitaban?

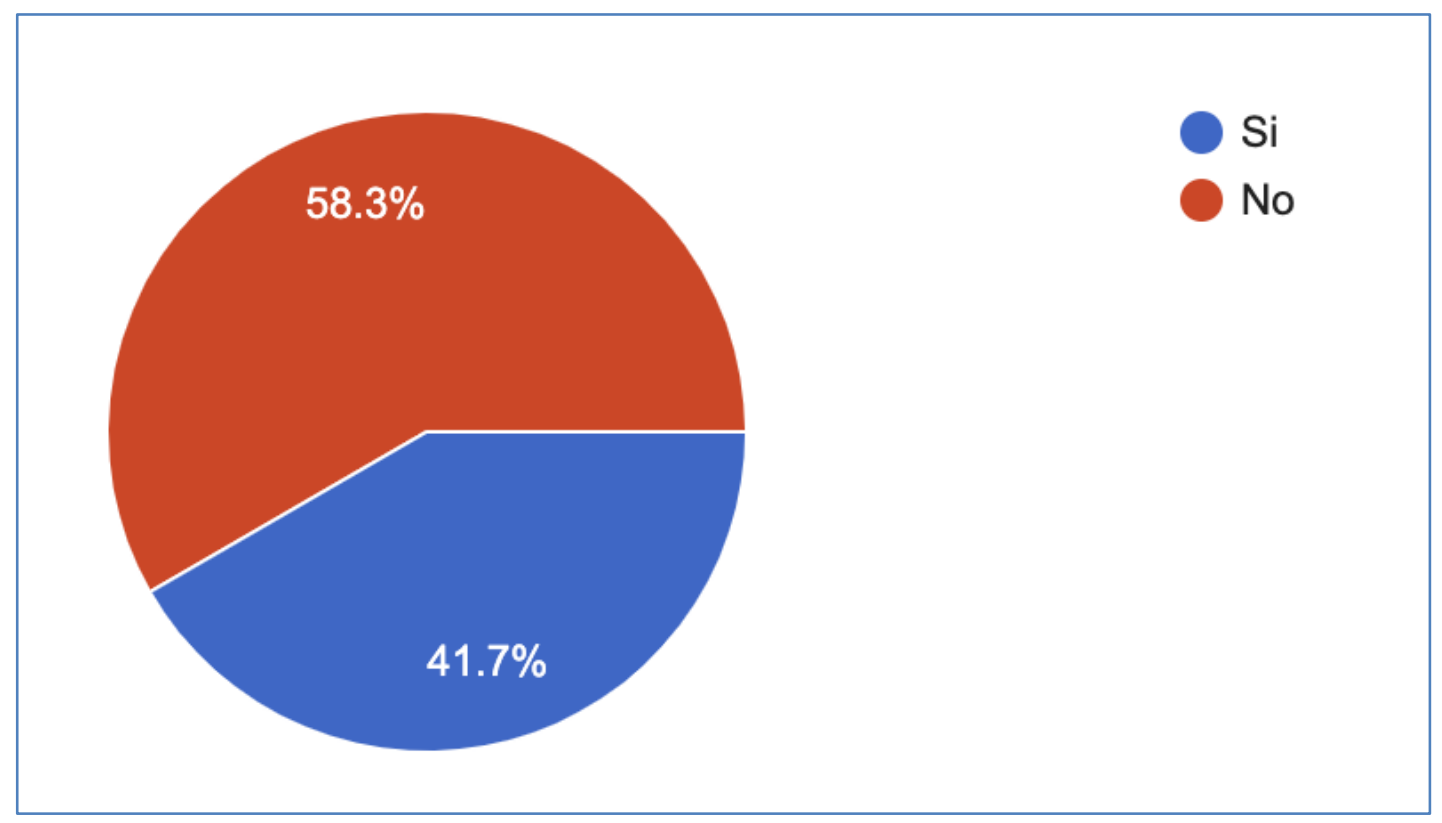

FIGURA 71

Fuente: Elaboración propia

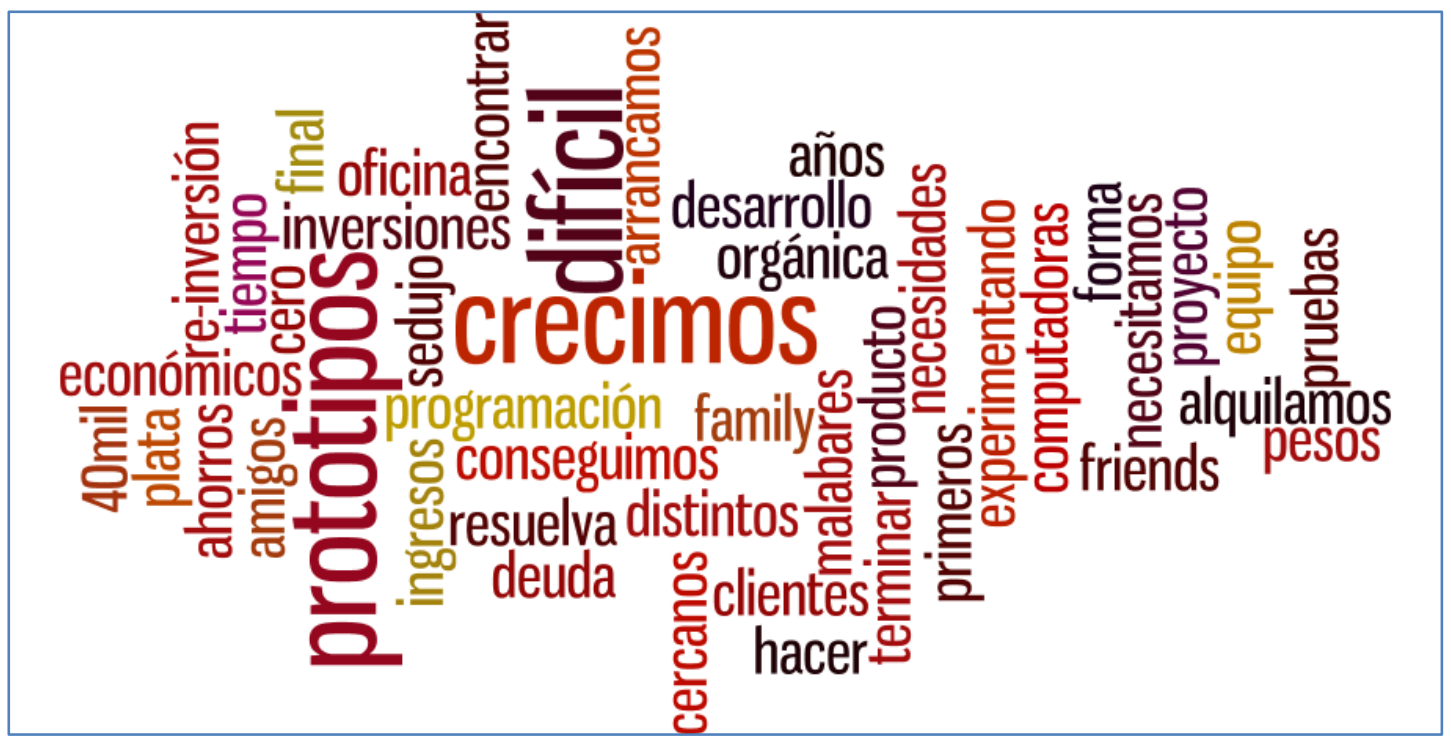

FIGURA 72

Fuente: Elaboración propia 
40. ¿Recibieron algún tipo de financiamiento o ayuda externa? ¿Accedieron a algún programa de financiamiento o aceleración?

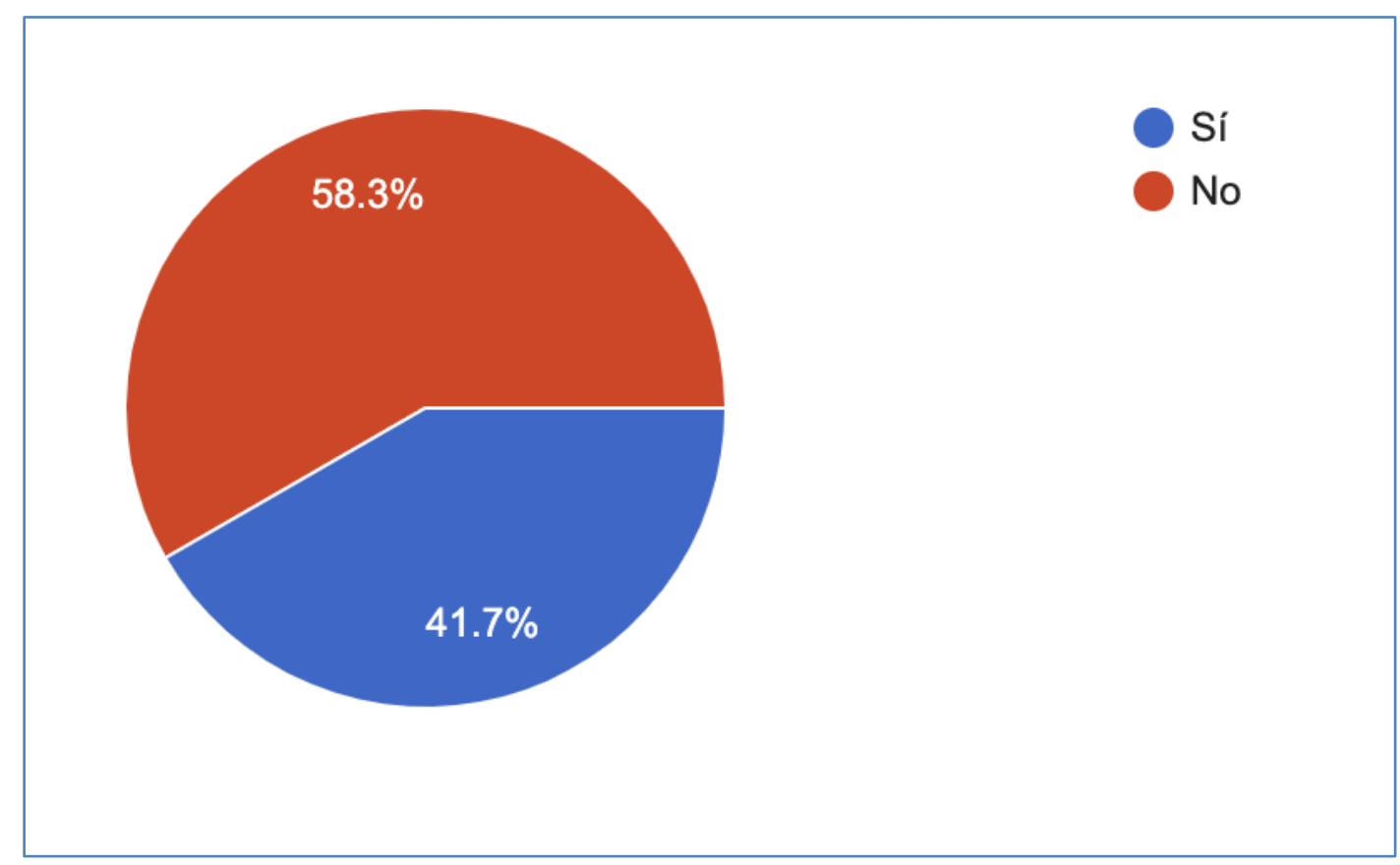

FIGURA 73

Fuente: Elaboración propia

41. En caso afirmativo, ¿de institución/es pública/s o privada/s?

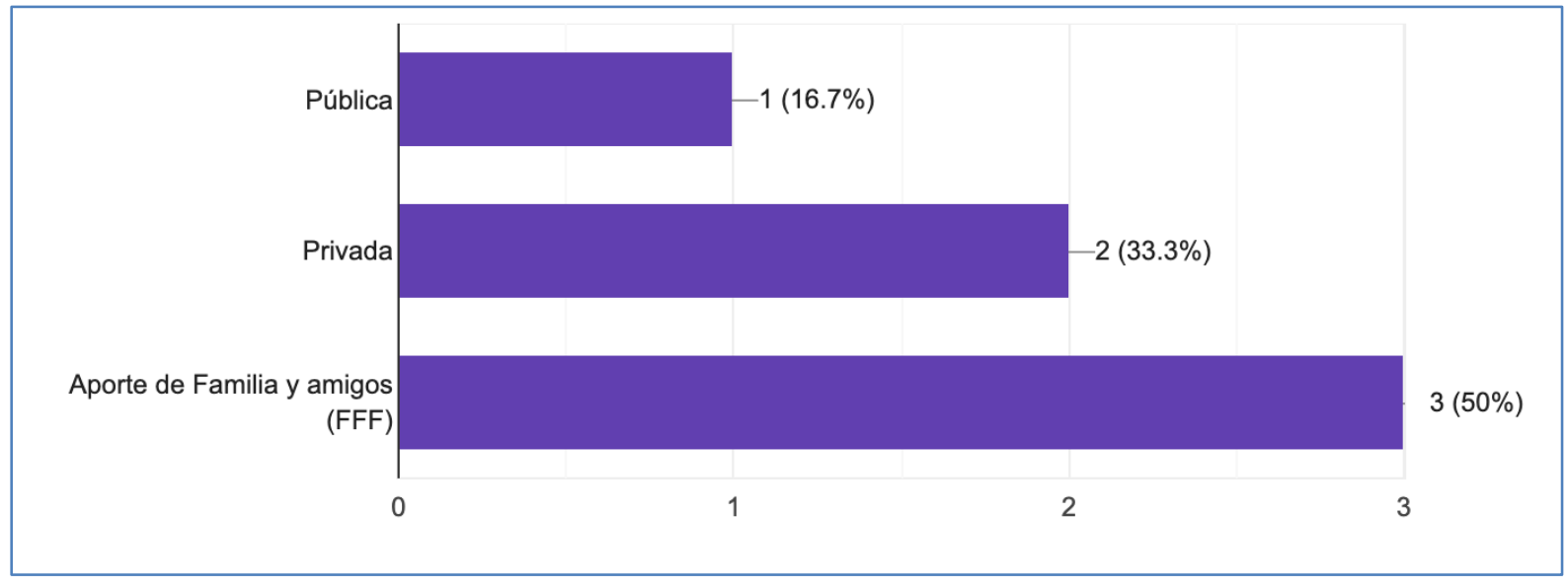

FIGURA 74

Fuente: Elaboración propia 
42. ¿Cuál/es considerás que fue/ron las herramientas que te ayudaron a llegar donde estás hoy? Marcá una o más opciones

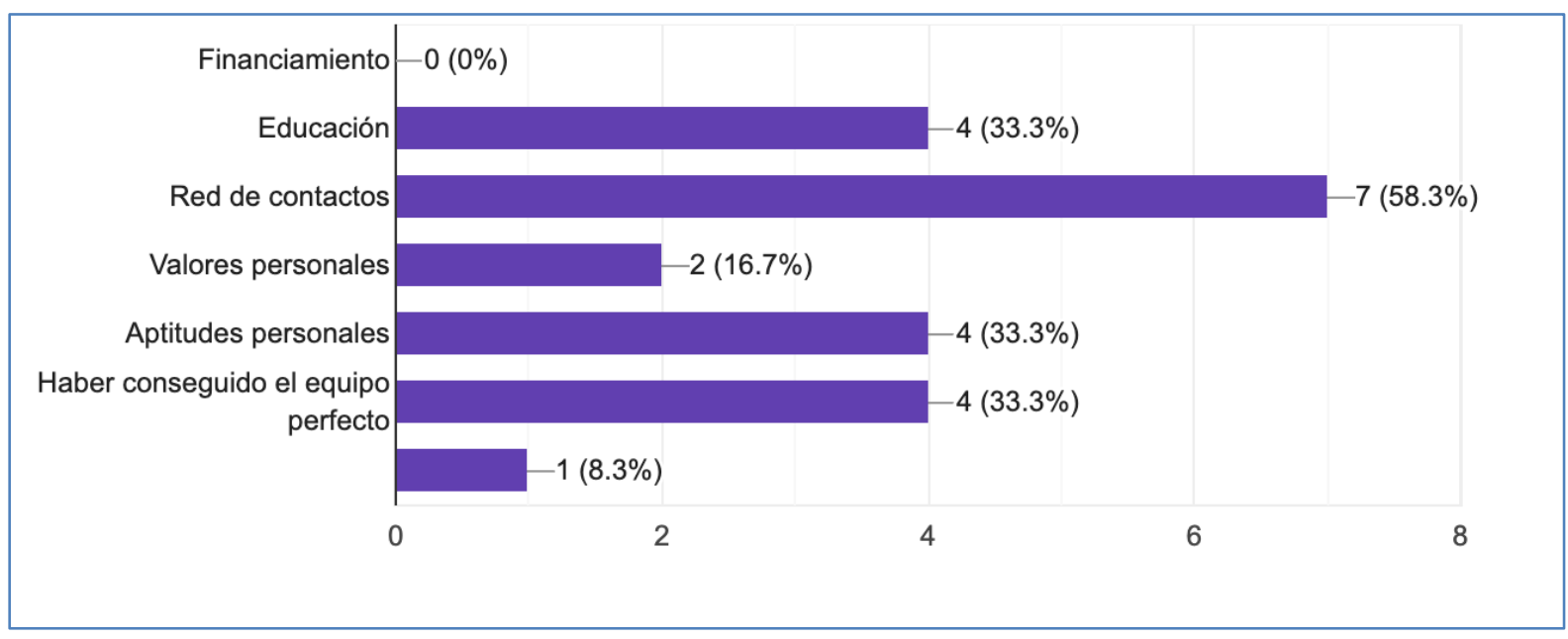

FIGURA 75

Fuente: Elaboración propia

43. ¿Qué opinás sobre las las mujeres emprendedoras? ¿Pensás que tienen las mismas oportunidades que los hombres a la hora de emprender?

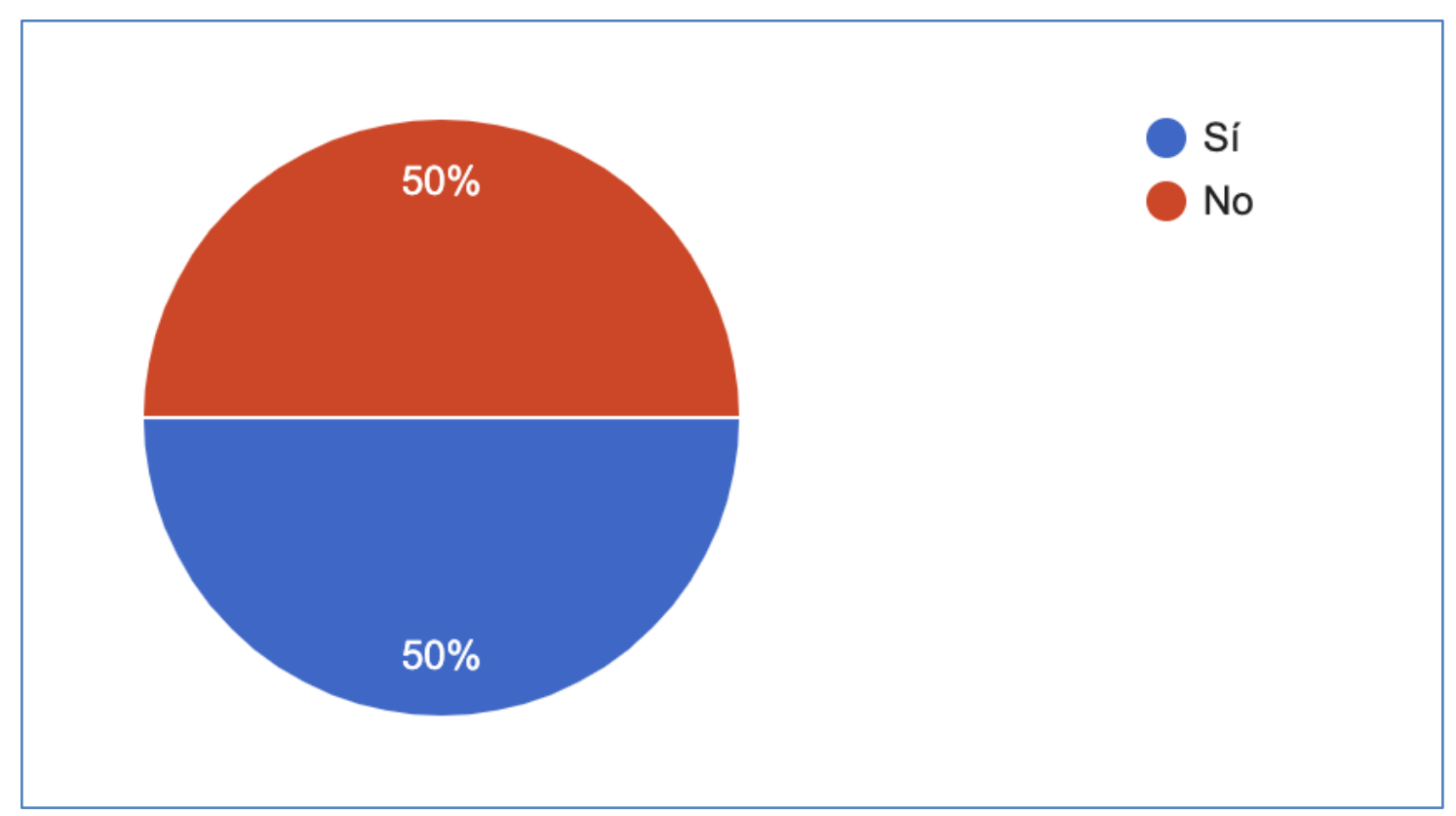

FIGURA 76

Fuente: Elaboración propia 


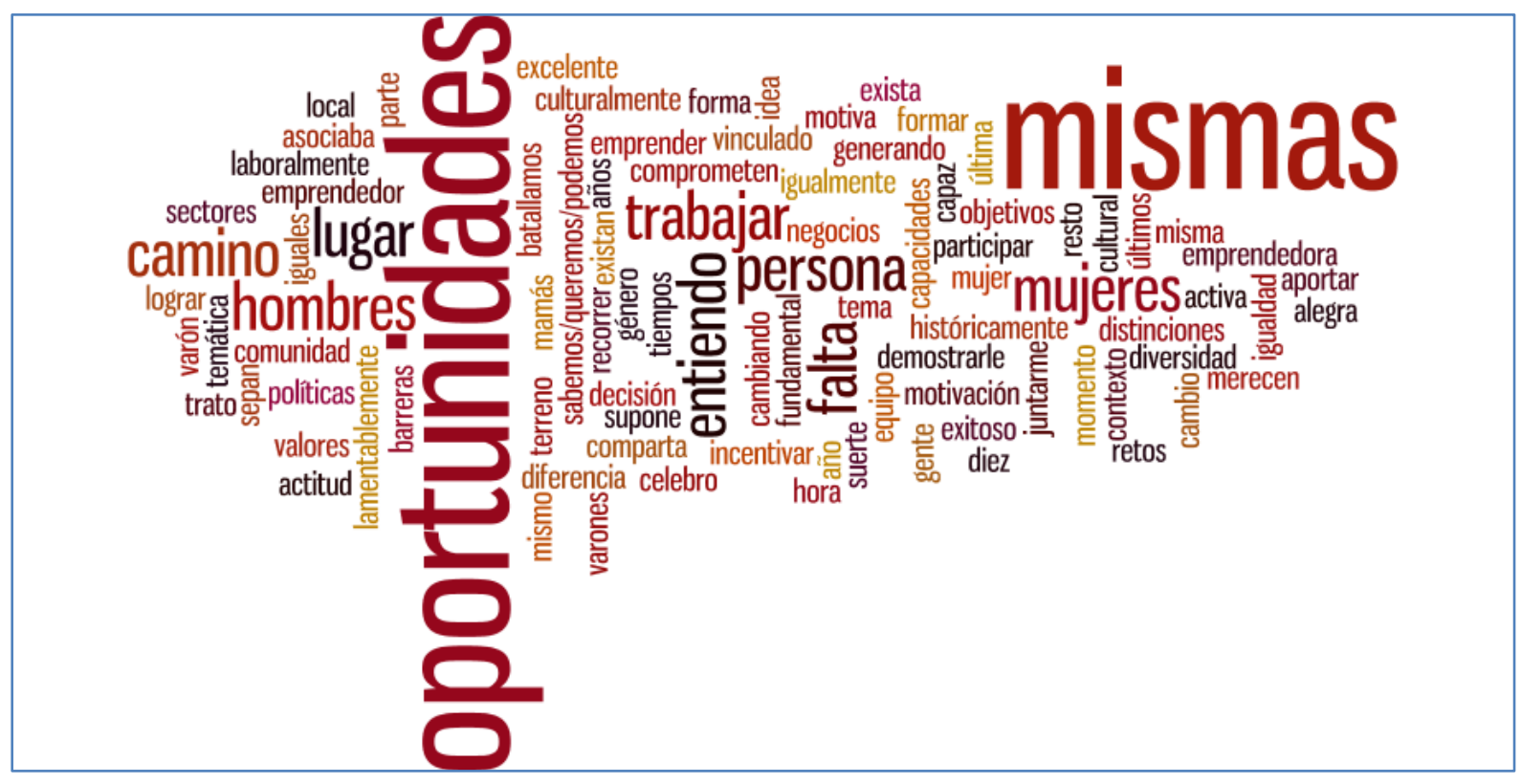

FIGURA 77

Fuente: Elaboración propia 